\title{
Role of dendritic cell subsets in hyperlipidemia and atherosclerosis
}

Citation for published version (APA):

Legein, B. (2016). Role of dendritic cell subsets in hyperlipidemia and atherosclerosis. [Doctoral Thesis, Maastricht University]. Uitgeverij BOXPress. https://doi.org/10.26481/dis.20160623bl

Document status and date:

Published: 01/01/2016

DOI:

$10.26481 /$ dis.20160623bl

Document Version:

Publisher's PDF, also known as Version of record

\section{Please check the document version of this publication:}

- A submitted manuscript is the version of the article upon submission and before peer-review. There can be important differences between the submitted version and the official published version of record.

People interested in the research are advised to contact the author for the final version of the publication, or visit the DOI to the publisher's website.

- The final author version and the galley proof are versions of the publication after peer review.

- The final published version features the final layout of the paper including the volume, issue and page numbers.

Link to publication

\footnotetext{
General rights rights.

- You may freely distribute the URL identifying the publication in the public portal. please follow below link for the End User Agreement:

www.umlib.nl/taverne-license

Take down policy

If you believe that this document breaches copyright please contact us at:

repository@maastrichtuniversity.nl

providing details and we will investigate your claim.
}

Copyright and moral rights for the publications made accessible in the public portal are retained by the authors and/or other copyright owners and it is a condition of accessing publications that users recognise and abide by the legal requirements associated with these

- Users may download and print one copy of any publication from the public portal for the purpose of private study or research.

- You may not further distribute the material or use it for any profit-making activity or commercial gain

If the publication is distributed under the terms of Article $25 \mathrm{fa}$ of the Dutch Copyright Act, indicated by the "Taverne" license above, 


\title{
Role of dendritic cell subsets in hyperlipidemia and atherosclerosis
}

\author{
Bart R.J. Legein
}


Layout: Bart Legein

Cover design: Bart Legein, Rolf Dobbelaere

Printed by: Proefschriftmaken.nl || Uitgeverij BOXPress

Published by: Uitgeverij BOXPress, Vianen

ISBN: $\quad$ 978-94-6295-487-8

(C)2016, Bart R.J. Legein, Maastricht

Funded by Financial support by the Dutch Heart Foundation the dutch heart foundation for the publication of this thesis is gratefully Hartstichting for the publication 


\title{
Role of dendritic cell subsets in \\ hyperlipidemia and atherosclerosis
}

\author{
PROEFSCHRIFT
}

ter verkrijging van de graad van doctor aan de Universiteit Maastricht, op gezag van de rector Magnificus, Prof. dr. L.L.G. Soete, volgens het besluit van het College van Decanen,

in het openbaar te verdedigen op

donderdag 23 juni 2016 om 10 uur

door

Bart Roger Jozef Legein

geboren op 16 juni 1988 te Knokke 


\section{Promotores:}

Prof. dr. E.A. Biessen

Prof. dr. E. Lutgens (Universiteit Amsterdam)

\section{Copromotor:}

dr. L. Temmerman

\section{Beoordelingscommissie:}

Prof. dr. S.R.B. Heymans (voorzitter)

Prof. dr. G.M.J. Bos

Prof. dr. J. Kuiper (Universiteit Leiden)

Prof. dr. Y. van Kooyk (Vrije Universiteit medisch centrum Amsterdam) dr. K. Wouters

\section{Financial support}

The research described in this thesis was supported by following grants: CARIM grant, DFG GRK1508 grant "Eucar", CTMM Circulating Cells, Established Investigator NHS2003D201, NWO VICl grant 016130676, SFB 1054, project B08, and SFB1123, project A5. 


\section{Contents}

Chapter 1 General Introduction 6-27

Chapter 2 Inflammation and Immune System Interactions in 28-73 Atherosclerosis

Chapter 3 Dendritic cells in cardiovascular diseases: 74-103

epiphenomenon, contributor or therapeutic opportunity?

Chapter 4 Ablation of $\mathrm{CD} 8 \alpha^{+}$dendritic cell mediated cross104-145 presentation does not impact atherosclerosis in hyperlipidemic mice

Chapter 5 Low density lipoprotein exposure interferes with TLR7 146-171 and 9 induced plasmacytoid dendritic cell activation

$\begin{array}{llll}\text { Chapter } 6 & \text { Early adaptive effects of peripheral dendritic cell 172-201 }\end{array}$ subsets to hyperlipidemia: impact on phenotype and capacity to prime naïve T cells

Chapter 7 Quaking deficiency in CD11c dendritic cells attenuates 202-239 atherosclerosis by shifting CD4 to CD8 T cell balance and favoring CD4 T cell polarization towards a regulatory phenotype

Chapter 8 Constitutively active Dendritic Cell CD40-signaling paradoxically retards atherosclerosis due to $\mathrm{Gl}$-tract inflammation and ensuing cholesterol lowering

Chapter 9 General Discussion 254-275

Summary 276-279

$\begin{array}{ll}\text { Samenvatting } & 280-283\end{array}$

$\begin{array}{ll}\text { Valorisation 284-289 } & \text { 280 }\end{array}$

$\begin{array}{ll}\text { Curriculum Vitae } & \text { 290-293 }\end{array}$

List of Abbreviations 294-303

Dankwoord 304-309 



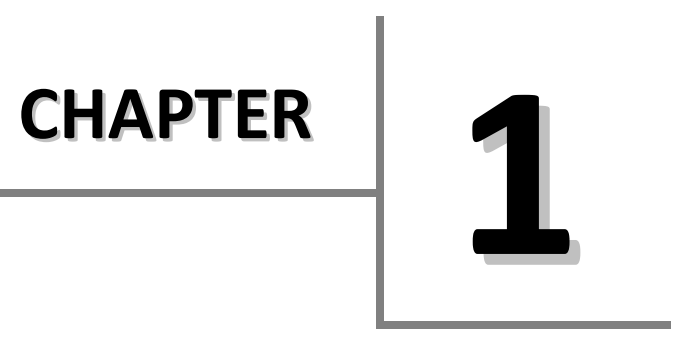

General Introduction

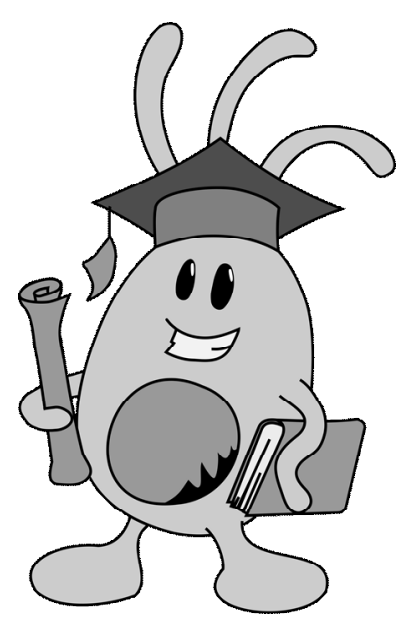




\section{1 | General Introduction}

\section{Cardiovascular diseases}

In the last century tremendous advances in hygiene, technology and medicine have improved living conditions and average life span of the world's population. Unfortunately, these advances also give rise to new medical challenges as they are accompanied by a dramatic increase in age-associated diseases, such as cancer, neurodegenerative diseases, type 2 diabetes and cardiovascular diseases (CVDs). In addition, industrialization and the growing world population led to an increase in pollution, not only a topic that is hotly debated on by environmental researchers and activists, but also a contributing factor to many of the above mentioned diseases. Moreover, some attributes of the Western life style such as insufficient exercise, smoking, diet and stress represent risk factors that further enhance the development of age-associated diseases. In numbers, of the roughly 150,000 worldwide deaths per day, about 100,000 are due to age-related causes (source: CIA - Population Reference Bureau \& The World Factbook), and this number is likely to increase in the future.

CVD is still the leading cause of mortality worldwide accounting for $31 \%$ of all global deaths (source: WHO). The underlying cause of most CVDs, such as myocardial infarction or stroke, is atherosclerosis, a lipid-driven chronic inflammatory disease. Research efforts in the past decades have significantly advanced the understanding of the pathogenesis of disease and have led to the development of new therapies, such as lipid lowering drugs (e.g. statins, ezetimide, fibrates) and antihypertensive drugs (e.g. ACE inhibitors, AT receptor antagonists, Ca blockers). Nevertheless, atherosclerosis remains the driving force behind cardiovascular mortality and therefore more research is needed to develop better tools and therapies for preventing/treating this disease.

While originally atherosclerosis was perceived to be a lipid-storage disorder of the arterial wall ${ }^{(1)}$, it is now recognized not only as a lipid storage but also as a chronic inflammatory disease ${ }^{(2)}$, with innate as well as adaptive immune cells playing crucial roles. The initial development of atherosclerotic lesions is characterized by activation, dysfunction and structural alterations of the endothelium leading to subendothelial retention of lipid components from the plasma, such as low-density lipoprotein (LDL). Subendothelial modification of these lipids initiates the vascular inflammatory process as it leads to endothelial activation. Upregulation of adhesion molecules (e.g. E-selectin and 
VCAM-1) and secretion of chemokines (e.g. CCL2) by these cells promote leukocyte infiltration. Early lesions contain monocytes, which differentiate into macrophages, and dendritic cells (DCs), that both engulf lipids and become 'foam' cells. Further accumulation of lipids and recruitment of leukocytes, such as $T$ cells, boost the inflammatory process, resulting in cell death and the subsequent formation of a necrotic core. Necrotic core expansion and secretion of matrix-degrading proteases (e.g. matrix metalloproteases (MMPs), elastases and cathepsins) by inflammatory cells eventually lead to plaque destabilization. Plaque rupture or erosion results in formation of thrombi and shedding of emboli, resulting in clinical complications, such as mycocardial infarction or stroke. Chapter $\mathbf{2}$ discusses the pathogenesis of atherosclerosis in more depth, with a focus on the immunological aspects of the disease.

As immune processes play an important role in all stages of atherosclerosis disease progression, a better understanding of the relevant immunological processes, be it innate or adaptive, will identify new possibilities for primary and secondary therapeutic intervention. This general introduction (with references to Chapter $\mathbf{2}$ and $\mathbf{3}$ ) will give an overview on the immune system and the most important players of the immune responses involved in atherosclerosis, with particular focus on dendritic cells.

\section{The immune system}

The body's immune system effectively eradicates and eliminates invading pathogens such as viruses, bacteria and parasites, to prevent them from harming the host. To efficiently do so, they need soldiers, called white blood cells or leukocytes and specialized infrastructures being the bone marrow and the complex network of lymphoid organs. The immune system can be divided into an innate (fast, non-specific) and an adaptive (acquired, specific) arm. The innate immunity is the body's first line of defense and is able to control the majority of infections. It includes natural barriers (skin, mucosae) and phagocytes (granulocytes, macrophages) that secrete microbicidal substances. Innate immunity is activated through microbial constituents called pathogen associated molecular patterns (PAMPs), which are recognized by pattern recognition receptors (PRRs). The best known PRRs are c-type lectin receptors (CLRs) and Toll-like receptors (TLRs). These are mainly expressed by the sentinels of the innate system, such as macrophages 


\section{1 | General Introduction}

and dendritic cells, which are strategically positioned throughout the body, such as in barriers (intestinal tract, lungs and skin) and in lymphoid organs (lymph nodes, spleen and thymus). The innate immune response acts very fast and the responses are identical for repeated encounters with the same microorganism, although the latter criterion has recently been challenged ${ }^{(3)}$. However, some pathogens evolved with the host and developed immune evasion mechanisms, which render innate immunity inadequate for their clearance. Here is where the adaptive arm kicks in. Adaptive immunity elicits very specific and strong immune responses, but is slower as it requires antigen presentation by antigen presenting cells (APCs), as well as selection and clonal expansion of its highly specialized effector cells. In contrast to the innate system, the adaptive immune system recognizes both microbial and nonmicrobial substances with high specificity and is able to generate memory cells. Immune memory will generate faster, stronger and more efficient immune responses upon exposure to a previously encountered antigen. Adaptive immunity includes humoral and cell-mediated mechanisms that are executed by $B$ and $T$ lymphocytes respectively. These effector cells are able to generate unique, non-germline encoded, antigen receptors, by de novo rearrangement of their gene segments ${ }^{(4)}$. This event leads to a unique and highly diverse repertoire of immune receptors that harbor the strength of the adaptive system. Adaptive immune responses are initiated by innate immunity and there is a permanent and bidirectional crosstalk between both arms of the immune system. As antigen uptake, processing, presentation and stimulation of lymphocytes towards clonal expansion are key features in initiating strong adaptive immune responses, there is a need for highly specialized forces called the (professional) antigen presenting cells (APCs), namely the dendritic cells (DCs). 


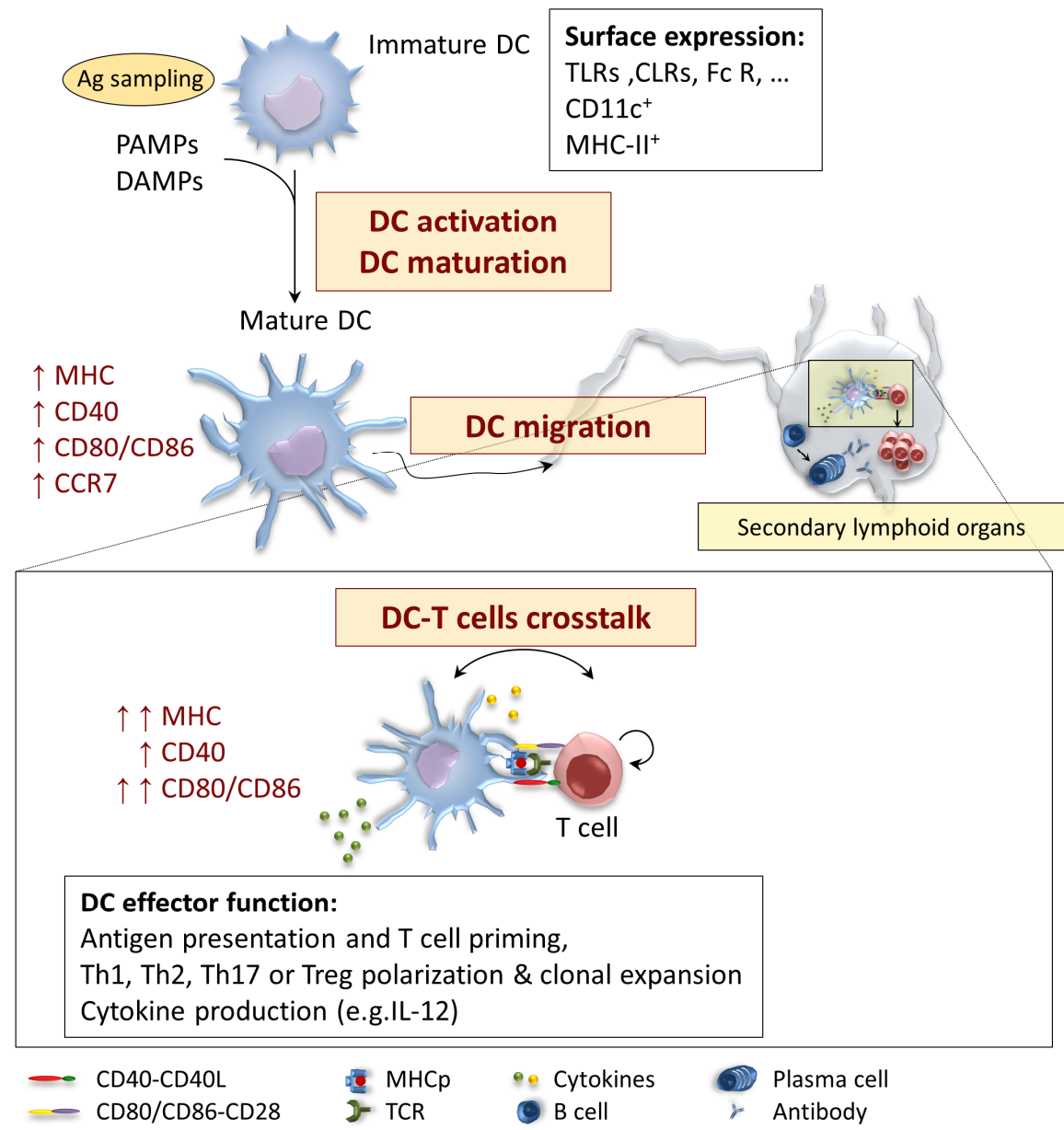

Figure 1 - Schematic representation of DC maturation and function Immature DCs are very efficient in capturing Ags from their local environment, using several pathways (micropinocytosis, receptor mediated endocytosis (PPR, Fc receptors), phagocytosis). Trigger of surface receptors and local inflammatory signals induce DC conversion (DC maturation). In addition, maturing DCs upregulate chemokine receptors, such as CCR7, for efficient migration towards secondary lymphoid organs. DC maturation is a continuous process that starts in the periphery and is completed during DC-T cell interaction. DC-CD40 interaction with CD40L on T cells is a key event for full DC maturation. Mature DCs are characterized by increased expression of CD40, MHC and costimulatory molecules, such as B7 family members. DC activation leads to enhanced DC effector functions, such as cytokine secretion and $T$ cell priming ability. In turn, Priming of $T$ cells can lead to formation of helper $T$ cell subsets that activate $B$ cells to become antibody secreting plasma cells. 


\section{1 | General Introduction}

Dendritic cells: translating innate to adaptive immunity

DCs are characterized by their capability to efficiently engulf and process antigen for presentation to naïve $\mathrm{T}$ cells, and are therefore called 'professional' APCs. They localize in both lymphoid and non-lymphoid tissues throughout the body, where they form sophisticated and complex networks allowing them to interact with different lymphocyte populations ${ }^{(5)}$. DCs, as orchestraters of innate and adaptive immunity, do not only play a critical role in host defense to pathogens and cancer, but are also regulators of tolerance to self, preventing autoimmunity ${ }^{(6)}$. In steady-state conditions, DCs exert an immature phagocytic phenotype (Figure 1). Triggering of PPRs such as TLRs, CLRs and CD1 receptors induce DC maturation ${ }^{(7)}$, leading to loss of endocytic capacity, increased migratory ability, upregulation of major histocompatibility complex (MHC) and costimulatory molecules, and production of cytokines, such as TNF $\alpha$, IL-12, IL-23 and IL-10 ${ }^{(7)}$ (Figure 1).

\section{DC differentiation and categorization}

DCs represent a heterogenous cell population and over the last decade different DC subsets have been identified. They vary in immune function specialization and therefore differ in their ontogeny, localization, migration and cytokine secretion pattern ${ }^{(8)}$ (Figure 2). Here I will mainly, but not exclusively, discuss the murine conventional and plasmacytoid DC subsets, as they are the main focus of this thesis. 
Lymph nodes

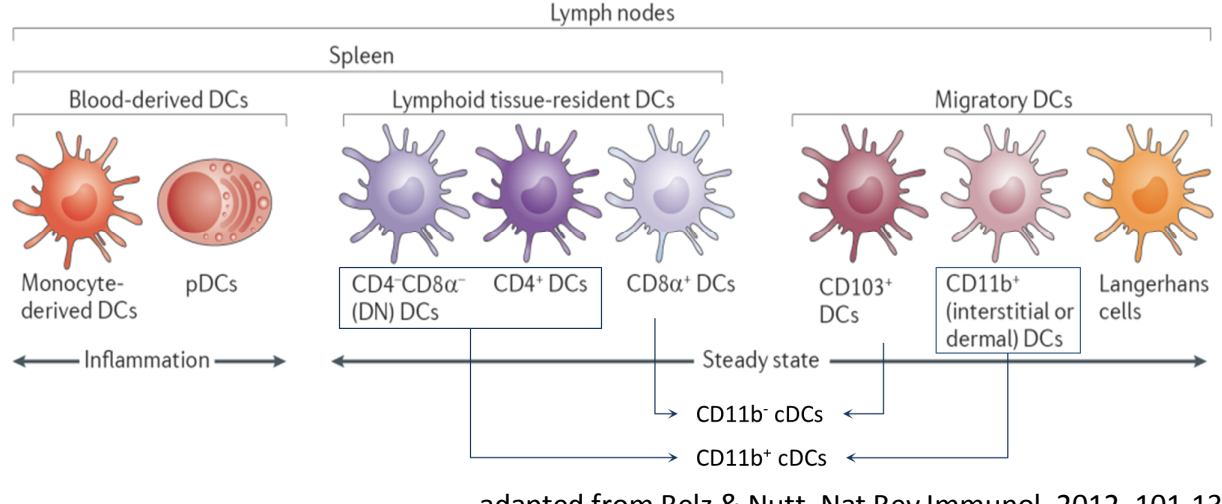

Figure 2: Characterization of murine DC subsets.

Figure shows key phenotype markers of different DC subsets. DCs are grouped according to the type of DC and their localization in secondary lymphoid tissues. Monocyte-derived DCs are generated during infection and are rapidly recruited to sites of inflammation, whereas other DC subsets are normally present in the steady state.

\section{Conventional DCs}

Conventional DCs (cDCs) share strict dependence of Flt3L for their development ${ }^{(9)}$ (Figure 3 ) and represent the scouts of the immune system. They constantly scan their immediate environment by capturing environmental and cell-associated antigens and persistently interact with the cavalry of $T$ lymphocytes. Uniquely, cDCs are equipped with superior antigen processing and presentation machinery that not only allows them to efficiently present endogenous and exogenous antigens on their MHC I and MHC II molecules respectively, called conventional presentation, but also render them capable of unconventional presentation of exogenous noncytosolic Ags in an $\mathrm{MHC}$ I context $^{(8,10)}$ (Figure 4). The latter process is referred to as cross-presentation and has been shown to be critical in immunity against viruses, cancer cells and intracellular bacteria ${ }^{(8,11)}$. 


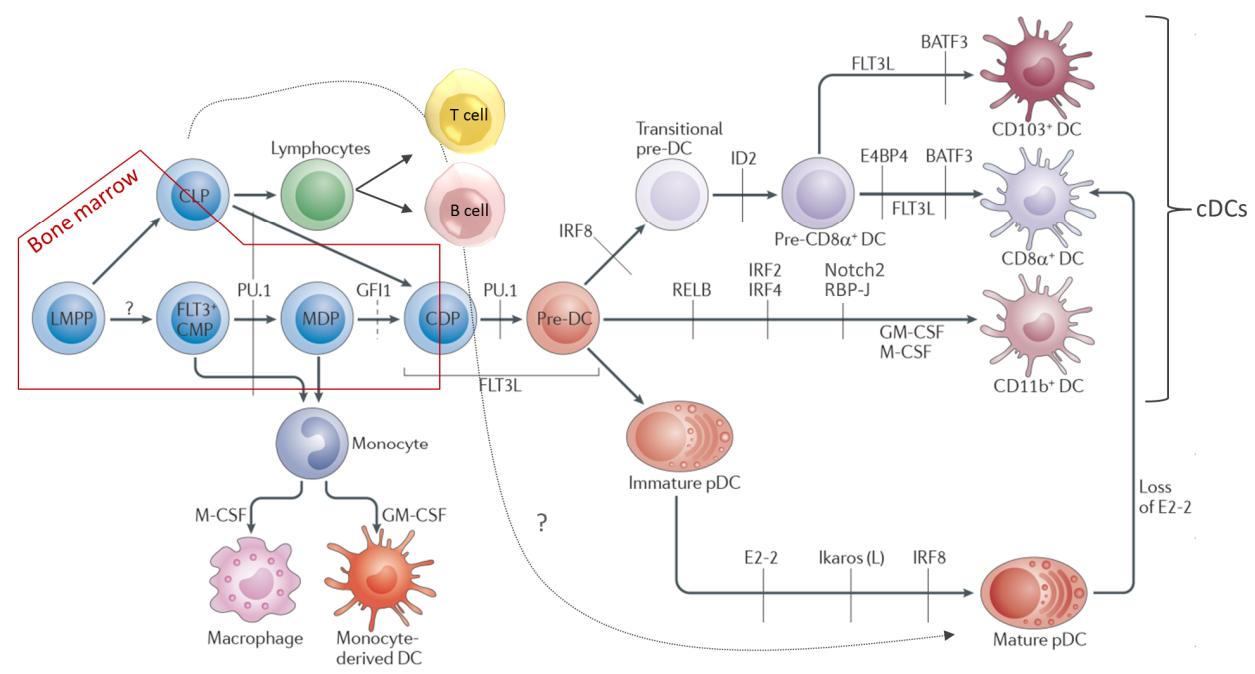

- adapted from Belz \& Nutt, Nat Rev Immunol, 2012, 101-13

Figure 3: Growth and transcription factors regulating murine DC development

Figure shows the developmental pathways of bone marrow progenitors (lymphoid and myeloid) to $T$ and B cells, macrophages and DC subsets. Vertical lines represent essential growth factors or transcription factors. Presence of progenitors in the bone marrow is indicated by the red line. Monocyte and DC development depend on strong expression of PU.1, which regulates the expression of the cytokine receptors FLT3R, M-CFSR, and GM-CSFR. The development of CD8 $\alpha^{+}$and $C D 103^{+}$DCs depends on IRF8, ID2, E4BP4 (also known as NFIL3) and BATF3, as well as on FLT3 signaling. CD11b ${ }^{+}$DCs development relies on expression of ReIB, IRF2, IRF4, Notch2 and RBP-J, as well as the growth factors GM-CSF and M-CSF. CD11 ${ }^{+}$cDCs are also reduced in FLT3 and FLT3L deficient mice, although to a lesser extent than $\mathrm{CD} \alpha^{+}{ }^{+} \mathrm{CDCs}{ }^{(10,12)}$. pDC can develop from CDPs requiring expression of E2-2, Ikaros and IRF8, low level of PU.1 and absence of ID2. However lymphoid progenitors were also shown to have pDC-generating potential (dotted arrow). LMPP: lymphoid-primed multipotent progenitor, CMP: common myeloid progenitor, MDP: macrophage and DC progenitor, CDP: common DC progenitor, CLP: common lymphoid progenitor, pDC: plasmacytoid DC, M-CSF: Macrophage colony-stimulating factor, GM-CSF: Granulocyte Macrophage colonystimulating factor, FLT3: FMS-related tyrosine kinase 3, FLT3L: FLT3 ligand, M-CSFR: macrophage colony-stimulating factor receptor, GM-CSFR: granulocyte-macrophage colony-stimulating factor receptor, IRF: interferon-regulatory factor, Notch2: Neurogenic locus notch homolog protein 2, ID2: inhibitor of DNA binding, E4BP4: promoter-binding protein 4, NFIL3: Nuclear factor interleukin 3 regulated, BATF3: basic leucine zipper transcription factor ATF-like 3, GFI1: growth factor independent 1, RBP-J: Recombining binding protein suppressor of hairless. 


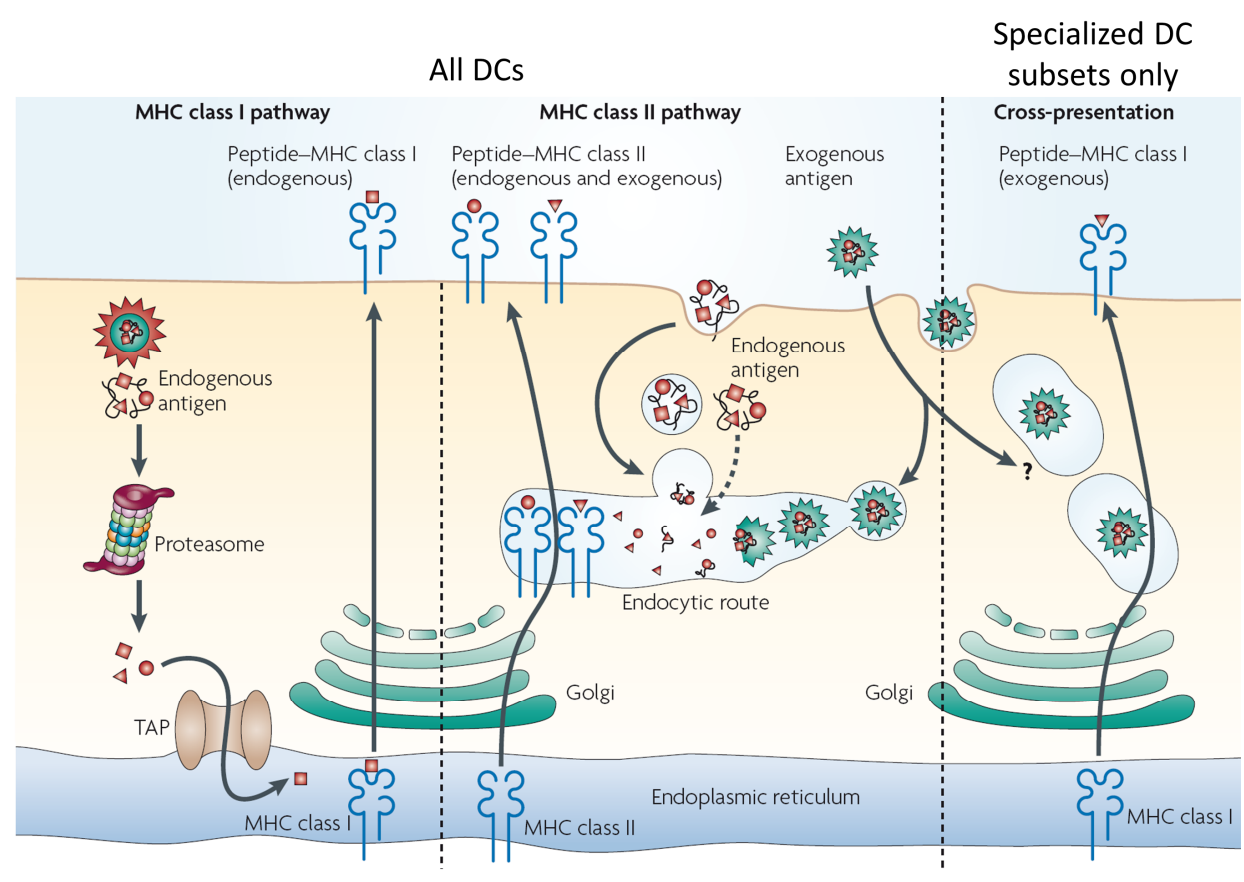

- adapted from Villadangos \& Schnorrer, Nat Rev Immunol, 2007, 543-55

Figure 4: Conventional antigen presentation and cross-presentation pathways in dendritic cells.

All dendritic cells (DCs) have the capacity to present antigens (Ags) using the MHC class I and MHC class II pathways. MHC class I molecules present cytosolic peptides, which comprise almost exclusively endogenous proteins. MHC class II molecules present peptide Ags generated by proteolytic degradation in endosomal compartments. Therefore, these Ags can represent endogenous or endocytosed exogenous material. $\mathrm{CD}^{+}$and $\mathrm{CD} 103^{+} \mathrm{DCs}$ (and to some extent monocyte-derived DCs) have a unique ability to present exogenous antigens in an MHC class I context (cross-presentation pathway). However, the mechanisms involved are not completely understood. TAP, transporter associated with antigen processing.

To increase the efficiency of DCs in finding their cognate lymphocyte for antigen presentation, the body uses compartmentalization (the lymphoid system), restricting the area of the lymphocyte pool for interaction with dendritic cells to about $10 \%$ of the body's volume. To reach naïve T cells in $\mathrm{T}$ cell zones of the lymphoid organs cDCs require exceptional directional migration ability $(8,10)$. CDCs are dependent on CCR7 to migrate through afferent lymphatics along CCL19 and CCL21 chemokines gradients. To regulate adaptive immune responses DCs are specialized in T cell crosstalk (being 


\section{1 | General Introduction}

bidirectional interaction influencing both cell types) ${ }^{(6,10)}$ and can both initiate naïve $T$ cell responses and restimulate memory $T$ cells. cDCs (and to some extent also pDCs) steer protective $\mathrm{T}$ cell responses, $\mathrm{T}$ helper (Th) cell polarization, memory formation but also $\mathrm{T}$ cell tolerance and silencing ${ }^{(8)}$, and this depends on three different signals: cognate MHC-peptide encounter, costimulatory signals (such as CD40 and B7 family members) and cytokine secretion. Inflammatory mediators can amplify responses but all three signals are needed to initiate responses ${ }^{(8)}$. In addition, lack of costimulation leads to $\mathrm{T}$ cell tolerance, as is the case in steady-state conditions. It should be noted that $\mathrm{CDCs}$ can also actively silence $T$ cells through inhibitory molecules such as Programmed cell death 1 ligand (PD-L1) ${ }^{(8)}$. Furthermore, DC-T cell crosstalk is bidirectional as $T$ cells can also promote $D C$ maturation ${ }^{(8)}$. The role of costimulatory and coinhibitory molecules in the context of atherosclerosis is discussed in Chapter 2.

cDCs develop from bone marrow precursors (CDPs and pre-DCs) (Figure 3) and migrate via the blood to peripheral tissues (such as skin, lung, liver, intestinal tract, etc.) or lymphoid organs (spleen, lymph nodes, thymus, peyer patches, etc.), where they give rise to migratory or lymphoid resident DCs, respectively ${ }^{(13)}$. Migratory DCs cannot be found in the spleen but migrate from the periphery towards lymph nodes (Figure 2). Classification of CDCs is quite complex, unique for most species and is a recent topic of debate (DC conference in Tours, France $)^{(14)}$. In humans, two main subsets with different functions can be found in blood: BDCA1/CD $1 c^{+}$DCs and BDCA3/CD141 ${ }^{+} \mathrm{DCs}{ }^{(15)}$. The main subsets in human skin, liver, lung, and intestine are $C D 1 c^{+} C D 1 a^{+} D C s$ and $C D 141^{+} \mathrm{Clec} \mathrm{A}^{+} \mathrm{DCs}{ }^{(15)}$. In mice, $\mathrm{CDC}$ s are subdivided by their expression of CD8 $\alpha$ (and CD103) or CD11b (Figure 2).

\section{$\underline{\mathrm{CD} 8 \alpha^{+}\left(\mathrm{CD} 11 \mathrm{~b}^{-}\right) \mathrm{cDCs} \text { and } \mathrm{CD} 103^{+}\left(\mathrm{CD} 11 \mathrm{~b}^{-}\right) \mathrm{CDCs}}$}

The lymphoid resident $\mathrm{CD} 8 \alpha^{+} \mathrm{DC}$ and its migratory counterpart $\mathrm{CD} 103^{+}$ $D C$ are the best characterized $C D C$ subsets thus far. Both subsets uniquely express XCR1, which was shown to be crucial for efficient cytotoxic immunity (16). Functionally, $C D 8 \alpha^{+} D C s$ are superior in cross-presentation of exogenous antigens to $\mathrm{CD}^{+} \mathrm{T}$ cells in a MHC-I restricted context ${ }^{(17,18)}$ (Figure 4). Development of $\mathrm{CD} \alpha^{+}$and $\mathrm{CD} 103^{+} \mathrm{DCs}$ depends on expression of IRF8, inhibitor of DNA binding 2 (ID2), E4BP4 and basic leucine zipper ATF-like 3 (BATF3) $^{(5,8)}$ (Figure 3). 


\section{$\underline{\mathrm{CD} 11 \mathrm{~b}^{+} \mathrm{cDCS}}$}

$\mathrm{CD}_{11} \mathrm{~b}^{+} \mathrm{cDCs}$ are less well defined. They are a heterogeneous group of cells and represent the most abundant DC type in most lymphoid tissues (lymphoid resident DCs), but can also be found in nonlympoid tissues (migratory DCs) ${ }^{(8)}$. CD11 $\mathrm{b}^{+}$lymphoid resident DCs can be subdivided into CD4 ${ }^{+}$ DCs and CD4CD8- (DN) DCs (Figure 2). However, massive parallel single cell RNA-seq revealed that this categorization is not fully correct in that the resulting classes do not represent homogenous subpopulations ${ }^{(19)}$. CD11b ${ }^{+}$ migratory DCs include dermal and interstitial DCs (Figure 2). The transcription factors involved in $\mathrm{CD}_{11} \mathrm{~b}^{+} \mathrm{CDC}$ development and their hierarchy during development is complicated by $\mathrm{CD} 11 \mathrm{~b}^{+} \mathrm{CDC}$ heterogeneity ${ }^{(8)}$, however following transcription factors have been shown to control $\mathrm{CD}_{11} \mathrm{~b}^{+} \mathrm{CDC}$ development: RelB ${ }^{(20)}$, IRF2 ${ }^{(21)}$, IRF4 ${ }^{(22)}$, NOTCH2 ${ }^{(23)}$ and RBP-J ${ }^{(24)}$ (Figure 3). Because of their heterogeneity $C D 11 b^{+}$DC function is mostly characterized by lack of $C D 8 \alpha^{+} D C$ associated functions ${ }^{(8)}$. CD11 $b^{+} D C$ s are less efficient in crosspresentation and production of specific cytokines, like IL-12 ${ }^{(8)}$. However, $\mathrm{CD} 11 \mathrm{~b}^{+} \mathrm{DCs}$ are efficient in production of IL-6 ${ }^{(25)}$ and IL-23 ${ }^{(26)}$, compared to $C D 8 a^{+} D C s$ they are better in inducing $\mathrm{CD}^{+} \mathrm{T}$ cell responses, what might be attributed to their prominent expression of $\mathrm{MHCll}$ presentation machinery ${ }^{(8,}$ 27). In addition, $C D 11 b^{+}$DCs are also potent producers of chemokines, for instance $\mathrm{CCL} 3, \mathrm{CCL} 4$ and $\mathrm{CCL}^{(8,28)}$.

\section{Monocyte derived DCs}

During inflammation circulating monocytes can be mobilized to migrate to the inflammatory focus and to give rise to DCs which are therefore called monocyte-derived DCs (moDCs) or inflammatory DCs (iDCs) ${ }^{(5,8)}$ (Figures 2\&3). MoDCs are difficult to distinguish from bona fide cDCs as they also express CD11c, MHC II and CD11b, however they keep some signatures from their ontogeny, such as expression of CD64 ${ }^{(8)}$, Fc gamma receptor $1(\mathrm{Fc} \gamma \mathrm{RI})^{(8)}$, MAC3 ${ }^{(5)}$ or DC-SIGN ${ }^{(5)}$. Like CDCs, moDC have potent antigen-presenting capabilities and some even attribute them the ability of cross-presentation ${ }^{(29,}$ 30) (Figure 4). Consequently, moDCs might represent a crucial reservoir of professional APCs during inflammation. However, moDCs remain poorly defined and, as they share similarities with $\mathrm{CD}_{11} \mathrm{~b}^{+} \mathrm{cDCs}$, further understanding of this subset might contribute to unravelling the heterogeneous $\mathrm{CD} 11 \mathrm{~b}^{+} \mathrm{cDC}$ compartment. 


\section{1 | General Introduction}

\section{Plasmacytoid DCs}

Plasmacytoid DCs (pDCs) are a distinct subset of DCs (Figures 2\&3). They originate in the bone marrow from a common DC progenitor and their development depends on the expression of E2-2, IRF8 and Ikaros ${ }^{(5)}$ (Figure 3). However, there is also evidence that pDCs can be generated from the lymphoid lineage $(8,31,32)$. They are round-shaped and, in contrast to most DCs, non-dendritic and relatively long-living circulating cells ${ }^{(13)}$. Human pDCs are defined by a unique cell surface phenotype, expressing blood leukocyte antigen 2 (BDCA-2), CD123 (IL-3R $\alpha$ ), immunoglobin-like transcript 7 (ILT7), ILT3, some CD4 and CD68, but lack expression of the lineage markers (CD3, CD19, $\mathrm{CD} 14, \mathrm{CD} 16)$ and $\mathrm{CD} 11 \mathrm{C}^{(33)}$. The murine counterpart is characterized by expression of bone marrow stromal antigen 2 (BST-2), sialic acid binding immunoglobulin -like lectin $\mathrm{H}$ (Siglec-H), B220 and Ly6C ${ }^{(33)}$. In contrast to human pDCs, mouse pDCs also express intermediate levels of CD11c ${ }^{(33)}$ and can express $\operatorname{CD} 8 \alpha$ in some cases ${ }^{(33)}$. Following their development in the bone marrow, pDCs circulate in the blood, but can also migrate into peripheral tissues and lymphoid organs. In healthy steady-state conditions pDCs are present in relatively low numbers in blood and peripheral organs, however during infection they migrate and accumulate in inflamed tissues ${ }^{\left({ }^{34}\right)}$. pDCs specialize in the rapid secretion of large quantities of type I interferons (IFNs) upon stimulation, a critical feature during viral responses. They do so by sensing oligonucletides and pathogens (such as viruses), through endosomal TLR7 and TLR9 ${ }^{(35)}$. Furthermore, pDCs were also shown to deploy other innate sensors such as TLR2, TLR12, DHX9 for pathogen detection ${ }^{(33)}$. Besides IFNs, they can also secrete cytokines, such as interleukin 12 (IL-12), IL-6 and tumor necrosis factor (TNF $\alpha)$, and release pro-inflammatory chemokines, such as CXC-chemokine ligand 8 (CXCL8), CXCL10, CC-chemokine ligand 3 (CCL3) and CCL4 ${ }^{(34)}$. In this manner, they attract and stimulate other immune cells. In addition, inflammatory stimuli induce conversion of pDCs into a dendritic cell like phenotype with upregulation of membrane $\mathrm{MHCll}$ and costimulatory molecule expression. This enables them to present antigens to $\mathrm{CD}^{+} \mathrm{T}$ cells ${ }^{(13,34)}$, although their $\mathrm{T}$ cell stimulating properties remain relatively low compared to conventional DCs (cDCs). All these features indicate that pDCs are a multifaceted subset of DCs influencing both innate and adaptive immune responses. 


\section{Modulating DC development and function}

\section{Post-transcriptional regulators of DC differentiation and function}

Cell differentiation and function in general is regulated at transcriptional level by transcription factors (TFs) and at post-transcriptional level by microRNAs (miR) and RNA binding proteins (RBPs), respectively. Transcription factors guide DC development by controlling gene expression, as can be appreciated from Figure 3. For example E2-2 is essential for pDC development, loss of Batf3 blocks development of CD8 ${ }^{+} D C s$ and IRF4 is critical

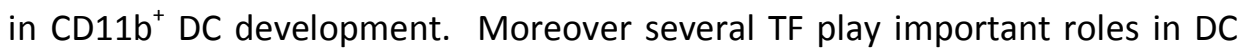
maturation/activation (e.g. NF-KB, STAT, RelB, IRF-8), migration (e.g. Runx3), and survival (e.g. NF-KB, AP-1) ${ }^{(36)}$, and in that sense represent targets for intervention in $D C$ function. In addition, numerous studies have identified critical roles for both miRs and RBPs in regulating immune cell biology, for example in monocytes ${ }^{(37,38)}$ and macrophages ${ }^{(39-42)}$. RBPs are emerging to be particularly interesting modulators of cell biology, as they, in contrast to miRs, are able to mediate both quantitative and qualitative changes to the transcriptome ${ }^{(43-45)}$. They do so by (alternative) splicing or editing of (pre-) mRNA, but also by influencing mRNA stability, subcellular localization and translational activation or repression $\left(^{43-45}\right.$ and de Bruin et al, Nat Commun, 2016, in press). Recently, we and others have identified RBPs, such as Quaking (QKI) as multifunctional regulators of lymphocyte and monocyte/macrophage development and function ( ${ }^{40,46}$ and de Bruin, Nat Commun, 2016, in press). Extrapolating these findings, it is conceivable that RBPs also influence DC development and function.

\section{DC maturation/activation, a crucial role for CD40}

As described earlier productive $\mathrm{T}$ cell priming is depend on three signals: cognate MHCp-TCR interaction, costimulation and instructing cytokines ${ }^{(8)}$. Immature DCs have low expression of costimulatory molecules on their surface and therefore have poor T cell priming capacity. However upon activation, DCs switch from an antigen-capturing cell towards to a professional $A P C$, upregulating MHC and costimulatory molecule expression (Figure 1). CD40 signaling has shown to be an important inducer of this transition ${ }^{(47)}$. Interaction of CD40 on DCs with CD40L (CD154) on T cells leads to proper DC activation and renders them potent in T cell priming (and cytokine production) 


\section{1 | General Introduction}

${ }^{(47)}$. Inefficient DC activation leads to lack or inadequate secondary signals, such as CD80 and CD86, resulting in apoptosis or anergic response by the lymphocyte.

CD40-CD40L interactions between non-immune as well as immune cells have been extensively studied in atherosclerosis and a crucial role for this axis in the pathogenesis of the disease is established. The role of CD40 as a driver of the atherosclerosis disease process will be elaborately discussed in Chapter 2. As abrogation of CD40 signaling under the $\mathrm{MHC}$ II promoter prevents atherosclerosis and DCs express high amount of $\mathrm{MHCII}$ and CD40, it is of interest to study the specific contribution of dendritic cell restricted CD40 in atherosclerosis.

\section{Dendritic cells in atherosclerosis}

The role for DCs in atherosclerosis is reviewed in Chapter $\mathbf{2}$, and is discussed in a broader context of cardiovascular diseases in Chapter $\mathbf{3}$. We here supplement this topic by discussing the most recent literature and current state of knowledge. DCs have been associated with many processes important in the pathogenesis of atherosclerosis, such as cholesterol homeostasis, lipid uptake and regulation of pro- and anti-atherosclerotic immune responses (see Chapter 2). Most of these studies however yielded indirect evidence of DC involvement, only recently a few studies have addressed the direct contribution of DCs in the immune response during atherosclerosis. For example, DCs were shown capable of processing and presenting model antigens to $\mathrm{CD}^{+} \mathrm{T}$ cells in a $\mathrm{MHC}$ II context ${ }^{(48)}$. In addition, $\mathrm{CD}^{+} \mathrm{T}^{+}$cells interacted with Ag-specific DCs in aorta explants $(48,49)$, leading to $\mathrm{T}$ cell proliferation and cytokine secretion ${ }^{(48)}$. Nevertheless, little is known regarding the outcome of these DC-T cell interactions, and studies manipulating the total DC pool show conflicting outcomes ${ }^{50}$, and Chapter 2 ). It is likely that the broad functions of the diverse DC pool blur the interpretation of the rather unspecific approaches used. For example, antibody-mediated depletion of pDCs yielded conflicting results regarding the role for pDCs in atherosclerosis, suggesting either a protective ${ }^{(51)}$ or deleterious ${ }^{(52,53)}$ effect on disease outcome. However, recently Sage et al. adopted elegant genetic approaches for selective deficiency in pDCs combined with model Ag presentation to study the role of pDCs in the development of atherosclerosis ${ }^{(49)}$. This work presents 
strong evidence for a critical role for $\mathrm{MHCll}$-restricted antigen presentation by pDCs, generating proatherogenic $T$ cell responses ${ }^{(49)}$. Besides effort on unraveling the role of the $\mathrm{pDC}$ subset, little is known regarding the role for $\mathrm{CDC}$ subsets and their functions in atherosclerosis pathogenesis. Flt3 deficient $\mathrm{LDLr}^{-/-}$mice indicated a protective role for flt3 signaling dependent $\mathrm{DCs}{ }^{(54)}$ and MyD88 signaling in $\mathrm{CD}_{11 \mathrm{C}^{+}} \mathrm{DCs}$ was shown to be important for an atheroprotective Treg response ${ }^{(55)}$. However, CDC heterogeneity complicates interpretation as it is likely that different DC subsets affect $T$ cell-mediated responses and disease severity very differently; therefore approaches targeting specific CDC subsets are needed to unravel the mechanisms of CDC involvement in the pathogenesis of atherosclerosis. Lack of specific tools, however, hamper research in that direction and few studies address this issue. Recently though, CCL17-expressing DCs, described as a subset of CD11b ${ }^{+} D C s$, were shown to drive atherosclerosis by restraining $T$ cell responses ${ }^{(56)}$. Whether these different effects depend on Ag presentation by DC subsets remains to be elucidated ${ }^{(49)}$. Moreover, many efforts shed some light on $\mathrm{CD}^{+} \mathrm{T}$ cell responses in atherosclerosis, nevertheless the role of $\mathrm{CD} 8^{+} \mathrm{T}$ cells and cross-presentation in atherosclerosis pathogenesis is still unclear.

In conclusion, dendritic cells, as regulators of innate and adaptive immunity, hold potential for the development of new efficient therapy, however the mechanisms by which DCs and more in particular specific DC subsets influence the pathogenesis of atherosclerosis remain to be unraveled. 


\section{1 | General Introduction}

\section{Hypothesis and study aims of this thesis}

The last decade, noticeable progress has been made in understanding the contribution of innate and adaptive immune responses in atherosclerosis disease initiation and progression. Dendritic cells regulate both arms of the immune system and are therefore an interesting cell type to study in the context of atherosclerosis. Accumulating evidence indicates a crucial role for these cells in the pathogenesis of atherosclerosis. However, how DC subsets function in a hyperlipidemic environment and what their individual contribution is to atherosclerosis remains poorly understood.

The hypothesis of this thesis is that the diverse dendritic cell subsets exert distinct roles in the pathophysiology of atherosclerosis by priming and tweaking immune responses, and that the local environment can influence DC function.

The central goal of my studies is to explore the involvement of several DC subsets, such as $\mathrm{CD}^{+}$dendritic cells and pDCs in the inflammatory process of atherosclerosis. In addition, I will zoom in on the impact of potential modulators of DC differentiation and functions relevant for atherosclerosis, such as hypercholesterolemia, costimulatory signals like CD40 and (post)transcriptional regulators of myeloid function, such as the RNA-binding protein Quaking.

In Chapter 2, I have reviewed the current insights regarding the pathogenesis of atherosclerosis as chronic inflammatory disorder, with particular emphasis on the involvement of the different immune cells of the innate as well as the adaptive immune system, along with the costimulatory and coinhibitory interactions which are relevant to atherosclerosis related immune processes. Chapter 3 summarizes the potential role of various DC subsets in cardiovascular diseases (CVDs), and their potential as therapeutic target in CVDs. As the exact role of $C D 8^{+} D C s$, and more in general of cross-presentation, in atherosclerosis was largely unknown, we sought to investigate their (causal) involvement in the pathogenesis of disease in Chapter 4. To study their impact on atherosclerosis, we made use of the Bat3f $\%$ mouse model, which essentially lacks CD8 ${ }^{+}$DCs and is defective in cross-presentation. In Chapter 5, we hypothesized that a hyperlipidemic environment may interfere with pDC 
differentiation and function, thereby compromising pDC's innate function and $T$ cell priming capacity. To this end, we investigated whether exposure of human pDCs to (modified) lipoproteins in vitro, affects human pDC maturation, TLR7 and 9 activation and T cell polarizing capability. Along the same line, we addressed in Chapter 6, whether a hyperlipidemic environment is influencing DC homeostasis, their maturation and T cell priming ability in vivo in mice. In Chapter $\mathbf{7}$ and 8, we investigated whether modulation of DC function can improve atherosclerosis disease outcome. Hereto we pursued genetic gain or loss of function approaches, interfering with DC differentiation at posttranscriptional level or modifying DC costimulatory abilities. In Chapter 7, we postulated in analogy to earlier studies by our group and that of Prof Zonneveld on other myeloid subsets, that DC development and function is regulated by the RNA-binding protein Quaking, and that its deficiency would influence atherosclerosis disease progression. Hence, we used the CD11c-cre $x$ Quaking ${ }^{\text {floxed }}$ conditional knockout mouse model to specifically study the impact of its loss in the dendritic cell lineage and its consequence in atherosclerosis. In Chapter 8, we used a model containing a constitutive active form of CD40 (Cd11c-LMP mice) to investigated the role of dendritic cell CD40 in atherosclerosis. Finally, Chapter 9 summarizes and discusses the most important findings of this thesis, puts them in a broader context and defines the most relevant, outstanding questions and future perspectives. 


\section{1 | General Introduction}

\section{References}

1. Wolf D, Zirlik A, Ley K. Beyond vascular inflammation--recent advances in understanding atherosclerosis. Cell Mol Life Sci. 2015;72:3853-3869

2. Ross R. The pathogenesis of atherosclerosis--an update. N Engl J Med. 1986;314:488-500

3. Lanier LL, Sun JC. Do the terms innate and adaptive immunity create conceptual barriers? Nat Rev Immunol. 2009;9:302-303

4. Iwasaki A, Medzhitov R. Regulation of adaptive immunity by the innate immune system. Science. 2010;327:291-295

5. Belz GT, Nutt SL. Transcriptional programming of the dendritic cell network. Nat Rev Immunol. 2012;12:101-113

6. Koltsova EK, Ley K. How dendritic cells shape atherosclerosis. Trends Immunol. 2011;32:540547

7. Banchereau J, Briere F, Caux C, Davoust J, Lebecque S, Liu YJ, Pulendran B, Palucka K. Immunobiology of dendritic cells. Annu Rev Immunol. 2000;18:767-811

8. Mildner A, Jung S. Development and function of dendritic cell subsets. Immunity. 2014;40:642-656

9. Kingston D, Schmid MA, Onai N, Obata-Onai A, Baumjohann D, Manz MG. The concerted action of gm-csf and flt3-ligand on in vivo dendritic cell homeostasis. Blood. 2009;114:835843

10. Merad M, Sathe P, Helft J, Miller J, Mortha A. The dendritic cell lineage: Ontogeny and function of dendritic cells and their subsets in the steady state and the inflamed setting. Annu Rev Immunol. 2013;31:563-604

11. Rock KL. The ins and outs of cross-presentation. Nat Immunol. 2003;4:941-943

12. McKenna HJ, Stocking KL, Miller RE, Brasel K, De Smedt T, Maraskovsky E, Maliszewski CR, Lynch DH, Smith J, Pulendran B, Roux ER, Teepe M, Lyman SD, Peschon JJ. Mice lacking flt3 ligand have deficient hematopoiesis affecting hematopoietic progenitor cells, dendritic cells, and natural killer cells. Blood. 2000;95:3489-3497

13. Shortman K, Naik SH. Steady-state and inflammatory dendritic-cell development. Nat Rev Immunol. 2007;7:19-30

14. Haniffa M, Collin M, Ginhoux F. Ontogeny and functional specialization of dendritic cells in human and mouse. Adv Immunol. 2013;120:1-49

15. Durand M, Segura E. The known unknowns of the human dendritic cell network. Front Immunol. 2015;6:129

16. Dorner BG, Dorner MB, Zhou X, Opitz C, Mora A, Guttler S, Hutloff A, Mages HW, Ranke K, Schaefer M, Jack RS, Henn V, Kroczek RA. Selective expression of the chemokine receptor $\mathrm{xcr} 1$ on cross-presenting dendritic cells determines cooperation with cd8+t cells. Immunity. 2009;31:823-833

17. Hildner K, Edelson BT, Purtha WE, Diamond M, Matsushita H, Kohyama M, Calderon B, SchramI BU, Unanue ER, Diamond MS, Schreiber RD, Murphy TL, Murphy KM. Batf3 deficiency reveals a critical role for cd8alpha+ dendritic cells in cytotoxic t cell immunity. Science. 2008;322:1097-1100

18. den Haan JM, Lehar SM, Bevan MJ. Cd8(+) but not cd8(-) dendritic cells cross-prime cytotoxic t cells in vivo. J Exp Med. 2000;192:1685-1696

19. Jaitin DA, Kenigsberg E, Keren-Shaul H, Elefant N, Paul F, Zaretsky I, Mildner A, Cohen N, Jung S, Tanay A, Amit I. Massively parallel single-cell rna-seq for marker-free decomposition of tissues into cell types. Science. 2014;343:776-779

20. Wu L, D'Amico A, Winkel KD, Suter M, Lo D, Shortman K. Relb is essential for the development of myeloid-related cd8alpha- dendritic cells but not of lymphoid-related cd8alpha+ dendritic cells. Immunity. 1998;9:839-847

21. Ichikawa E, Hida S, Omatsu Y, Shimoyama S, Takahara K, Miyagawa S, Inaba K, Taki S. Defective development of splenic and epidermal cd4+ dendritic cells in mice deficient for ifn regulatory factor-2. Proc Natl Acad Sci U S A. 2004;101:3909-3914 
22. Suzuki S, Honma K, Matsuyama T, Suzuki K, Toriyama K, Akitoyo I, Yamamoto K, Suematsu T, Nakamura M, Yui K, Kumatori A. Critical roles of interferon regulatory factor 4 in cd11bhighcd8alpha- dendritic cell development. Proc Natl Acad Sci U S A. 2004;101:89818986

23. Lewis KL, Caton ML, Bogunovic M, Greter M, Grajkowska LT, Ng D, Klinakis A, Charo IF, Jung $\mathrm{S}$, Gommerman JL, Ivanov, II, Liu K, Merad M, Reizis B. Notch2 receptor signaling controls functional differentiation of dendritic cells in the spleen and intestine. Immunity. 2011;35:780-791

24. Caton ML, Smith-Raska MR, Reizis B. Notch-rbp-j signaling controls the homeostasis of cd8dendritic cells in the spleen. J Exp Med. 2007;204:1653-1664

25. Persson EK, Uronen-Hansson H, Semmrich M, Rivollier A, Hagerbrand K, Marsal J, Gudjonsson S, Hakansson U, Reizis B, Kotarsky K, Agace WW. Irf4 transcription-factordependent $c d 103(+) c d 11 b(+)$ dendritic cells drive mucosal t helper 17 cell differentiation. Immunity. 2013;38:958-969

26. Schlitzer A, McGovern N, Teo P, Zelante T, Atarashi K, Low D, Ho AW, See P, Shin A, Wasan PS, Hoeffel G, Malleret B, Heiseke A, Chew S, Jardine L, Purvis HA, Hilkens CM, Tam J, Poidinger M, Stanley ER, Krug AB, Renia L, Sivasankar B, Ng LG, Collin M, Ricciardi-Castagnoli $P$, Honda K, Haniffa M, Ginhoux F. Irf4 transcription factor-dependent cd11b+ dendritic cells in human and mouse control mucosal il-17 cytokine responses. Immunity. 2013;38:970-983

27. Dudziak D, Kamphorst AO, Heidkamp GF, Buchholz VR, Trumpfheller C, Yamazaki S, Cheong C, Liu K, Lee HW, Park CG, Steinman RM, Nussenzweig MC. Differential antigen processing by dendritic cell subsets in vivo. Science. 2007;315:107-111

28. Proietto Al, O'Keeffe M, Gartlan K, Wright MD, Shortman K, Wu L, Lahoud MH. Differential production of inflammatory chemokines by murine dendritic cell subsets. Immunobiology. 2004;209:163-172

29. Cheong C, Matos I, Choi JH, Dandamudi DB, Shrestha E, Longhi MP, Jeffrey KL, Anthony RM, Kluger C, Nchinda G, Koh H, Rodriguez A, Idoyaga J, Pack M, Velinzon K, Park CG, Steinman RM. Microbial stimulation fully differentiates monocytes to dc-sign/cd209(+) dendritic cells for immune t cell areas. Cell. 2010;143:416-429

30. McDonnell AM, Prosser AC, van Bruggen I, Robinson BW, Currie AJ. Cd8alpha+ dc are not the sole subset cross-presenting cell-associated tumor antigens from a solid tumor. Eur J Immunol. 2010;40:1617-1627

31. Manz MG, Traver D, Miyamoto T, Weissman IL, Akashi K. Dendritic cell potentials of early lymphoid and myeloid progenitors. Blood. 2001;97:3333-3341

32. Onai N, Kurabayashi K, Hosoi-Amaike M, Toyama-Sorimachi N, Matsushima K, Inaba K, Ohteki T. A clonogenic progenitor with prominent plasmacytoid dendritic cell developmental potential. Immunity. 2013;38:943-957

33. Swiecki M, Colonna M. The multifaceted biology of plasmacytoid dendritic cells. Nat Rev Immunol. 2015;15:471-485

34. Swiecki M, Colonna M. Unraveling the functions of plasmacytoid dendritic cells during viral infections, autoimmunity, and tolerance. Immunol Rev. 2010;234:142-162

35. Gilliet M, Cao W, Liu YJ. Plasmacytoid dendritic cells: Sensing nucleic acids in viral infection and autoimmune diseases. Nat Rev Immunol. 2008;8:594-606

36. Bharadwaj AS, Agrawal DK. Transcription factors in the control of dendritic cell life cycle. Immunol Res. 2007;37:79-96

37. Dang TM, Wong WC, Ong SM, Li P, Lum J, Chen J, Poidinger M, Zolezzi F, Wong SC. Microrna expression profiling of human blood monocyte subsets highlights functional differences. Immunology. 2015;145:404-416

38. Sahlberg AS, Ruuska M, Granfors K, Penttinen MA. Altered regulation of elavl1/hur in hlab27-expressing u937 monocytic cells. PLoS One. 2013;8:e70377

39. Tili E, Chiabai M, Palmieri D, Brown M, Cui R, Fernandes C, Richmond T, Kim T, Sheetz T, Sun HL, Lagana A, Veneziano D, Volinia S, Rassenti L, Kipps T, Awad H, Michaille JJ, Croce CM. Quaking and mir-155 interactions in inflammation and leukemogenesis. Oncotarget.

2015;6:24599-24610 


\section{1 | General Introduction}

40. Fu H, Yang G, Wei M, Liu L, Jin L, Lu X, Wang L, Shen L, Zhang J, Lu H, Yao L, Lu Z. The rnabinding protein qki5 is a direct target of c/ebpalpha and delays macrophage differentiation. Mol Biol Cell. 2012;23:1628-1635

41. Tian FJ, An LN, Wang GK, Zhu JQ, Li Q, Zhang YY, Zeng A, Zou J, Zhu RF, Han XS, Shen N, Yang HT, Zhao XX, Huang S, Qin YW, Jing Q. Elevated microrna-155 promotes foam cell formation by targeting hbp1 in atherogenesis. Cardiovasc Res. 2014;103:100-110

42. Wei Y, Nazari-Jahantigh M, Neth P, Weber C, Schober A. Microrna-126, -145, and -155: A therapeutic triad in atherosclerosis? Arterioscler Thromb Vasc Biol. 2013;33:449-454

43. Kafasla P, Skliris A, Kontoyiannis DL. Post-transcriptional coordination of immunological responses by rna-binding proteins. Nat Immunol. 2014;15:492-502

44. Fu XD, Ares M, Jr. Context-dependent control of alternative splicing by rna-binding proteins. Nat Rev Genet. 2014;15:689-701

45. Chenard CA, Richard S. New implications for the quaking rna binding protein in human disease. J Neurosci Res. 2008;86:233-242

46. Turner $M$, Hodson DJ. An emerging role of rna-binding proteins as multifunctional regulators of lymphocyte development and function. Adv Immunol. 2012;115:161-185

47. Ma DY, Clark EA. The role of cd40 and cd154/cd40I in dendritic cells. Semin Immunol. 2009;21:265-272

48. Koltsova EK, Garcia Z, Chodaczek G, Landau M, McArdle S, Scott SR, von Vietinghoff S, Galkina E, Miller YI, Acton ST, Ley K. Dynamic t cell-apc interactions sustain chronic inflammation in atherosclerosis. J Clin Invest. 2012;122:3114-3126

49. Sage AP, Murphy D, Maffia P, Masters LM, Sabir SR, Baker LL, Cambrook H, Finigan AJ, AitOufella H, Grassia G, Harrison JE, Ludewig B, Reith W, Hansson GK, Reizis B, Hugues S, Mallat Z. Mhc class ii-restricted antigen presentation by plasmacytoid dendritic cells drives proatherogenic t cell immunity. Circulation. 2014;130:1363-1373

50. Gautier EL, Huby T, Saint-Charles F, Ouzilleau B, Pirault J, Deswaerte V, Ginhoux F, Miller ER, Witztum JL, Chapman MJ, Lesnik P. Conventional dendritic cells at the crossroads between immunity and cholesterol homeostasis in atherosclerosis. Circulation. 2009;119:2367-2375

51. Daissormont IT, Christ A, Temmerman L, Sampedro Millares S, Seijkens T, Manca M, Rousch $M$, Poggi $M$, Boon $L$, van der Loos $C$, Daemen $M$, Lutgens $E$, Halvorsen $B$, Aukrust $P$, Janssen $\mathrm{E}$, Biessen EA. Plasmacytoid dendritic cells protect against atherosclerosis by tuning t-cell proliferation and activity. Circ Res. 2011;109:1387-1395

52. Doring Y, Manthey HD, Drechsler M, Lievens D, Megens RT, Soehnlein O, Busch M, Manca M, Koenen RR, Pelisek J, Daemen MJ, Lutgens E, Zenke M, Binder CJ, Weber C, Zernecke A. Auto-antigenic protein-DNA complexes stimulate plasmacytoid dendritic cells to promote atherosclerosis. Circulation. 2012;125:1673-1683

53. Macritchie N, Grassia G, Sabir SR, Maddaluno M, Welsh P, Sattar N, lalenti A, KurowskaStolarska M, Mclnnes IB, Brewer JM, Garside P, Maffia P. Plasmacytoid dendritic cells play a key role in promoting atherosclerosis in apolipoprotein e-deficient mice. Arterioscler Thromb Vasc Biol. 2012;32:2569-2579

54. Choi JH, Cheong C, Dandamudi DB, Park CG, Rodriguez A, Mehandru S, Velinzon K, Jung IH, Yoo JY, Oh GT, Steinman RM. Flt3 signaling-dependent dendritic cells protect against atherosclerosis. Immunity. 2011;35:819-831

55. Subramanian M, Thorp E, Hansson GK, Tabas I. Treg-mediated suppression of atherosclerosis requires myd88 signaling in dcs. J Clin Invest. 2013;123:179-188

56. Weber C, Meiler S, Doring Y, Koch M, Drechsler M, Megens RT, Rowinska Z, Bidzhekov K, Fecher C, Ribechini E, van Zandvoort MA, Binder CJ, Jelinek I, Hristov M, Boon L, Jung S, Korn T, Lutz MB, Forster I, Zenke M, Hieronymus T, Junt T, Zernecke A. Ccl17-expressing dendritic cells drive atherosclerosis by restraining regulatory t cell homeostasis in mice. $J$ Clin Invest. 2011;121:2898-2910 
General Introduction | 1 


\section{Bart Legein}

Lieve Temmerman

Erik A.L. Biessen

Esther Lutgens 


\section{CHAPTER}

Inflammation and Immune System Interactions in Atherosclerosis

- Cellular and Molecular Life Sciences 2013; 70(20):3847-69 (adapted) -

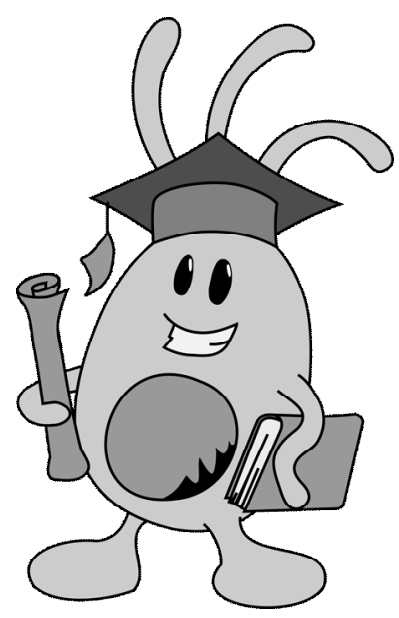




\begin{abstract}
Cardiovascular disease (CVD) is the leading cause of mortality worldwide, accounting for 16.7 million deaths each year. The underlying cause of the majority of CVD is atherosclerosis. In the past, atherosclerosis was considered to be the result of passive lipid accumulation in the vessel wall. Today's picture is far more complex. Atherosclerosis is considered a chronic inflammatory disease that results in the formation of plaques in large and midsized arteries. Both cells of the innate and the adaptive immune system play a crucial role in its pathogenesis. By transforming immune cells into pro- and anti-inflammatory chemokine and cytokine producing units, and by guiding the interactions between the different immune cells, the immune system decisively influences the propensity of a given plaque to rupture and cause clinical symptoms like myocardial infarction and stroke. In this review, we give an overview on the newest insights in the role of different immune cells and subtypes in atherosclerosis.
\end{abstract}




\section{Introduction}

The most common underlying cause of cardiovascular diseases, such as myocardial infarction or stroke, is atherosclerosis ${ }^{(1,2)}$. Atherosclerosis is a slowly progressing disease in which lesions (plaques) are formed in large and mid-sized arteries. Risk factors are hypertension, diabetes, smoking, excessive food intake, but also previous infections (influenza, oral pathogens) or underlying (auto)immune diseases like lupus, Wegener's granulomatosis or rheumatoid arthritis ${ }^{(3-6)}$. Although plaques can grow to a sufficiently large size to compromise blood flow, most of its clinical complications are attributable to arterial occlusion due to plaque erosion or rupture ${ }^{(7)}$. Plaques form at predisposed regions characterized by disturbed blood flow dynamics, such as curvatures and branch points ${ }^{(7)}$. The past 2-3 decades, experimental and patient studies have fueled the notion that atherosclerosis is a lipid driven chronic inflammatory disease of the arterial wall in which several components of both the innate and adaptive immune system play a pivotal role.

The development of atherosclerosis is initiated by activation, dysfunction and structural alterations of the endothelium cells leading to subendothelial retention of lipid components from the plasma, such as lowdensity lipoprotein (LDL). Here, lipids are susceptible to modification by oxygen radicals (like reactive oxygen species) and enzymes (such as myeloperoxidase and lipoxygenases) initiating the inflammatory process. The endothelium becomes activated, secretes chemokines such as CCL2, and starts expressing adhesion molecules, such as E-selectin and VCAM-1, thereby promoting the adhesion of leukocytes and activated platelets to the endothelium. Activated platelets secrete additional chemokines (like CCL5 and CXCL4) and undergo interactions with leukocytes to further boost immune cell infiltration ${ }^{(8)}$. Monocytes, $T$ cells and dendritic cells (DCs) are the first cell types present in the lesions. In the intima, monocytes differentiate into macrophages (or DCs). Subsequently, these phagocytes start to ingest (modified) lipids and become 'foam cells'. T cells are recruited in parallel with macrophages and also produce atherogenic mediators. DCs are already present in normal arteries but are actively recruited during atherosclerosis ${ }^{(9)}$.

Most of our recent insights are derived from experiments performed in atherosclerotic mouse models, i.e. the $\mathrm{ApoE}^{-/-}$mouse and the $\mathrm{LDLr}^{-/-}$mouse, which have slightly different characteristics. ApoE ${ }^{-/-}$mice have a spontaneously hyperlipidemic profile, and develop atherosclerosis without dietary 
intervention, whereas $\mathrm{LDLr}^{-/}$mice only develop atherosclerosis when fed a high fat diet. By varying the amount of cholesterol and fat in the diet, atherosclerotic plaque progression in both mouse models can be modulated, and atherosclerotic plaque burden, activation of the immune system and lipid levels are thus dependent on the setting and model in which the experiment has been performed ${ }^{(10)}$. These factors can potentially influence the outcome of the results. Therefore, the findings listed in this review should be interpreted with some caution. Moreover, atherosclerosis is not a homogeneous disease, but can differ in its progression in the different sites of the arterial tree. Data obtained from one site are therefore not necessarily true for the other sites, although in most of the cases, the effects of an intervention are similar at different sites ${ }^{(10-12)}$.

In this review we discuss the newest insights on the role of the individual immune cell-types and their interactions during innate and the adaptive immune responses in atherosclerosis. The review is based on data that are obtained from, and confirmed by, multiple experiments performed by different laboratories in humans and mouse models of atherosclerosis.

\section{Innate immune cells in atherosclerosis (Figure 1)}

The innate or non-specific immune system is the first line of defense in the body and includes anatomical (e.g. the skin) and humoral barriers (e.g. complement), as well as cellular components (e.g. phagocytes). In contrast to the adaptive immune system, the innate immune system has no memory, recognizes, responds to and combats pathogenic substances fast and in a nonspecific manner.

\subsection{Monocytes and Macrophages}

Monocytes are short-lived mononuclear phagocytes of myeloid origin that represent about $3-8 \%$ of total leukocytes in the blood ${ }^{(13)}$. In mice, two monocyte subsets have been identified ${ }^{(14)}$ : The inflammatory monocyte, which is preferentially recruited to inflamed tissues and has a Ly $6 \mathrm{C}^{\text {high }} \mathrm{CX} 3 \mathrm{CR} 1^{\text {low }} \mathrm{CCR} 2^{+}$ profile; and the resident or patrolling monocyte, that is characterized by CX3CR1-dependent homing to non-inflamed tissues and has a Ly6C ${ }^{\text {low }}$ CX3CR $1^{\text {high }}$ CCR2 profile ${ }^{(13-16)}$. Both subsets can differentiate into macrophages and dendritic cells and $\mathrm{Ly}_{6 \mathrm{C}^{+}}$cells are able to convert to $\mathrm{Ly}_{\mathrm{CC}}$ cells in vivo ${ }^{(13,15)}$. In humans, three major monocyte subsets exist ${ }^{(17,18)}$. The 
"classical" CD14 ${ }^{++} \mathrm{CD} 16$ subset resembles the mouse Ly6C ${ }^{\text {high }}$ inflammatory subset and also highly expresses CCR2, whereas the "non-classical" $\mathrm{CD} 14^{+} \mathrm{CD} 16^{++}$monocytes are a possible counterpart of mouse Ly6C cells, expressing high levels of CX3CR1 and CCR5 but low levels of CCR2 ${ }^{(19)}$. Additionally, an "intermediate" $\mathrm{CD} 14^{++} \mathrm{CD} 16^{+} \mathrm{CCR} 2^{+}$subset can be distinguished (20)

\subsubsection{Monocyte recruitment and adhesion to atherosclerotic plaques}

Hypercholesterolemia induces monocytosis in $\mathrm{ApoE}^{-1-}$ mice and especially increases inflammatory Ly6 $\mathrm{C}^{\text {high }}$ monocyte counts ${ }^{(21)}$, which are more prone to enter the atherosclerotic plaque ${ }^{(21,22)}$. The increase in monocytes is due to an increase in hematopoietic stem and progenitor cells (HSPCs) in the bone marrow, which are outsourced to the spleen and exert extra-medullary hematopoiesis, thereby generating a splenic reservoir of monocytes that are also able to 'feed' the atherosclerotic plaque ${ }^{(23,24)}$. Interestingly, proteins involved in cholesterol efflux pathways tightly regulate proliferation and migration of HSPCs. The ATP binding cassette transporter A1 and $\mathrm{G1}$, as well as apolipoprotein $\mathrm{E}$ are strong inhibitors of myelopoiesis in the bone marrow, and their inhibition induces increased proliferation and mobilization of HSPCS, resulting in monocytosis and neutrophilia, and increased atherosclerosis ${ }^{(25,26)}$.

Besides a rise in monocyte numbers, chemokine dependent monocyte recruitment and survival is also increased in atherosclerosis ${ }^{(16,22,27)}$. Tracking of blood monocytes in mice indicates their continuous recruitment to plaques, which increases proportionally with lesion size ${ }^{(28)}$. Chemokines and their receptors direct cells towards sites of inflammation via interactions with glycosaminoglycans (GAGs) ${ }^{(29)}$. Blocking CCR2, CX3CR1 or CCR5 or deficiency in their ligands $C C L 2, C X 3 C L 1$ or CCL5 invariably leads to a reduction of monocyte influx in the plaque (both $L y 6 C^{\text {high }}$ and $L y 6 C^{10}$ ) and an attenuation of atherosclerosis ${ }^{(27,30-34)}$. Cheng et al. reported an increase in CX3CL1 expression in advanced plaques. Other studies report only a minor effect of CCR2 blockade or bone marrow deficiency at later stages of atherosclerosis, suggesting that $\mathrm{Ly} 6 \mathrm{C}^{\mathrm{hi}}$ are mainly important at earlier stages, whereas, Ly $6 \mathrm{C}^{10}$ or $\mathrm{Ly}_{6 \mathrm{C}^{-}}$are particularly prominent at later stages of plaque development ${ }^{(35-37)}$. 
Following chemokinesis, monocytes adhere to and roll on endothelial cells through interaction with selectins (such as E- and P-selectin) ${ }^{(38,39)}$. During rolling, monocytes upregulate integrins, like $\alpha_{4} \beta_{1}$, leading to firm adhesion, arrest and subsequent diapedesis. Within the intima, monocytes secrete lipoprotein-binding proteoglycans resulting in increased accumulation of modified LDL, which sustains inflammation ${ }^{(40,41)}$. The endothelial cell itself also becomes activated and expresses chemokines and proteases, thereby perpetuating the inflammatory response ${ }^{(42-44)}$.

Platelets can promote monocyte-endothelial cell interactions by their expression of P-selectin ${ }^{(8)}$. Repeated injections of P-selectin deficient platelets into $\mathrm{ApoE}^{-/-}$mice resulted in smaller lesions compared to mice injected with P-selectin expressing platelets ${ }^{(8)}$. Platelet P-selectin is important in the formation of platelet-leukocyte aggregates, which promote the release of chemokines, such as CCL2, CCL5, and cytokines, like IL-1 $\beta$, enhancing endothelial activation, leukocyte recruitment, rolling and transmigration ${ }^{(45,46)}$. In addition, platelets can deposit chemokines, like CCL5, on activated endothelium, which enhances monocyte recruitment and adhesion to the vascular wall ${ }^{(8)}$.

An alternative route for inflammatory cells to enter the arterial wall is via the adventitia through vasa vasorum $(47,48)$. However, the relative contribution of this process to atherosclerotic plaque development and progression is still under debate.

\subsubsection{Macrophages and atherosclerosis}

Once in the intima, differentiation factors like macrophage-colony stimulating factor (M-CSF) differentiate monocytes into macrophages $(39,49)$. Macrophages are phagocytic cells, but can also instruct other immune cells by producing various immune effector molecules and by acting as antigen presenting cells (APCs).

Osteopetrotic (op/op) mice, mice that are deficient in M-CSF and lack macrophages, are extremely resistant to atherosclerosis ${ }^{(50,51)}$. CD11b-DTR mice, in which monocytes/macrophages are selectively depleted by diphtheria toxin, show a profound reduction in early plaque development. However, when macrophages are depleted when established plaques have formed the reduction in atherosclerosis is less clear suggesting a more important role for macrophages in the initiation of atherosclerosis ${ }^{(52)}$. 


\subsubsection{Foam cell formation and cholesterol efflux}

Once macrophages start to ingest and process LDL they acquire lipid droplets in their cytoplasm. When uptake exceeds efflux, or efflux is disturbed, lipids accumulate and macrophages become 'foam cells'. Scavenger receptors SRA and CD36 mediate LDL uptake, and gene-deletion or bone-marrow transplantation experiments emphasize their function in (ox)LDL uptake and atherosclerosis ${ }^{(53-56)}$. However, other studies indicate that SRA and CD36 deficiency do not completely abolish foam cell formation ${ }^{(57,58)}$, therefore additional mechanisms, like macropinocytosis or other classes of scavenger receptors, may also play a role.

Once taken up, lipoproteins release entrapped cholesterol, which downregulates the expression of LDL receptors and decreases endogenous cholesterol synthesis. Intracellular free cholesterol undergoes re-esterification by ACAT (acyl-CoA cholesterol ester transferase) ${ }^{(39,59)}$, but can also traffic to the plasma membrane to become available for efflux ${ }^{(39,60)}$. Impairment of efflux or ACAT function leads to cytotoxicity, and macrophage death ${ }^{(60)}$. Removal of cholesterol from the cell occurs at the plasma membrane by passive diffusion or transfer to apolipoprotein $A 1$ and $H D L$, a process involving ATP-binding cassette $(A B C)$ transporters, in particular $A B C A 1$ and $A B C G 1{ }^{(60)}$. Deficiency of $A B C A 1$ or both $A B C A 1$ and $A B C G 1$ in bone marrow derived cells enhances atherosclerosis, and mice expressing the human ApoA-1 transgene, which increases HDL and cholesterol efflux, have reduced leukocytosis and atherosclerosis ${ }^{(60-62)}$.

\subsubsection{Macrophages mediate plaque inflammation}

Macrophages express a myriad of receptors including pattern recognition receptors (PPRs, e.g. TLRs, CLRs, NLRs, scavenger receptors) and cytokine receptors (e.g. TNFRs, interleukin receptors, growth factor receptors) through which they scan their environment for activation or polarization signals (e.g. PAMPs (pathogen associated molecular patterns), DAMPS (danger

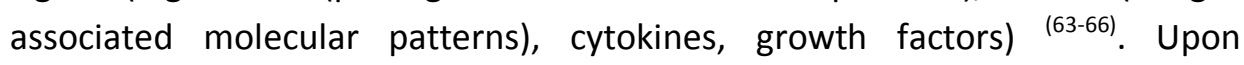
activation, macrophages/foam cells produce inflammatory cytokines and chemokines that enhance inflammation and further regulate monocyte/T cell infiltration ${ }^{(67-70)}$. Macrophages in the atherosclerotic plaque are capable of releasing a large repertoire of proinflammatory cytokines including IL-1, IL-6, IL-12, IL-15, IL-18, TNF family members (such as TNF $\alpha$ ), and MIF, as well as 
anti-inflammatory cytokines like IL-10 and TGF- $\beta$ family members (TGF- $\beta 1$, BMPs, GDFs) ${ }^{(67,71,72)}$. In particular, TLR 2 and 4 were shown to be important stimulators of macrophage cytokine production in an atherosclerotic context (73-76).

Macrophage exposure to crystalline material, like cholesterol crystals that form in the macrophage foam cell after massive uptake of (modified) lipids, but also increased oxidative stress within plaques can lead to the formation of an inflammasome complex affecting protein maturation and secretion ${ }^{(77)}$. Inflammasome formation leads to activation of caspase-1 that rapidly cleaves pro-IL1 $\beta$ and pro-IL18 into their mature forms, which are both pathogenic inflammatory cytokines. Transplantation of NIrp3, ASC and IL-1 (essential components of the inflammasome complex) deficient bone marrow in $\mathrm{LDLr}^{-/}$mice revealed a crucial involvement of the inflammasome in atherosclerosis as both plaque size and serum IL-18 were significantly reduced (77).

Within the atherosclerotic plaque, sustained inflammation, growth factor deprivation, oxidative stress accompanied by prolonged activation of endoplasmic reticulum (ER) stress pathways result in macrophage apoptosis and necrosis. The unfolded protein response (UPR) $\left({ }^{78)}\right.$, with factors like C/EBP homologous protein, $\mathrm{Ca}^{+} /$calmodulin-dependent protein kinase II, STAT1 and NOX, plays a major role in this process ${ }^{(79-82)}$. Necrosis and apoptosis, and the subsequent defective efferocytosis of macrophage cell debris result in the formation of a necrotic lipid core within the plaque, and can induce a vulnerable plaque ${ }^{(83)}$.

Besides producing inflammatory mediators, macrophages as well as SMCs and neutrophils, produce proteases, such as matrixmetalloproteases, tPA, uPA, elastases and cathepsins ${ }^{(84)}$, capable of degrading extracellular matrix components. These proteases significantly contribute to thinning of the fibrous cap, making atherosclerotic plaques more vulnerable for rupture.

\subsubsection{Macrophage heterogeneity in plaques}

Macrophages are a heterogeneous population that can be divided into classically activated (M1) and alternatively activated (M2) macrophages. M1

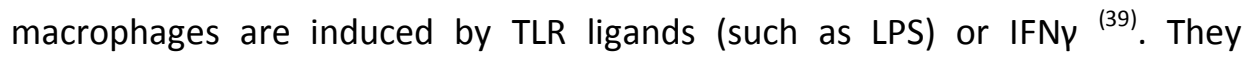
enhance and sustain inflammatory responses via production of TNF $\alpha$, IL-6, $\mathrm{IL}-1 \beta$ and IL-12 ${ }^{\left({ }^{39}\right)}$, and produce killing agents like iNOS. Continuous M1 activation results in tissue damage and eventually impaired wound healing. M2 macrophages are stimulated by cytokines such as IL-4 or IL-13, but also by 
immune complexes and parasitic antigens ${ }^{(39)}$ and secrete IL-10 and TGF $\beta$. M2 macrophages promote tissue repair and healing, stimulate angiogenesis, scavenge debris and dampen immune responses ${ }^{(85,86)}$. M1/M2 macrophages can switch phenotype depending on their microenvironment ${ }^{(87)}$.

The concept of $\mathrm{M} 1$ and $\mathrm{M} 2$ macrophages in atherosclerosis is not so clear-cut. Both $\mathrm{M} 1$ and $\mathrm{M} 2$ subsets are present in human atherosclerotic plaques ${ }^{(88)}$ in all plaque stages ${ }^{(89)}$, with M1 macrophages present at sites of plaque rupture, and M2 macrophages far from the lipid core ${ }^{(90)}$ and in the adventitia ${ }^{(91)}$. M2 macrophage foam cells contain smaller lipid droplets than M1 macrophages, suggesting less lipid uptake than M1 macrophages ${ }^{(90)}$. However, other reports show that ER stress promotes $M 2$ polarization and that M2 macrophages contain a higher expression of SR-A and CD36 ${ }^{(91,92)}$. In ApoE ${ }^{-/-}$ mice, early plaques predominantly contained $\mathrm{M} 2$ (arginase $\mathrm{I}^{+}$) macrophages. With plaque progression, a phenotypic switch towards an M1 (arginase $\mathrm{II}^{+}$) dominant profile was observed ${ }^{(93)}$. Upon plaque regression macrophages reduce the expression of $\mathrm{M} 1$ markers (i.e. MCP-1, TNF) and exhibit more $\mathrm{M} 2$ markers (i.e. Arg I, MNR) ${ }^{(94)}$. These data indicate that the microenvironment at later stages of atherosclerosis promotes M1 polarization, and thus atherosclerotic plaque progression. Interestingly, when macrophages in $\mathrm{ApoE}^{-/-}$mice were polarized towards $\mathrm{M} 2$ by schistosoma infection, circulating cholesterol levels decreased and plaque sized was reduced or not affected ${ }^{(95-}$ 97).

Kadl et al. described a new macrophage subset, Mox, present in advanced murine atherosclerotic plaques ${ }^{(98)}$. Mox are macrophages stimulated with oxidized phospholipids and are characterized by an anti-oxidant response (through NRF2). They have low phagocytic and chemotactic capacity and typically express Heme oxygenase-1 (HO-1). Whether Mox macrophages are atheroprotective needs further investigation. Gleissner et al. introduced M4 macrophages, being human macrophages differentiated by $\mathrm{CXCL4}{ }^{(99)}$. This subset is weakly phagocytic, shows lower expression of scavenger receptors, but increased levels of cholesterol efflux transporters.

In conclusion, macrophages, as the most abundant cell type in atherosclerotic plaques, strongly affect plaque formation and progression through a profound effect on intra-plaque cholesterol homeostasis, inflammation, necrotic core formation as well as extracellular matrix degradation. Affecting atherosclerosis on multiple levels makes macrophages an interesting cell type for the development of therapeutic strategies. 


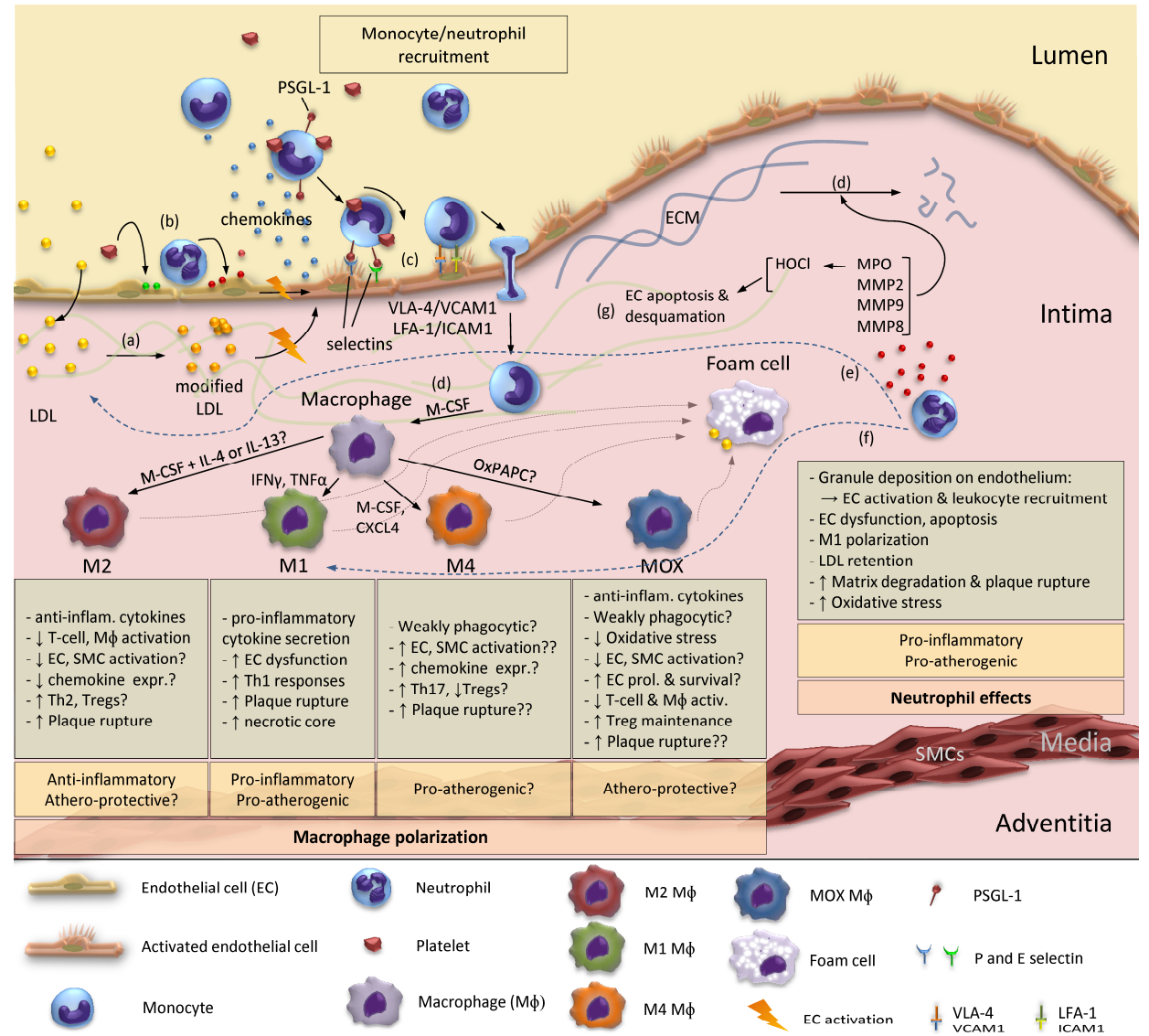

Figure 1: Role of monocytes and neutrophils in atherosclerosis

(a) Lipoproteins enter the intima, bind to proteoglycans, accumulate, become modified and activate the endothelium. (b) Platelets deposit C-C motif chemokine ligand 5 (CCL5) on the endothelium, promoting neutrophil recruitment to the vessel wall. Activated neutrophils secrete granule proteins such as myeloperoxidase, azurocidin, and proteinase- 3 that will enhance endothelial activation and dysfunction by inducing adhesion molecule expression, permeability changes and limiting the bioavailability of nitric oxide. Moreover, granule proteins secreted or deposited on the endothelium induce adhesion and recruitment of inflammatory monocytes, but can also modify chemokines, enhancing their ability to attract monocytes. (c) Activated endothelial cells release chemokines, such as MCP-1, that attract circulating monocytes. Monocytes bind to $P$ and $E$ selectin on endothelial cells, roll and finally come to arrest by adherence of their adhesion molecules (VLA-4, LFA-1) to VCAM-1 and ICAM1 on the endothelium. Platelets promote monocyte-endothelial interactions by expression of P-selectin, but can also form monocyte-platelet aggregates that further promote recruitment. Eventually, monocytes enter the intima through trans-endothelial diapedesis. (d) Infiltrated monocytes differentiate to macrophages, involving M-CSF, 
after which they polarize into various macrophage subsets (M1, M2, M4 or MOX) that exert numerous effects and can become foams cells. Subset functions reviewed in Butcher et al. (e) Plaque neutrophils trap LDL in the vessel wall by secretion of $\alpha$ defensin that binds LDL. (f) Neutrophils promote M1 polarization of macrophages. (g) Neutrophil-derived MMPs and MPO-dependent oxidative stress induces apoptosis of endothelial cells and degradation of basement membrane, leading to endothelial desquamation. (h) Neutrophil MMPs can also degrade ECM components affecting plaque stability. ECM, extracellular matrix; MMP, matrix metalloproteinase; MPO, myeloperoxidase; LDL, low-density lipoprotein; M-CSF, macrophage colony stimulating factor; IFN, interferon; TNF, tumor necrosis factor; OxPAPC, Oxidation products of 1palmitoyl-2-arachidonoyl-sn-glycerol-3-phosphatidylcholine; EC, endothelial cell; $\mathrm{HOCl}$, hypochlorous acid; PSGL-1, P-selectin glycoprotein ligand-1; VLA-4, Very Late Antigen4; VCAM-1, Vascular cell adhesion molecule-1; LFA-1, Leukocyte function-associated molecule 1 ;ICAM-1, intercellular adhesion molecule; SMC, Smooth Muscle Cell.

\subsection{Neutrophils}

Neutrophils are among the first cell types to respond to invading micro-organisms or tissue damage by inducing rapid neutralization and clearance of pathogens via endocytosis of foreign material and production of reactive oxygen species, myeloperoxidase (MPO) and proteolytic enzymes. In humans, an association between intra-plaque neutrophil numbers and features of unstable plaques (large lipid core, low collagen and smooth muscle cell content) ${ }^{(100)}$ was reported. In $\mathrm{ApoE}^{-/-}$mice, neutrophils interact with endothelial cells and accumulate in regions of high inflammatory activity (101${ }^{103)}$. In early atherosclerotic mouse plaques, neutrophils localize in the subendothelial space while in more advanced to rupture prone plaques they can be found in the shoulder region, fibrous cap, adventitia and in areas of intraplaque bleeding ${ }^{(101,102,104)}$.

\subsubsection{Neutrophil granule proteins and atherosclerosis}

Much of the neutrophil proinflammatory activity can be attributed to the release of granule proteins. MPO, azurocidin, LL-37, $\alpha$-defensins, and NGAL, have been identified inside human atherosclerotic lesions ${ }^{(105-109)}$ and are also secreted into the plasma upon neutrophil activation.

Recently, Soehnlein et al. reported that $\mathrm{Cramp}^{-/-} \mathrm{ApoE}^{-/-}$mice had smaller plaques with reduced macrophage numbers compared to $\mathrm{ApoE}^{-/-}$mice ${ }^{(110)}$. This effect was attributed to the lack of endothelial CRAMP deposition by neutrophils, resulting in reduced adhesion of classical monocytes and 
neutrophils. $\alpha$-defensin, another granule protein, is able to trap LDL in the vessel wall, leading to accumulation of LDL that will be oxidized and eventually contribute to local inflammation and plaque growth ${ }^{(111,112)}$.

Neutrophils also affect advanced atherosclerosis by secretion and activation of different matrix metalloproteinases and elaborate MMP8 and a few cathepsins amongst others, which in turn degrade the basement membrane as well as components of the extracellular matrix leading to plaque fragility and eventually erosion or rupture ${ }^{(113,114)}$.

In conclusion, various cell types of the innate immune system play important roles in both initiation and progression of atherosclerosis, either reducing or aggravating disease burden. However, as the local inflammation of the arterial wall sustains, many of the immunomodulatory agents secreted by innate immune cells have the capacity to tune or even activate adaptive immune responses, directly or by recruiting key players in adaptive immunity to inflammatory foci.

\section{The adaptive immune system in atherosclerosis (Figure 2)}

The adaptive immune system comprises highly specialized cell-types that respond to both microbial as well as non-microbial substances in a very specific way. Adaptive immune responses are slow, are initiated by the innate immune system and require antigen presentation by APCs. Adaptive immunity includes humoral as well as cell-mediated mechanisms, which are executed by $B$ and $T$ lymphocytes respectively. Important features of the adaptive immune response are antigen recognition, clonal expansion and differentiation of lymphocytes to effector or memory cells. Upon exposure to a previously encountered antigen, the appropriate memory cells will generate faster, stronger and more efficient immune responses.

\subsection{Dendritic cells}

Dendritic cells (DCs) are professional APCs that play a critical role in

innate, but also in regulation of adaptive immune responses ${ }^{(9)}$. DCs originate from DC precursors, coming from the bone marrow, or from monocytes. They can be found in both lymphoid and non-lymphoid tissues throughout the body where they form sophisticated and complex networks allowing them to interact with different lymphocyte populations. DCs provide an important link 
between innate and adaptive immune responses and play a critical role in host defense to pathogens and cancer, but also in tolerance to self and prevention of autoimmunity ${ }^{(9)}$.

\subsubsection{DC heterogeneity}

The dendritic cell population is heterogeneous and can be divided into four major categories ${ }^{(115)}$ : Conventional DCs (cDCs), plasmacytoid DCs (pDCs), monocyte-derived DCs and Langerhans cells. cDCs predominate in a steady state and are specialized for antigen processing and presentation. Two main classes of cDCs exist: migratory DCs (mDCs) and lymphoid tissue resident DCs (rDCs). mDCs are antigen sampling sentinels originating from early precursors in peripheral tissues, are restricted to lymph nodes and cannot be found in the spleen. rDCs are found in lymph nodes, spleen and thymus. They can be subdivided into $C D 4^{+} D C s, C D 8 \alpha^{+} D C s$ and $C D 4 C D 8 \alpha^{-}$DCs. CD $8 \alpha^{+}$DCs are professional cross-presenting cells and play a major role in priming cytotoxic $C D 8^{+}$T-cell responses, whereas $C D 4^{+} D C s$ and $C D 4^{-} C D 8 \alpha^{-}$DCs are more efficient at presenting $\mathrm{MHC}$ class II-associated antigens to $\mathrm{CD} 4^{+} \mathrm{T}$ cells. $\mathrm{rDC}$ do not traffic from other tissues but develop from local lymphoid tissue precursor DCs.

During inflammation and in response to growth factors like GM-CSF or TLR4 ligands, monocytes fully differentiate into monocyte-derived DCs. Similar to cDCs these cells express CD11c, MHC II, CD24 and SIRP $\alpha$, but also MAC3. Monocyte-derived DCs have antigen-presenting capacity, including the ability to cross-present antigens.

Acting at the interface of innate and adaptive immunity, pDCs have the unique ability to rapidly produce large amounts of type I interferons, but have only poor antigen presenting capacity. pDCs are broadly distributed over the body and, at least in mice express SIGLEC-H, BST2 and CD45RA. Human pDCs also are CD45RA ${ }^{+}$but also express BDCA-2 and LILRA4 (ILT7).

\subsection{2. $D C s$ and macrophages}

One of the major problems in studying the role of DCs in non-lymphoid tissues, and especially in the aorta, is that the distinction between macrophages and DCs is not so clear. There is little agreement about the utility of specific markers for identifying distinct cell types in tissues. In a recent paper by Becker et al. ${ }^{(116)}$, a proteomic approach was applied to find 
membrane markers specific for macrophages, M1 and M2 macrophages, and dendritic cells. Although unique membrane signatures for (M1 vs M2) macrophages vs DCs could be detected, some frequently used markers proved to be not cell-type specific. One of those common markers to distinguish DCs in mice is $\mathrm{CD} 11 \mathrm{c}^{(116)}$. In atherosclerosis, this problem is even more relevant, since macrophage foam cells in the plaque, as well as lipid filled DCs both show an abundant expression of CD11c ${ }^{(117)}$. However, macrophages and DCs also have unique membrane expression profiles, morphological different features, and exert specific functions, and are therefore truly different cell types.

\subsection{3. $\quad D C s$ in atherosclerosis}

Although DCs were discovered in 1973 by Steinman \& Cohn ${ }^{(118)}$, it took until 1995 before DCs were described in the aorta ${ }^{(119)}$. Few DCs are present in the normal aorta of healthy mice, where they preferentially reside in the adventitia, apart from a few scattered intimal DCs ${ }^{(120)}$. DCs are mainly found at sites prone to develop atherosclerosis, such as the lesser curvature and branch points of the aortic arch ${ }^{(121,122)} . \mathrm{CD} 11 \mathrm{c}^{+} \mathrm{DC}$ numbers dramatically increase in both intima and adventitia during atherosclerosis ${ }^{(123-125)}$. In advanced lesions, DCs cluster with T cells and localize in the plaque shoulder and rupture-prone regions of plaques $(121,126,127)$. In patients with angina pectoris or acute myocardial infarction, blood-derived DC precursors are reduced, while in CAD patients blood-DC numbers are down, which might be explained by increased recruitment to plaques ${ }^{(128-130)}$.

Dendritic cells are central to atherogenesis as they are directly implicated in both cholesterol homeostasis and the immune response. Selective ablation of DCs or extension of their lifespan both were found to result in an increase or decrease in plasma cholesterol levels respectively ${ }^{(131)}$. However, increasing DC-lifespan did not affect atherosclerosis progression since the protective effects of cholesterol lowering were counterbalanced by enhanced Th1 and Th17 mediated autoantibody responses. Transfer of DCs pulsed with atherosclerosis specific antigens results in either protection or aggravation of atherosclerosis depending on environmental signals during DC pulsing and animal model used ${ }^{(132,133)}$. Moreover, vaccination strategies with oxLDL-pulsed DCs before atherosclerosis induction showed a promising reduction in plaque size and overall amelioration of immune-inflammatory responses ${ }^{(134)}$. 
Two papers were published recently showing opposing roles for pDCs in atherosclerosis. Daissormont et al. reported a protective role for pDCs as depletion of these cells in LDLr ${ }^{-/-}$mice using an anti-PDCA-1 antibody resulted in enhanced T-cell accumulation and CD4+ T cell activation and exacerbation of plaque development ${ }^{(135)}$. In the $\mathrm{ApoE}^{-/-}$mouse, Döring et al. ${ }^{(136)}$ as well as Macritchie et al. ${ }^{(137)}$ recently observed decreases in early plaque formation upon treatment with an antibody against PDCA-1, an effect that was attributed to a TLR9 dependent IFN $\alpha$ release upon PDC activation by the neutrophil derived DNA/CRAMP complexes ${ }^{(136)}$. These divergent findings might be explained by the different methodologies used, such as the kind of depletion antibodies and administration regimens.

\subsubsection{DC accumulation in plaques}

DC accumulation in plaques can result from three different events: direct recruitment, local proliferation and/or impaired egress. Different immune cells in the aorta can attract preDCs and monocytes by expression and secretion of different receptors and cytokines. Absence of CX3CR1, CCR2 or VCAM-1 reduces atherosclerosis not only by an effect on monocyte recruitment, but also correlates with decreased DC accumulation ${ }^{(27,125,138,139)}$. Accumulation of DCs in the arterial wall can also be influenced by interactions with platelets. For example, through P-selectin for rolling and mac1 for firm adhesion ${ }^{(8)}$. DCs might predominantly differentiate from Ly6C ${ }^{\text {low }}$ monocytes that act as precursors for inflammatory DCs ${ }^{(22)}$. Recruited or resident DCs can proliferate locally, as was recently demonstrated in the aorta and secondary lymphoid organs $(140,141)$, contributing to increased numbers of DCs. In early atherosclerotic lesions, monocyte-derived DCs can emigrate from lesions, however in hyperlipidemic mice, the egress from developed plaques might be impaired $^{(142,143)}$.

\subsubsection{DCs and lipid uptake}

In addition to macrophages, DCs can accumulate lipids and contribute to disease initiation and progression ${ }^{(144)}$. Only a few days after high-fat diet feeding of $\mathrm{LDLr}^{-/}$mice, lipid-loaded CD11 $\mathrm{C}^{+} \mathrm{DCs}$ can be detected in the aorta. OxLDL promotes differentiation of macrophages into DCs ${ }^{(145)}$. Uptake of lipids induces DC maturation markers and enhances antigen presentation to NKT and $T$ cells ${ }^{(146)}$, but does not affect the antigen presenting capacity of monocytederived macrophages ${ }^{(142)}$, and impairs CD40 or TLR induced dendritic cell maturation $^{(147)}$. 


\subsubsection{DCs and antigen presentation}

In atherosclerotic plaques, $\mathrm{T}$ cells are found in close proximity with DCs, implying DC-T-cell interactions ${ }^{(127,148)}$. Several studies indicated that oxLDL induces several changes that are characteristic for DC maturation, including enhanced expression of co-stimulatory molecules and increased ability to stimulate $\mathrm{T}$ cells ${ }^{(146,149)}$. Moreover, deficiency of co-stimulatory molecules involved in antigen-loading, immunological synapse formation and T cell activation (CD80, CD86, CD40) all led to reduced atherosclerosis ${ }^{(150,151)}$. Several studies using DC transfer, depletion or modulation, indicated that DCs are capable of skewing immune responses in atherosclerosis either towards an athero-protective or promoting profile ${ }^{(131-134)}$. It is likely that under atherosclerotic conditions, DCs take up atherosclerosis-specific antigens ${ }^{(152)}$, become locally activated and migrate out of the plaque towards either local draining or distant lymph nodes, where they induce $T$ cell activation and proliferation. Indeed, DCs sorted from the aorta have the capacity to induce antigen-specific proliferation of $T$ cells ${ }^{(122,124,153)}$. Moreover, aortic DC were reported to take up injected OVA from the blood, cross present it to $C D 8^{+} \mathrm{TCR}$ transgenic OT-I T-cells and subsequently induce OT-I T cell proliferation after isolation ${ }^{(122)}$, while another study showed that OVA-loaded bone marrow derived DCs induced OT-I T cell proliferation in the adventitia of OT-I Rag $2^{-/}$ mice ${ }^{(123)}$. It is also possible that $\mathrm{T}$ cells, originally primed in secondary lymphoid organs, migrate into the plaque to be re-stimulated by DCs locally, which may be more important at later stages of atherosclerosis where DC egress is reduced ${ }^{(154)}$. Overall these processes perpetuate local inflammation and increase plaque growth.

\subsubsection{DCs and cytokine production}

Dendritic cells have the ability to produce various anti- and proinflammatory cytokines. TLR engagement, for example, can lead to the production of pro-inflammatory cytokines, including TNF, IL-6 and IL-12, all of which have been shown to be atherogenic ${ }^{(152,155-160)}$, but TLR induction can also lead to IL-10 production which is atheroprotective ${ }^{(161)}$. IL12p $40^{-/-} \mathrm{ApoE}^{-/}$ mice have smaller lesions ${ }^{(157)}$, whereas recombinant IL-12 injection increases lesion size ${ }^{(158)}$. IL-12 affects atherosclerosis by driving Th1 polarization and T cell recruitment ${ }^{(160)}$. Dendritic cells also produce many other cytokines, like IL-23 or IL-27 of which the role in atherosclerosis remains unclear ${ }^{(162)}$. pDCs 
typically produce high amounts of IFN $\alpha$ and $\beta$ upon TLR9 activation, of which the latter has been shown to promote atherosclerosis by stimulation of macrophage recruitment ${ }^{(163)}$.

Some cytokines produced by DCs in an atherosclerotic environment are chemokines that influence immune cell recruitment into the lesion. Most DC chemokines are involved in T cell recruitment. For example CCL17 (TARC) and $\mathrm{CCL} 22$ (MDC) ${ }^{(164)}$ are expressed in the plaque and attract $\mathrm{T}$ cells by interaction with the CCR4 receptor. Recently Weber et al ${ }^{(124)}$ described CCL17expressing $\mathrm{CDCS}$ in the aorta of $\mathrm{ApoE}^{-/}$mice. These cells associated with T-cell recruitment, however Treg accumulation was decreased combined with restrained Treg homeostasis in lymph nodes, contributing to atherosclerosis. Secretion of CCL2 by DCs was shown to play a role in the recruitment of monocytes, memory T cells and DCs to the site of inflammation ${ }^{(165)}$. In addition DCs also produce CCL4 that attracts NK cells, monocytes and some other immune cells ${ }^{(166)}$.

\subsubsection{DCs and tolerance}

Under homeostatic conditions DCs are known to have a tolerogenic effect ${ }^{(167)}$. In the normal artery wall, resident DCs are thought to promote tolerance to antigen by silencing $T$ cells. However, the inflammatory atherosclerotic microenvionment can activate DCs to switch from tolerance to activation of the immune system ${ }^{(168,169)}$. Interestingly, Hermansson et al. recently showed that this switch can be reversed as injection of DCs pulsed with ApoB100 in the presence of the immunosuppressive cytokine IL-10 conferred protection against atherosclerosis in ApoB100 ${ }^{\mathrm{tg}} \mathrm{LDLr}^{-1-}$ mice ${ }^{(133)}$. Therefore, inducing tolerance to atherosclerosis specific antigens might be a promising therapeutic target for the treatment of atherosclerosis.

In conclusion, dendritic cells influence atherosclerosis by production of chemokines and cytokines, antigen presentation and lipid uptake either promoting inflammation or inducing tolerance. However, the exact role of dendritic cells in directing different $\mathrm{T}$ and $\mathrm{B}$ cell subsets during atherosclerosis is not yet fully understood. 
2 | Inflammation and Immune System Interactions in Atherosclerosis

\section{4. $\underline{T \text { cells }}$}

T cells are lymphocytes that are characterized by the presence of a $T$ cell receptor (TCR) on their cell surface. They originate from haematopoietic stem cells in the bone marrow that give rise to progenitors which migrate to the thymus for further development, maturation and selection to become $T$ cells. After maturation, $T$ cells are released from the thymus and are present in the blood and lymph nodes, where they play a central role in adaptive immunity. However, subsets of T-cells, such as the $\mathrm{CD}^{+}{ }^{+} \mathrm{T}$-cells also exert innate immune cell functions by activating various innate immune cells and helping macrophages to kill intracellular pathogens ${ }^{(170)}$. When $T$ cells encounter an antigen-presenting cell (APC) that presents a peptide specific for their TCR an efficient $T$ cell response can be initiated.

First evidence for a role of T cells in atherosclerosis was their detection in human plaques in $1985^{(171)}$, followed by the observations that HLA/MHCII and $T$ cell cytokines, such as IFNY, were present as well. The detection of antibodies and $T$ cells specific for oxLDL, combined with the presence of oligoclonal $\mathrm{T}$ cell populations in lesions confirmed a role for adaptive immunity in atherosclerosis ${ }^{(171-176)}$. Further confirmation came from Rag knockout studies in atherosclerosis mouse models $\left(\mathrm{ApoE}^{-/}\right.$or $\mathrm{LDLr}^{-/}$) showing a reduction in atherosclerosis $(29,83)$. Interestingly, these affects were less profound upon prolonged diet or using diet containing higher cholesterol content, suggesting that $T$ and $B$ cells play a more important role early in atherogenesis. Of note, work by Reardon et al showed that reduced atherosclerosis by $\mathrm{T}$ and $\mathrm{B}$ cell deficiency is site-specific depending on genetic background $^{(84)}$.

T cells are recruited to the vessel wall in parallel with macrophages, but in less quantity. Mechanisms involved are similar to monocyte recruitment ${ }^{(177)}$. In the arterial wall, $\mathrm{T}$ cells become activated in response to antigens and start to produce pro-inflammatory mediators (e.g. IFN $\gamma$ ), which further amplify the inflammatory response, aggravating disease progression ${ }^{(177,178)}$. Different $\mathrm{T}$ cell subsets exist that can influence atherosclerosis in various ways both at early plaque stages as well as advanced lesions. $\mathrm{CD}^{+} \mathrm{T}$ cells and to a lesser extent $\mathrm{CD}^{+}$and $\gamma \delta \mathrm{T}$ cells are present in plaques of atherosclerotic mice. Knockout, depleting antibodies and cell transfer experiments suggest an overall proatherogenic role for $\mathrm{CD}^{+} \mathrm{T}$ cells starting early during atherosclerotic disease progression ${ }^{(179-181)}$. However, in one report, $\mathrm{CD}^{-/-} \mathrm{ApoE}^{-/-}$females exhibited an 
increased load of atherosclerosis, predominantly at the lower aorta ${ }^{(11)}$. This increase could be due to the absence of $\mathrm{CD}^{+}$Tregs and a compensatory increase in $\mathrm{CD}^{+}{ }^{+} \mathrm{T}$ cells in this mouse model ${ }^{(11)}$. The role of $\mathrm{CD}^{+} \mathrm{T}$ cells in atherogenesis is still controversial ${ }^{(182,183)}$.

Classically, T cell responses are initiated by APCs (DCs, macrophages and $B$ cells), but can also be antigen independent. After antigen presentation, $T$ cell activation occurs through simultaneous interaction of the TCR with cognate peptide antigen loaded on MHC class complexes and co-stimulatory molecules with their ligands. In atherosclerosis, the antigen that triggers the immune response and induces T-cell proliferation and polarization is still not completely identified. However, recent evidence points towards atherosclerosis-specific antigens such as (the ApoB100 part of) LDL, and postulate that intimal DCs present these in draining or even distant lymph nodes ${ }^{(126,184)}$. As the plaque itself contains classical as well as non-classical APCs (e.g. SMCs and endothelial cells), effector T cells immigrating into the lesion can be (re)activated by antigen presentation inside lesions ${ }^{(171,172,184)}$. In line with this, oligoclonal T-cell populations have been identified inside the plaque $^{(176,185,186)}$.

\subsection{1. $C D 4+T$ cell subsets in atherosclerosis}

\subsubsection{Th1 response in atherosclerosis}

The majority of $\mathrm{T}$ cells in atherosclerosis are of the Th1 profile, characterized by the production of high levels of IFN $\gamma$. IFNY promotes the recruitment of $\mathrm{T}$ cells and macrophages to the plaques contributing to plaque growth, augments macrophage uptake of lipids leading to the formation of foam cells, increases the activation of APCs and enhances their MHC II expression, and enhances the secretion of Th1-promoting cytokines $(67,187,188)$. These events lead to an expansion of atherosclerotic plaque burden and aggravation of the pathogenic Th1 response ${ }^{(189)}$. IFNY also contributes to plaque vulnerability and rupture by inhibition of SMC infiltration, proliferation and collagen production, but also by increasing the production of matrix metalloproteinases ${ }^{(67,190-192)}$. Studies deleting IFNY or its receptors report reduced atherosclerosis, while injection of recombinant IFN $\gamma$ leads to increased lesion size ${ }^{(193-196)}$. Besides their role in T cell activation by antigen presentation, DCs and macrophages are instrumental in Th1 differentiation through secretion of IL-12. IL-12 activates Th1 transcription factors (such as 
STAT4 and T-bet), upregulates IFN $\gamma$ expression, while downregulating IL-4 and IL-5 in T cells ${ }^{(197)}$. Patients with coronary artery disease (CAD) show increased STAT4 levels in $\mathrm{CD}^{+} \mathrm{T}$ lymphocytes ${ }^{(198)}$. Moreover, a study on cytokine expression in advanced human atherosclerotic plaques confirmed the dominance of pro-inflammatory Th1 cytokines ${ }^{(199)}$. In addition, Zhao et al. reported Th1 and Th17 activation in patients with CAD ${ }^{(200)}$. Interference in IL-12 or IL-18 gene or receptor function reduces plaque development in mice, while administration of these cytokines accelerates disease progression, suggesting atherosclerosis is affected by an imbalance in T cell subsets ${ }^{1157,158,}$ 201-205). Collectively, these data point towards a pro-atherogenic function of Th1 responses.

\subsubsection{Th2 response in atherosclerosis}

Th2 cells are known for their secretion of IL-4, IL-5, IL-10, and IL-13, but also provide help for antibody production by plasma cells ${ }^{(189,197)}$. Although Th2 cells are rare in atherosclerotic lesions, their number is increased in hyperlipidemia. Th2 cells were thought to be atheroprotective as they oppose the pro-atherogenic Th1 differentiation. However, the role of Th2 cells in atherosclerosis is still controversial and depends on the site and stage of the lesions as well as on the experimental model used ${ }^{(197)}$. Studies on IL-4, the prototypic Th2 cytokine, report either no (in $\mathrm{ApoE}^{-/-}$mice given angiotensin II) ${ }^{(206)}$ or pro-atherogenic (in LDLR ${ }^{-/}$mice) effects ${ }^{(207)}$. Possible pro-atherogenic effects of IL-4 might include activation of mast cells or MMPs (208). Administration of IL-13, another prominent Th2 cytokine favorably affects atherosclerotic plaque morphology by reducing plaque inflammation and inducing plaque fibrosis in $\mathrm{LDLR}^{-/}$mice, and inducing a protective $\mathrm{M} 2$ macrophage phenotype ${ }^{(197)}$. Accordingly, IL13 ${ }^{-/} \mathrm{LDLR}^{-/}$mice have accelerated atherosclerosis ${ }^{(197)}$. IL-5 and IL-33 show overt anti-atherogenic properties (209, ${ }^{210)}$. IL-5 protects against atherosclerosis by promoting B-1 cell development and, ensuing production of protective antibodies ${ }^{(211)}$, while IL-33 may exert its effect through induction of IL-5 ${ }^{(189,209)}$.

\subsubsection{Treg response in atherosclerosis}

Natural regulatory $\mathrm{T}$ cells (Tregs) are characterized by expression of CD4, CD25 and the transcription factor FoxP3. Tregs maintain self-tolerance and prevent autoimmunity by suppression of immune responses, such as Th1 and Th2 responses. Natural Tregs (Th3) develop in the thymus and recognize 48 
specific self-antigens. However, Treg cells can also be generated in the periphery in the presence of TGF $\beta$ or IL-10, the so-called induced Tregs (iTregs, $\operatorname{Tr} 3)$.

Regulatory $T$ cells are present in plaques ${ }^{(212,213)}$ and depletion using anti-CD25 antibodies in atherosclerotic mice results in increased lesion size ${ }^{(214)}$. Furthermore, transfer of bone marrow cells from $\mathrm{CD} 80^{-1-} \mathrm{CD} 86^{-/}$or $\mathrm{CD} 28^{-/-}$ mice (which do not contain T regs) in $\mathrm{LDLr}^{-/-}$mice resulted in increased lesion size, whereas transfer of Tr1 cells, regulatory T-cells that produce high levels of IL-10 and low levels of TGF $\beta$, or natural $\mathrm{CD}^{+}{ }^{+} \mathrm{CD} 25^{+}$Tregs significantly reduced atherosclerosis ${ }^{(214,215)}$, showing a protective role for regulatory T-cells in atherosclerosis.

Regulatory T cells are known to produce large amounts of TGF $\beta$ and IL-10. Although TGF $\beta$ has an atheroprotective role ${ }^{(214)}$, it is not clear whether Tregs exert their protective function directly through secretion of TGF $\beta$, or through other immunosuppressive mechanisms ${ }^{(208,216)}$. Interestingly, DCs are able to induce Treg formation and play a role in the maintenance of Treg function through production of TGF $\beta^{(217,218)}$. Production of IL-10 by regulatory $T$ cells may also contribute to their athero-protective effects, as IL-10 was shown to repress atherosclerotic development ${ }^{(219,220)}$.

Regulatory $\mathrm{T}$ cells play an important role in the development of atherosclerosis by repressing immune function and provide an interesting target for the modulation of the disease.

\subsubsection{Th17 cells}

IL-17-producing helper T cells (Th17 cells) are protective against fungal and bacterial infections, but are also involved in the development of some autoimmune diseases ${ }^{(208,221)}$. Th17 cells mainly produce IL-17A and IL-17F as well as IL-21 and IL-22. In mice, both TGF $\beta$ and IL-6 are necessary for Th17 differentiation ${ }^{(222)}$, whereas IL-21 and IL-23 are respectively required for Th17 proliferation and maintenance.

Although Th17 cells are present in both murine and human atherosclerotic lesions ${ }^{(223-225)}$, their role remains controversial as both atherogenic as well as atheroprotective effects have been reported. Both Th17 cells and IL-17 protein accumulate in lesions. Increased IL-17 expression in human lesions was associated with lower macrophage numbers, higher SMC content and an overall more fibrotic phenotype, suggesting that IL-17 
promotes plaque stability ${ }^{(221)}$. However, others report increased IL-17 mRNA expression in symptomatic plaques compared to non-symptomatic ones, with a correlation between IL-17 expression and complicated, unstable and lipidrich lesions $(221,224)$. Many studies interfered with IL-17 signaling in atherosclerosis (223, 226-228): Transplantation of IL17 receptor deficient bone marrow into $\mathrm{LDLr}^{-/-}$mice, as well as antibody treatment against IL17A reduced plaque size ${ }^{(223,227,228)}$. IL $17 \mathrm{~A}^{-/} \mathrm{ApoE}^{-/}$mice show a profound reduction in atherosclerosis, and a decreased recruitment of immune cells in the aortic arch region, but not in the abdominal aorta, suggesting a site-specific effect ${ }^{(229)}$. In contrast, Taleb et al. ${ }^{(230)}$ found a protective role for Th17 cells in atherosclerosis by using $\mathrm{T}$ cell specific SOCS3 deletion in $\mathrm{LDLr}^{-/}$mice. Suppressor of cytokine signaling 3 (SOCS3) is a major negative feedback regulator of STAT3, a transcription factor crucial for Th17 differentiation. In this same study, administration of an anti-IL17A antibody accelerated atherosclerosis, indicating that Th17 cells may be protective ${ }^{(230)}$.

The interplay and imbalances between the different T-cell subsets are important in the pathogenesis of atherosclerosis. An imbalance in Th1/Th2 towards the Th1 response promotes the progression of atherosclerosis, whereas prominent Th2 and Treg responses are anti-inflammatory and result in a reduction of atherosclerosis and/or a more favourable plaque morphology. How Th17 cells affect atherogenesis still needs to be determined.

\subsection{2. $C D 8^{+} T$ cells in atherosclerosis}

$\mathrm{CD}^{+} \mathrm{T}$ cells are important in cell-mediated immunity, capable of inducing death in infected or dysfunctional somatic cells. $\mathrm{CD} 8^{+} \mathrm{T}$ cells express T-cell receptors that recognize specific antigens presented on MHC class I molecules, present on all nucleated cells. As $\mathrm{MHCl}$ molecules mainly present cytosolic peptides, this represents an effective mechanism for clearing viruses and other intracellular pathogens. Once activated, $\mathrm{CD}^{+} \mathrm{T}$ cells induce apoptosis in their target cells by releasing cytotoxins, like perforin, granzymes, and granulysin. However, $\mathrm{CD}^{+} \mathrm{T}$ cells also secrete cytokines such as IFNY and TNFa.

$\mathrm{CD}^{+} \mathrm{T}$ cells are present in both murine and human plaques ${ }^{(231,232)}$. Although $\mathrm{CD}^{+} \mathrm{T}$ cells are only present in low numbers in early lesions, they appear to be the dominating $T$ cell type in advanced human lesions ${ }^{(232)}$. While no effects on plaque size are observed in $\mathrm{CD}^{+} \mathrm{T}$ cell deficient $\mathrm{ApoE}^{-/}$mice, 
atherosclerosis is reduced in MHC class I deficient C57BI/6 mice on high-fat diet ${ }^{(170)}$. In addition, stimulation of $\mathrm{CD}^{+}{ }^{+}$cells responses with a $\mathrm{CD} 137$ agonist resulted in increased lesion size accompanied by enhanced $\mathrm{CD}^{+} \mathrm{T}$ cell recruitment to the lesions, suggesting a proatherogenic role for this $T$ cell subset ${ }^{(183)}$. Kolbus et al. recently reported activation of $\mathrm{CD}^{+} \mathrm{T}$ cells after feeding $\mathrm{ApoE}^{-/}$mice a high-fat diet ${ }^{(233)}$. Interestingly, these cells were detected in plaque draining lymph nodes and preceded $\mathrm{CD}^{+} \mathrm{T}$ cell activation, suggesting a role for $\mathrm{CD} 8^{+} \mathrm{T}$ cells in early atherogenesis.

\subsection{NKT cells in atherosclerosis}

Unlike conventional $T$ cells, which recognize peptide antigens presented by MHC molecules, NKT cells recognize a variety of (glyco)lipid antigens presented by a unique TCR on CD1d molecules APCs. Upon activation, NKT cells secrete both pro-inflammatory cytokines, such as IFN, and antiinflammatory cytokines, like IL-4, IL-10 and IL-13 ${ }^{(234)}$. Activated NKT cells can interact in a CD1d dependent manner with other immune cells, promoting DC maturation and monocyte activation ${ }^{(234)}$ and can induce tolerance by communicating with Tregs ${ }^{(235)}$.

NKT cells are present in the shoulder region of human carotid artery plaques, and in abdominal aortic aneurysms ${ }^{(236)}$. Both $\mathrm{CD}^{-\mathrm{d}^{-/}}$mice (lacking NKT cells) on a high fat diet or $\mathrm{CD}^{-1 /}$ mice on $\mathrm{ApoE}^{-/}$background show decreased atherosclerosis ${ }^{(237-239)}$. Moreover, repeated exogenous activation of NKT cells by $\alpha$-GalCer in ApoE ${ }^{-/-}$mice, or adoptive transfer of unstimulated NKT cells in Rag1 ${ }^{-/} \mathrm{LDLR}^{-/}$mice aggravate atherosclerosis ${ }^{(237-239240)}$. Other studies showed that invariant $\mathrm{V}$ alpha 14 NKT cells are responsible for increasing early plaque formation ${ }^{(241)}$, that the CD4 ${ }^{+} \mathrm{NKT}$ cell subset is responsible for the proatherogenic activity of NKT cells ${ }^{(242)}$, and that the contribution of NKT cells in atherosclerosis is restricted to early lesion development ${ }^{(243)}$.

\section{6. $\underline{\text { B cells }}$}

$B$ cells originate from the bone marrow and play an important role in humoral immune responses. They are characterized by the presence of a B-cell receptor and are classically known for their ability to produce antibodies important for the clearance of antigens. B cells possess antigen presenting capacities, activating both $\mathrm{CD} 4^{+}$and $\mathrm{CD}^{+} \mathrm{T}$ cells. In addition, they can also secrete a variety of cytokines (e.g. IFN- $\gamma$, IL-2, IL-12, IL-4, IL-6 and IL-10) and 
promote chemokine production (e.g. CXCL12, CXCL13, CCL19 and CCL21), key players in modulating chronic immune responses by promoting leukocyte recruitment and polarizing $T$ cells $(244,245)$.

According to their surface antigens, mature B cells can be categorized into B1, conventional B2 or marginal zone B cells ${ }^{(244)}$. B1 cells reside in serosal cavities and participate in innate immunity by $T$ cell independent production of the majority of natural IgM antibodies. Conventional B2 cells are present in bone marrow and lymphoid organs and are the B cells important in adaptive immunity by production of specific IgG antibodies to their cognate antigen. Marginal zone B cells can be found in the spleen, where they play a role in the first-line defense against blood-borne antigens. Upon antigen recognition, all mature B cells can differentiate into plasma cells. However, only B2 cells have the ability to become memory B cells.

Although B cells are only occasionally detected in the atherosclerotic intima (246), early plaques contain large amounts of (SOCS3) and IgG (247). Furthermore, both IgM and IgG antibodies have been described in plaques at all stages of lesion development ${ }^{(248)}$.

Recent studies evaluated the role of B cells in the immune response during atherosclerosis. Splenectomy in mice resulted in larger plaques, which could be prevented by adoptive transfer of unfractionated splenic B cells ${ }^{(249)}$. Furthermore, transfer of B cell-deficient bone marrow ( $\mu \mathrm{MT}$ ) into $\mathrm{LDLr}^{-/-}$mice resulted in increased lesions size in parallel with reduced antigen presentation and antibody and cytokine production in both early and late atherosclerosis (250). These data indicate that atheroprotective immunity develops during atherosclerosis progression with $\mathrm{B}$ cells playing a beneficial role. Paradoxically, some studies also reported detrimental effects for B cells. CD20-targeted B cell depletion in mouse models of atherosclerosis reduced lesions size ${ }^{(251,252)}$. Furthermore, deficiency or adoptive transfer of B2 B cells revealed this B cell subtype to be pro-atherogenic ${ }^{(253)}$. These findings not only imply that B cells have both pro and anti-atherogenic roles in atherosclerosis, but also indicate that different B cell subtypes are involved in atherosclerosis immunity, complicating the role of B cells in the disease. However, these studies do not discriminate between cellular B cell functions and production of antibodies. 
OxLDL is highly immunogenic and anti-oxLDL antibodies can be detected in atherosclerotic plaques as well as in the circulation of mice and men ${ }^{(254,255)}$. OxLDL specific antibody IgG titers correlate with atherosclerosis (256-258), while oxLDL-specific IgM titers are associated with atheroprotection ${ }^{(259,260)}$. Accordingly, Binder et al. showed that pneumococcal vaccination of $\mathrm{LDLr}^{-/}$mice reduced atherosclerosis by expanding T15 (antioxLDL) natural IgM antibodies ${ }^{(261)}$. In addition, the same group indicated that the atheroprotective effect seen after immunization with MDA-LDL was due to increased T15 antibody titers that resulted from IL-5 production by Th2 T cells (210). This was confirmed as deficiency in bone marrow IL-5, a cytokine important in non-cognate maturation and Ig secretion of B1 cells, reduces oxLDL-reactive IgM levels and accelerates atherosclerosis ${ }^{(210)}$. In addition, Lewis et al. reported a dramatic increase in atherosclerosis in mice lacking IgM in their serum, again supporting a protective role for IgM in atherosclerosis ${ }^{(262)}$. Similar conclusions were drawn from some well-powered human clinical studies $(256,263,264)$. IgM antibodies are therefore considered anti-atherogenic, while antigen-driven IgG responses are considered to be pro-atherogenic.

As with $T$ cells, the $B$ cell population also contains B cell subsets capable of dampening immune responses. These regulatory $B$ cells modulate the immune response through mechanisms similar to $T$ cells, via secretion of IL-10 and TGF ${ }^{(265)}$, or via their Ag presentation ability or interactions with other immune cells via their secretion of Abs ${ }^{(265)}$. This way regulatory $B$ cells might suppress both Th1 and Th2 polarization and reduce antigen presentation and pro-inflammatory cytokine production by dendritic cells and macrophages. Regulatory B cells may act on atherosclerotic lesions either remotely (LNs or ATLOs) or within lesions. However, their functions and impact on atherosclerosis remains to be investigated.

In conclusion, we can state that B cell subtypes, exerting both pro and anti-atherogenic effects, are important in atherosclerosis and provide some interesting therapeutic options. However, there is still much to learn about $B$ cell subsets and their mechanisms influencing atherosclerosis. 


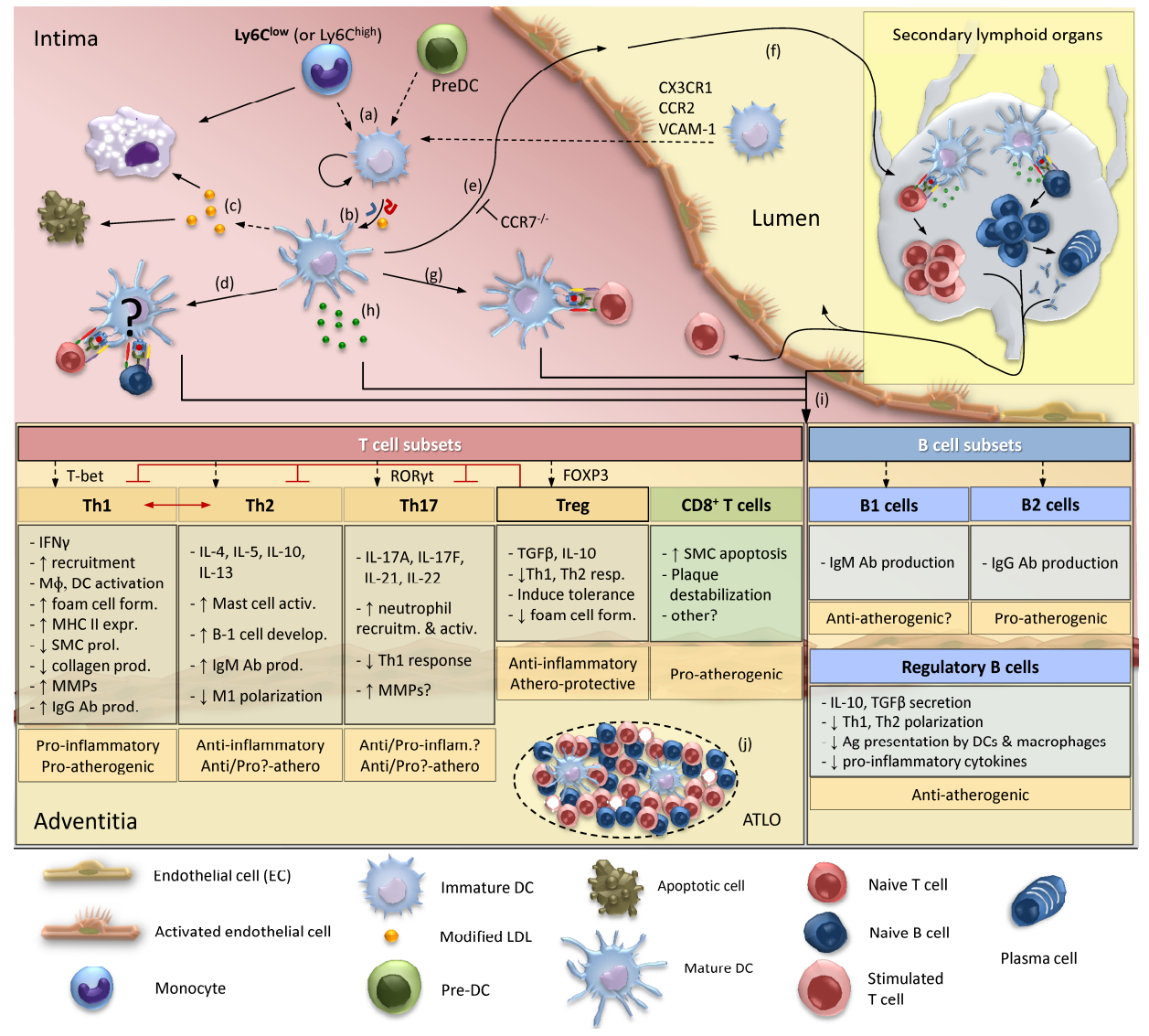

Figure 2: Dendritic cell functions in atherosclerosis

(a) Dendritic cells (DC) accumulate in the plaque through direct recruitment from the lumen, local proliferation and differentiation from either monocytes (preferentially Ly6Clow) or DC precursors. Recruitment of DCs from the plaque to the lumen is CX3CR1, CCR2 and VCAM-1 dependent. (b) Plaque DCs take up (atherosclerosisspecific) antigens, become activated and mature. (c) DCs take up oxLDL and can become foam cells. OxLDL induces DC maturation, but can also trigger DC apoptosis that might contribute to necrotic core formation. (d) Mature DCs are professional antigen presenting cells, however whether direct antigen presentation occurs in the plaque is not known. (e) Dendritic cells can emigrate from the plaque into the lumen, a process that is inhibited by both CCR7 deficiency as well as dyslipidemia. Dendritic cells can also emigrate from the plaque via lymphatics. (f) Emigrated DCs migrate towards secondary lymphoid organs (spleen \& lymph nodes), where they present the antigens to $T$ and $B$ lymphocytes. T cells become activated and clonally expand, after which they enter the blood stream and are attracted to the plaque. After DC antigen presentation $B$ cells divide and eventually differentiate into plasma cells. Plasma cells produce 
various types of Immunoglobulin antibodies that will end up in the blood and affect immune responses. Stimulated $\mathrm{T}$ (and B cells) can enter the plaque where they exert different effector functions, either promoting or reducing atherosclerosis. (g) Dendritic cells inside the plaque can restimulate primed $T$ cells entering the plaque, boosting immune responses. (h) Dendritic cells secrete several chemokines that influence leukocyte recruitment to the plaque. Most DC-derived chemokines, like CCL17 and CCL22, are involved in T cell recruitment. Dendritic cells also secrete various proinflammatory (e.g. TNF $\alpha$, IFNy, IL-6, IL-12) and anti-inflammatory (e.g. IL-10) cytokines that either stimulate or dampen immune responses. (i) DC antigen presentation and cytokine production directly activate various $B$ and $T$ cell subsets that all affect atherosclerosis in specific ways. (j) DCs also contribute to the formation of arterial tertiary lymphoid organs (ATLOs), that affect plaque development remotely. MMP, matrix metalloproteinase; LDL, low-density lipoprotein; EC, endothelial cell; VCAM-1, Vascular cell adhesion molecule-1; pre-DC, DC precursor; Ig, immunoglobin; SMC, smooth muscle cell; M $\phi$, macrophage, MHC major histocompatibility; TGF, transforming growth factor.

\section{Costimulatory/coinhibitory interactions}

The interaction between the different immune cells, and the (consequent) secretion of immune-regulatory and activating cytokines and chemokines determines the progression of atherosclerosis.

Key players in modulating these complex immune interactions and responses are the group of co-stimulatory and co-inhibitory molecules belonging to the CD28/B7 family and the tumor necrosis factor (TNF)/TNFreceptor family. Classically, co-stimulatory molecules provide the signal for proliferation and polarization of T-cells and thereby also regulate the phenotype of the APC upon interaction of a T-cell (TCR) with an antigenpresenting cell (MHCII/HLA). However, expression of co-stimulatory molecules is ubiquitous, and we know now that most of them are not only present on the majority of immune cells, but also on platelets, endothelial cells and vascular smooth muscle cells where they regulate inflammation ${ }^{(266)}$.

In atherosclerosis, co-stimulatory molecules play a major, but diverse role in atherosclerosis ${ }^{(266)}$. In the B7/CD28 family, genetic deficiency or inhibition of B7-1, B7-2, ICOS and PD-L1/2 affected atherosclerosis. Deficiency of B7-1 and B7-2 in $\mathrm{LDLR}^{-/-}$mice was shown to inhibit early atherosclerotic lesion development, and reduced the amount of $\mathrm{MHCll}$ expression in atherosclerotic plaques, and their $\mathrm{CD}^{+} \mathrm{T}$-cells produced less IFN $\gamma(48,151)$. 
However, different results were obtained when $\mathrm{B} 7-1 / \mathrm{B} 7-2^{-/-}$or $\mathrm{CD} 28^{-/-}$bone marrow was given to irradiated $\mathrm{LDLR}^{-/}$mice. These chimeric mice developed more atherosclerosis and this was attributed to their impaired Treg development ${ }^{(267)}$. Similar contradictory results were obtained by studying inhibition of ICOS, a positive co-stimulatory molecule for $\mathrm{CD}^{+}$cells. Instead of the expected reduction in atherosclerosis, both immunization with ICOS as well as bone marrow transplantation of $\mathrm{ICOS}^{-/}$bone marrow into $\mathrm{LDLR}^{-/-}$mice showed an aggravation of atherosclerosis, which was also due to an impaired Treg function $(268,269)$. Moreover, deficiency of PD-PD-L1/2 interactions, a co-inhibitory dyad, aggravated atherosclerosis, and induced a pro-inflammatory plaque phenotype ${ }^{(270)}$. These studies with sometimes opposing results illustrate the complexity of co-stimulatory and co-inhibitory pathways which can influence functions of both pro-inflammatory effector T-cells and Treg suppression.

For the TNF and TNF-R family members, the results are more consistent. Inhibition of $\mathrm{Ox} 40-\mathrm{O} \times 40 \mathrm{~L}$ signalling results in an impaired atherosclerosis development while mice over-expressing $\mathrm{Ox40 \textrm {L }}$ have accelerated atherosclerosis $(271,272)$. The same is true for CD137-CD137L (4-1BB/4-1BBL), where treatment with an agonistic CD137 antibody results in accelerated atherosclerosis and the development of an inflammatory, vulnerable plaque phenotype ${ }^{(183)}$.

One of the most elaborately studied co-stimulatory molecules in atherosclerosis is the CD4OL-CD40 dyad. Inhibition of CD40L not only decreased atherosclerotic plaque burden, but also induced plaques with a beneficial plaque phenotype that were rich in collagen and only contained a limited amount of immune cells $(273,274)$. Blocking of CD4OL when atherosclerotic plaques had established was even capable of transforming vulnerable plaques with a high level of inflammation and a low level of collagen towards the inflammatory-poor beneficial plaque phenotype ${ }^{(275,276)}$. CD4OL antagonists are therefore known as the most potent plaque reducers and plaque stabilizers in a laboratory setting. For CD40, the results are somewhat divergent. In one study, $\mathrm{CD}_{40} 0^{-1-} \mathrm{ApoE}^{-/-}$mice, as well as the $\mathrm{CD} 40^{-/}$ bone marrow chimeras showed a clear decrease in atherosclerosis ${ }^{(277)}$, while in another study, $\mathrm{CD}^{-1 /} \mathrm{LDLr}^{-/-}$mice showed no reduction in atherosclerosis (278). 
The actions of CD40 and CD40L are rather cell type specific. Bone marrow transplantation of $\mathrm{CD} 40^{-/}$, but not $\mathrm{CD} \mathrm{CL}^{-/-}$bone marrow results in a decrease in atherosclerosis, suggesting that bone marrow derived CD40, but not $\mathrm{CD} 40 \mathrm{~L}$ is crucial in atherosclerosis ${ }^{(277,279,280)}$. Transfer of $\mathrm{CD}^{2} 0 \mathrm{~L}^{-1-}$ platelets prevented the platelet induced increased in atherosclerosis, by impairing leukocyte-platelet interactions and inducing a transient increase in Tregs ${ }^{(281)}$.

Interestingly, different cell-type specific CD40-signal transduction pathways tightly regulate atherosclerosis. CD40 does not have intrinsic signal capabilities, but needs adaptor molecules, the TNF-receptor associated factors (TRAFs) to exert signaling. By using $C D 40^{-/}$mice that carried chimeric human/murine CD40 transgenes with mutations in the TRAF2/3/5 or TRAF6 binding domains or both under $\mathrm{MHCll}$, we found that mice deficient in the CD40-TRAF2/3/5 binding site develop normal atherosclerosis, have more CD4 ${ }^{+}$ effector T cells, but also more regulatory T cells. Mice deficient in CD40-TRAF6 interactions hardly develop any atherosclerosis and their plaques contain only few inflammatory cells ${ }^{(277)}$, which is also true for neointima formation ${ }^{(282)}$. Systemically, the different CD40-TRAF interactions induce several immunological patterns in blood, spleen and lymph nodes. Deficiency of CD40TRAF6 interactions results in low numbers of $\mathrm{CD} 4^{+}$effector T cells, pDCs and a switch towards Ly6Clow monocytes and an M2 macrophage phenotype, whereas deficiency of CD40-TRAF2/3/5 interactions induce increased Treg numbers and a change in DC phenotype ${ }^{(277)}$.

The family of co-stimulatory molecules is very powerful in mediating immune cell interactions and immune cell phenotypes in atherosclerosis. However, most of the actions of co-stimulatory molecules are cell-type specific, and dependent on a variety of signaling pathways. Although the first pathways of co-stimulation in atherosclerosis have been unraveled, many more of these pathways will be discovered in the upcoming years. 


\section{Conclusions}

Over the past few years, new immune cell subsets, among which are several that have immune-modulating properties, have been discovered to play an important role in atherosclerosis.

Skewing the vascular immune response towards an anti-inflammatory profile would be beneficial for patients suffering from atherosclerosis, and immune-based cell-therapies are therefore of interest. Dendritic cells, as potent regulators of immune responses, represent an important cell type in this view. Several studies using vaccination strategies in animals already showed promising results for such techniques. M2 macrophages, regulatory Tand B-cells and B1 cells are other cell-types with an immune regulatory function, which should be exploited as potential therapy options for atherosclerosis.

A major challenge is to tweak immune responses to avoid compromising the patient's host defense. An interesting therapeutic option is therefore to modulation of the immune system by co-stimulatory molecules.

However, the precise functions, and the interactions of these immune(modulatory) cells with other immune cells within the plaque, but also systemically, still needs to be unraveled. Only then, we will be successful in developing immunemodulatory strategies to treat atherosclerosis safely and effectively. 


\section{References}

1. Organisation WH. Global health observatory data repository - mortality and burden of disease who regions. 2008;2012

2. Mendis SP, P.; Norrving, B. Global atlas on cardiovascular disease prevention and control. 2011

3. Rosenfeld ME, Campbell LA. Pathogens and atherosclerosis: Update on the potential contribution of multiple infectious organisms to the pathogenesis of atherosclerosis. Thromb Haemost. 2011;106:858-867

4. Sozeri B, Deveci M, Dincel N, Mir S. The early cardiovascular changes in pediatric patients with systemic lupus erythematosus. Pediatr Nephrol. 2012

5. de Leeuw K, Sanders JS, Stegeman C, Smit A, Kallenberg CG, Bijl M. Accelerated atherosclerosis in patients with wegener's granulomatosis. Ann Rheum Dis. 2005;64:753-759

6. Gonzalez-Gay MA, Szekanecz Z, Popa CD, Dessein P. Atherosclerosis in rheumatoid arthritis. Mediators Inflamm. 2012;2012:489608

7. Lusis AJ. Atherosclerosis. Nature. 2000;407:233-241

8. Lievens D, von Hundelshausen P. Platelets in atherosclerosis. Thromb Haemost. 2011;106:827838

9. Koltsova EK, Ley K. How dendritic cells shape atherosclerosis. Trends Immunol. 2011;32:540-547

10. VanderLaan PA, Reardon CA, Getz GS. Site specificity of atherosclerosis: Site-selective responses to atherosclerotic modulators. Arterioscler Thromb Vasc Biol. 2004;24:12-22

11. Elhage R, Gourdy P, Brouchet L, Jawien J, Fouque MJ, Fievet C, Huc X, Barreira Y, Couloumiers JC, Arnal JF, Bayard F. Deleting tcr alpha beta+ or $\mathrm{cd} 4+\mathrm{t}$ lymphocytes leads to opposite effects on site-specific atherosclerosis in female apolipoprotein e-deficient mice. Am J Pathol. 2004;165:2013-2018

12. Teupser D, Pavlides S, Tan M, Gutierrez-Ramos JC, Kolbeck R, Breslow JL. Major reduction of atherosclerosis in fractalkine (cx3cl1)-deficient mice is at the brachiocephalic artery, not the aortic root. Proc Natl Acad Sci U S A. 2004;101:17795-17800

13. Woollard KJ, Geissmann F. Monocytes in atherosclerosis: Subsets and functions. Nat Rev Cardiol. 2010;7:77-86

14. Geissmann F, Jung S, Littman DR. Blood monocytes consist of two principal subsets with distinct migratory properties. Immunity. 2003;19:71-82

15. Weber C, Zernecke A, Libby P. The multifaceted contributions of leukocyte subsets to atherosclerosis: Lessons from mouse models. Nat Rev Immunol. 2008;8:802-815

16. Gautier EL, Jakubzick C, Randolph GJ. Regulation of the migration and survival of monocyte subsets by chemokine receptors and its relevance to atherosclerosis. Arterioscler Thromb Vasc Biol. 2009;29:1412-1418

17. Ziegler-Heitbrock L, Ancuta P, Crowe S, Dalod M, Grau V, Hart DN, Leenen PJ, Liu YJ, MacPherson G, Randolph GJ, Scherberich J, Schmitz J, Shortman K, Sozzani S, Strobl H, Zembala M, Austyn JM, Lutz MB. Nomenclature of monocytes and dendritic cells in blood. Blood. 2010;116:e74-80

18. Shantsila E, Lip GY. Monocyte diversity in myocardial infarction. J Am Coll Cardiol. 2009;54:139142

19. Weber C, Belge KU, von Hundelshausen P, Draude G, Steppich B, Mack M, Frankenberger M, Weber KS, Ziegler-Heitbrock HW. Differential chemokine receptor expression and function in human monocyte subpopulations. J Leukoc Biol. 2000;67:699-704

20. Zawada AM, Rogacev KS, Rotter B, Winter P, Marell RR, Fliser D, Heine GH. Supersage evidence for cd14++cd16+ monocytes as a third monocyte subset. Blood. 2011;118:e50-61

21. Swirski FK, Libby P, Aikawa E, Alcaide P, Luscinskas FW, Weissleder R, Pittet MJ. Ly-6chi monocytes dominate hypercholesterolemia-associated monocytosis and give rise to macrophages in atheromata. J Clin Invest. 2007;117:195-205

22. Tacke F, Alvarez D, Kaplan TJ, Jakubzick C, Spanbroek R, Llodra J, Garin A, Liu J, Mack M, van Rooijen N, Lira SA, Habenicht AJ, Randolph GJ. Monocyte subsets differentially employ ccr2, ccr5, and cx3cr1 to accumulate within atherosclerotic plaques. J Clin Invest. 2007;117:185-194 


\section{I Inflammation and Immune System Interactions in Atherosclerosis}

23. Robbins CS, Chudnovskiy A, Rauch PJ, Figueiredo JL, Iwamoto Y, Gorbatov R, Etzrodt M, Weber GF, Ueno T, van Rooijen N, Mulligan-Kehoe MJ, Libby P, Nahrendorf M, Pittet MJ, Weissleder R, Swirski FK. Extramedullary hematopoiesis generates ly-6c(high) monocytes that infiltrate atherosclerotic lesions. Circulation. 2012;125:364-374

24. Swirski FK, Nahrendorf M, Etzrodt M, Wildgruber M, Cortez-Retamozo V, Panizzi P, Figueiredo JL, Kohler RH, Chudnovskiy A, Waterman P, Aikawa E, Mempel TR, Libby P, Weissleder R, Pittet MJ. Identification of splenic reservoir monocytes and their deployment to inflammatory sites. Science. 2009;325:612-616

25. Murphy AJ, Akhtari M, Tolani S, Pagler T, Bijl N, Kuo CL, Wang M, Sanson M, Abramowicz S, Welch C, Bochem AE, Kuivenhoven JA, Yvan-Charvet L, Tall AR. Apoe regulates hematopoietic stem cell proliferation, monocytosis, and monocyte accumulation in atherosclerotic lesions in mice. J Clin Invest. 2011;121:4138-4149

26. Tall AR, Yvan-Charvet L, Westerterp M, Murphy AJ. Cholesterol efflux: A novel regulator of myelopoiesis and atherogenesis. Arterioscler Thromb Vasc Biol. 2012;32:2547-2552

27. Combadiere C, Potteaux S, Rodero M, Simon T, Pezard A, Esposito B, Merval R, Proudfoot A, Tedgui A, Mallat Z. Combined inhibition of ccl2, cx3cr1, and ccr5 abrogates ly $6 c$ (hi) and ly6c(lo) monocytosis and almost abolishes atherosclerosis in hypercholesterolemic mice. Circulation. 2008;117:1649-1657

28. Swirski FK, Pittet MJ, Kircher MF, Aikawa E, Jaffer FA, Libby P, Weissleder R. Monocyte accumulation in mouse atherogenesis is progressive and proportional to extent of disease. Proc Natl Acad Sci U S A. 2006;103:10340-10345

29. Dansky HM, Charlton SA, Harper MM, Smith JD. T and b lymphocytes play a minor role in atherosclerotic plaque formation in the apolipoprotein e-deficient mouse. Proc Natl Acad Sci US A. 1997;94:4642-4646

30. Saederup N, Chan L, Lira SA, Charo IF. Fractalkine deficiency markedly reduces macrophage accumulation and atherosclerotic lesion formation in ccr2-/- mice: Evidence for independent chemokine functions in atherogenesis. Circulation. 2008;117:1642-1648

31. Boring L, Gosling J, Cleary M, Charo IF. Decreased lesion formation in ccr2-/- mice reveals a role for chemokines in the initiation of atherosclerosis. Nature. 1998;394:894-897

32. Braunersreuther V, Zernecke A, Arnaud C, Liehn EA, Steffens S, Shagdarsuren E, Bidzhekov K, Burger F, Pelli G, Luckow B, Mach F, Weber C. Ccr5 but not ccr1 deficiency reduces development of diet-induced atherosclerosis in mice. Arterioscler Thromb Vasc Biol. 2007;27:373-379

33. Veillard NR, Kwak B, Pelli G, Mulhaupt F, James RW, Proudfoot AE, Mach F. Antagonism of rantes receptors reduces atherosclerotic plaque formation in mice. Circ Res. 2004;94:253-261

34. Brito V, Mellal K, Portelance SG, Perez A, Soto Y, Deblois D, Ong H, Marleau S, Vazquez AM. Induction of anti-anti-idiotype antibodies against sulfated glycosaminoglycans reduces atherosclerosis in apolipoprotein e-deficient mice. Arterioscler Thromb Vasc Biol. 2012

35. Cheng C, Tempel D, van Haperen R, de Boer HC, Segers D, Huisman M, van Zonneveld AJ, Leenen PJ, van der Steen A, Serruys PW, de Crom R, Krams R. Shear stress-induced changes in atherosclerotic plaque composition are modulated by chemokines. J Clin Invest. 2007;117:616626

36. Guo J, de Waard V, Van Eck M, Hildebrand RB, van Wanrooij EJ, Kuiper J, Maeda N, Benson GM, Groot PH, Van Berkel TJ. Repopulation of apolipoprotein e knockout mice with ccr2-deficient bone marrow progenitor cells does not inhibit ongoing atherosclerotic lesion development. Arterioscler Thromb Vasc Biol. 2005;25:1014-1019

37. Aiello RJ, Perry BD, Bourassa PA, Robertson A, Weng W, Knight DR, Smith AH, Frederick KS, Kalgutkar A, Gladue RP. Ccr2 receptor blockade alters blood monocyte subpopulations but does not affect atherosclerotic lesions in apoe(-/-) mice. Atherosclerosis. 2010;208:370-375

38. Mestas J, Ley K. Monocyte-endothelial cell interactions in the development of atherosclerosis. Trends Cardiovasc Med. 2008;18:228-232

39. Moore KJ, Tabas I. Macrophages in the pathogenesis of atherosclerosis. Cell. 2011;145:341-355

40. Williams KJ, Tabas I. The response-to-retention hypothesis of early atherogenesis. Arterioscler Thromb Vasc Biol. 1995;15:551-561 


\section{Inflammation and Immune System Interactions in Atherosclerosis | 2}

41. Tabas I. Macrophage death and defective inflammation resolution in atherosclerosis. Nat Rev Immunol. 2010;10:36-46

42. Burke-Gaffney A, Brooks AV, Bogle RG. Regulation of chemokine expression in atherosclerosis. Vascul Pharmacol. 2002;38:283-292

43. Platt MO, Ankeny RF, Shi GP, Weiss D, Vega JD, Taylor WR, Jo H. Expression of cathepsin $k$ is regulated by shear stress in cultured endothelial cells and is increased in endothelium in human atherosclerosis. Am J Physiol Heart Circ Physiol. 2007;292:H1479-1486

44. Hennig T, Mogensen C, Kirsch J, Pohl U, Gloe T. Shear stress induces the release of an endothelial elastase: Role in integrin alpha(v)beta(3)-mediated fgf-2 release. J Vasc Res. 2011;48:453-464

45. Dole VS, Bergmeier W, Mitchell HA, Eichenberger SC, Wagner DD. Activated platelets induce weibel-palade-body secretion and leukocyte rolling in vivo: Role of p-selectin. Blood. 2005;106:2334-2339

46. Dong ZM, Brown AA, Wagner DD. Prominent role of p-selectin in the development of advanced atherosclerosis in apoe-deficient mice. Circulation. 2000;101:2290-2295

47. Campbell KA, Lipinski MJ, Doran AC, Skaflen MD, Fuster V, McNamara CA. Lymphocytes and the adventitial immune response in atherosclerosis. Circ Res. 2012;110:889-900

48. Gotsman I, Sharpe AH, Lichtman AH. T-cell costimulation and coinhibition in atherosclerosis. Circ Res. 2008;103:1220-1231

49. Johnson JL, Newby AC. Macrophage heterogeneity in atherosclerotic plaques. Curr Opin Lipidol. 2009;20:370-378

50. Smith JD, Trogan E, Ginsberg M, Grigaux C, Tian J, Miyata M. Decreased atherosclerosis in mice deficient in both macrophage colony-stimulating factor (op) and apolipoprotein e. Proc Natl Acad Sci U S A. 1995;92:8264-8268

51. Qiao JH, Tripathi J, Mishra NK, Cai Y, Tripathi S, Wang XP, Imes S, Fishbein MC, Clinton SK, Libby $P$, Lusis AJ, Rajavashisth TB. Role of macrophage colony-stimulating factor in atherosclerosis: Studies of osteopetrotic mice. Am J Pathol. 1997;150:1687-1699

52. Stoneman V, Braganza D, Figg N, Mercer J, Lang R, Goddard M, Bennett M. Monocyte/macrophage suppression in cd11b diphtheria toxin receptor transgenic mice differentially affects atherogenesis and established plaques. Circ Res. 2007;100:884-893

53. Babaev VR, Gleaves LA, Carter KJ, Suzuki H, Kodama T, Fazio S, Linton MF. Reduced atherosclerotic lesions in mice deficient for total or macrophage-specific expression of scavenger receptor-a. Arterioscler Thromb Vasc Biol. 2000;20:2593-2599

54. Suzuki H, Kurihara $Y$, Takeya M, Kamada N, Kataoka M, Jishage K, Ueda O, Sakaguchi H, Higashi T, Suzuki T, Takashima Y, Kawabe Y, Cynshi O, Wada Y, Honda M, Kurihara H, Aburatani H, Doi T, Matsumoto A, Azuma S, Noda T, Toyoda Y, Itakura H, Yazaki Y, Kodama T, et al. A role for macrophage scavenger receptors in atherosclerosis and susceptibility to infection. Nature. 1997;386:292-296

55. Sakaguchi H, Takeya M, Suzuki H, Hakamata H, Kodama T, Horiuchi S, Gordon S, van der Laan LJ, Kraal G, Ishibashi S, Kitamura N, Takahashi K. Role of macrophage scavenger receptors in dietinduced atherosclerosis in mice. Lab Invest. 1998;78:423-434

56. Febbraio M, Podrez EA, Smith JD, Hajjar DP, Hazen SL, Hoff HF, Sharma K, Silverstein RL. Targeted disruption of the class $b$ scavenger receptor cd36 protects against atherosclerotic lesion development in mice. J Clin Invest. 2000;105:1049-1056

57. Moore KJ, Kunjathoor VV, Koehn SL, Manning JJ, Tseng AA, Silver JM, McKee M, Freeman MW. Loss of receptor-mediated lipid uptake via scavenger receptor a or cd36 pathways does not ameliorate atherosclerosis in hyperlipidemic mice. J Clin Invest. 2005;115:2192-2201

58. Manning-Tobin JJ, Moore KJ, Seimon TA, Bell SA, Sharuk M, Alvarez-Leite JI, de Winther MP, Tabas I, Freeman MW. Loss of sr-a and cd36 activity reduces atherosclerotic lesion complexity without abrogating foam cell formation in hyperlipidemic mice. Arterioscler Thromb Vasc Biol. 2009;29:19-26

59. Brown MS, Ho YK, Goldstein JL. The cholesteryl ester cycle in macrophage foam cells. Continual hydrolysis and re-esterification of cytoplasmic cholesteryl esters. J Biol Chem. 1980;255:93449352 


\section{I Inflammation and Immune System Interactions in Atherosclerosis}

60. Tall AR, Yvan-Charvet L, Terasaka N, Pagler T, Wang N. Hdl, abc transporters, and cholesterol efflux: Implications for the treatment of atherosclerosis. Cell Metab. 2008;7:365-375

61. Yvan-Charvet L, Pagler T, Gautier EL, Avagyan S, Siry RL, Han S, Welch CL, Wang N, Randolph GJ, Snoeck HW, Tall AR. Atp-binding cassette transporters and hdl suppress hematopoietic stem cell proliferation. Science. 2010;328:1689-1693

62. Voloshyna I, Reiss $A B$. The abc transporters in lipid flux and atherosclerosis. Prog Lipid Res. 2011;50:213-224

63. Seneviratne AN, Sivagurunathan B, Monaco C. Toll-like receptors and macrophage activation in atherosclerosis. Clin Chim Acta. 2012;413:3-14

64. Liu G, Yang H. Modulation of macrophage activation and programming in immunity. J Cell Physiol. 2012

65. Kzhyshkowska J, Neyen C, Gordon S. Role of macrophage scavenger receptors in atherosclerosis. Immunobiology. 2012;217:492-502

66. Gordon S. Alternative activation of macrophages. Nat Rev Immunol. 2003;3:23-35

67. Tedgui A, Mallat Z. Cytokines in atherosclerosis: Pathogenic and regulatory pathways. Physiol Rev. 2006;86:515-581

68. Gui T, Shimokado A, Sun Y, Akasaka T, Muragaki Y. Diverse roles of macrophages in atherosclerosis: From inflammatory biology to biomarker discovery. Mediators Inflamm. 2012;2012:693083

69. Wolfs IM, Donners MM, de Winther MP. Differentiation factors and cytokines in the atherosclerotic plaque micro-environment as a trigger for macrophage polarisation. Thromb Haemost. 2011;106:763-771

70. Koenen RR, Weber C. Chemokines: Established and novel targets in atherosclerosis. EMBO Mol Med. 2011;3:713-725

71. Galkina E, Ley K. Immune and inflammatory mechanisms of atherosclerosis (*). Annu Rev Immunol. 2009;27:165-197

72. de Jager SC, Bermudez B, Bot I, Koenen RR, Bot M, Kavelaars A, de Waard V, Heijnen CJ, Muriana FJ, Weber C, van Berkel TJ, Kuiper J, Lee SJ, Abia R, Biessen EA. Growth differentiation factor 15 deficiency protects against atherosclerosis by attenuating ccr2-mediated macrophage chemotaxis. J Exp Med. 2011;208:217-225

73. Bulut Y, Faure E, Thomas L, Karahashi H, Michelsen KS, Equils O, Morrison SG, Morrison RP, Arditi M. Chlamydial heat shock protein 60 activates macrophages and endothelial cells through toll-like receptor 4 and $\mathrm{md} 2$ in a myd88-dependent pathway. J Immunol. 2002;168:1435-1440

74. Miller YI, Viriyakosol S, Binder CJ, Feramisco JR, Kirkland TN, Witztum JL. Minimally modified Idl binds to cd14, induces macrophage spreading via t/r4/md-2, and inhibits phagocytosis of apoptotic cells. J Biol Chem. 2003;278:1561-1568

75. Bae YS, Lee JH, Choi SH, Kim S, Almazan F, Witztum JL, Miller YI. Macrophages generate reactive oxygen species in response to minimally oxidized low-density lipoprotein: Toll-like receptor 4and spleen tyrosine kinase-dependent activation of nadph oxidase 2. Circ Res. 2009;104:210218, 221p following 218

76. Xu XH, Shah PK, Faure E, Equils O, Thomas L, Fishbein MC, Luthringer D, Xu XP, Rajavashisth TB, Yano J, Kaul S, Arditi M. Toll-like receptor-4 is expressed by macrophages in murine and human lipid-rich atherosclerotic plaques and upregulated by oxidized Idl. Circulation. 2001;104:31033108

77. Duewell P, Kono H, Rayner KJ, Sirois CM, Vladimer G, Bauernfeind FG, Abela GS, Franchi L, Nunez G, Schnurr M, Espevik T, Lien E, Fitzgerald KA, Rock KL, Moore KJ, Wright SD, Hornung V, Latz E. Nlrp3 inflammasomes are required for atherogenesis and activated by cholesterol crystals. Nature. 2010;464:1357-1361

78. Tabas I. The role of endoplasmic reticulum stress in the progression of atherosclerosis. Circ Res. 2010;107:839-850

79. Thorp E, Li G, Seimon TA, Kuriakose G, Ron D, Tabas I. Reduced apoptosis and plaque necrosis in advanced atherosclerotic lesions of apoe-/- and Idlr-/- mice lacking chop. Cell Metab. 2009;9:474-481 
80. Tsukano H, Gotoh T, Endo M, Miyata K, Tazume H, Kadomatsu T, Yano M, Iwawaki T, Kohno K, Araki K, Mizuta H, Oike Y. The endoplasmic reticulum stress-c/ebp homologous protein pathway-mediated apoptosis in macrophages contributes to the instability of atherosclerotic plaques. Arterioscler Thromb Vasc Biol. 2010;30:1925-1932

81. Timmins JM, Ozcan L, Seimon TA, Li G, Malagelada C, Backs J, Backs T, Bassel-Duby R, Olson EN, Anderson ME, Tabas I. Calcium/calmodulin-dependent protein kinase ii links er stress with fas and mitochondrial apoptosis pathways. J Clin Invest. 2009;119:2925-2941

82. Collins AR, Lyon CJ, Xia X, Liu JZ, Tangirala RK, Yin F, Boyadjian R, Bikineyeva A, Pratico D, Harrison DG, Hsueh WA. Age-accelerated atherosclerosis correlates with failure to upregulate antioxidant genes. Circ Res. 2009;104:e42-54

83. Song L, Leung C, Schindler C. Lymphocytes are important in early atherosclerosis. J Clin Invest. 2001;108:251-259

84. Reardon CA, Blachowicz L, Lukens J, Nissenbaum M, Getz GS. Genetic background selectively influences innominate artery atherosclerosis: Immune system deficiency as a probe. Arterioscler Thromb Vasc Biol. 2003;23:1449-1454

85. Gordon S, Martinez FO. Alternative activation of macrophages: Mechanism and functions. Immunity. 2010;32:593-604

86. Martinez FO, Sica A, Mantovani A, Locati M. Macrophage activation and polarization. Front Biosci. 2008;13:453-461

87. Lee S, Huen S, Nishio H, Nishio S, Lee HK, Choi BS, Ruhrberg C, Cantley LG. Distinct macrophage phenotypes contribute to kidney injury and repair. J Am Soc Nephrol. 2011;22:317-326

88. Bouhlel MA, Derudas B, Rigamonti E, Dievart R, Brozek J, Haulon S, Zawadzki C, Jude B, Torpier G, Marx N, Staels B, Chinetti-Gbaguidi G. Ppargamma activation primes human monocytes into alternative $\mathrm{m} 2$ macrophages with anti-inflammatory properties. Cell Metab. 2007;6:137-143

89. Stoger JL, Gijbels MJ, van der Velden S, Manca M, van der Loos CM, Biessen EA, Daemen MJ, Lutgens $E$, de Winther MP. Distribution of macrophage polarization markers in human atherosclerosis. Atherosclerosis. 2012;225:461-468

90. Chinetti-Gbaguidi G, Baron M, Bouhlel MA, Vanhoutte J, Copin C, Sebti Y, Derudas B, Mayi T, Bories G, Tailleux A, Haulon S, Zawadzki C, Jude B, Staels B. Human atherosclerotic plaque alternative macrophages display low cholesterol handling but high phagocytosis because of distinct activities of the ppargamma and Ixralpha pathways. Circ Res. 2011;108:985-995

91. Oh J, Riek AE, Weng S, Petty M, Kim D, Colonna M, Cella M, Bernal-Mizrachi C. Endoplasmic reticulum stress controls $\mathrm{m} 2$ macrophage differentiation and foam cell formation. $J$ Biol Chem. 2012;287:11629-11641

92. Martinez FO, Gordon S, Locati M, Mantovani A. Transcriptional profiling of the human monocyte-to-macrophage differentiation and polarization: New molecules and patterns of gene expression. J Immunol. 2006;177:7303-7311

93. Khallou-Laschet J, Varthaman A, Fornasa G, Compain C, Gaston AT, Clement M, Dussiot M, Levillain O, Graff-Dubois S, Nicoletti A, Caligiuri G. Macrophage plasticity in experimental atherosclerosis. PLoS One. 2010;5:e8852

94. Feig JE, Parathath S, Rong JX, Mick SL, Vengrenyuk Y, Grauer L, Young SG, Fisher EA. Reversal of hyperlipidemia with a genetic switch favorably affects the content and inflammatory state of macrophages in atherosclerotic plaques. Circulation. 2011;123:989-998

95. La Flamme AC, Harvie M, Kenwright D, Cameron K, Rawlence N, Low YS, McKenzie S. Chronic exposure to schistosome eggs reduces serum cholesterol but has no effect on atherosclerotic lesion development. Parasite Immunol. 2007;29:259-266

96. Doenhoff MJ, Stanley RG, Griffiths K, Jackson CL. An anti-atherogenic effect of schistosoma mansoni infections in mice associated with a parasite-induced lowering of blood total cholesterol. Parasitology. 2002;125:415-421

97. Stanley RG, Jackson CL, Griffiths K, Doenhoff MJ. Effects of schistosoma mansoni worms and eggs on circulating cholesterol and liver lipids in mice. Atherosclerosis. 2009;207:131-138

98. Kadl A, Meher AK, Sharma PR, Lee MY, Doran AC, Johnstone SR, Elliott MR, Gruber F, Han J, Chen W, Kensler T, Ravichandran KS, Isakson BE, Wamhoff BR, Leitinger N. Identification of a 


\section{2 | Inflammation and Immune System Interactions in Atherosclerosis}

novel macrophage phenotype that develops in response to atherogenic phospholipids via nrf2. Circ Res. 2010;107:737-746

99. Gleissner CA, Shaked I, Little KM, Ley K. Cxc chemokine ligand 4 induces a unique transcriptome in monocyte-derived macrophages. J Immunol. 2010;184:4810-4818

100. Ionita MG, van den Borne P, Catanzariti LM, Moll FL, de Vries JP, Pasterkamp G, Vink A, de Kleijn DP. High neutrophil numbers in human carotid atherosclerotic plaques are associated with characteristics of rupture-prone lesions. Arterioscler Thromb Vasc Biol. 2010;30:1842-1848

101. Drechsler M, Megens RT, van Zandvoort M, Weber C, Soehnlein O. Hyperlipidemia-triggered neutrophilia promotes early atherosclerosis. Circulation. 2010;122:1837-1845

102. Rotzius P, Thams S, Soehnlein O, Kenne E, Tseng CN, Bjorkstrom NK, Malmberg KJ, Lindbom L, Eriksson EE. Distinct infiltration of neutrophils in lesion shoulders in apoe-/- mice. Am J Pathol. 2010;177:493-500

103. Rotzius $\mathrm{P}$, Soehnlein $\mathrm{O}$, Kenne E, Lindbom L, Nystrom K, Thams S, Eriksson EE. Apoe(-/)/lysozyme $\mathrm{m}(\mathrm{egfp} / \mathrm{egfp}$ ) mice as a versatile model to study monocyte and neutrophil trafficking in atherosclerosis. Atherosclerosis. 2009;202:111-118

104. van Leeuwen M, Gijbels MJ, Duijvestijn A, Smook M, van de Gaar MJ, Heeringa P, de Winther MP, Tervaert JW. Accumulation of myeloperoxidase-positive neutrophils in atherosclerotic lesions in Idlr-/- mice. Arterioscler Thromb Vasc Biol. 2008;28:84-89

105. Daugherty A, Dunn JL, Rateri DL, Heinecke JW. Myeloperoxidase, a catalyst for lipoprotein oxidation, is expressed in human atherosclerotic lesions. J Clin Invest. 1994;94:437-444

106. Lee TD, Gonzalez ML, Kumar P, Chary-Reddy S, Grammas P, Pereira HA. Cap37, a novel inflammatory mediator: Its expression in endothelial cells and localization to atherosclerotic lesions. Am J Pathol. 2002;160:841-848

107. Edfeldt K, Agerberth B, Rottenberg ME, Gudmundsson GH, Wang XB, Mandal K, Xu Q, Yan ZQ. Involvement of the antimicrobial peptide II-37 in human atherosclerosis. Arterioscler Thromb Vasc Biol. 2006;26:1551-1557

108. Barnathan ES, Raghunath PN, Tomaszewski JE, Ganz T, Cines DB, Higazi Aa-R. Immunohistochemical localization of defensin in human coronary vessels. Am J Pathol. 1997;150:1009-1020

109. Hemdahl AL, Gabrielsen A, Zhu C, Eriksson P, Hedin U, Kastrup J, Thoren P, Hansson GK. Expression of neutrophil gelatinase-associated lipocalin in atherosclerosis and myocardial infarction. Arterioscler Thromb Vasc Biol. 2006;26:136-142

110. Doring Y, Drechsler M, Wantha S, Kemmerich K, Lievens D, Vijayan S, Gallo RL, Weber C, Soehnlein O. Lack of neutrophil-derived cramp reduces atherosclerosis in mice. Circ Res. 2012;110:1052-1056

111. Higazi AA, Lavi E, Bdeir K, Ulrich AM, Jamieson DG, Rader DJ, Usher DC, Kane W, Ganz T, Cines DB. Defensin stimulates the binding of lipoprotein (a) to human vascular endothelial and smooth muscle cells. Blood. 1997;89:4290-4298

112. Bdeir K, Cane W, Canziani G, Chaiken I, Weisel J, Koschinsky ML, Lawn RM, Bannerman PG, Sachais BS, Kuo A, Hancock MA, Tomaszewski J, Raghunath PN, Ganz T, Higazi AA, Cines DB. Defensin promotes the binding of lipoprotein(a) to vascular matrix. Blood. 1999;94:2007-2019

113. Soehnlein O. Multiple roles for neutrophils in atherosclerosis. Circ Res. 2012;110:875-888

114. Dorweiler B, Torzewski M, Dahm M, Kirkpatrick CJ, Lackner KJ, Vahl CF. Subendothelial infiltration of neutrophil granulocytes and liberation of matrix-destabilizing enzymes in an experimental model of human neo-intima. Thromb Haemost. 2008;99:373-381

115. Belz GT, Nutt SL. Transcriptional programming of the dendritic cell network. Nat Rev Immunol. 2012;12:101-113

116. Becker L, Liu NC, Averill MM, Yuan W, Pamir N, Peng Y, Irwin AD, Fu X, Bornfeldt KE, Heinecke JW. Unique proteomic signatures distinguish macrophages and dendritic cells. PLOS One. 2012;7:e33297

117. Ley K, Miller YI, Hedrick CC. Monocyte and macrophage dynamics during atherogenesis. Arterioscler Thromb Vasc Biol. 2011;31:1506-1516

118. Steinman RM, Cohn ZA. Identification of a novel cell type in peripheral lymphoid organs of mice. I. Morphology, quantitation, tissue distribution. J Exp Med. 1973;137:1142-1162 


\section{Inflammation and Immune System Interactions in Atherosclerosis | 2}

119. Bobryshev YV, Lord RS. S-100 positive cells in human arterial intima and in atherosclerotic lesions. Cardiovasc Res. 1995;29:689-696

120. Millonig G, Niederegger H, Rabl W, Hochleitner BW, Hoefer D, Romani N, Wick G. Network of vascular-associated dendritic cells in intima of healthy young individuals. Arterioscler Thromb Vasc Biol. 2001;21:503-508

121. Yilmaz A, Lochno M, Traeg F, Cicha I, Reiss C, Stumpf C, Raaz D, Anger T, Amann K, Probst T, Ludwig J, Daniel WG, Garlichs CD. Emergence of dendritic cells in rupture-prone regions of vulnerable carotid plaques. Atherosclerosis. 2004;176:101-110

122. Choi JH, Do Y, Cheong C, Koh H, Boscardin SB, Oh YS, Bozzacco L, Trumpfheller C, Park CG, Steinman RM. Identification of antigen-presenting dendritic cells in mouse aorta and cardiac valves. J Exp Med. 2009;206:497-505

123. Galkina E, Kadl A, Sanders J, Varughese D, Sarembock IJ, Ley K. Lymphocyte recruitment into the aortic wall before and during development of atherosclerosis is partially l-selectin dependent. $J$ Exp Med. 2006;203:1273-1282

124. Weber C, Meiler S, Doring Y, Koch M, Drechsler M, Megens RT, Rowinska Z, Bidzhekov K, Fecher C, Ribechini E, van Zandvoort MA, Binder CJ, Jelinek I, Hristov M, Boon L, Jung S, Korn T, Lutz $M B$, Forster I, Zenke M, Hieronymus $T$, Junt $T$, Zernecke A. Ccl17-expressing dendritic cells drive atherosclerosis by restraining regulatory t cell homeostasis in mice. J Clin Invest. 2011;121:28982910

125. Liu P, Yu YR, Spencer JA, Johnson AE, Vallanat CT, Fong AM, Patterson C, Patel DD. Cx3cr1 deficiency impairs dendritic cell accumulation in arterial intima and reduces atherosclerotic burden. Arterioscler Thromb Vasc Biol. 2008;28:243-250

126. Bobryshev YV. Dendritic cells in atherosclerosis: Current status of the problem and clinical relevance. Eur Heart J. 2005;26:1700-1704

127. Erbel C, Sato K, Meyer FB, Kopecky SL, Frye RL, Goronzy JJ, Weyand CM. Functional profile of activated dendritic cells in unstable atherosclerotic plaque. Basic Res Cardiol. 2007;102:123-132

128. Yilmaz A, Weber J, Cicha I, Stumpf C, Klein M, Raithel D, Daniel WG, Garlichs CD. Decrease in circulating myeloid dendritic cell precursors in coronary artery disease. J Am Coll Cardiol. 2006;48:70-80

129. Van Vre EA, Hoymans VY, Bult H, Lenjou M, Van Bockstaele DR, Vrints CJ, Bosmans JM. Decreased number of circulating plasmacytoid dendritic cells in patients with atherosclerotic coronary artery disease. Coron Artery Dis. 2006;17:243-248

130. Van Vre EA, Van Brussel I, de Beeck KO, Hoymans VY, Vrints CJ, Bult H, Bosmans JM. Changes in blood dendritic cell counts in relation to type of coronary artery disease and brachial endothelial cell function. Coron Artery Dis. 2010;21:87-96

131. Gautier EL, Huby T, Saint-Charles F, Ouzilleau B, Pirault J, Deswaerte V, Ginhoux F, Miller ER, Witztum JL, Chapman MJ, Lesnik P. Conventional dendritic cells at the crossroads between immunity and cholesterol homeostasis in atherosclerosis. Circulation. 2009;119:2367-2375

132. Hjerpe C, Johansson D, Hermansson A, Hansson GK, Zhou X. Dendritic cells pulsed with malondialdehyde modified low density lipoprotein aggravate atherosclerosis in apoe(-/-) mice. Atherosclerosis. 2010;209:436-441

133. Hermansson A, Johansson DK, Ketelhuth DF, Andersson J, Zhou X, Hansson GK. Immunotherapy with tolerogenic apolipoprotein b-100-loaded dendritic cells attenuates atherosclerosis in hypercholesterolemic mice. Circulation. 2011;123:1083-1091

134. Habets KL, van Puijvelde GH, van Duivenvoorde LM, van Wanrooij EJ, de Vos P, Tervaert JW, van Berkel TJ, Toes RE, Kuiper J. Vaccination using oxidized low-density lipoprotein-pulsed dendritic cells reduces atherosclerosis in Idl receptor-deficient mice. Cardiovasc Res. 2010;85:622-630

135. Daissormont IT, Christ A, Temmerman L, Sampedro Millares S, Seijkens T, Manca M, Rousch M, Poggi M, Boon L, van der Loos C, Daemen M, Lutgens E, Halvorsen B, Aukrust P, Janssen E, Biessen EA. Plasmacytoid dendritic cells protect against atherosclerosis by tuning t-cell proliferation and activity. Circ Res. 2011;109:1387-1395

136. Doring Y, Manthey HD, Drechsler M, Lievens D, Megens RT, Soehnlein O, Busch M, Manca M, Koenen RR, Pelisek J, Daemen MJ, Lutgens E, Zenke M, Binder CJ, Weber C, Zernecke A. Auto- 
2 | Inflammation and Immune System Interactions in Atherosclerosis

antigenic protein-DNA complexes stimulate plasmacytoid dendritic cells to promote atherosclerosis. Circulation. 2012;125:1673-1683

137. Macritchie N, Grassia G, Sabir SR, Maddaluno M, Welsh P, Sattar N, lalenti A, KurowskaStolarska M, Mclnnes IB, Brewer JM, Garside P, Maffia P. Plasmacytoid dendritic cells play a key role in promoting atherosclerosis in apolipoprotein e-deficient mice. Arterioscler Thromb Vasc Biol. 2012;32:2569-2579

138. Combadiere C, Potteaux S, Gao JL, Esposito B, Casanova S, Lee EJ, Debre P, Tedgui A, Murphy PM, Mallat Z. Decreased atherosclerotic lesion formation in $\mathrm{cx3}$ cr1/apolipoprotein e double knockout mice. Circulation. 2003;107:1009-1016

139. Jongstra-Bilen J, Haidari M, Zhu SN, Chen M, Guha D, Cybulsky MI. Low-grade chronic inflammation in regions of the normal mouse arterial intima predisposed to atherosclerosis. $J$ Exp Med. 2006;203:2073-2083

140. Zhu SN, Chen M, Jongstra-Bilen J, Cybulsky MI. Gm-csf regulates intimal cell proliferation in nascent atherosclerotic lesions. J Exp Med. 2009;206:2141-2149

141. Kabashima K, Banks TA, Ansel KM, Lu TT, Ware CF, Cyster JG. Intrinsic Iymphotoxin-beta receptor requirement for homeostasis of lymphoid tissue dendritic cells. Immunity. 2005;22:439-450

142. Packard RR, Maganto-Garcia E, Gotsman I, Tabas I, Libby P, Lichtman AH. Cd11c(+) dendritic cells maintain antigen processing, presentation capabilities, and cd4(+) t-cell priming efficacy under hypercholesterolemic conditions associated with atherosclerosis. Circ Res. 2008;103:965973

143. Packard RR, Shi GP. Atherosclerosis progression and monocyte emigration from plaque. Future Cardiol. 2006;2:415-418

144. Paulson KE, Zhu SN, Chen M, Nurmohamed S, Jongstra-Bilen J, Cybulsky MI. Resident intimal dendritic cells accumulate lipid and contribute to the initiation of atherosclerosis. Circ Res. 2010;106:383-390

145. Cho HJ, Shashkin P, Gleissner CA, Dunson D, Jain N, Lee JK, Miller Y, Ley K. Induction of dendritic cell-like phenotype in macrophages during foam cell formation. Physiol Genomics. 2007;29:149160

146. Alderman CJ, Bunyard PR, Chain BM, Foreman JC, Leake DS, Katz DR. Effects of oxidised low density lipoprotein on dendritic cells: A possible immunoregulatory component of the atherogenic micro-environment? Cardiovasc Res. 2002;55:806-819

147. Bluml S, Kirchberger S, Bochkov VN, Kronke G, Stuhlmeier K, Majdic O, Zlabinger GJ, Knapp W, Binder BR, Stockl J, Leitinger N. Oxidized phospholipids negatively regulate dendritic cell maturation induced by tlrs and cd40. J Immunol. 2005;175:501-508

148. Boulesteix T, Pena AM, Pages N, Godeau G, Sauviat MP, Beaurepaire E, Schanne-Klein MC. Micrometer scale ex vivo multiphoton imaging of unstained arterial wall structure. Cytometry $A$. 2006;69:20-26

149. Perrin-Cocon L, Coutant F, Agaugue S, Deforges S, Andre P, Lotteau V. Oxidized low-density lipoprotein promotes mature dendritic cell transition from differentiating monocyte. J Immunol. 2001;167:3785-3791

150. Sun J, Hartvigsen K, Chou MY, Zhang Y, Sukhova GK, Zhang J, Lopez-Ilasaca M, Diehl CJ, Yakov N, Harats D, George J, Witztum JL, Libby P, Ploegh H, Shi GP. Deficiency of antigen-presenting cell invariant chain reduces atherosclerosis in mice. Circulation. 2010;122:808-820

151. Buono C, Pang H, Uchida $Y$, Libby $P$, Sharpe AH, Lichtman AH. B7-1/b7-2 costimulation regulates plaque antigen-specific t-cell responses and atherogenesis in low-density lipoprotein receptordeficient mice. Circulation. 2004;109:2009-2015

152. Hermansson A, Ketelhuth DF, Strodthoff D, Wurm M, Hansson EM, Nicoletti A, Paulsson-Berne $\mathrm{G}$, Hansson GK. Inhibition of $\mathrm{t}$ cell response to native low-density lipoprotein reduces atherosclerosis. J Exp Med. 2010;207:1081-1093

153. Choi JH, Cheong C, Dandamudi DB, Park CG, Rodriguez A, Mehandru S, Velinzon K, Jung IH, Yoo JY, Oh GT, Steinman RM. Flt3 signaling-dependent dendritic cells protect against atherosclerosis. Immunity. 2011;35:819-831 


\section{Inflammation and Immune System Interactions in Atherosclerosis | 2}

154. Llodra J, Angeli V, Liu J, Trogan E, Fisher EA, Randolph GJ. Emigration of monocyte-derived cells from atherosclerotic lesions characterizes regressive, but not progressive, plaques. Proc Natl Acad Sci U S A. 2004;101:11779-11784

155. Schieffer B, Selle T, Hilfiker A, Hilfiker-Kleiner D, Grote K, Tietge UJ, Trautwein C, Luchtefeld M, Schmittkamp C, Heeneman S, Daemen MJ, Drexler H. Impact of interleukin-6 on plaque development and morphology in experimental atherosclerosis. Circulation. 2004;110:3493-3500

156. Huber SA, Sakkinen P, Conze D, Hardin N, Tracy R. Interleukin-6 exacerbates early atherosclerosis in mice. Arterioscler Thromb Vasc Biol. 1999;19:2364-2367

157. Davenport P, Tipping PG. The role of interleukin-4 and interleukin-12 in the progression of atherosclerosis in apolipoprotein e-deficient mice. Am J Pathol. 2003;163:1117-1125

158. Lee TS, Yen HC, Pan CC, Chau LY. The role of interleukin 12 in the development of atherosclerosis in apoe-deficient mice. Arterioscler Thromb Vasc Biol. 1999;19:734-742

159. Hauer AD, Uyttenhove C, de Vos P, Stroobant V, Renauld JC, van Berkel TJ, van Snick J, Kuiper J. Blockade of interleukin-12 function by protein vaccination attenuates atherosclerosis. Circulation. 2005;112:1054-1062

160. Zhang X, Niessner A, Nakajima T, Ma-Krupa W, Kopecky SL, Frye RL, Goronzy JJ, Weyand CM. Interleukin 12 induces t-cell recruitment into the atherosclerotic plaque. Circ Res. 2006;98:524531

161. Samarasinghe R, Tailor P, Tamura T, Kaisho T, Akira S, Ozato K. Induction of an antiinflammatory cytokine, il-10, in dendritic cells after toll-like receptor signaling. J Interferon Cytokine Res. 2006;26:893-900

162. Kastelein RA, Hunter CA, Cua DJ. Discovery and biology of il-23 and il-27: Related but functionally distinct regulators of inflammation. Annu Rev Immunol. 2007;25:221-242

163. Goossens P, Gijbels MJ, Zernecke A, Eijgelaar W, Vergouwe MN, van der Made I, Vanderlocht J, Beckers L, Buurman WA, Daemen MJ, Kalinke U, Weber C, Lutgens E, de Winther MP. Myeloid type $\mathrm{i}$ interferon signaling promotes atherosclerosis by stimulating macrophage recruitment to lesions. Cell Metab. 2010;12:142-153

164. Greaves DR, Hakkinen T, Lucas AD, Liddiard K, Jones E, Quinn CM, Senaratne J, Green FR, Tyson K, Boyle J, Shanahan C, Weissberg PL, Gordon S, Yla-Hertualla S. Linked chromosome 16q13 chemokines, macrophage-derived chemokine, fractalkine, and thymus- and activation-regulated chemokine, are expressed in human atherosclerotic lesions. Arterioscler Thromb Vasc Biol. 2001;21:923-929

165. Huang DR, Wang J, Kivisakk P, Rollins BJ, Ransohoff RM. Absence of monocyte chemoattractant protein 1 in mice leads to decreased local macrophage recruitment and antigen-specific $t$ helper cell type 1 immune response in experimental autoimmune encephalomyelitis. $J$ Exp Med. 2001;193:713-726

166. Bystry RS, Aluvihare V, Welch KA, Kallikourdis M, Betz AG. B cells and professional apcs recruit regulatory t cells via ccl4. Nat Immunol. 2001;2:1126-1132

167. Banchereau J, Briere F, Caux C, Davoust J, Lebecque S, Liu YJ, Pulendran B, Palucka K. Immunobiology of dendritic cells. Annu Rev Immunol. 2000;18:767-811

168. Niessner A, Sato K, Chaikof EL, Colmegna I, Goronzy JJ, Weyand CM. Pathogen-sensing plasmacytoid dendritic cells stimulate cytotoxic t-cell function in the atherosclerotic plaque through interferon-alpha. Circulation. 2006;114:2482-2489

169. Niessner A, Weyand CM. Dendritic cells in atherosclerotic disease. Clin Immunol. 2010;134:2532

170. Wigren M, Nilsson J, Kolbus D. Lymphocytes in atherosclerosis. Clin Chim Acta. 2012;413:15621568

171. Jonasson L, Holm J, Skalli O, Gabbiani G, Hansson GK. Expression of class ii transplantation antigen on vascular smooth muscle cells in human atherosclerosis. J Clin Invest. 1985;76:125131

172. Hansson GK, Jonasson L, Holm J, Claesson-Welsh L. Class ii mhc antigen expression in the atherosclerotic plaque: Smooth muscle cells express hla-dr, hla-dq and the invariant gamma chain. Clin Exp Immunol. 1986;64:261-268 


\section{I Inflammation and Immune System Interactions in Atherosclerosis}

173. Hansson GK, Holm J, Jonasson L. Detection of activated $t$ lymphocytes in the human atherosclerotic plaque. Am J Pathol. 1989;135:169-175

174. Palinski W, Rosenfeld ME, Yla-Herttuala S, Gurtner GC, Socher SS, Butler SW, Parthasarathy S, Carew TE, Steinberg D, Witztum JL. Low density lipoprotein undergoes oxidative modification in vivo. Proc Natl Acad Sci U S A. 1989;86:1372-1376

175. Stemme S, Faber B, Holm J, Wiklund O, Witztum JL, Hansson GK. T Iymphocytes from human atherosclerotic plaques recognize oxidized low density lipoprotein. Proc Natl Acad Sci U S A. 1995;92:3893-3897

176. Paulsson G, Zhou X, Tornquist E, Hansson GK. Oligoclonal t cell expansions in atherosclerotic lesions of apolipoprotein e-deficient mice. Arterioscler Thromb Vasc Biol. 2000;20:10-17

177. Hansson GK, Robertson AK, Soderberg-Naucler C. Inflammation and atherosclerosis. Annu Rev Pathol. 2006;1:297-329

178. Kovanen PT. Mast cells: Multipotent local effector cells in atherothrombosis. Immunol Rev. 2007;217:105-122

179. Huber SA, Sakkinen P, David C, Newell MK, Tracy RP. T helper-cell phenotype regulates atherosclerosis in mice under conditions of mild hypercholesterolemia. Circulation. 2001;103:2610-2616

180. Emeson EE, Shen ML, Bell CG, Qureshi A. Inhibition of atherosclerosis in cd4 t-cell-ablated and nude (nu/nu) c57bl/6 hyperlipidemic mice. Am J Pathol. 1996;149:675-685

181. Zhou X, Nicoletti A, Elhage R, Hansson GK. Transfer of cd4(+) t cells aggravates atherosclerosis in immunodeficient apolipoprotein e knockout mice. Circulation. 2000;102:2919-2922

182. Ludewig B, Freigang S, Jaggi M, Kurrer MO, Pei YC, VIk L, Odermatt B, Zinkernagel RM, Hengartner $H$. Linking immune-mediated arterial inflammation and cholesterol-induced atherosclerosis in a transgenic mouse model. Proc Natl Acad Sci U S A. 2000;97:12752-12757

183. Olofsson PS, Soderstrom LA, Wagsater D, Sheikine Y, Ocaya P, Lang F, Rabu C, Chen L, Rudling M, Aukrust P, Hedin U, Paulsson-Berne G, Sirsjo A, Hansson GK. Cd137 is expressed in human atherosclerosis and promotes development of plaque inflammation in hypercholesterolemic mice. Circulation. 2008;117:1292-1301

184. Bobryshev YV, Lord RS. Mapping of vascular dendritic cells in atherosclerotic arteries suggests their involvement in local immune-inflammatory reactions. Cardiovasc Res. 1998;37:799-810

185. De Palma R, Del Galdo F, Abbate G, Chiariello M, Calabro R, Forte L, Cimmino G, Papa MF, Russo MG, Ambrosio G, Giombolini C, Tritto I, Notaristefano S, Berrino L, Rossi F, Golino P. Patients with acute coronary syndrome show oligoclonal t-cell recruitment within unstable plaque: Evidence for a local, intracoronary immunologic mechanism. Circulation. 2006;113:640-646

186. Liuzzo G, Goronzy JJ, Yang H, Kopecky SL, Holmes DR, Frye RL, Weyand CM. Monoclonal t-cell proliferation and plaque instability in acute coronary syndromes. Circulation. 2000;101:28832888

187. Leon ML, Zuckerman SH. Gamma interferon: A central mediator in atherosclerosis. Inflamm Res. 2005;54:395-411

188. Harvey EJ, Ramji DP. Interferon-gamma and atherosclerosis: Pro- or anti-atherogenic? Cardiovasc Res. 2005;67:11-20

189. Mallat Z, Taleb S, Ait-Oufella H, Tedgui A. The role of adaptive t cell immunity in atherosclerosis. J Lipid Res. 2009;50 Suppl:S364-369

190. Hansson GK, Hellstrand M, Rymo L, Rubbia L, Gabbiani G. Interferon gamma inhibits both proliferation and expression of differentiation-specific alpha-smooth muscle actin in arterial smooth muscle cells. J Exp Med. 1989;170:1595-1608

191. Amento EP, Ehsani N, Palmer H, Libby P. Cytokines and growth factors positively and negatively regulate interstitial collagen gene expression in human vascular smooth muscle cells. Arterioscler Thromb. 1991;11:1223-1230

192. McLaren JE, Ramji DP. Interferon gamma: A master regulator of atherosclerosis. Cytokine Growth Factor Rev. 2009;20:125-135

193. Whitman SC, Ravisankar P, Daugherty A. Ifn-gamma deficiency exerts gender-specific effects on atherogenesis in apolipoprotein e-/- mice. J Interferon Cytokine Res. 2002;22:661-670 


\section{Inflammation and Immune System Interactions in Atherosclerosis | 2}

194. Gupta S, Pablo AM, Jiang X, Wang N, Tall AR, Schindler C. Ifn-gamma potentiates atherosclerosis in apoe knock-out mice. J Clin Invest. 1997;99:2752-2761

195. Buono C, Come CE, Stavrakis G, Maguire GF, Connelly PW, Lichtman AH. Influence of interferongamma on the extent and phenotype of diet-induced atherosclerosis in the Idlr-deficient mouse. Arterioscler Thromb Vasc Biol. 2003;23:454-460

196. Whitman SC, Ravisankar P, Elam H, Daugherty A. Exogenous interferon-gamma enhances atherosclerosis in apolipoprotein e-/- mice. Am J Pathol. 2000;157:1819-1824

197. Ait-Oufella H, Taleb S, Mallat Z, Tedgui A. Recent advances on the role of cytokines in atherosclerosis. Arterioscler Thromb Vasc Biol. 2011;31:969-979

198. Methe H, Brunner S, Wiegand D, Nabauer M, Koglin J, Edelman ER. Enhanced t-helper-1 lymphocyte activation patterns in acute coronary syndromes. J Am Coll Cardiol. 2005;45:19391945

199. Frostegard J, Ulfgren AK, Nyberg P, Hedin U, Swedenborg J, Andersson U, Hansson GK. Cytokine expression in advanced human atherosclerotic plaques: Dominance of pro-inflammatory (th1) and macrophage-stimulating cytokines. Atherosclerosis. 1999;145:33-43

200. Zhao Z, Wu Y, Cheng M, Ji Y, Yang X, Liu P, Jia S, Yuan Z. Activation of th17/th1 and th1, but not th17, is associated with the acute cardiac event in patients with acute coronary syndrome. Atherosclerosis. 2011;217:518-524

201. Gerdes N, Sukhova GK, Libby P, Reynolds RS, Young JL, Schonbeck U. Expression of interleukin (il)-18 and functional il-18 receptor on human vascular endothelial cells, smooth muscle cells, and macrophages: Implications for atherogenesis. J Exp Med. 2002;195:245-257

202. Mallat Z, Corbaz A, Scoazec A, Graber P, Alouani S, Esposito B, Humbert Y, Chvatchko Y, Tedgui A. Interleukin-18/interleukin-18 binding protein signaling modulates atherosclerotic lesion development and stability. Circ Res. 2001;89:E41-45

203. Elhage R, Jawien J, Rudling M, Ljunggren HG, Takeda K, Akira S, Bayard F, Hansson GK. Reduced atherosclerosis in interleukin-18 deficient apolipoprotein e-knockout mice. Cardiovasc Res. 2003;59:234-240

204. Whitman SC, Ravisankar P, Daugherty A. Interleukin-18 enhances atherosclerosis in apolipoprotein e(-/-) mice through release of interferon-gamma. Circ Res. 2002;90:E34-38

205. Tenger C, Sundborger A, Jawien J, Zhou X. II-18 accelerates atherosclerosis accompanied by elevation of ifn-gamma and cxcl16 expression independently of $\mathrm{t}$ cells. Arterioscler Thromb Vasc Biol. 2005;25:791-796

206. King VL, Cassis LA, Daugherty A. Interleukin-4 does not influence development of hypercholesterolemia or angiotensin ii-induced atherosclerotic lesions in mice. Am J Pathol. 2007;171:2040-2047

207. King VL, Szilvassy SJ, Daugherty A. Interleukin-4 deficiency decreases atherosclerotic lesion formation in a site-specific manner in female Idl receptor-/- mice. Arterioscler Thromb Vasc Biol. 2002;22:456-461

208. Andersson J, Libby P, Hansson GK. Adaptive immunity and atherosclerosis. Clin Immunol. 2010;134:33-46

209. Miller AM, Xu D, Asquith DL, Denby L, Li Y, Sattar N, Baker AH, Mclnnes IB, Liew FY. II-33 reduces the development of atherosclerosis. J Exp Med. 2008;205:339-346

210. Binder CJ, Hartvigsen K, Chang MK, Miller M, Broide D, Palinski W, Curtiss LK, Corr M, Witztum JL. II-5 links adaptive and natural immunity specific for epitopes of oxidized Idl and protects from atherosclerosis. J Clin Invest. 2004;114:427-437

211. Horkko S, Bird DA, Miller E, Itabe H, Leitinger N, Subbanagounder G, Berliner JA, Friedman P, Dennis EA, Curtiss LK, Palinski W, Witztum JL. Monoclonal autoantibodies specific for oxidized phospholipids or oxidized phospholipid-protein adducts inhibit macrophage uptake of oxidized low-density lipoproteins. J Clin Invest. 1999;103:117-128

212. Veillard NR, Steffens S, Burger F, Pelli G, Mach F. Differential expression patterns of proinflammatory and antiinflammatory mediators during atherogenesis in mice. Arterioscler Thromb Vasc Biol. 2004;24:2339-2344 


\section{2 | Inflammation and Immune System Interactions in Atherosclerosis}

213. de Boer OJ, van der Meer JJ, Teeling P, van der Loos CM, van der Wal AC. Low numbers of foxp3 positive regulatory $\mathrm{t}$ cells are present in all developmental stages of human atherosclerotic lesions. PLoS One. 2007;2:e779

214. Ait-Oufella H, Salomon BL, Potteaux S, Robertson AK, Gourdy P, Zoll J, Merval R, Esposito B, Cohen JL, Fisson S, Flavell RA, Hansson GK, Klatzmann D, Tedgui A, Mallat Z. Natural regulatory $t$ cells control the development of atherosclerosis in mice. Nat Med. 2006;12:178-180

215. Mallat Z, Gojova A, Brun V, Esposito B, Fournier N, Cottrez F, Tedgui A, Groux H. Induction of a regulatory t cell type 1 response reduces the development of atherosclerosis in apolipoprotein e-knockout mice. Circulation. 2003;108:1232-1237

216. Fahlen L, Read S, Gorelik L, Hurst SD, Coffman RL, Flavell RA, Powrie F. T cells that cannot respond to tgf-beta escape control by cd4(+)cd25(+) regulatory t cells. J Exp Med. 2005;201:737746

217. Ait-Oufella H, Kinugawa K, Zoll J, Simon T, Boddaert J, Heeneman S, Blanc-Brude O, Barateau V, Potteaux S, Merval R, Esposito B, Teissier E, Daemen MJ, Leseche G, Boulanger C, Tedgui A, Mallat Z. Lactadherin deficiency leads to apoptotic cell accumulation and accelerated atherosclerosis in mice. Circulation. 2007;115:2168-2177

218. Jinushi M, Nakazaki Y, Dougan M, Carrasco DR, Mihm M, Dranoff G. Mfg-e8-mediated uptake of apoptotic cells by apcs links the pro- and antiinflammatory activities of gm-csf. J Clin Invest. 2007;117:1902-1913

219. Mallat Z, Besnard S, Duriez M, Deleuze V, Emmanuel F, Bureau MF, Soubrier F, Esposito B, Duez H, Fievet C, Staels B, Duverger N, Scherman D, Tedgui A. Protective role of interleukin-10 in atherosclerosis. Circ Res. 1999;85:e17-24

220. Caligiuri G, Rudling M, Ollivier V, Jacob MP, Michel JB, Hansson GK, Nicoletti A. Interleukin-10 deficiency increases atherosclerosis, thrombosis, and low-density lipoproteins in apolipoprotein e knockout mice. Mol Med. 2003;9:10-17

221. Lahoute C, Herbin O, Mallat Z, Tedgui A. Adaptive immunity in atherosclerosis: Mechanisms and future therapeutic targets. Nat Rev Cardiol. 2011;8:348-358

222. McGeachy MJ, Bak-Jensen KS, Chen Y, Tato CM, Blumenschein W, McClanahan T, Cua DJ. Tgfbeta and il- 6 drive the production of il-17 and il-10 by $t$ cells and restrain $t(h)-17$ cell-mediated pathology. Nat Immunol. 2007;8:1390-1397

223. Smith E, Prasad KM, Butcher M, Dobrian A, Kolls JK, Ley K, Galkina E. Blockade of interleukin-17a results in reduced atherosclerosis in apolipoprotein e-deficient mice. Circulation. 2010;121:1746-1755

224. Erbel C, Dengler TJ, Wangler S, Lasitschka F, Bea F, Wambsganss N, Hakimi M, Bockler D, Katus HA, Gleissner CA. Expression of il-17a in human atherosclerotic lesions is associated with increased inflammation and plaque vulnerability. Basic Res Cardiol. 2011;106:125-134

225. Xie JJ, Wang J, Tang TT, Chen J, Gao XL, Yuan J, Zhou ZH, Liao MY, Yao R, Yu X, Wang D, Cheng Y, Liao $\mathrm{YH}$, Cheng $\mathrm{X}$. The th17/treg functional imbalance during atherogenesis in apoe(-/-) mice. Cytokine. 2010;49:185-193

226. van Es T, van Puijvelde GH, Ramos OH, Segers FM, Joosten LA, van den Berg WB, Michon IM, de Vos $\mathrm{P}$, van Berkel TJ, Kuiper J. Attenuated atherosclerosis upon il-17r signaling disruption in Idlr deficient mice. Biochem Biophys Res Commun. 2009;388:261-265

227. Erbel C, Chen L, Bea F, Wangler S, Celik S, Lasitschka F, Wang Y, Bockler D, Katus HA, Dengler TJ. Inhibition of il-17a attenuates atherosclerotic lesion development in apoe-deficient mice. J Immunol. 2009;183:8167-8175

228. Gao Q, Jiang Y, Ma T, Zhu F, Gao F, Zhang P, Guo C, Wang Q, Wang X, Ma C, Zhang Y, Chen W, Zhang L. A critical function of th17 proinflammatory cells in the development of atherosclerotic plaque in mice. J Immunol. 2010;185:5820-5827

229. Butcher MJ, Gjurich BN, Phillips T, Galkina EV. The il-17a/il-17ra axis plays a proatherogenic role via the regulation of aortic myeloid cell recruitment. Circ Res. 2012;110:675-687

230. Taleb S, Romain M, Ramkhelawon B, Uyttenhove C, Pasterkamp G, Herbin O, Esposito B, Perez $\mathrm{N}$, Yasukawa H, Van Snick J, Yoshimura A, Tedgui A, Mallat Z. Loss of socs3 expression in t cells reveals a regulatory role for interleukin-17 in atherosclerosis. J Exp Med. 2009;206:2067-2077 


\section{Inflammation and Immune System Interactions in Atherosclerosis | 2}

231. Roselaar SE, Kakkanathu PX, Daugherty A. Lymphocyte populations in atherosclerotic lesions of apoe -/- and Idl receptor -/- mice. Decreasing density with disease progression. Arterioscler Thromb Vasc Biol. 1996;16:1013-1018

232. Gewaltig J, Kummer M, Koella C, Cathomas G, Biedermann BC. Requirements for cd8 t-cell migration into the human arterial wall. Hum Pathol. 2008;39:1756-1762

233. Kolbus D, Ramos OH, Berg KE, Persson J, Wigren M, Bjorkbacka H, Fredrikson GN, Nilsson J. Cd8+ t cell activation predominate early immune responses to hypercholesterolemia in apoe(-)(/)(-) mice. BMC Immunol. 2010;11:58

234. Braun NA, Covarrubias R, Major AS. Natural killer t cells and atherosclerosis: Form and function meet pathogenesis. J Innate Immun. 2010;2:316-324

235. Nowak M, Stein-Streilein J. Invariant nkt cells and tolerance. Int Rev Immunol. 2007;26:95-119

236. Bobryshev YV, Lord RS. Co-accumulation of dendritic cells and natural killer $t$ cells within rupture-prone regions in human atherosclerotic plaques. J Histochem Cytochem. 2005;53:781785

237. Major AS, Wilson MT, McCaleb JL, Ru Su Y, Stanic AK, Joyce S, Van Kaer L, Fazio S, Linton MF. Quantitative and qualitative differences in proatherogenic nkt cells in apolipoprotein e-deficient mice. Arterioscler Thromb Vasc Biol. 2004;24:2351-2357

238. Nakai Y, Iwabuchi K, Fujii S, Ishimori N, Dashtsoodol N, Watano K, Mishima T, Iwabuchi C, Tanaka S, Bezbradica JS, Nakayama T, Taniguchi M, Miyake S, Yamamura T, Kitabatake A, Joyce $\mathrm{S}$, Van Kaer L, Onoe K. Natural killer $t$ cells accelerate atherogenesis in mice. Blood. 2004;104:2051-2059

239. Tupin E, Nicoletti A, Elhage R, Rudling M, Ljunggren HG, Hansson GK, Berne GP. Cd1d-dependent activation of nkt cells aggravates atherosclerosis. J Exp Med. 2004;199:417-422

240. VanderLaan PA, Reardon CA, Sagiv Y, Blachowicz L, Lukens J, Nissenbaum M, Wang CR, Getz GS. Characterization of the natural killer t-cell response in an adoptive transfer model of atherosclerosis. Am J Pathol. 2007;170:1100-1107

241. Rogers L, Burchat S, Gage J, Hasu M, Thabet M, Willcox L, Ramsamy TA, Whitman SC. Deficiency of invariant $v$ alpha 14 natural killer $t$ cells decreases atherosclerosis in Idl receptor null mice. Cardiovasc Res. 2008;78:167-174

242. To K, Agrotis A, Besra G, Bobik A, Toh BH. Nkt cell subsets mediate differential proatherogenic effects in apoe-/- mice. Arterioscler Thromb Vasc Biol. 2009;29:671-677

243. Aslanian AM, Chapman HA, Charo IF. Transient role for cd1d-restricted natural killer $t$ cells in the formation of atherosclerotic lesions. Arterioscler Thromb Vasc Biol. 2005;25:628-632

244. Kyaw T, Tipping $\mathrm{P}$, Toh $\mathrm{BH}$, Bobik A. Current understanding of the role of $\mathrm{b}$ cell subsets and intimal and adventitial b cells in atherosclerosis. Curr Opin Lipidol. 2011;22:373-379

245. Harris DP, Haynes L, Sayles PC, Duso DK, Eaton SM, Lepak NM, Johnson LL, Swain SL, Lund FE. Reciprocal regulation of polarized cytokine production by effector b and t cells. Nat Immunol. 2000;1:475-482

246. van der Wal AC, Das PK, Bentz van de Berg D, van der Loos CM, Becker AE. Atherosclerotic lesions in humans. In situ immunophenotypic analysis suggesting an immune mediated response. Lab Invest. 1989;61:166-170

247. Yla-Herttuala S, Palinski W, Butler SW, Picard S, Steinberg D, Witztum JL. Rabbit and human atherosclerotic lesions contain igg that recognizes epitopes of oxidized Idl. Arterioscler Thromb. 1994;14:32-40

248. van Leeuwen M, Damoiseaux J, Duijvestijn A, Tervaert JW. The therapeutic potential of targeting b cells and anti-oxldl antibodies in atherosclerosis. Autoimmun Rev. 2009;9:53-57

249. Caligiuri G, Nicoletti A, Poirier B, Hansson GK. Protective immunity against atherosclerosis carried by b cells of hypercholesterolemic mice. J Clin Invest. 2002;109:745-753

250. Major AS, Fazio S, Linton MF. B-lymphocyte deficiency increases atherosclerosis in Idl receptornull mice. Arterioscler Thromb Vasc Biol. 2002;22:1892-1898

251. Kyaw T, Tay C, Khan A, Dumouchel V, Cao A, To K, Kehry M, Dunn R, Agrotis A, Tipping P, Bobik A, Toh BH. Conventional b2 b cell depletion ameliorates whereas its adoptive transfer aggravates atherosclerosis. J Immunol. 2010;185:4410-4419 


\section{I Inflammation and Immune System Interactions in Atherosclerosis}

252. Ait-Oufella H, Herbin O, Bouaziz JD, Binder CJ, Uyttenhove C, Laurans L, Taleb S, Van Vre E, Esposito B, Vilar J, Sirvent J, Van Snick J, Tedgui A, Tedder TF, Mallat Z. B cell depletion reduces the development of atherosclerosis in mice. J Exp Med. 2010;207:1579-1587

253. Kyaw T, Tay C, Hosseini H, Kanellakis P, Gadowski T, MacKay F, Tipping P, Bobik A, Toh BH. Depletion of b2 but not b1a b cells in baff receptor-deficient apoe mice attenuates atherosclerosis by potently ameliorating arterial inflammation. PLoS One. 2012;7:e29371

254. Palinski W, Horkko S, Miller E, Steinbrecher UP, Powell HC, Curtiss LK, Witztum JL. Cloning of monoclonal autoantibodies to epitopes of oxidized lipoproteins from apolipoprotein e-deficient mice. Demonstration of epitopes of oxidized low density lipoprotein in human plasma. $J$ Clin Invest. 1996;98:800-814

255. Tsimikas S. Oxidized low-density lipoprotein biomarkers in atherosclerosis. Curr Atheroscler Rep. 2006;8:55-61

256. Tsimikas S, Brilakis ES, Lennon RJ, Miller ER, Witztum JL, McConnell JP, Kornman KS, Berger PB. Relationship of igg and igm autoantibodies to oxidized low density lipoprotein with coronary artery disease and cardiovascular events. J Lipid Res. 2007;48:425-433

257. Salonen JT, Yla-Herttuala S, Yamamoto R, Butler S, Korpela H, Salonen R, Nyyssonen K, Palinski $\mathrm{W}$, Witztum JL. Autoantibody against oxidised Idl and progression of carotid atherosclerosis. Lancet. 1992;339:883-887

258. Palinski W, Tangirala RK, Miller E, Young SG, Witztum JL. Increased autoantibody titers against epitopes of oxidized Idl in Idl receptor-deficient mice with increased atherosclerosis. Arterioscler Thromb Vasc Biol. 1995;15:1569-1576

259. Shaw PX, Horkko S, Chang MK, Curtiss LK, Palinski W, Silverman GJ, Witztum JL. Natural antibodies with the $\mathrm{t} 15$ idiotype may act in atherosclerosis, apoptotic clearance, and protective immunity. J Clin Invest. 2000;105:1731-1740

260. Nilsson J, Hansson GK, Shah PK. Immunomodulation of atherosclerosis: Implications for vaccine development. Arterioscler Thromb Vasc Biol. 2005;25:18-28

261. Binder CJ, Horkko S, Dewan A, Chang MK, Kieu EP, Goodyear CS, Shaw PX, Palinski W, Witztum JL, Silverman GJ. Pneumococcal vaccination decreases atherosclerotic lesion formation: Molecular mimicry between streptococcus pneumoniae and oxidized Idl. Nat Med. 2003;9:736743

262. Lewis MJ, Malik TH, Ehrenstein MR, Boyle JJ, Botto M, Haskard DO. Immunoglobulin $m$ is required for protection against atherosclerosis in low-density lipoprotein receptor-deficient mice. Circulation. 2009;120:417-426

263. Hulthe J, Bokemark L, Fagerberg B. Antibodies to oxidized Idl in relation to intima-media thickness in carotid and femoral arteries in 58-year-old subjectively clinically healthy men. Arterioscler Thromb Vasc Biol. 2001;21:101-107

264. Karvonen J, Paivansalo M, Kesaniemi YA, Horkko S. Immunoglobulin m type of autoantibodies to oxidized low-density lipoprotein has an inverse relation to carotid artery atherosclerosis. Circulation. 2003;108:2107-2112

265. Mizoguchi A, Bhan AK. A case for regulatory b cells. J Immunol. 2006;176:705-710

266. Gerdes N, Zirlik A. Co-stimulatory molecules in and beyond co-stimulation - tipping the balance in atherosclerosis? Thromb Haemost. 2011;106:804-813

267. Ait-Oufella H, Salomon BL, Potteaux S, Robertson AK, Gourdy P, Zoll J, Merval R, Esposito B, Cohen JL, Fisson S, Flavell RA, Hansson GK, Klatzmann D, Tedgui A, Mallat Z. Natural regulatory $t$ cells control the development of atherosclerosis in mice. Nat Med. 2006;12:178-180

268. Afek A, Harats D, Roth A, Keren G, George J. A functional role for inducible costimulator (icos) in atherosclerosis. Atherosclerosis. 2005;183:57-63

269. Gotsman I, Grabie N, Gupta R, Dacosta R, MacConmara M, Lederer J, Sukhova G, Witztum JL, Sharpe $\mathrm{AH}$, Lichtman $\mathrm{AH}$. Impaired regulatory t-cell response and enhanced atherosclerosis in the absence of inducible costimulatory molecule. Circulation. 2006;114:2047-2055

270. Gotsman I, Grabie N, Dacosta R, Sukhova G, Sharpe A, Lichtman AH. Proatherogenic immune responses are regulated by the pd-1/pd-I pathway in mice. J Clin Invest. 2007;117:2974-2982

271. Wang X, Ria M, Kelmenson PM, Eriksson P, Higgins DC, Samnegard A, Petros C, Rollins J, Bennet AM, Wiman B, de Faire U, Wennberg C, Olsson PG, Ishii N, Sugamura K, Hamsten A, Forsman- 


\section{Inflammation and Immune System Interactions in Atherosclerosis | 2}

Semb K, Lagercrantz J, Paigen B. Positional identification of tnfsf4, encoding ox40 ligand, as a gene that influences atherosclerosis susceptibility. Nat Genet. 2005;37:365-372

272. van Wanrooij EJ, van Puijvelde GH, de Vos P, Yagita $H$, van Berkel TJ, Kuiper J. Interruption of the tnfrsf4/tnfsf4 (ox40/ox40l) pathway attenuates atherogenesis in low-density lipoprotein receptor-deficient mice. Arterioscler Thromb Vasc Biol. 2007;27:204-210

273. Mach F, Schonbeck U, Sukhova GK, Atkinson E, Libby P. Reduction of atherosclerosis in mice by inhibition of cd40 signalling. Nature. 1998;394:200-203

274. Lutgens E, Gorelik L, Daemen MJ, de Muinck ED, Grewal IS, Koteliansky VE, Flavell RA. Requirement for cd154 in the progression of atherosclerosis. Nat Med. 1999;5:1313-1316

275. Lutgens E, Cleutjens KB, Heeneman S, Koteliansky VE, Burkly LC, Daemen MJ. Both early and delayed anti-cd40l antibody treatment induces a stable plaque phenotype. Proc Natl Acad Sci U S A. 2000;97:7464-7469

276. Schonbeck U, Sukhova GK, Shimizu K, Mach F, Libby P. Inhibition of cd40 signaling limits evolution of established atherosclerosis in mice. Proc Natl Acad Sci U S A. 2000;97:7458-7463

277. Lutgens E, Lievens D, Beckers L, Wijnands E, Soehnlein O, Zernecke A, Seijkens T, Engel D, Cleutjens J, Keller AM, Naik SH, Boon L, Oufella HA, Mallat Z, Ahonen CL, Noelle RJ, de Winther MP, Daemen MJ, Biessen EA, Weber C. Deficient cd40-traf6 signaling in leukocytes prevents atherosclerosis by skewing the immune response toward an antiinflammatory profile. J Exp Med. 2010;207:391-404

278. Zirlik A, Maier C, Gerdes N, MacFarlane L, Soosairajah J, Bavendiek U, Ahrens I, Ernst S, Bassler N, Missiou A, Patko Z, Aikawa M, Schonbeck U, Bode C, Libby P, Peter K. Cd40 ligand mediates inflammation independently of cd40 by interaction with mac-1. Circulation. 2007;115:15711580

279. Bavendiek U, Zirlik A, LaClair S, MacFarlane L, Libby P, Schonbeck U. Atherogenesis in mice does not require cd40 ligand from bone marrow-derived cells. Arterioscler Thromb Vasc Biol. 2005;25:1244-1249

280. Smook ML, Heeringa P, Damoiseaux JG, Daemen MJ, de Winther MP, Gijbels MJ, Beckers L, Lutgens E, Tervaert JW. Leukocyte cd40l deficiency affects the $\mathrm{cd} 25(+) \mathrm{cd} 4 \mathrm{t}$ cell population but does not affect atherosclerosis. Atherosclerosis. 2005;183:275-282

281. Lievens D, Zernecke A, Seijkens T, Soehnlein O, Beckers L, Munnix IC, Wijnands E, Goossens P, van Kruchten R, Thevissen L, Boon L, Flavell RA, Noelle RJ, Gerdes N, Biessen EA, Daemen MJ, Heemskerk JW, Weber C, Lutgens E. Platelet cd40l mediates thrombotic and inflammatory processes in atherosclerosis. Blood. 2010;116:4317-4327

282. Donners MM, Beckers L, Lievens D, Munnix I, Heemskerk J, Janssen BJ, Wijnands E, Cleutjens J, Zernecke A, Weber C, Ahonen CL, Benbow U, Newby AC, Noelle RJ, Daemen MJ, Lutgens E. The cd40-traf6 axis is the key regulator of the cd40/cd40l system in neointima formation and arterial remodeling. Blood. 2008;111:4596-4604 
Anette Christ

Lieve Temmerman

Bart Legein

Mat J.A.P. Daemen*

Erik A.L. Biessen*

74 


\section{CHAPTER}

Dendritic cells in cardiovascular diseases: epiphenomenon, contributor or therapeutic opportunity?

- Circulation 2013; 128(24):2603-13 -

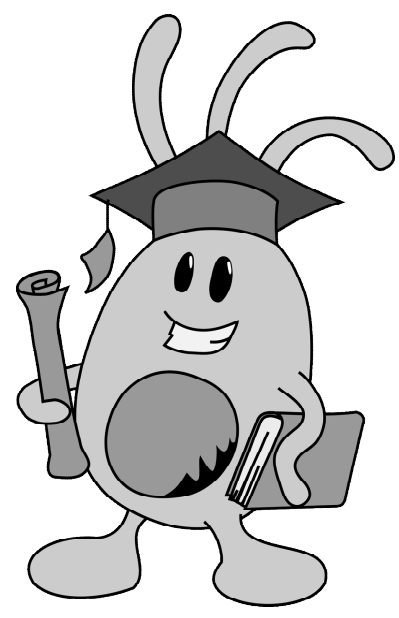




\section{Introduction}

Cardiovascular diseases (CVDs) are one of the leading causes of mortality worldwide ${ }^{(1)}$. A growing body of evidence points to a pivotal role of the immune system in the pathophysiology of a variety of CVDs such as atherosclerosis, ischemic stroke, chronic heart failure, and other myocardial conditions like myocardial ischemia and reperfusion, viral myocarditis and cardiac transplantation ${ }^{(2-4)}$. In many of these disorders so-called dangerassociated molecular patterns (DAMP), released from necrotic tissue and dying cells, can lead to the activation of certain immune cell populations such as monocytes/ macrophages, granulocytes and T cells, thus aggravating ongoing inflammatory processes at the lesion site. Dendritic cells (DCs) are key modulators of immunity, pivotal in directing innate and adaptive immune responses against microbial, but also modified self-antigens present at sites of injury ${ }^{(5)}$. Given the tissue trauma underlying various CVDs, it is not surprising that recent observations have allocated a regulatory role for DCs in CVDassociated immune responses. Interestingly, non-diseased arteries of young individuals were seen to host a network of resident vascular $D C^{(6)}$, a finding that was confirmed for the atherosclerotic-prone lesser curvature and sinus of aorta in mouse models of atherosclerosis ${ }^{(7)}$. DCs, exhibiting an immature phenotype with low expression of co-stimulatory molecules, are present in the subendothelial space with occasional probing into the vascular lumen. DCs have also been observed in human heart and in cardiac valves of healthy $\mathrm{C} 57 \mathrm{BL} / 6$ mice ${ }^{(8)}$. It is assumed that these immature, resident DCs contribute to the maintenance of vascular homeostasis and tolerance by scanning their microenvironment for self and non-self antigens. Indeed, Choi et al. were able to show that resident DCs, isolated from the aorta and the valves of wild-type mice, have the capacity to present antigens to $\mathrm{CD} 8^{+} \mathrm{T}$ cells in vitro and in vivo, indicating that they are fully functional in eliciting a T cell response ${ }^{(9)}$.

In diseased vessels, heart and brain of human CVD patients, but also in the circulation, DC subset numbers were reported to be modified, associating DCs with CVD onset and progression ${ }^{(10-12)}$. This notion is substantiated by a wealth of experimental animal studies addressing the involvement of DCs in CVDs. However, it remains mainly unsettled whether actions of different DC subsets are either detrimental or beneficial for lesion formation. Then again, DCs might function both-ways, dependent on the lesion stage. This review thus aims to provide an in depth overview of the role of DC subsets in several 
cardiovascular conditions in human and experimental animal models to reveal underlying patterns, expose lacunae in our current understanding of DC's function in CVDs, and explore possible therapeutic opportunities, exerted by modified DCs.

\section{Dendritic cells: conductors of innate and adaptive immune responses}

DC are professional antigen-presenting cells (APC) that originate from hematopoietic precursors in the bone marrow and are distributed throughout the whole body. DCs have the unique ability to induce $T$ cell responses by capturing, processing and presenting antigens to naïve $T$ cells. As such, they are central mediators of adaptive immune responses, and, depending on subset and activation status, of the development of immunological memory and tolerance ${ }^{(5)}$. Since the discovery by Steinmann and Cohn ${ }^{(13)}$, DCs were seen to represent a heterogeneous family of cells, differing in terms of development, migratory cues, compartmentalization, phenotype and immunological functions. DCs are categorized into conventional DCs(CDCs) and non-conventional DCs, the latter comprising plasmacytoid DCs (pDCs) and monocyte-derived inflammatory $\mathrm{DCs},{ }^{(5)}$ characterized by the expression of a panel of specific surface markers. For further details we refer the reader to a variety of excellent reviews on DC development, phenotyping and/or DC functions ${ }^{(14,15)}$.

\section{Circulating DC subsets in patients with coronary and peripheral arterial disease}

As an indirect measure of DC's association with CVDs, DC (precursor) numbers and functionality have been evaluated in blood of patients with CVD, such as coronary and peripheral artery disease. ${ }^{(16,17)}$ In 2006, van Vre et al. were the first to describe a marked decrease in circulating DC precursors (circulating $\mathrm{CDC}$ and $\mathrm{pDC}$ ) in patients with coronary artery disease (CAD), defined by angiography as $>50 \%$ stenosis in one or more coronary arteries ${ }^{(18)}$. Until now, several studies confirmed a significant decrease in blood DCs (CDC and $\mathrm{PDC}$ ) in CAD patients, irrespective of CAD grade (stable vs unstable angina pectoris, AMI), number of diseased vessels, or subset markers used for DC enumeration ${ }^{(16,19-25)}$. In sharp contrast, Shi et al. reported increased circulating CDC and unaltered PDC numbers in patients with stable CAD ${ }^{(26)}$. By investigating the distribution of circulating DCs in patients with different stages 
of peripheral arterial disease, including patients with intermittent claudication and critical limb ischemia, Dopheide and coworkers showed that blood CDC numbers were increased, whereas PDC numbers were reduced in peripheral arterial disease patients compared to healthy controls ${ }^{(17)}$. Of note, both cDCs and $\mathrm{pDCs}$ from critical limb ischemia patients revealed an immature phenotype, suggesting that severe ischemia and/or prolonged inflammation in this ailment might lead to an attenuation in the pro-inflammatory membrane patterns of circulating DC subsets ${ }^{(17)}$. Generally, most patient studies show declined blood DC numbers in CAD patients. Inconsistent results may be explained by differences in the extent and localization of disease, the timing of blood sampling (before/ after a surgical intervention; lesion onset versus progression), the prevalence of risk factors across the patients included in these studies, and the cohort sizes consulted (Table 1). Nevertheless, the actual cause for reduced circulating DC numbers remains unaddressed. One possibility for the decrease in circulating DCs might be their enhanced recruitment to the disease site (hence plaque or the ischemic heart) ${ }^{(10)}$. Alterations in circulating DCs have been described in other autoimmune diseases as well, such as systemic lupus erythematosus (SLE) ${ }^{(27)}$, where markedly lowered blood DC numbers correlated with an accumulation of activated DC in the inflamed tissue. In analogy, DCs could well be recruited to secondary lymphoid organs to prime naïve T cells ${ }^{(28)}$. Circulating oxidized lowdensity lipoprotein (oxLDL) or circulating immunocomplexes ${ }^{(29)}$, but also ischemic tissue derived DAMPs were seen to induce DC activation ${ }^{(30)}$, thus promoting their extravasation to spleen or lymph nodes. Actually, several studies have shown in CAD patients a more mature phenotype on a minor subset of circulating CD11 $\mathrm{c}^{\text {high }}\left(\mathrm{BDCA}-1^{+}\right) \mathrm{cDCs}, \mathrm{BDCA}-2^{+} \mathrm{pDCs}$, as well as on monocyte-derived DCs, represented by the up-regulation of CD83, CD80, CD86 and/ or CCR7 ${ }^{(31,32)}$. Second, the apparent blood DC depletion could however also be explained by increased DC turnover, due to increased circulating cholesterol levels. Indeed, Alderman et al. have demonstrated in vitro that high concentrations of oxLDL provoke DC apoptosis ${ }^{(33)}$. Otherwise, declines in DC numbers could be a temporary response to acute ischemia. Third, reduced blood DC numbers might also result from decreased release from bone marrow. Interestingly, van Brussel et al. have shown diminished plasma levels of FMS-like tyrosine kinase 3 ligand (FIt3L) in CAD patients, a growth factor that is responsible for DC differentiation and release from bone marrow ${ }^{(22)}$. 
Fourth, the altered blood DC abundance, phenotype and function could be owing to CAD patient's medication, including aspirin, statins, beta-blockers and angiotensin-converting enzyme (ACE-) inhibitors. While supported by several in vitro studies $^{(34-37)}$, the validity of this notion needs further investigation.

Recapitulating, circulating DC decline cannot be exclusively linked to the compartmentalization of this subset, be it to atherosclerotic plaque or lymphoid organs, as other covariates may as well modify blood DC numbers and functionality. This needs to be further addressed in future studies. Moreover, these observational studies leave unaddressed whether DCs are active contributors or just casual bystanders. 
3 | Dendritic cells in cardiovascular diseases

\begin{tabular}{|c|c|c|c|c|}
\hline Cohort size & Total DCs & $\mathrm{cDCs}$ & pDCs & Reference \\
\hline \multicolumn{5}{|c|}{ CORONARY ARTERY DISEASE } \\
\hline $\begin{array}{l}\text { CTR: } 19 \\
\text { SAP: } 20 \\
\text { UAP: } 19 \\
\text { AMI: } 17\end{array}$ & & $\begin{array}{c}\downarrow \\
\text { All CAD groups }\end{array}$ & $=$ & Yilmaz ${ }^{1}$ \\
\hline $\begin{array}{l}\text { CTR: } 18 \\
\text { CAD: } 18\end{array}$ & & $\begin{array}{c}\downarrow \\
\left(\mathrm{BDCA}-1^{+} \mathrm{mDCs}\right)\end{array}$ & $\begin{array}{c}\downarrow \\
\left(\mathrm{BDCA}^{+} 2^{+} \mathrm{pDCs}\right)\end{array}$ & $\operatorname{Van} \operatorname{Vré}^{-18}$ \\
\hline $\begin{array}{l}\text { CTR: } 11 \\
\text { Stable CAD: } 21\end{array}$ & $\uparrow$ & $\begin{array}{c}\uparrow \\
\left(\mathrm{CD} 11 \mathrm{c}^{+} \mathrm{cDCs}\right)\end{array}$ & $\begin{array}{c}= \\
\left(\mathrm{CD} 123^{+} \mathrm{pDCs}\right)\end{array}$ & $\mathrm{Shi}^{26}$ \\
\hline $\begin{array}{l}\text { CAD excluded: } 57 \\
\text { Early CAD: } 63 \\
\text { Moderate CAD: } 85 \\
\text { Advanced CAD: } 85\end{array}$ & $\begin{array}{l}\downarrow \\
\text { correlates } \\
\text { with } \\
\text { severity of } \\
\text { CAD }\end{array}$ & $\begin{array}{c}\downarrow \\
\text { correlates with } \\
\text { severity of CAD }\end{array}$ & $\begin{array}{c}\downarrow \\
\text { correlates with } \\
\text { severity of CAD }\end{array}$ & Yilmaz $^{20}$ \\
\hline $\begin{array}{l}\text { CTR: } 15 \\
\text { SAP (1 vessel): } 15 \\
\text { SAP ( } 3 \text { vessels): } \\
15 \\
\text { UAP (1 vessel): } 16\end{array}$ & $\begin{array}{c}\qquad \\
\text { All CAD } \\
\text { groups }\end{array}$ & $\begin{array}{c}\downarrow \\
\text { (BDCA-1 }{ }^{+} \text {mDCs) } \\
\text { All CAD groups }\end{array}$ & $\begin{array}{c}\downarrow \\
\text { (BDCA-2 } 2^{+} \text {pDCs) } \\
\text { All CAD groups }\end{array}$ & Van Vré ${ }^{16}$ \\
\hline $\begin{array}{l}\text { CTR: } 10 \\
\text { SAP: } 10\end{array}$ & $\begin{array}{c}\downarrow \\
\text { (irrespecti } \\
\text { ve of } \\
\text { marker } \\
\text { used) }\end{array}$ & $\begin{array}{c}\downarrow \\
\left(\mathrm{BDCA}-1^{+} \text {or }\right. \\
\text { CD11chi mDCs) }\end{array}$ & $\begin{array}{c}\downarrow \\
\left(\mathrm{BDCA}-2^{+} \text {or }\right. \\
\text { CD123+ pDCs) }\end{array}$ & Van Brusse $\left.\right|^{21}$ \\
\hline $\begin{array}{l}\text { CTR: } 12 \\
\text { CAD: } 15\end{array}$ & & $\begin{array}{c}\downarrow \\
\left.\text { (CD11 }^{+} \mathrm{cDCs}\right) \\
\text { less CD86 } \\
\text { CCR7 }{ }^{+} \text {cDCs } \\
\text { no functional } \\
\text { differences }\end{array}$ & $\begin{array}{c}\downarrow \\
\left.\text { (CD123 }^{+} \mathrm{pDCs}\right) \\
\text { Less functional }\end{array}$ & Van Brussel $\left.\right|^{22}$ \\
\hline
\end{tabular}




\begin{tabular}{|c|c|c|c|c|}
\hline Cohort size & Total DCs & cDCs & pDCs & Reference \\
\hline $\begin{array}{l}\text { CTR: } 29 \\
\text { SAP: } 30 \\
\text { UAP: } 56 \\
\text { AMI: } 50\end{array}$ & & $\begin{array}{c}\downarrow \\
\text { UAP and AMI }\end{array}$ & $=$ & Wen $^{23}$ \\
\hline \multicolumn{5}{|c|}{ PERIPHERAL ARTERY DISEASE } \\
\hline $\begin{array}{l}\text { CTR: } 30 \\
\text { IC:30 } \\
\text { CLI:30 }\end{array}$ & & $\begin{array}{c}\uparrow \\
\text { lower HLA-DR, } \\
\text { CD86, CD40 in } \\
\text { CLI compared to } \\
\text { IC }\end{array}$ & $\begin{array}{c}\downarrow \\
\text { lower HLA-DR, } \\
\text { CD86, CD40 in } \\
\text { CLI compared to } \\
\text { IC }\end{array}$ & Dopheide $^{17}$ \\
\hline \multicolumn{5}{|c|}{ ACUTE MYOCARDIAL INFARCTION } \\
\hline $\begin{array}{l}\text { CTR: } 19 \\
\text { SAP: } 19 \\
\text { AMI: } 26\end{array}$ & & $\begin{array}{c}\downarrow \\
\text { More activated in } \\
\text { AMI }\end{array}$ & $\begin{array}{c}\downarrow \\
\text { Less functional }\end{array}$ & Fukui $^{25}$ \\
\hline $\begin{array}{l}\text { CTR: } 45 \\
\text { NSTEMI: } 44 \\
\text { STEMI: } 34\end{array}$ & 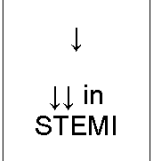 & $\begin{array}{c}\downarrow \\
\downarrow \downarrow \text { in STEMI }\end{array}$ & $\begin{array}{c}\downarrow \\
\downarrow \downarrow \text { in STEMI }\end{array}$ & Kretzschmar $^{24}$ \\
\hline \multicolumn{5}{|l|}{ ACUTE STROKE } \\
\hline $\begin{array}{l}\text { CTR: } 29 \\
\text { ACI-S: } 46 \\
\text { TIA: } 39 \\
\text { AIS: } 73 \\
\text { AHS: } 31\end{array}$ & $\begin{array}{c}\downarrow \\
\text { (AIS and } \\
\text { AHS) } \\
\\
\\
\text { correlates } \\
\text { with stroke } \\
\text { severity }\end{array}$ & $\begin{array}{c}\qquad \\
\text { (AIS and AHS) } \\
\text { correlates with } \\
\text { stroke severity }\end{array}$ & $\begin{array}{c}\downarrow \\
\text { (AIS and AHS) } \\
\text { correlates with } \\
\text { stroke severity }\end{array}$ & Yilmaz $^{11}$ \\
\hline \multicolumn{5}{|l|}{ TYPE 2 DIABETES } \\
\hline $\begin{array}{l}\text { CTR: } 44 \\
\text { (no atherosclerotic } \\
\text { complications) } \\
\text { EXP: } 11 \\
\text { (atherosclerotic }\end{array}$ & $\downarrow$ & $\begin{array}{c}\downarrow \\
\left(\mathrm{CD}^{+} 3^{+}\right) \\
\text {less functional }\end{array}$ & $\begin{array}{c}\downarrow \\
\left(\mathrm{CD} 33^{-}\right) \\
\text {less functional }\end{array}$ & Corrales $^{64}$ \\
\hline
\end{tabular}


3 | Dendritic cells in cardiovascular diseases

\begin{tabular}{|c|c|c|c|c|}
\hline Cohort size & Total DCs & cDCs & pDCs & Reference \\
\hline \multicolumn{5}{|l|}{ complications) } \\
\hline $\begin{array}{l}\text { CTR: } 15 \\
\text { UAP: } 18 \\
\text { T2D: } 18 \\
\text { T2D + UAP: } 21\end{array}$ & $\begin{array}{c}\downarrow \\
(\text { in T2D + } \\
\text { UAP) }\end{array}$ & $\begin{array}{c}\downarrow \\
\text { (in T2D + UAP) } \\
\text { But more } \\
\text { mature/active }\end{array}$ & $\begin{array}{c}= \\
(\text { in } T 2 D+U A P)\end{array}$ & $Y_{a o^{63}}$ \\
\hline $\begin{array}{l}\text { CTR: } 21 \\
\text { T2D: } 21\end{array}$ & & $=$ & $\begin{array}{c}\downarrow \\
\text { (subgroup "poor } \\
\text { glycemic control" } \\
\text { within T2D) } \\
\text { Less functional } \\
\text { (all T2D) }\end{array}$ & 更 \\
\hline \multicolumn{5}{|l|}{ HEART FAILURE } \\
\hline $\begin{array}{l}\text { CTR: } 14 \\
\text { HF: } 16 \text { (pre- } \\
\text { transplant) }\end{array}$ & $\uparrow$ & $\begin{array}{c}\uparrow \\
\underset{\text { More CD83 }}{\text { CCR7 }}{ }^{+}\end{array}$ & $=$ & Athanassopoulos ${ }^{73}$ \\
\hline $\begin{array}{l}\text { CTR: } 18 \\
\text { NYHA Class II: } 12 \\
\text { NYHA Class III-IV: } \\
28\end{array}$ & $\begin{array}{c}\uparrow \\
\text { Increase } \\
\text { in end- } \\
\text { stage } \\
\text { (III-IV) }\end{array}$ & $\begin{array}{c}\uparrow \uparrow \\
\text { More CD83 } \\
\text { CCR }^{+}\end{array}$ & $\begin{array}{c}\uparrow \\
\text { No difference in } \\
\text { CD83/CCR7 }\end{array}$ & Athanassopoulos ${ }^{74}$ \\
\hline $\begin{array}{l}\text { CTR: } 21 \\
\text { NYHA Class III-IV: } \\
27\end{array}$ & & $\begin{array}{c}\downarrow \\
\text { (During acute } \\
\text { decompensated } \\
\text { phase) } \\
\text { but more activated }\end{array}$ & $\begin{array}{c}\downarrow \\
\text { (During acute } \\
\text { decompensated } \\
\text { phase) } \\
\text { but more activated }\end{array}$ & Sugi ${ }^{12}$ \\
\hline
\end{tabular}

\section{Table 1. Circulating DC populations in human CVDs}

Overview of the most important studies describing DC numbers in blood of patients suffering from various cardiovascular conditions. Publications are grouped per condition, and results on total DC, CDC and pDC numbers are summarized. In addition, information about the build-up of the cohort size is given as well as the article citation. CAD: coronary artery disease, PAD: peripheral artery disease, T2D: type 2 diabetes, HF: heart failure, CTR: control, EXP: experimental group, SAP: stable angina pectoris, UAP: unstable angina pectoris, AMI: acute myocardial infarction, mDC: myeloid DCs, 
STEMI: ST-segment elevation myocardial infarction, NSTEMI: non-STEMI, IC: intermittent claudication, CLI: critical limb ischemia, ACI-S: asymptomatic cerebral infarction stenosis, TIA: transient ischemic attack, AIS: acute ischemic stroke, AHS: acute haemorrhagic stroke, NYHA: New York Heart Association (classification for heart failure).

\section{DC involvement in vascular inflammatory processes}

Beside their presence in atherosclerosis, DC attendance has been described in other chronic inflammatory vasculopathies, such as giant cell arteritis, Takayasu's arteritis and Kawasaki disease ${ }^{(38-40)}$. It is hypothesized that they contribute to the first critical steps in disease pathogenesis through breakdown of vascular tolerance. In these vasculopathies resident DCs are located in the adventitia and adventitia-media border, and (c)DC numbers are seen to increase with disease progression ${ }^{(40)}$. Dense infiltrates of mature CDCs and $T$ cells have been described at later stages as well, reflective of DCinitiated, antigen-specific immune responses. Considering that DC networks are present in healthy arteries and that they function as professional APCs, they might well be involved in disease onset and progression through presentation of modified (self-) antigens to $T$ cells. The actual triggers to activate vascular DCs are yet unknown, as is their relative contribution to immune priming in comparison to other vascular resident APCs such as macrophages. Altogether, a functional role for DCs in the pathogenesis of these diverse inflammatory vasculopathies remains to be established, as studies are of rather descriptive nature.

\section{A functional role for dendritic cells in atherosclerosis}

In human atherosclerotic plaques, fully mature DCs $\left(\mathrm{CD} 83^{+} \mathrm{CD} 86^{+}\right)$ accumulate within the rupture-prone atherosclerotic plaque shoulder where they produce $\mathrm{T}$ cell chemotactic (CCL19 and CCL21), and pro-inflammatory cytokines (interleukin-12 (IL-12), IL-23 and tumor necrosis factor $\alpha($ TNF- $\alpha))^{(41)}$. Mapping of plaque-residing DCs revealed a close contact between DCs and activated T and NKT cells, suggesting that DCs tune or even orchestrate immune responses relevant to atherosclerosis ${ }^{(41)}$. Of note, many of the histology studies are thwarted by the moderate/poor specificity of most DC markers, rendering DC's immunohistochemical detection a delicate issue. The additional use of other techniques, such as flow cytometric cell isolation, could 
help here to better appreciate DC presence and phenotype in different stages of atherosclerosis.

Mouse models have been very insightful in elucidating DC functions in atherosclerosis. For instance, lipid accumulation in the initial stages of atherosclerosis was recently shown to be directed and regulated by intimal $C D 11 c^{+} D C s$, residing in the atherosclerotic-prone lesser curvature of the aortic arch ${ }^{(42)}$. The impact of lipid uptake by resident vascular DCs on their functionality remains a controversial subject. Dyslipidemia was seen to lead to a retention of DCs and macrophages in the atherosclerotic plaque ${ }^{(43,44)}$. However, as reported in several studies antigen-presentation and $\mathrm{T}$ cell priming ability by DC remains unaffected under hyperlipidemic conditions, even after excessive lipid-loading ${ }^{(45,46)}$. In a transgenic mouse model with $\mathrm{CDC}$ specific overexpression of the anti-apoptotic gene $h B c l-2$, the induced enhanced lifespan and immunogenicity of circulating CDCs was associated with enhanced T cell activation, elevated levels of T helper 1 (Th1) and Th17 cytokines and increased production of Th1-driven IgG2c antibodies under hyperlipidemic conditions ${ }^{(45)}$. This major functional DC expansion did not aggravate lesion formation, as it was compensated for by decreased plasma cholesterol levels. Further support for a link between DC function and lipid metabolism was derived from the augmented plasma cholesterol levels after CDC depletion in hyperlipidemic $A p o E^{/-}$mice crossed to $\mathrm{CD} 11 \mathrm{c}$ diphtheria toxin receptor (CD11c-DTR) transgenic mice ${ }^{(45)}$. Precise mechanisms that underlie CDC involvement in cholesterol homeostasis have only scarcely been explored. Cholesterol lowering by DCs is suggested to occur in the periphery where DCs are amongst others exposed to lipoproteins. The behavior of circulating CDCs in patients with familial hypercholesterolemia has not yet been analyzed. Such data will allow to elucidate whether DCs are involved in lipoprotein clearance and how this is influencing DC functionality. Several lines of evidence suggest that oxLDL, present in the plaque, can impact DC maturation already in the initial stages of atherosclerosis. In vitro exposure to oxLDL during differentiation of human monocytes resulted in phenotypically mature DCs with upregulated HLA-DR, CD40 and CD86 and induced capacity to T cell activation ${ }^{(33,47)}$. However, incubation with high concentrations of oxLDL attenuated DC function and induced apoptosis ${ }^{(33)}$. A strong inhibition of oxLDL on expression of CCR7 and its ligand CCL21 by monocyte-derived DCs was recently reported by Nickel et al., which likely will impact their migratory 
capacity in plaque ${ }^{(48)}$. As shown by Kopf and coworkers, dyslipidemia also affects $C D 8 \alpha^{-}$cDC function, impairing their response to Toll-like receptor (TLR) stimulation in vitro and in vivo during Leishmania major infection. OxLDL appeared to be directly responsible for this effect, as it uncoupled TLRmediated signaling in DCs, leading to decreased DC activation and dampened Th1 responses ${ }^{(49)}$. Similarly, Blueml et al. have shown that oxidized phospholipids impair DC maturation by blocking TLR3 and TLR4 mediated upregulation of co-stimulatory molecules and induction of pro-inflammatory cytokines in human DCs ${ }^{(50)}$. These data are in line with previous studies, showing an anti-inflammatory effect of oxLDL in LPS-stimulated macrophages $(51,52)$

Taken together, considerable controversy exists on DC function(s) in hyperlipidemia-associated atherosclerosis. The still ongoing characterization of classical DC subsets within the vasculature ${ }^{(30,53)}$ makes it even more complex to comprehend DC (subset) contribution to plaque burden. It will be of importance to uncover how early and more advanced stages of hyperlipidemia impair DC (precursor) homeostasis, including their development in the bone marrow, DC mobilization into the circulation, peripheral phenotype, and migratory routes. In addition, extensive knowledge about DC actions within a lipid-rich environment such as the atherosclerotic plaque is lacking. How lipid uptake and prolonged intracellular storage interfere with signaling pathways responsible for DC activation is still controversial and will require further study.

\section{A functional role for plasmacytoid dendritic cells in atherosclerosis}

The group of Weyand and coworkers has recently shown the presence of $\mathrm{CD} 123^{+} \mathrm{pDCs}$ in human carotid atherosclerotic plaques, mainly located in the shoulder region that was also enriched in interferon- $\alpha$ (IFN- $\alpha$ ) positive cells, thus associating PDC presence with IFN- $\alpha$ production ${ }^{(54)}$. Furthermore, pDC numbers were significantly increased in unstable compared to stable human lesions. In vitro $\mathrm{CpG}$-induced IFN- $\alpha$ release by pDCs induced a 10-fold up-regulation of tumor necrosis factor-related apoptosis-inducing ligand (TRAIL) expression on $\mathrm{CD}^{+} \mathrm{T}$ cells, thus promoting apoptosis of vascular smooth muscle cells (VSMC) and endothelial cells (ECs), processes that tremendously contribute to plaque destabilization ${ }^{(54)}$. However, these data leave unaddressed whether pDCs are functional in the atherosclerotic plaque in vivo. We and others have recently shown that CD123 displays only moderate 


\section{3 | Dendritic cells in cardiovascular diseases}

specificity for human pDCs, being co-localized also with $\mathrm{CD}^{+} 8^{+}$macrophages and with $\mathrm{ASMA}^{+}$VSMC ${ }^{(10,55)}$. Use of the human PDC specific marker blood dendritic cell antigen 4 (BDCA-4) by our group revealed the scanty and equivalent presence of pDCs in human stable and unstable plaques. Moreover, we demonstrated that expression of IFN- $\alpha$ in human unstable versus stable carotid endarterectomy tissue specimens did not differ, suggesting that in chronic low grade inflammatory processes, such as atherosclerosis, pDC activation may not be a prominent feature ${ }^{(55)}$.

Our group has recently shown that selective depletion of pDCs by $120 \mathrm{G} 8$ monoclonal antibody administration in Ldlr $^{-/}$mice fed a high fat diet (HFD) exacerbated lesion size in the carotid artery and the aortic roots, and promoted plaque $\mathrm{T}$ cell accumulation as well as peripheral $\mathrm{CD}^{+} \mathrm{T}$ cell activation. pDCs isolated from atherosclerotic mice suppressed $\mathrm{CD}^{+} \mathrm{T}$ cell proliferation in an indoleamine-2,3-dioxygenase (IDO)-dependent manner, pleading for an athero-protective role for pDCs in atherosclerosis ${ }^{(55)}$. In contrast to our study, Doering et al. and MacRitchie et al. reported significantly decreased diet-induced lesion formation in the aortic root and the aorta of pDC-depleted $A p O E^{/-}$mice, while plaques showed a more stable phenotype. Both groups investigated the impact of pDC depletion by use of the PDCA-1 depletion antibody on early lesion development (4 weeks of HFD feeding) ${ }^{(29,}$ 56). These controversial findings are intriguing. A seeming paradox was in the presence of pDCs in the atherosclerotic plaque. While pDCs could barely be detected in mouse atherosclerotic lesions in $\mathrm{LdIr}^{-1-}$ mice ${ }^{\left({ }^{55)}\right.}$, Doering et al. showed the presence of $\mathrm{pDCs}$ in lesions of $A p O E^{/-}$mice, mainly in the plaque shoulder, at which pDC abundance was increased with HFD feeding and lesion progression ${ }^{(29)}$. Conversily, MacRitchie et al. described the constitutive presence of mostly immature pDCs in non-inflamed aortic tissue of normolipidemic mice, at numbers similar to those seen in atherosclerotic $A p o E^{/-}$mice. Nevertheless, antigen presentation capacity of aortic pDCs from $A p o E^{/-}$mice was enhanced ${ }^{(56)}$. In line, Doering et al. showed that sorted aortic pDCs from hyperlipidemic mice, ex vivo primed, were capable to trigger T cell stimulation in vivo ${ }^{(29)}$. Finally, baseline IFN- $\alpha$ levels were below detection levels or not affected by pDCs in our study and the study of MacRitchie et al. $(55,56)$, whereas Doering et al. demonstrated elevated IFN- $\alpha$ levels in plaque (mRNA) and serum in HFD fed $A p o E^{-/}$mice, being reduced after pDC depletion ${ }^{(29)}$. It has to be noted that the groups employed different methodologies, such 
as the use of the depletion antibody, administration regimen and mouse models. As instance, $A p o E^{--}$, the model used by Doering et al. and MacRitchie et al., displays more aggressive atherosclerosis than the $\mathrm{Ldll}^{-{ }^{-}}$, which may favor pDC switching to an immunogenic mode. Regarding the complex pathophysiology of atherosclerosis, pDCs could well exert dual functions in early and advanced stages of disease, dependent on their microenvironmental context. During episodes of fulminant plaque inflammation pDCs acquire proatherogenic functions by rapid secretion of type I IFNs and pro-inflammatory cytokines, while during low grade chronic inflammatory stages, pDCs may act tolerogenic by inhibiting proliferation of $\mathrm{CD}^{+}{ }^{+}$cells. Indeed, $\mathrm{pDCs}$ are involved in the pathogenesis of a range of autoimmune diseases characterized by a type I IFN-signature ${ }^{(57)}$, whereas alternatively activated pDCs are considered to contribute to tolerance induction ${ }^{(57)}$. Further studies are warranted to elucidate the actual pathways that are activated in pDCs during different stages of atherosclerosis by using more advanced animal models, such as conditional E2-2 knockout ${ }^{(57,58)}$. Nevertheless, the above findings clearly identify this cell type as an interesting new target for future therapeutic intervention studies in the treatment of atherosclerosis.

\section{CVD risk factors: contribution of DCs?}

Type 2 diabetes mellitus (T2D) and hypertension are major risk factors for the development of atherosclerosis and its cardiovascular complications. Chronic inflammation is thought to accelerate the progression of these pathological conditions ${ }^{(59,60)}$, DCs are likely to contribute here by triggering cell-mediated immune responses. The following two sections outline the current knowledge on potential DC functions in T2D and hypertension.

A role for DCs in type 2 diabetic patients with atherosclerotic complications

Insulin resistance and hyperglycemia in T2D are associated with a systemic pro-inflammatory state (increase in pro-inflammatory cytokines such as IL-6, activation of immune cells) that facilitate the development of atherosclerosis ${ }^{(52)}$. In vitro studies have shown that advanced glycosylation end products (AGEs) ${ }^{(61)}$ and hyperinsulinemia ${ }^{(62)}$ enhance DC maturation and induce an antigen-specific $T$ cell activation, thus supporting a contributory role of DC (subsets) on the immune reactions in diabetic atherosclerosis. Yao et al. recently reported a significant decline in circulating CDCs in T2D patients with unstable angina pectoris (UAP) vs. healthy controls and T2D patients, while 


\section{3 | Dendritic cells in cardiovascular diseases}

pDC numbers remained mainly unaltered. cDCs showed a more mature and activated phenotype, evidenced by the up-regulation of CD86 and the enhanced capability to stimulate $T$ cell proliferation in vitro ${ }^{(63)}$. Reduced circulating DC numbers in T2D patients with atherosclerotic complications was attributed to an increased trafficking into the inflamed vulnerable plaque or to neighbouring lymph nodes as patients had significantly increased levels of fractalkine, an important chemokine for DC attraction to sites of inflammation ${ }^{(63)}$. In contrast to these findings, Orfao and coworkers showed both quantitatively and functionally impaired pro-inflammatory cytokine response by circulating DCs from T2D patients with atherosclerotic complications ${ }^{(64)}$. Conceivably, the increased plasma TNF- $\alpha$ levels observed in patients with diabetic atherosclerosis may underlie this impairment, as it can tone blood DC differentiation ${ }^{(65)}$. This notion is encouraged by studies, describing an inverse correlation between blood DC numbers and plasma TNF$\alpha$ concentrations in T2D ${ }^{(66,67)}$. Of note, medication employed for glycemic control and/or for the treatment of diabetes-related comorbidities (ACE antagonists, angiotensin receptor blockers, or statins) could be partly causal in the altered blood DC abundance ${ }^{(60)}$. Altogether, although DC function is clearly perturbed in T2D, the present state of knowledge does not allow to segregate atherosclerosis from T2D intrinsic DC effects.

\section{A role for DCs in hypertension}

T cells have been described to contribute to hypertension ${ }^{(68)}$, a process that likely involves their priming by APCs, such as DCs, with the capacity to present neoepitopes, generated by necrotic and apoptotic cells ${ }^{(59)}$. However, less is known regarding the role of DCs in hypertension. DC accumulation in alveolar lesions of human and experimental pulmonary arterial hypertension has been described ${ }^{(69)}$. Recently, Vinh et al. have shown that the CD28 blocking agent Abatacept prevents angiotensin II (Ang II)-induced hypertension in mice, supporting a contributory role for DCs as APCs in hypertension ${ }^{(70)}$. Additionally, they observed increased activated DC numbers in spleen and lymph nodes of hypertensive mice ${ }^{(70)}$. However, these data leave unaddressed whether DCs are the primary cell type responsible for antigen presentation. The more abundant vascular macrophages in the vessel wall might as well function as APCs. Interestingly, the renin-angiotensin-aldosterone system can by itself initiate/ modulate innate and adaptive immune responses and inflict target-organ damage as shown by the group of Mueller and coworkers in a 
compound transgenic rat model harboring human renin/angiotensin genes ${ }^{(59)}$. Activation of the AT-IA receptor, amongst others expressed on DCs, promoted DC migration to the kidneys and their activation, potentially inducing renal damage ${ }^{(59)}$. Moreover, Id $2^{-1}$ mice - lacking Langerhans cells (LC) and $\mathrm{CD}^{+} \mathrm{DCs}$ - infused with Ang II remained normotensive and failed to develop albuminuria and renal damage, firmly establishing a role for LCs and $C D 8^{+}$DCs in Ang II-induced hypertension ${ }^{(59)}$. These data support the idea that Ang II itself can influence T cell 'fate' both directly or indirectly.

\section{DC contribution to ischemic stroke: friend, foe or bystander?}

Only recently immune mechanisms were recognized to contribute to the pathophysiology of ischemic stroke, and involve both the innate and adaptive immune system ${ }^{(4)}$. A potential role for DCs as potent mediators of inflammation in stroke has not been investigated extensively. Yilmaz et al. have shown that circulating $\mathrm{CDC}$ as well as $\mathrm{pDC}$ numbers were transiently reduced in patients with acute stroke ${ }^{(11)}$. They postulated that circulating DCs are recruited into the infarcted brain to elicit antigen-specific immune responses through $T$ cell activation. Indeed, HLA-DR expressing CDCs colocalized with T cells in dense infiltrates around cerebral vessels in the stroke area ${ }^{(60)}$. The pro-oxidant conditions of ischemia-reperfusion may give rise to the formation of neoepitopes, which can well be presented by APCs, such as HLA-DR expressing residential microglia or recruited DCs. It cannot be excluded that other factors, such as increased cell apoptosis may contribute to the declined circulating DC numbers, as it has been shown for lymphocytes after stroke ${ }^{(71)}$. Interestingly, Gelderblom et al. revealed in a rodent stroke model (temporary middle cerebral artery occlusion) the early accumulation of DCs, peaking on day 3 after reperfusion ${ }^{(72)}$. DCs showed strong and sustained upregulation of $\mathrm{MHC}$ class II, but an absent concomitant up-regulation of costimulatory molecules, possibly leading to disrupted $T$ cell activation. While such a phenotype is conceivable, this warrants further study on whether DCs are active contributors to local immune responses after stroke, either in an immunogenic or immunosuppressive way. 


\section{3 | Dendritic cells in cardiovascular diseases}

\section{DC involvement in the diseased heart}

\section{Circulating DCs in heart failure patients}

The association between circulating DCs and heart failure has only been subject of a few scattered studies and study outcomes are rather divergent. Athanassopoulos et al. have revealed an increase in total blood DCs in patients with chronic heart failure (non-ischemic dilated cardiomyopathy) compared to controls due to an increase in the mature fraction of the $c D C$ subset $\left(\mathrm{CD} 3^{+} \mathrm{CCR}^{+}\right)$, suggesting a possible Th1 response in end-stage heart failure ${ }^{(73,74)}$. In seeming contrast, Sugi et al. showed that total circulating DC numbers were transiently declined, but residual DCs appeared more activated during the acute decompensated phase of heart failure ${ }^{(12)}$. Comparable to the decline in circulating DC counts in CAD patients, the authors associate diminished DC numbers in heart failure with DC recruitment from systemic circulation into the damaged tissue in response to released DAMPs. Clearly, other confounders with the potential to modify circulating DC counts (e.g. development in the bone marrow and release into the circulation, cell apoptosis, trafficking routes) have to be taken into account. To conclude, a direct involvement of DCs in the pathophysiology of heart failure, while plausible, remains elusive. Moreover, further studies are warranted to precisely define the cause of systemic DC modifications, taking different disease stages (acute versus chronic) into account.

\section{Myocardial Ischemia and Reperfusion}

A role for DCs in the pathogenesis of cardiac ischemia/ reperfusion injury (IRI) is not well-established. In 1993, Zhang et al. demonstrated the rapid accumulation of interstitial DCs in the border zones 7 days post myocardial infarction (left coronary artery ligation) in the rat heart ${ }^{(75)}$. DCs tended to be assembled in small clusters with $\mathrm{CD}^{+} \mathrm{T}$ cells, which disappeared 21 days after coronary ligation. It is assumed that these DCs are involved in post-ischemic short-term cytoprotective responses through TLR2 and TLR4 stimulation by tissue released DAMPs ${ }^{(76)}$. Maekawa et al. on the contrary demonstrated in a murine myocardial infarction model (left coronary artery ligation) that deletion of interleukin-1 receptor-associated kinase-4 (IRAK-4), a downstream effector of the TLR/MyD88 axis, had beneficial effects on survival and function after myocardial infarction by blunting DC mobilization into the heart and attenuating local inflammatory processes ${ }^{(77)}$. Of note, cardiomyocytes and 
residential macrophages also express TLR2 and TLR4, and are able to respond to endogenous DAMPs, thereby contributing to inflammatory processes after myocardial infarction ${ }^{(3)}$.

Altogether, the presence of DCs in the heart and their post-ischemic accumulation has been demonstrated. Concerning their role as professional APCs in parallel to phagocytes and cardiomyocytes, DCs likely exert functions in acute myocarditis by steering cell-mediated immune responses.

\section{Viral myocarditis}

Even less is known about a contribution of DCs to the pathogenesis of viral myocarditis. Virus infections can inflict significant damage on cardiomyocytes by (1) immune-response mediated, (2) autoimmune-mediated, or (3) direct virus-induced myocardial injury, which can cause myocarditis and dilated cardiomyopathy. Many animal studies have been performed in this field using models of myocarditis caused by coxsackievirus B3 (CVB3) ${ }^{(78)}$. In response to viral infections, immune cells, such as cardiomyocytes, endothelial cells, fibroblasts, and DCs were reported to infiltrate up to five days postinfection, supposed to limit viral replication by the release of proinflammatory cytokines (IL-1 $\alpha$, IL-1 $\beta$, IL-6, IL-18, TNF- $\alpha$, TNF- $\beta$, and IFN- $\gamma$ ) ${ }^{(79,80)}$. In the subacute phase (within two weeks after viral infection) the release of progeny virus into the interstitium stimulates the infiltration of proinflammatory natural killer (NK) cells and macrophages, followed by a considerable influx of antigen-specific $\mathrm{CD}^{+} \mathrm{Th}$ and cytotoxic $\mathrm{CD} 8^{+} \mathrm{T}$ cells, which recognize viral antigens presented via $\mathrm{MHC}$ molecules on the surface of infected cardiomyocytes $(80,81)$. Interestingly, in a mouse model of Coxsackievirus myocarditis it has been shown that $\mathrm{CD}^{+} \mathrm{DCs}$, next to cardiomyocytes, are implicated in $\mathrm{CD}^{+} \mathrm{T}$ cell priming, thereby curtailing viral infection in the acute phase (within 8 days postinfection) ${ }^{(82)}$. Whether or not DCs are implicated in low-grade inflammation during chronic myocarditis (days 15-90 postinfection) remains unclear. In particular pDCs, the major type I IFN producers in response to viral infection, have not received much attention so far, but may be likely mediators in anti-viral defense in the heart, although endogenous type I IFN release by infected cardiomyocytes could as well limit viral replication in the heart. 


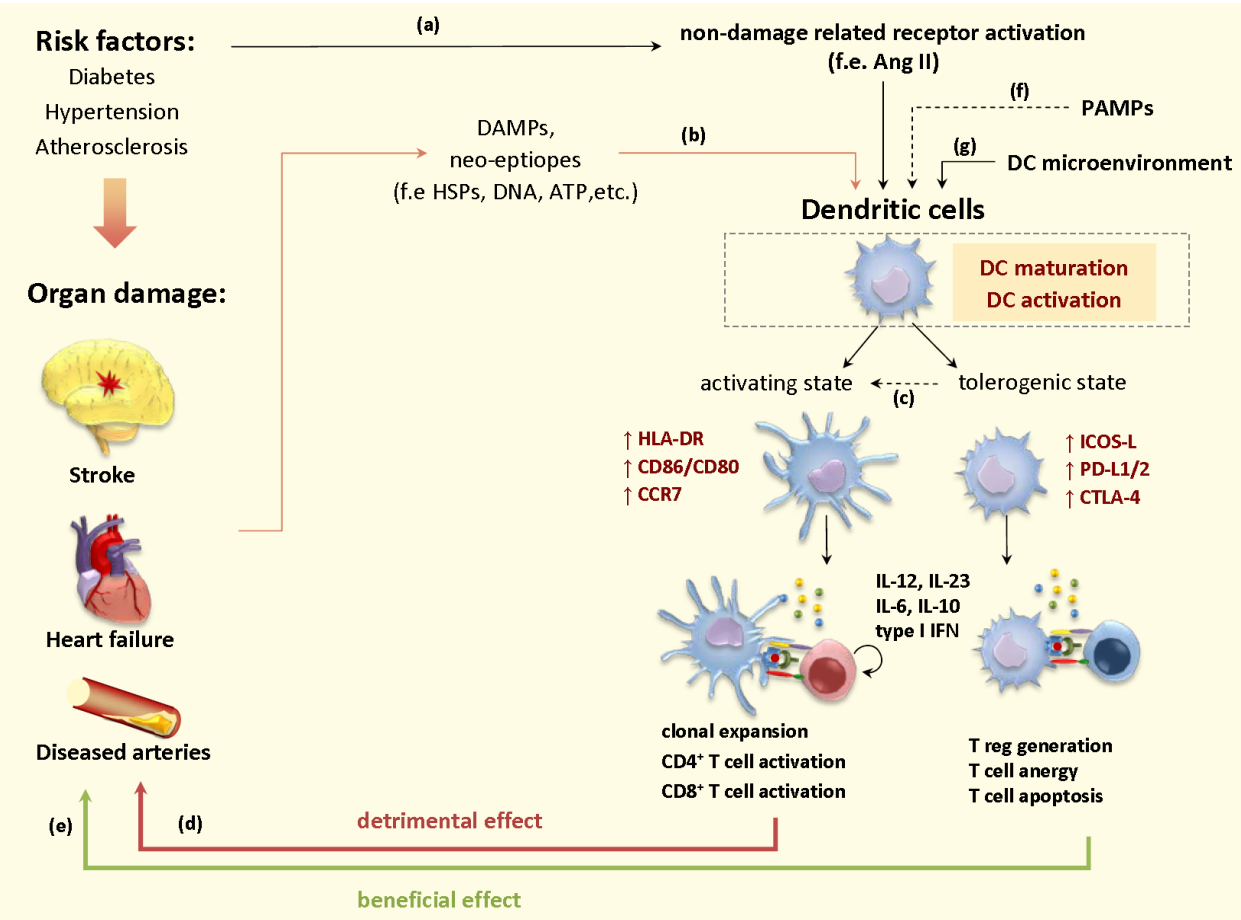

Figure 1. Schematic overview representing the possible impact of DCs in CVDs

(a) Risk factors critically contributing to ischemic stroke and heart failure can directly interfere with the activation state of DCs. (b) Epitopes released from necrotic tissue or dying cells of the damaged organs could additionally induce phenotypic changes in DCS (indirect effect), thus finally leading to (c) DC immunogenicity or tolerance. (d) Chronic DC activation potentially constitutes detrimental effects due to release of proinflammatory cytokines and the activation of $\mathrm{CD}^{+}$and $\mathrm{CD}^{+} \mathrm{T}$ cells, which in turn causes further organ damage. Otherwise, (e) induction of tolerance by DCs may thwart immunogenic responses by eliciting $T$ cell anergy/ apoptosis and the generation of regulatory $T$ cells. (f) Pathogen-derived signals, and (g) the local environment most likely impair DC functionality sustained through (a) or (b), thereby boosting or abating DC-mediated immune responses. 


\section{DC targeted therapeutic opportunities in cardiovascular disease}

Targeting DCs in cardiac transplantation: contributors to graft rejection or useful tools in tolerance induction

The role of DCs as modulators of alloreactive and autoreactive $T$ cell responses after transplantion has been extensively studied ${ }^{(83)}$. DCs hold promise as therapeutic tools to ameliorate or prevent graft rejection or graftversus-host disease (GVHD), and to treat autoimmune diseases ${ }^{(84,85)}$. DCs are implicated in the recognition of allo-antigens by the host's immune system. As Larsen et al. demonstrated, mature donor-derived DCs are homing to $\mathrm{T}$ cell areas in the draining lymph nodes in the first days after transplantation, where they trigger naïve T cells by presenting graft-derived epitopes. Thus potentially contributes to acute rejection of cardiac allografts ${ }^{\left({ }^{(8)}\right.}$. Similarly, Kofler et al. reported pronounced infiltration of recipient DCs into the cardiac allograft, picking up and processing the donor antigens, and activating the recipient's adaptive immune system in the first postoperative year after human heart transplantation ${ }^{(87)}$. Summarized, DCs appear to be main culprits in organ rejection, but have otherwise been shown to mediate transplant tolerance by preventing T cell-mediated immunity. Ochando et al. have demonstrated an essential role for pDCs as phagocytotic APCs in tolerance induction in vascularized cardiac grafts, in that adoptive transfer of tolerized pDCs induced regulatory $\mathrm{T}$ cell development and prolonged graft survival in mice ${ }^{(88)}$. Likewise, a single pre-operative infusion of donor-mobilized immature pDCs in combination with anti-CD154 monoclonal antibody was able to effectively suppress allograft rejection and prolonged graft survival in mice ${ }^{(89)}$. These findings are concordant with a recent study in human that examined total peripheral blood DC numbers in patients with clinical heart transplantation $(H T)$, revealing significantly diminished DC frequency one week post $H T$, which probably reflects immunological quiescence through adequate immunosuppression ${ }^{(90)}$. 
In summary, adoptive transfer of pre-primed (tolerogenic) DCs seems to hold great promise for preventing graft rejection after cardiac transplantation. For all that, a better understanding of how graft-infiltrating DCs function, may also help to appreciate their contributory roles in chronic heart failure and postmyocardial infarct healing. At first glance these processes seem unrelated, but similar immune pathways activated in the different disease settings may help to refine DC's contribution to certain CVD.

\section{DCs as potential therapeutic tools in the treatment of atherosclerosis}

As alluded to, DC-based vaccination and immunization strategies, based on application of ex vivo antigen loaded or genetically engineered autologous DCs to tune T cell responses have meanwhile evolved into a viable therapeutic option for cancer ${ }^{(91)}$. This success has inspired several groups to explore the potential of DC-based vaccination for atherosclerosis. Studies in animal models so far are at least encouraging and support the notion that DCbased vaccination and immunization hold promise for therapeutic immunomodulation of atherosclerosis ${ }^{(92)}$. Kuiper and coworkers have shown that transferred oxLDL-pulsed mature DCs into Ldlr $^{-/}$mice reduce atherosclerotic lesion size. DC vaccination led to quenched Th1 responses and elevated oxLDL-specific IgG titers indicating that oxLDL-pulsed DCs may confer protection against atherosclerosis, by favoring humoral immune responses to oxLDL ${ }^{(93)}$. Other groups have shown that repeated injection of antigen-loaded immunogenic DCs (oxLDL or malondialdehyde modified LDL (MDA-LDL)) aggravated atherosclerosis ${ }^{(94)}$. A recent study proposed immunotherapy with DCs, pulsed with apolipoprotein B100 in the presence of IL-10 to render them immunosuppressive, as an effective strategy to attenuate atherosclerosis. DC immunotherapy resulted in reduced proliferation of effector T cells, dampened Th1 and Th2 immunity and diminished atherosclerotic lesion formation in mice ${ }^{(95)}$. Taken together, the outcome of these studies indicates that DC vaccination emerges as a new, potentially powerful approach in the treatment of atherosclerosis, although translation of these largely animal experimental findings to human disease needs further investigation. A second thwart will be the establishment of exclusively atherosclerosis-specific antigens to avoid systemic immunity. 
Furthermore, therapy timing and the immunological status of the patient are additional important issues that need to be considered carefully, given that atherosclerosis mainly affects the elderly. Indeed, age-dependent alterations in expression and function of innate immune receptors and signal transduction pathways may translate in defective DC activation, thus diminishing the DCbased vaccination efficacy ${ }^{(96)}$. Nevertheless, promising developments in the cancer field, where ex vivo pulsed DC have been successfully applied in phase I/II clinical trials, stem hopeful and prompt to further investigations in DC therapy for CVD treatment.

\section{Concluding remarks}

This review summarizes the current state of knowledge on the role of different $D C$ subsets in the pathogenesis of CVDs, pinpoints shortcomings/gaps and delineates the future perspectives for DCs as therapeutic target in CVDs. By now several DC subsets have been reported to accumulate not only in atherosclerotic or hypertensive vessels, but also in failing, cardiomyopathic or ischemic heart tissue and in ischemic brain, suggestive of a role in the underlying pathophysiology. DC (precursor) numbers and functionality in blood of patients with CVD have been embraced as measure of DC association with disease onset and progression, although cause and implications of these disease-associated changes in DC homeostasis still are subject of discussion. Moreover, the actual value of circulating DCs as biomarkers in CVDs needs to be established, but it is fairly improbable that DC subset numbers will offer the precision, specificity and discriminative power to be useful as biomarkers. Of all cardiovascular disorders, atherosclerosis is by far most extensively studied for impact of DC subsets in its disease ontogenesis, albeit that the majority of these studies involve murine animal models. Much less is known about the contribution of DCs to cardiovascular pathologies such as stroke, heart failure and myocardial diseases. Conceivably, also here injury associated DAMP release will lead to the recruitment and subsequent activation of DCs with $T$ cell priming ability at the inflamed locus, skewing the adaptive immune system towards Th1/17-like immune responses or towards a state of tolerance, dependent on disease stage and environmental context. 
Recent findings in mice plead for a beneficial role for pre-primed DCs as therapeutic agents in the treatment of atherosclerosis. Nevertheless, the efficacy of DC immunotherapy for preventing plaque progression and destabilisation in humans remains to be seen. In this regard, it will be vital to target the relevant disease-associated antigens for DC pulsing. Donormobilized DCs could be otherwise cultured in vitro without further adjuvants, as the use of non-pulsed immature DCs has been proven to be an attractive approach to induce tolerance. Alternatively strategies could be employed to instruct endogenous DCs in situ, f.e. by receptor-specific manipulation, albeit that the options for targeting DC subset specific surface receptors are rather limited.

Summarizing, despite the limitations in our current understanding in DC functions in various CVDs, the recently shown efficacy of DC-based tolerance and immunization strategies in ameliorating murine atherosclerosis and diminishing allograft rejection, in combination with the current dynamics in this rapidly progressing research field inspire confidence that (some of) these approaches will evolve into viable modalities for the treatment and may be even prevention of human cardiovascular disorders. 


\section{References}

1. Lloyd-Jones DM. Cardiovascular risk prediction: Basic concepts, current status, and future directions. Circulation. 2010;121:1768-1777

2. Weber C, Zernecke A, Libby P. The multifaceted contributions of leukocyte subsets to atherosclerosis: Lessons from mouse models. Nature reviews. Immunology. 2008;8:802-815

3. Marchant DJ, Boyd JH, Lin DC, Granville DJ, Garmaroudi FS, McManus BM. Inflammation in myocardial diseases. Circ Res. 2012;110:126-144

4. Magnus T, Wiendl H, Kleinschnitz C. Immune mechanisms of stroke. Curr Opin Neurol. 2012;25:334-340

5. Shortman K, Naik SH. Steady-state and inflammatory dendritic-cell development. Nature reviews. Immunology. 2007;7:19-30

6. Millonig G, Niederegger H, Rabl W, Hochleitner BW, Hoefer D, Romani N, Wick G. Network of vascular-associated dendritic cells in intima of healthy young individuals. Arteriosclerosis, thrombosis, and vascular biology. 2001;21:503-508

7. Jongstra-Bilen J, Haidari M, Zhu SN, Chen M, Guha D, Cybulsky MI. Low-grade chronic inflammation in regions of the normal mouse arterial intima predisposed to atherosclerosis. The Journal of experimental medicine. 2006;203:2073-2083

8. Hart DN, Fabre JW. Demonstration and characterization of ia-positive dendritic cells in the interstitial connective tissues of rat heart and other tissues, but not brain. The Journal of experimental medicine. 1981;154:347-361

9. Choi JH, Do Y, Cheong C, Koh H, Boscardin SB, Oh YS, Bozzacco L, Trumpfheller C, Park CG, Steinman RM. Identification of antigen-presenting dendritic cells in mouse aorta and cardiac valves. The Journal of experimental medicine. 2009;206:497-505

10. Van Vre EA, Van Brussel I, Bosmans JM, Vrints CJ, Bult H. Dendritic cells in human atherosclerosis: From circulation to atherosclerotic plaques. Mediators Inflamm. 2011;2011:941396

11. Yilmaz A, Fuchs T, Dietel B, Altendorf R, Cicha I, Stumpf C, Schellinger PD, Blumcke I, Schwab S, Daniel WG, Garlichs CD, Kollmar R. Transient decrease in circulating dendritic cell precursors after acute stroke: Potential recruitment into the brain. Clin Sci (Lond). 2010;118:147-157

12. Sugi Y, Yasukawa H, Kai H, Fukui D, Futamata N, Mawatari K, Oba T, Nagata N, Kyougoku S, Koga M, Imaizumi T. Reduction and activation of circulating dendritic cells in patients with decompensated heart failure. International journal of cardiology. 2011;147:258-264

13. Steinman RM, Cohn ZA. Identification of a novel cell type in peripheral lymphoid organs of mice. I. Morphology, quantitation, tissue distribution. The Journal of experimental medicine. 1973;137:1142-1162

14. Xia ML, Gao Q, Zhou XM, Qian LB, Shen ZH, Jiang HD, Xia Q. [vascular effect of extract from mulberry leaves and underlying mechanism]. Zhejiang da xue xue bao. Yi xue ban = Journal of Zhejiang University. Medical sciences. 2007;36:48-53

15. Liu K, Nussenzweig MC. Origin and development of dendritic cells. Immunol Rev. 2010;234:4554

16. Van Vre EA, Van Brussel I, de Beeck KO, Hoymans VY, Vrints CJ, Bult H, Bosmans JM. Changes in blood dendritic cell counts in relation to type of coronary artery disease and brachial endothelial cell function. Coronary artery disease. 2010;21:87-96

17. Dopheide JF, Obst V, Doppler C, Radmacher MC, Scheer M, Radsak MP, Gori T, Warnholtz A, Fottner C, Daiber A, Munzel T, Espinola-Klein C. Phenotypic characterisation of pro- 
3 | Dendritic cells in cardiovascular diseases

inflammatory monocytes and dendritic cells in peripheral arterial disease. Thromb Haemost. 2012;108:1198-1207

18. Van Vre EA, Hoymans VY, Bult H, Lenjou M, Van Bockstaele DR, Vrints CJ, Bosmans JM. Decreased number of circulating plasmacytoid dendritic cells in patients with atherosclerotic coronary artery disease. Coronary artery disease. 2006;17:243-248

19. Yilmaz A, Weber J, Cicha I, Stumpf C, Klein M, Raithel D, Daniel WG, Garlichs CD. Decrease in circulating myeloid dendritic cell precursors in coronary artery disease. Journal of the American College of Cardiology. 2006;48:70-80

20. Yilmaz A, Schaller T, Cicha I, Altendorf R, Stumpf C, Klinghammer L, Ludwig J, Daniel WG, Garlichs $C D$. Predictive value of the decrease in circulating dendritic cell precursors in stable coronary artery disease. Clin Sci (Lond). 2009;116:353-363

21. Van Brussel I, Van Vre EA, De Meyer GR, Vrints CJ, Bosmans JM, Bult H. Expression of dendritic cell markers cd11c/bdca-1 and cd123/bdca-2 in coronary artery disease upon activation in whole blood. J Immunol Methods. 2010;362:168-175

22. Van Brussel I, Van Vre EA, De Meyer GR, Vrints CJ, Bosmans JM, Bult H. Decreased numbers of peripheral blood dendritic cells in patients with coronary artery disease are associated with diminished plasma flt3 ligand levels and impaired plasmacytoid dendritic cell function. Clin Sci (Lond). 2011;120:415-426

23. Wen J, Wen Y, Zhiliang L, Lingling C, Longxing C, Ming W, Qiang F. A decrease in the percentage of circulating mdc precursors in patients with coronary heart disease: A relation to the severity and extent of coronary artery lesions? Heart and vessels. 2013;28:135-142

24. Kretzschmar D, Betge S, Windisch A, Pistulli R, Rohm I, Fritzenwanger M, Jung C, Schubert K, Theis B, Petersen I, Drobnik S, Mall G, Figulla HR, Yilmaz A. Recruitment of circulating dendritic cell precursors into the infarcted myocardium and pro-inflammatory response in acute myocardial infarction. Clin Sci (Lond). 2012;123:387-398

25. Fukui D, Yasukawa H, Sugi Y, Oba T, Nagata T, Kyogoku S, Futamata N, Yokoyama T, Yokoyama S, Kai $\mathrm{H}$, Ueno $\mathrm{T}$, Kage M, Imaizumi T. Transient reduction and activation of circulating dendritic cells in patients with acute myocardial infarction. International journal of cardiology. 2012;160:216-219

26. Shi H, Ge J, Fang W, Yao K, Sun A, Huang R, Jia Q, Wang K, Zou Y, Cao X. Peripheral-blood dendritic cells in men with coronary heart disease. The American journal of cardiology. 2007;100:593-597

27. Gill MA, Blanco P, Arce E, Pascual V, Banchereau J, Palucka AK. Blood dendritic cells and dcpoietins in systemic lupus erythematosus. Human immunology. 2002;63:1172-1180

28. Bobryshev YV. Dendritic cells in atherosclerosis: Current status of the problem and clinical relevance. Eur Heart J. 2005;26:1700-1704

29. Doring $Y$, Manthey HD, Drechsler M, Lievens D, Megens RT, Soehnlein O, Busch M, Manca M, Koenen RR, Pelisek J, Daemen MJ, Lutgens E, Zenke M, Binder CJ, Weber C, Zernecke A. Autoantigenic protein-DNA complexes stimulate plasmacytoid dendritic cells to promote atherosclerosis. Circulation. 2012;125:1673-1683

30. Seong SY, Matzinger P. Hydrophobicity: An ancient damage-associated molecular pattern that initiates innate immune responses. Nature reviews. Immunology. 2004;4:469-478

31. Kofler S, Sisic Z, Shvets N, Lohse P, Weis M. Expression of circulatory dendritic cells and regulatory t-cells in patients with different subsets of coronary artery disease. J Cardiovasc Pharmacol. 2011;57:542-549 
32. Dopheide JF, Sester U, Schlitt A, Horstick G, Rupprecht HJ, Munzel T, Blankenberg S. Monocytederived dendritic cells of patients with coronary artery disease show an increased expression of costimulatory molecules cd40, cd80 and cd86 in vitro. Coronary artery disease. 2007;18:523-531

33. Alderman CJ, Bunyard PR, Chain BM, Foreman JC, Leake DS, Katz DR. Effects of oxidised low density lipoprotein on dendritic cells: A possible immunoregulatory component of the atherogenic micro-environment? Cardiovasc Res. 2002;55:806-819

34. Kim HJ, Lee YH, Im SA, Kim K, Lee CK. Cyclooxygenase inhibitors, aspirin and ibuprofen, inhibit mhc-restricted antigen presentation in dendritic cells. Immune Netw. 2010;10:92-98

35. Yilmaz A, Reiss C, Tantawi O, Weng A, Stumpf C, Raaz D, Ludwig J, Berger T, Steinkasserer A, Daniel WG, Garlichs CD. Hmg-coa reductase inhibitors suppress maturation of human dendritic cells: New implications for atherosclerosis. Atherosclerosis. 2004;172:85-93

36. Lapteva N, Ide K, Nieda M, Ando Y, Hatta-Ohashi Y, Minami M, Dymshits G, Egawa K, Juji T, Tokunaga K. Activation and suppression of renin-angiotensin system in human dendritic cells. Biochemical and biophysical research communications. 2002;296:194-200

37. Jo Y, Anzai T, Sugano Y, Naito K, Ueno K, Kohno T, Yoshikawa T, Ogawa S. Early use of betablockers attenuates systemic inflammatory response and lung oxygenation impairment after distal type acute aortic dissection. Heart and vessels. 2008;23:334-340

38. Krupa WM, Dewan M, Jeon MS, Kurtin PJ, Younge BR, Goronzy JJ, Weyand CM. Trapping of misdirected dendritic cells in the granulomatous lesions of giant cell arteritis. The American journal of pathology. 2002;161:1815-1823

39. Inder SJ, Bobryshev YV, Cherian SM, Wang AY, Lord RS, Masuda K, Yutani C. Immunophenotypic analysis of the aortic wall in takayasu's arteritis: Involvement of lymphocytes, dendritic cells and granulocytes in immuno-inflammatory reactions. Cardiovasc Surg. 2000;8:141-148

40. Yilmaz A, Rowley A, Schulte DJ, Doherty TM, Schroder NW, Fishbein MC, Kalelkar M, Cicha I, Schubert K, Daniel WG, Garlichs CD, Arditi M. Activated myeloid dendritic cells accumulate and co-localize with $\mathrm{cd} 3+\mathrm{t}$ cells in coronary artery lesions in patients with kawasaki disease. Exp Mol Pathol. 2007;83:93-103

41. Yilmaz A, Lochno M, Traeg F, Cicha I, Reiss C, Stumpf C, Raaz D, Anger T, Amann K, Probst T, Ludwig J, Daniel WG, Garlichs CD. Emergence of dendritic cells in rupture-prone regions of vulnerable carotid plaques. Atherosclerosis. 2004;176:101-110

42. Paulson KE, Zhu SN, Chen M, Nurmohamed S, Jongstra-Bilen J, Cybulsky MI. Resident intimal dendritic cells accumulate lipid and contribute to the initiation of atherosclerosis. Circ Res. 2010;106:383-390

43. Llodra J, Angeli V, Liu J, Trogan E, Fisher EA, Randolph GJ. Emigration of monocyte-derived cells from atherosclerotic lesions characterizes regressive, but not progressive, plaques. Proceedings of the National Academy of Sciences of the United States of America. 2004;101:11779-11784

44. Angeli V, Llodra J, Rong JX, Satoh K, Ishii S, Shimizu T, Fisher EA, Randolph GJ. Dyslipidemia associated with atherosclerotic disease systemically alters dendritic cell mobilization. Immunity. 2004;21:561-574

45. Gautier EL, Huby T, Saint-Charles F, Ouzilleau B, Pirault J, Deswaerte V, Ginhoux F, Miller ER, Witztum JL, Chapman MJ, Lesnik P. Conventional dendritic cells at the crossroads between immunity and cholesterol homeostasis in atherosclerosis. Circulation. 2009;119:2367-2375

46. Packard RR, Maganto-Garcia E, Gotsman I, Tabas I, Libby P, Lichtman AH. Cd11c(+) dendritic cells maintain antigen processing, presentation capabilities, and cd4(+) t-cell priming efficacy under hypercholesterolemic conditions associated with atherosclerosis. Circ Res. 2008;103:965973 


\section{3 | Dendritic cells in cardiovascular diseases}

47. Perrin-Cocon L, Coutant F, Agaugue S, Deforges S, Andre P, Lotteau V. Oxidized low-density lipoprotein promotes mature dendritic cell transition from differentiating monocyte. J Immunol. 2001;167:3785-3791

48. Nickel T, Pfeiler S, Summo C, Kopp R, Meimarakis G, Sicic Z, Lambert M, Lackermair K, David R, Beiras-Fernandez A, Kaczmarek I, Weis M. Oxldl downregulates the dendritic cell homing factors ccr7 and ccl21. Mediators Inflamm. 2012;2012:320953

49. Shamshiev AT, Ampenberger F, Ernst B, Rohrer L, Marsland BJ, Kopf M. Dyslipidemia inhibits toll-like receptor-induced activation of cd8alpha-negative dendritic cells and protective th1 type immunity. The Journal of experimental medicine. 2007;204:441-452

50. Bluml S, Kirchberger S, Bochkov VN, Kronke G, Stuhlmeier K, Majdic O, Zlabinger GJ, Knapp W, Binder BR, Stockl J, Leitinger N. Oxidized phospholipids negatively regulate dendritic cell maturation induced by tIrs and cd40. J Immunol. 2005;175:501-508

51. Averill MM, Kerkhoff C, Bornfeldt KE. S100a8 and S100a9 in cardiovascular biology and disease. Arteriosclerosis, thrombosis, and vascular biology. 2012;32:223-229

52. Averill MM, Barnhart S, Becker L, Li X, Heinecke JW, Leboeuf RC, Hamerman JA, Sorg C, Kerkhoff C, Bornfeldt KE. S100a9 differentially modifies phenotypic states of neutrophils, macrophages, and dendritic cells: Implications for atherosclerosis and adipose tissue inflammation. Circulation. 2011;123:1216-1226

53. Choi JH, Cheong C, Dandamudi DB, Park CG, Rodriguez A, Mehandru S, Velinzon K, Jung IH, Yoo JY, Oh GT, Steinman RM. Flt3 signaling-dependent dendritic cells protect against atherosclerosis. Immunity. 2011;35:819-831

54. Niessner A, Sato K, Chaikof EL, Colmegna I, Goronzy JJ, Weyand CM. Pathogen-sensing plasmacytoid dendritic cells stimulate cytotoxic t-cell function in the atherosclerotic plaque through interferon-alpha. Circulation. 2006;114:2482-2489

55. Daissormont IT, Christ A, Temmerman L, Sampedro Millares S, Seijkens T, Manca M, Rousch M, Poggi M, Boon L, van der Loos C, Daemen M, Lutgens E, Halvorsen B, Aukrust P, Janssen E, Biessen EA. Plasmacytoid dendritic cells protect against atherosclerosis by tuning t-cell proliferation and activity. Circ Res. 2011;109:1387-1395

56. Macritchie N, Grassia G, Sabir SR, Maddaluno M, Welsh P, Sattar N, lalenti A, KurowskaStolarska M, McInnes IB, Brewer JM, Garside P, Maffia P. Plasmacytoid dendritic cells play a key role in promoting atherosclerosis in apolipoprotein e-deficient mice. Arteriosclerosis, thrombosis, and vascular biology. 2012;32:2569-2579

57. Swiecki M, Colonna M. Unraveling the functions of plasmacytoid dendritic cells during viral infections, autoimmunity, and tolerance. Immunol Rev. 2010;234:142-162

58. Reizis B. Regulation of plasmacytoid dendritic cell development. Curr Opin Immunol. 2010;22:206-211

59. Luft FC, Dechend R, Muller DN. Immune mechanisms in angiotensin ii-induced target-organ damage. Annals of medicine. 2012;44 Suppl 1:S49-54

60. Dandona P, Aljada A, Chaudhuri A, Bandyopadhyay A. The potential influence of inflammation and insulin resistance on the pathogenesis and treatment of atherosclerosis-related complications in type 2 diabetes. J Clin Endocrinol Metab. 2003;88:2422-2429

61. Ge J, Jia Q, Liang C, Luo Y, Huang D, Sun A, Wang K, Zou Y, Chen H. Advanced glycosylation end products might promote atherosclerosis through inducing the immune maturation of dendritic cells. Arteriosclerosis, thrombosis, and vascular biology. 2005;25:2157-2163

62. Lu H, Qian JY, Yao K, Sun AJ, Huang RC, Hao Y, Shi HY, Wang KQ, Zou YZ, Ge JB. [hyperinsulinemia induced immune maturation of human monocyte derived dendritic cells: 
Bridging between diabetes and atherosclerosis]. Zhonghua xin xue guan bing za zhi. 2007;35:1151-1154

63. Yao K, Lu H, Huang R, Zhang S, Hong X, Shi H, Sun A, Qian J, Zou Y, Ge J. Changes of dendritic cells and fractalkine in type 2 diabetic patients with unstable angina pectoris: A preliminary report. Cardiovasc Diabetol. 2011;10:50

64. Corrales JJ, Almeida M, Burgo RM, Hernandez P, Miralles JM, Orfao A. Decreased production of inflammatory cytokines by circulating monocytes and dendritic cells in type 2 diabetic men with atherosclerotic complications. J Diabetes Complications. 2007;21:41-49

65. Santiago-Schwarz F, Divaris N, Kay C, Carsons SE. Mechanisms of tumor necrosis factorgranulocyte-macrophage colony-stimulating factor-induced dendritic cell development. Blood. 1993;82:3019-3028

66. Seifarth CC, Hinkmann C, Hahn EG, Lohmann T, Harsch IA. Reduced frequency of peripheral dendritic cells in type 2 diabetes. Exp Clin Endocrinol Diabetes. 2008;116:162-166

67. Blank SE, Johnson EC, Weeks DK, Wysham CH. Circulating dendritic cell number and intracellular tnf-alpha production in women with type 2 diabetes. Acta Diabetol. 2012;49 Suppl 1:25-32

68. Guzik TJ, Hoch NE, Brown KA, McCann LA, Rahman A, Dikalov S, Goronzy J, Weyand C, Harrison DG. Role of the $t$ cell in the genesis of angiotensin ii induced hypertension and vascular dysfunction. The Journal of experimental medicine. 2007;204:2449-2460

69. Perros F, Dorfmuller P, Souza R, Durand-Gasselin I, Mussot S, Mazmanian M, Herve P, Emilie D, Simonneau G, Humbert $M$. Dendritic cell recruitment in lesions of human and experimental pulmonary hypertension. Eur Respir J. 2007;29:462-468

70. Vinh A, Chen W, Blinder Y, Weiss D, Taylor WR, Goronzy JJ, Weyand CM, Harrison DG, Guzik TJ. Inhibition and genetic ablation of the b7/cd28 t-cell costimulation axis prevents experimental hypertension. Circulation. 2010;122:2529-2537

71. Urra X, Cervera A, Villamor N, Planas AM, Chamorro A. Harms and benefits of lymphocyte subpopulations in patients with acute stroke. Neuroscience. 2009;158:1174-1183

72. Gelderblom M, Leypoldt F, Steinbach K, Behrens D, Choe CU, Siler DA, Arumugam TV, Orthey E, Gerloff C, Tolosa E, Magnus T. Temporal and spatial dynamics of cerebral immune cell accumulation in stroke. Stroke; a journal of cerebral circulation. 2009;40:1849-1857

73. Athanassopoulos P, Vaessen LM, Maat AP, Balk AH, Weimar W, Bogers AJ. Peripheral blood dendritic cells in human end-stage heart failure and the early post-transplant period: Evidence for systemic th1 immune responses. European journal of cardio-thoracic surgery : official journal of the European Association for Cardio-thoracic Surgery. 2004;25:619-626

74. Athanassopoulos P, Balk AH, Vaessen LM, Caliskan K, Takkenberg JJ, Weimar W, Bogers AJ. Blood dendritic cell levels and phenotypic characteristics in relation to etiology of end-stage heart failure: Implications for dilated cardiomyopathy. International journal of cardiology. 2009;131:246-256

75. Zhang J, Yu ZX, Fujita S, Yamaguchi ML, Ferrans VJ. Interstitial dendritic cells of the rat heart. Quantitative and ultrastructural changes in experimental myocardial infarction. Circulation. 1993;87:909-920

76. Wang L, Li D, Yang K, Hu Y, Zeng Q. Toll-like receptor-4 and mitogen-activated protein kinase signal system are involved in activation of dendritic cells in patients with acute coronary syndrome. Immunology. 2008;125:122-130

77. Maekawa Y, Mizue N, Chan A, Shi Y, Liu Y, Dawood S, Chen M, Dawood F, de Couto G, Li GH, Suzuki N, Yeh WC, Gramolini A, Medin JA, Liu PP. Survival and cardiac remodeling after myocardial infarction are critically dependent on the host innate immune interleukin-1 


\section{3 | Dendritic cells in cardiovascular diseases}

receptor-associated kinase-4 signaling: A regulator of bone marrow-derived dendritic cells. Circulation. 2009;120:1401-1414

78. Esfandiarei M, McManus BM. Molecular biology and pathogenesis of viral myocarditis. Annu Rev Pathol. 2008;3:127-155

79. Seko Y, Takahashi N, Yagita H, Okumura K, Yazaki Y. Expression of cytokine mrnas in murine hearts with acute myocarditis caused by coxsackievirus b3. The Journal of pathology. 1997;183:105-108

80. Fuse K, Chan G, Liu Y, Gudgeon P, Husain M, Chen M, Yeh WC, Akira S, Liu PP. Myeloid differentiation factor-88 plays a crucial role in the pathogenesis of coxsackievirus b3-induced myocarditis and influences type i interferon production. Circulation. 2005;112:2276-2285

81. Seko Y, Ishiyama S, Nishikawa T, Kasajima T, Hiroe M, Kagawa N, Osada K, Suzuki S, Yagita H, Okumura $\mathrm{K}$, et al. Restricted usage of $\mathrm{t}$ cell receptor $\mathrm{v}$ alpha-v beta genes in infiltrating cells in the hearts of patients with acute myocarditis and dilated cardiomyopathy. J Clin Invest. 1995;96:1035-1041

82. Weinzierl AO, Szalay G, Wolburg H, Sauter M, Rammensee HG, Kandolf R, Stevanovic S, Klingel K. Effective chemokine secretion by dendritic cells and expansion of cross-presenting cd4-/cd8+ dendritic cells define a protective phenotype in the mouse model of coxsackievirus myocarditis. Journal of virology. 2008;82:8149-8160

83. Figdor CG, de Vries IJ, Lesterhuis WJ, Melief CJ. Dendritic cell immunotherapy: Mapping the way. Nat Med. 2004;10:475-480

84. Kim IK, Bedi DS, Denecke C, Ge X, Tullius SG. Impact of innate and adaptive immunity on rejection and tolerance. Transplantation. 2008;86:889-894

85. Morelli AE, Thomson AW. Tolerogenic dendritic cells and the quest for transplant tolerance. Nature reviews. Immunology. 2007;7:610-621

86. Larsen CP, Steinman RM, Witmer-Pack M, Hankins DF, Morris PJ, Austyn JM. Migration and maturation of langerhans cells in skin transplants and explants. The Journal of experimental medicine. 1990;172:1483-1493

87. Kofler S, Petrakopoulou P, Grimm C, Kaczmarek I, Meiser BM, Weis M. Graft-infiltrating dendritic cells and coronary endothelial dysfunction after human heart transplantation. $J$ Heart Lung Transplant. 2008;27:387-393

88. Ochando JC, Homma C, Yang Y, Hidalgo A, Garin A, Tacke F, Angeli V, Li Y, Boros P, Ding Y, Jessberger R, Trinchieri G, Lira SA, Randolph GJ, Bromberg JS. Alloantigen-presenting plasmacytoid dendritic cells mediate tolerance to vascularized grafts. Nature immunology. 2006;7:652-662

89. Bjorck P, Coates PT, Wang Z, Duncan FJ, Thomson AW. Promotion of long-term heart allograft survival by combination of mobilized donor plasmacytoid dendritic cells and anti-cd154 monoclonal antibody. J Heart Lung Transplant. 2005;24:1118-1120

90. Athanassopoulos P, Vaessen LM, Balk AH, Takkenberg JJ, Maat AP, Weimar W, Bogers AJ. Impaired circulating dendritic cell reconstitution identifies rejecting recipients after clinical heart transplantation independent of rejection therapy. European journal of cardio-thoracic surgery : official journal of the European Association for Cardio-thoracic Surgery. 2005;27:783-789

91. Farkas A, Conrad C, Tonel G, Borbenyi Z, Kemeny L, Dobozy A, Nestle FO. Current state and perspectives of dendritic cell vaccination in cancer immunotherapy. Skin Pharmacol Physiol. 2006;19:124-131

92. de Jager SC, Kuiper J. Vaccination strategies in atherosclerosis. Thromb Haemost. 2011;106:796803 
93. Habets KL, van Puijvelde GH, van Duivenvoorde LM, van Wanrooij EJ, de Vos P, Tervaert JW, van Berkel TJ, Toes RE, Kuiper J. Vaccination using oxidized low-density lipoprotein-pulsed dendritic cells reduces atherosclerosis in Idl receptor-deficient mice. Cardiovasc Res. 2010;85:622-630

94. Hjerpe C, Johansson D, Hermansson A, Hansson GK, Zhou X. Dendritic cells pulsed with malondialdehyde modified low density lipoprotein aggravate atherosclerosis in apoe(-/-) mice. Atherosclerosis. 2010;209:436-441

95. Hermansson A, Johansson DK, Ketelhuth DF, Andersson J, Zhou X, Hansson GK. Immunotherapy with tolerogenic apolipoprotein b-100-loaded dendritic cells attenuates atherosclerosis in hypercholesterolemic mice. Circulation. 2011;123:1083-1091

96. Solana R, Tarazona R, Gayoso I, Lesur O, Dupuis G, Fulop T. Innate immunosenescence: Effect of aging on cells and receptors of the innate immune system in humans. Semin Immunol. 2012;24:331-34 


\section{Bart Legein}

Edith Janssen

Thomas Theelen

Marion Gijbels

Joep Walraven

Jared Klarquist

Cassandra Hennies

Kristiaan Wouters

Tom T.P. Seijkens

Erwin Wijnands

Judith Sluimer

Esther Lutgens

Martin Zenke

Kai Hildner

Erik A.L. Biessen

Lieve Temmerman 


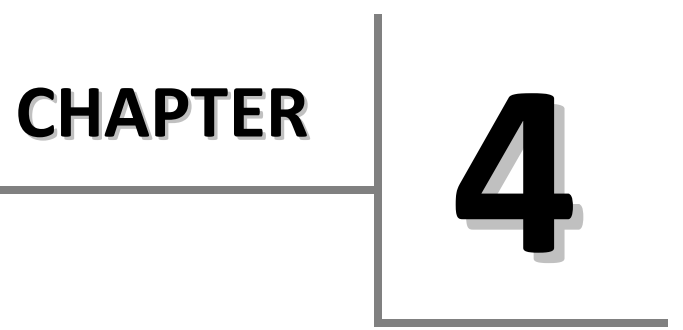

Ablation of $\mathrm{CD} 8 \alpha^{+}$dendritic cell mediated cross-presentation does not impact atherosclerosis in hyperlipidemic mice

- Scientific Reports 2015;5:15414 -

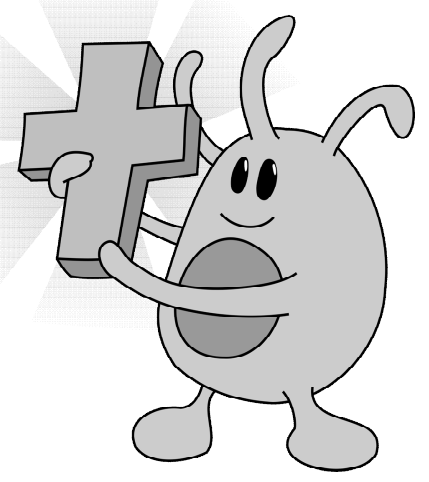




\section{Abstract}

Clinical complications of atherosclerosis are almost exclusively linked to destabilization of the atherosclerotic plaque. Batf3-dependent dendritic cells specialize in cross-presentation of necrotic tissue-derived epitopes to directly activate cytolytic CD8 Tcells. The mature plaque (necrotic, containing dendritic cells and CD8 Tcells) could offer the ideal environment for crosspresentation, resulting in cytotoxic immunity and plaque destabilization.

Ldll ${ }^{-/}$mice were transplanted with batf $3^{-/-}$or wt bone marrow and put on a western type diet. Hematopoietic batf3 deficiency sharply decreased $\mathrm{CD} 8 \alpha^{+} \mathrm{DC}$ numbers in spleen and lymph nodes $(>80 \% ; \mathrm{P}<0,001)$. Concordantly, batf $3^{-1}$ chimeras had a $75 \%$ reduction in OT-I cross-priming capacity in vivo. Batf3 $^{\%}$ chimeric mice did not show lower Tcell or other leukocyte subset numbers. Despite dampened cross-presentation capacity, batf $3^{\%}$ chimeras had equal atherosclerosis burden in aortic arch and root. Likewise, batf $3^{-/}$chimeras and wt mice revealed no differences in parameters of plaque stability: plaque Tcell infiltration, cell death, collagen composition, and macrophage and vascular smooth muscle cell content were unchanged.

These results show that $C D 8 \alpha^{+} D C$ loss in hyperlipidemic mice profoundly reduces cross-priming ability, nevertheless it does not influence lesion development. Taken together, we clearly demonstrate that CD8 $\alpha^{+} \mathrm{DC}$ mediated cross-presentation does not significantly contribute to atherosclerotic plaque formation and stability. 


\section{Introduction}

Immune responses play a significant role in the pathophysiology of atherosclerosis ${ }^{(1,2)}$. They offer a promising new therapeutic angle to directly touch on pathogenic mechanisms of cardiovascular disease. Necrosis - a prime hallmark of clinical atherosclerosis - was recently linked to immunity. Necrotic tumor cell-derived epitopes are able to elicit a strong cytolitic immune response, allowing tumor elimination ${ }^{(3,4)}$. Key to this finding is a process called cross-presentation: direct presentation of exogenous antigen on an $\mathrm{MHCl}$ molecule followed by a potent $\mathrm{CD} 8^{+} \mathrm{T}$ cell activation ${ }^{(5)}$. Mouse dendritic cells $\left(\mathrm{CD} 8 \alpha^{+}\right.$or $\left.\mathrm{CD}_{103^{+}} \mathrm{DCs}\right)$ appear to be highly efficient cross-presenting cells ${ }^{(6)}$, uniquely qualified to cross-present dead cell-associated antigens (7). Identification of their human counterparts ${ }^{(8-12)}$ emphasizes the importance of cross-presentation in human health and disease.

In a mature atherosclerotic plaque, necrotic cell or tissue-associated epitopes, dendritic cells ${ }^{(13)}$ and $\mathrm{CD} 8^{+} \mathrm{T}_{\text {cells }}{ }^{(14,15)}$ are abundantly present and in close contact. Significantly more DCs are found in rupture-prone, vulnerable plaques ${ }^{(16)}$, and $\mathrm{CD}^{+}{ }^{\mathrm{T}}$ cells increase to up to $50 \%$ of the total lymphocyte pool in human advanced plaques ${ }^{(17)}$, linking both $\mathrm{DC}$ and cytotoxic $\mathrm{T}$ cell presence to plaque stability. In addition, $\mathrm{CD}^{+} \mathrm{T}$ cells isolated from human plaque atherectomy specimens are highly activated, much more so than plaque CD4 ${ }^{+}$ $T$ cells or $T$ cells isolated from the blood of the same patients ${ }^{(18)}$. Moreover, reflective of plaque-directed immunity, different auto-antigens are identified targets of immune responses in atherosclerosis. Oxidized low density lipoprotein (oxLDL) is the most well described ${ }^{(19)}$, but $T$ cells isolated from patients with advanced atherosclerosis also respond to F-actin, a known target in necrosis-associated cross-presentation ${ }^{20,21)}$. Lastly, a recent study has demonstrated that cytotoxic $\mathrm{CD} 8^{+} \mathrm{T}$ cells promote development of a vulnerable atherosclerotic plaque in mice, implicating cytolytic $\mathrm{T}$ cell immunity in plaque destabilization ${ }^{(22)}$. Combining these arguments led to the following intriguing hypothesis: Cross-presentation, by mounting a cytolytic $\mathrm{CD}^{+} \mathrm{T}$ cell immune response against cap/plaque material, might be crucial in the destabilization of the advanced plaque which generally precedes plaque rupture, thrombi formation and infarcts. 
However, complete knockout of the CD8 gene in atherosclerosissusceptible $A p o E^{--}$mice, presumably affecting both $\mathrm{CD} 8 \alpha^{+} \mathrm{DC}$ and $\mathrm{CD} 8^{+} \mathrm{T}$ cell function, did not lead to the expected reduction in atherosclerosis ${ }^{(23)}$. Similarly, $A p o E^{--}$mice deficient in Antigen Peptide Transporter 1 (TAP1, involved in antigen cross-presentation), displayed an equivalent atherogenic response ${ }^{(24)}$. Moreover, $\mathrm{MHCl}$ knockout (KO) mice on a 15 week high fat diet showed increased plaque formation (+150\%), suggesting that $\mathrm{MHCl}$-dependent antigen presentation, inducing cytotoxic $\mathrm{CD} 8^{+} \mathrm{T}$ cells, is atheroprotective ${ }^{(25)}$. Possible protection by cross-presenting DCs was also observed in the $\mathrm{flt}^{-/} \mathrm{Idl} \mathrm{r}^{-/-}$mouse, where depletion of Flt3L-dependent DCs resulted in aggrevated atherosclerosis ${ }^{(26)}$. Unfortunately, each of these studies implies severe modifications of the entire immune system, which greatly impedes assessment of purely cross-presentation related effects. Thus, evidence for a direct role of cross-presentation in a "plaque-targeted" immune response remains circumstantial and inconclusive.

This study aimed at dissecting the mechanism behind the strong cytotoxic $T$ cell response in advanced atherosclerosis. We hypothesized that cross-presentation of necrotic plaque epitopes will prime $\mathrm{CD} 8^{+} \mathrm{T}$ cells to attack plaque components. In order to investigate this, we took a loss-of-function approach making use of chimeric batf3 $3^{\%}$ mice, which specifically lack CD8 $\alpha^{+}$ $\mathrm{DCs}$ and $\mathrm{CD}_{103^{+}} \mathrm{DCs}$, the most important cell populations for crosspresentation ${ }^{(27,28)}$. Unexpectedly, the severe defect in cross-presentation in batf3 $3^{--}$chimeras did not translate into apparent differences in $\mathrm{CD}^{+} \mathrm{T}$ cell numbers, nor did it significantly affect atherosclerotic plaque size or composition. 


\section{Methods}

\section{RNA isolation from human atherosclerotic plaque lesions}

Total RNA was extracted from freshly frozen atherosclerotic tissue samples obtained from endarterectomy surgery. Collection, storage in the Maastricht Pathology Tissue Collection (MPTC) and patient data confidentiality as well as tissue usage were in accordance with the "Code for Proper Secondary Use of Human Tissue in the Netherlands" (http://www.fmwv.nl, http://www.federa.org/sites/default/files/digital_version_first_part_code_of_ conduct_in_uk_2011_12092012.pdf). Tissue samples destined for RNA isolation were snap-frozen immediately after resection, staged by histological analysis of adjacent tissue sections according to Virmani et al. ${ }^{(29)}$ and grouped as early lesions (IT: intimal thickening/PIT: pathological intimal thickening, $n=5$ ), advanced lesions (Tk/Tn FCA: thick or thin fibrous cap atheroma, $n=6$ ) or advanced unstable lesions (IPH: intra plaque hemorrhage, $n=5$ ). RNA was isolated with the Guanidine Thiocyanate (GTC)/CsCl gradient method and the NucleoSpin RNA II kit (Macherey-Nagel GmbH \& Co. KG) ${ }^{(30)}$. RNA concentration was determined using the Nanodrop ND-1000 (Thermo Scientific) and quality was assessed by RNA 6000 Nano/Pico LabChip (Agilent 2100 Bioanalyzer, Palo Alto, CA, USA) analysis based on RIN (RNA integration number) values. RIN values above 5.6 were considered acceptable.

\section{RNA isolation from mouse aorta}

Total RNA was extracted from freshly frozen mouse aorta. For early plaques 68 weeks old C57BL/6 mice were used, for advanced plaques 5 C57BL6 $\mathrm{ApoE}^{\prime-}$ mice of over 35 weeks old were used. Snap-frozen aorta was disrupted using Trizol (Life Technologies), glass beads and a Mini-Beadbeater. RNA isolation was then performed using the Qiagen RNAeasy Micro Kit following manufacturer's instructions. RNA concentration and purity was determined on a Nanodrop 2000 spectrophotometer.

\section{Real-time PCR on human and mouse atherosclerotic plaque lesions}

500 ng total plaque RNA was cDNA transcribed with the iScript cDNA Synthesis Kit (BioRad) following manufacturer's instructions. Real time PCR was performed for expression of human TAP1, ADFP, BDCA3, IRF8, Rab11b, Necl2 and Batf3 or mouse Rab11b, TAP1 and XCR1 using SensiMix SYBR Green (Bio- 
Rad) on a Bio-Rad CFX96 Real-Time System, C1000 Thermal Cycler. Gene expression of one housekeeping gene, i.e. human $\beta$-actin or mouse GAPDH, was assessed for normalization. Due to the limited quantity of plaque material, more house-keeping genes could not be included in the analysis. Nevertheless, for analysis of plaque material human $\beta$-actin and mouse GAPDH are both considered stable housekeeping genes within our laboratory, based on various qPCR experiments to select a viable housekeeping gene for atherosclerotic plaques (data not shown). Gene specific intron-spanning primers (Eurogentec) were designed with Roche Applied Science's Universal ProbeLibrary Assay Design Center (Supplemental Table I). For validation of primer specificity a primer BLAST (NCBI) specificity analysis was performed. Real time PCR data was analyzed using Bio-Rad CFX Manager v2.0 Software.

\section{Immunohistochemistry and colocalization on human plaque sections}

The co-localization of the DC marker with a marker for crosspresentation in human plaques was measured by multispectral imaging of immunohistochemical staining. Frozen human plaque sections were stained for CD11c (BD Pharmingen) and XCR1 (Novus Biologicals). From double staining, spectral imaging data sets from maximal three random regions of interest were taken between $420-720 \mathrm{~nm}$ (10 nm interval) at a $5 \mathrm{x}$ as well as at a $20 \mathrm{x}$ magnification using a Nuance spectral imaging system (Perkin Elmer/Caliper Life Sciences, Hopkinton, MA, USA) mounted on a Zeiss Axiophot microscope. Slides stained for a single chromogen (Vector Red and Vector Blue, both Vector Laboratories) only were used to create a spectral library. The spectral library was used for computational segregation of the individual image components using the NuanceTM 3.0.2 software as described ${ }^{(31)}$. After spectral unmixing, pseudo-colors were assigned to unmixed images, and composite images showing co-localization were generated with the Nuance 3.0.2 software.

\section{Animals}

All animal work was approved by the local regulatory authority of Maastricht University and in accordance with EU and Dutch government laws and guidelines. Mouse experiments performed in Cincinnati (US) complied with approved Institutional Animal Care and Use Committee guidelines and the guidelines of the Association for Assessment and Accreditation of Laboratory Animal Care International. Male $/ d / r^{-/}$mice were obtained from the Jackson 
Laboratory (Bar Harbor, $\mathrm{ME}$ ) and had been backcrossed at least 10 generations on a C57BL/6J background. For CD45.1/2 studies male $/ d / r^{-/-}$mice have been crossed in-house at our SPF breeding facility into the CD45.1 background. Batf $^{\%}$ mice were a kind gift from Prof. Dr. K. Hildner (Uniklinikum Erlangen, Germany) or purchased directly from the Jackson Laboratory. OT-I mice were a gift from Prof. Dr. M. Zenke (Uniklinikum Aachen, Germany) or purchased at the Jackson Laboratory and crossed to the CD45.1 (B6.SJL-Ptprca Pepcb/BoyJ) background at the Cincinnati in-house SPF mouse breeding facility. B6. PL-Thy-1a/Cy (CD90.1) mice and C3H Act-mOVA mice were bred in the Cincinnati in-house SPF mouse breeding facility. All mice were fed a standard diet (Cat\# V1535, sniff Spezialdiäten GmbH, Soest, Germany) unless indicated otherwise, had ad libitum access to food and water and were housed under a 12 hour light-dark cycle.

\section{Bone marrow transplantation and atherosclerosis induction in mice}

Male C57BL/6 CD45.2 ld $\mathrm{lr}^{-/}$mice of at least 12 weeks of age were housed under filter top cages and given antibiotics supplemented water (Neomycin (100mg/L; Gibco, Carlsbad, CA, USA) and Polymyxin B sulfate $(60.000 \mathrm{U} / \mathrm{L}$; Gibco)), starting 2 weeks before until 6 weeks after bone marrow transplantation. To induce bone marrow aplasia, $I d r^{-/}$mice $(n=69)$ were exposed to two doses of $6 \mathrm{~Gy}$ total body irradiation $(0.5 \mathrm{~Gy} / \mathrm{min}$, Philips MU15F/225kV, Hamburg, Germany) one day before bone marrow transplantation, with $12 \mathrm{hrs}$ recuperation time in between each dose. Irradiated recipients (Maastricht study $\mathrm{n}=15 \mathrm{wt}, \mathrm{n}=12 \mathrm{batf3}^{--}$, Cincinnati study $\mathrm{n}=15$ for both groups, CD45.1/2 study $\mathrm{n}=12$ ) were injected via tail vein with bone marrow cell suspensions $\left(10^{6}\right.$ cells/mouse), prepared from homozygous C57BL/6J batf $3^{-1}$ female donor mice or wt littermate controls by tibia/ femur lavage. For the CD45.1/2 study, donor mice were male C57BL/6 CD45.1 /d/r/. For atherosclerosis induction, mice were allowed to recover for 6 weeks after bone marrow transplantation, blood samples were taken from the tail vein and mice were put on a Western type diet (WTD) containing $0,25 \%$ cholesterol (Special Diets Services, Witham, Essex, UK) for 10 weeks. At sacrifice, mice were euthanized by a pentobarbital overdose $(115 \mathrm{mg} / \mathrm{kg})$, injected intraperitoneally. Blood was taken by left ventricular puncture. Spleen, aortic lymph nodes and a mix of peripheral lymph nodes (axillary, mesenteric, 
mandibular, aorta-draining lymph nodes (Inn. mediastinalis dorsalis, located in the precordial mediastinum: a group of two to four larger dorsal nodes attached to the thymus cranial to the aortic arch and lateral to the cranial caval veins) were isolated. For flow cytometry experiments, aorta and carotids were dissected before perfusion. For histological sampling, mice were perfused with phosphate buffered saline (PBS) ( $\left.\mathrm{NaCl} / \mathrm{Na}_{2} \mathrm{HPO}_{4} / \mathrm{KH}_{2} \mathrm{PO}_{4}, \mathrm{pH} 7.4\right)$ containing sodium nitroprusside $(0.1 \mathrm{mg} / \mathrm{ml}$, Sigma) and $1 \%$ paraformaldehyde (PFA) and heart, aorta and carotids were dissected.

\section{Histology and immunohistochemistry of mouse atherosclerotic lesions}

After isolation, the carotid arteries, aorta and the heart were fixed overnight in $1 \%$ PFA and paraffinembedded sections $(4 \mu \mathrm{m})$ were cut. For frozen sections, aortic root was snap-frozen in OCT, and $4 \mu \mathrm{m}$ frozen sections were cut. To determine plaque volume and necrotic core content in the aortic arch and aortic root, plaque area and necrotic core were measured on four consecutive $H \& E$ stained sections at $20 \mu \mathrm{m}$ intervals that covered the entire lesion and averaged, as described before ${ }^{(32)}$. In the aortic root, measurements were calculated for each valve separately and then added to obtain total root plaque area and necrotic core size.

Collagen content was detected by Sirius Red (Sigma) staining and expressed as a percentage of plaque area. Slides were analyzed in a blinded manner using a Leica DM3000 light microscope (Leica Microsystems, Wetzlar, Germany) coupled to a computerized morphometric system (Leica Qwin 3.5.1). Immunohistochemical stainings were performed on paraffin or frozen aortic root sections for CD3 (DAKO, Glostrup, Denmark), $\alpha$-smooth muscle actin (ASMA) (DAKO), Mac3 (BD), cleaved caspase 3 (Cell Signaling), CD11c (supernatant of N418 Hybridoma Cells), CD8 $\alpha$ (Thermo Scientific), biotinylated CD45.1 (BD Biosciences) or biotinylated CD45.2 (BD Biosciences). Slides were analyzed blindly using a Leica Qwin program (for ASMA and Mac3) or counted manually (for CD3 and cleaved caspase 3). The amount of positive cells was expressed as percentage positively stained area per total plaque area (for ASMA and Mac3) or as number of positive cells per $\mathrm{mm}^{2}$ plaque area (for CD3 and cleaved caspase 3). 


\section{Plasma cholesterol analysis}

Cholesterol levels in plasma were measured in duplicate using a colorimetric assay (DiaSys, Diagnostic Systems) according to the kit's instructions.

\section{Flow cytometry}

Blood, spleen, aortic lymph nodes and peripheral lymph nodes (a mixture of mesenteric, mandibular and axillary lymph nodes) were removed before perfusion, gently dissociated through a $70 \mu \mathrm{m}$ cell strainer (Greiner), treated with erylysis buffer $\left(8.4 \mathrm{~g} \mathrm{NH}_{4} \mathrm{Cl}, 0.84 \mathrm{~g} \mathrm{NaHCO}_{3}\right.$ in $\left.1 \mathrm{PBS}\right)$ and stained for total leukocytes $\left(\mathrm{CD}^{2} 5^{+}\right.$, BioLegend), total $\mathrm{T}$ cells $\left(\mathrm{CD}^{+}\right.$, eBioscience), $\mathrm{T}$ helper cells ( $\mathrm{CD} 4^{+}, \mathrm{BD}$ Bioscience), cytotoxic T cells ( $\mathrm{CD} 8 \alpha^{+}, \mathrm{BD}$ Bioscience), $B$ cells (B220 ${ }^{+}, B D$ Bioscience), NK cells (CD3 ${ }^{-}$NK1.1 $1^{+}, B D$ Bioscience) monocytes (CD11b $b^{\text {high }}$ Ly6G $^{\text {low }}, B D$ Bioscience), granulocytes $\left(C D 11 b^{\text {high }}\right.$ Ly6G ${ }^{\text {high }}, B D$ Bioscience), conventional dendritic cells ( $C D C s ; C D 11 c^{\text {high }} \mathrm{MHCII}^{\text {high }}$, either CD8 $8^{-} \mathrm{CD} 11 \mathrm{~b}^{+}$, double negative $\mathrm{CD} 8^{-} \mathrm{CD} 11 \mathrm{~b}^{-}$or $\mathrm{CD}^{+} / \mathrm{CD} 103^{+} \mathrm{CD} 11 \mathrm{~b}^{-}$, eBioscience) and plasmacytoid DCs (pDCs; PDCA-1 ${ }^{\text {high }} B 220^{+}$, eBioscience). $T$ cell subtypes were analyzed performing additional cell surface staining on FoxP3 (eBioscience), CD44 (BD Bioscience) and CD62L (eBioscience). Cross presenting macrophages were analyzed using a cocktail of CD45 (BioLegend), CD3 (eBioscience), CD19 (eBioscience), CD11c (eBioscience), CD11b (BD Bioscience), F4/80 (BioLegend), and CD169 (BioLegend), and defined as $\mathrm{CD}_{4} 5^{+} \mathrm{CD} 3 / \mathrm{CD} 19^{-} \mathrm{CD} 11 \mathrm{c}^{-} \mathrm{CD} 11 \mathrm{~b}^{+} \mathrm{F} 4 / 80^{+} \mathrm{CD} 169^{+}$. For $\mathrm{CDC}$ and $\mathrm{pDC}$ analysis, spleen and lymph nodes were pretreated for 30 minutes with a cocktail of liberase $(32 \mu \mathrm{g} / \mathrm{ml}$, Roche) and DNase $(0.8 \mu \mathrm{g} / \mathrm{ml}$, Roche) in RPMI medium (Gibco). Absolute cell numbers in blood were calculated by use of Trucount tubes (BD Bioscience). All flow cytometry analysis was performed on a BDCanto II (BD Bioscience) using FACS Diva Analysis Software vs6.

\section{Flow cytometry of mouse aorta}

Aortic arch, carotids and thoracic aorta were dissected, transferred to an enzymatic cocktail consisting of hyaluronidase $(85 \mathrm{U} / \mathrm{ml}$, Sigma), liberase $(32 \mu \mathrm{g} / \mathrm{ml}$, Roche) and DNase $(0.8 \mu \mathrm{g} / \mathrm{ml}$, Roche) in RPMI medium (Gibco) and with forceps and syringe dissociated in pieces small enough to be taken up with a $1 \mathrm{ml}$ Greiner pipet. Tissue was incubated in this enzymatic cocktail for 1 hour at 37 degrees with regular shaking and filtered through a $70 \mu \mathrm{m}$ cell 
strainer (Greiner). Two aortas were pooled together for consequent FACS analysis and samples were stained with a cocktail of CD45 (BioLegend), CD3 (eBioscience), CD19 (eBioscience), NK1.1 (eBioscience), Ly6G (eBioscience), F4/80 (eBioscience), CD11c (eBioscience), MHCll (eBioscience), CD45.1 (BD Biosciences) and CD45.2 (BD Biosciences). CD3, CD19, Ly6G and F4/80 were used as dump gate to identify $\mathrm{CD} 45^{+} \mathrm{CD} 11 \mathrm{c}^{\text {high }}, \mathrm{MHCII}^{\text {high }}$ dendritic cells. Analysis was performed on a BDCanto II (BD Bioscience) using FACS Diva Analysis Software vs6.

\section{OT - I cross presentation analysis}

Batf3 $^{-1-}$ or wt $/$ dll $^{-1-}$ recipient mice $(n=3-8)$ on chow or high fat diet received intravenous $5 \times 10^{4}$ CFSE-labeled (Life Technologies) purified OVA specific OT-I/CD45.1 CD8 ${ }^{+}$T cells together with $5 \times 10^{5}$ purified CD90.1 wt CD8 ${ }^{+}$ $T$ cells that served as an internal control. All injected $C D 8^{+} T$ cells were purified using the $\mathrm{CD}^{+} \mathrm{T}$ Cell Isolation Kit II (Miltenyi Biotec $\mathrm{GmbH}$, Bergisch Gladbach, Germany) according to the kit's manual. The next day, mice received i.v. $5 \times 10^{5}$ irradiated (1500 rad) $\mathrm{C} 3 \mathrm{H}$-actmOVA splenocytes. Three days later, spleen and lymph nodes were isolated and stained for CD8 (BioLegend), Va2 (BioLegend), CD45.1 (BD) and CD90.1 (BioLegend). Subsequently, OT-I/CD90.1 proliferation and expansion were determined based on CFSE dilution and the ratio of OT-I/CD45.1 to CD90.1 control CD8 ${ }^{+} \mathrm{T}$ cells.

\section{Statistics}

All data is presented as mean + SEM. Data was processed using GraphPad Prism 5 (Graph Pad Software Inc., San Diego, CA, USA). Individual groups of normally distributed data were analyzed with a Student's $t$-test, otherwise a non-parametric Mann-Whitney $U$ test was used. Data containing more than two groups was analyzed with 1-way ANOVA or the non-parametric Kruksal-Wallis test, and results were corrected for multiple testing. Correlation analysis was performed using a Spearman correlation test. Different outcomes were considered significant on several levels: *: $p<0.05,{ }^{* *}: p<0.01, * * *$ : $\mathrm{p}<0.001$. 


\section{Results}

\section{Cross-presentation markers increase in advanced atherosclerotic plaques}

First, to evaluate the validity for a role of cross-presentation in plaque destabilization, expression of key cross-presentation markers in human and mouse atherosclerotic lesions was examined. We investigated RNA expression levels of Thrombomodulin, Basic leucine zipper transcription factor, ATF-like 3, Interferon regulatory factor 8 and nectin-like molecule 2 (BDCA3, Batf3, IRF8 and Necl2: markers of the main cross-presenting DC population in humans ${ }^{(33)}$ ) and of Antigen Peptide Transporter 1, Ras-related protein 11b, and Adipocyte Differentiation-related Protein (TAP1, Rab11b and ADFP: involved in antigen processing and presumed cross-presentation pathways ${ }^{(34-36)}$ ) in early, advanced and unstable human plaque material. BDCA3, IRF8 and ADFP were all significantly upregulated in ruptured plaques compared to initial lesions, and Batf3, TAP1 and Necl2 all showed a similar trend (Figure 1a). Rab11b expression did not correlate with plaque progression (data not shown). XCR1 (12) and CD11c immunohistochemical staining revealed few cross-presenting cells were present in advanced and unstable human plaques, while they could not be found in early plaques (Figure 1b, Supplementary Figure 1a). In mouse advanced plaques, Rab11b, TAP1 and XCR1 RNA expression levels were increased compared to early plaques (Figure 1c). Similar to human plaques, cross-presenting DCs were scarce in mice and only found in advanced plaques (Figure 1d, Supplementary Figure 1b). Overall, RNA expression patterns of cross-presentation markers correlated with a phenotype of increased plaque burden and instability, and cross-presenting cells were almost exclusively found in the more advanced plaque types, pointing to a potential role for cross-presentation in plaque progression and destabilization in human and mouse atherosclerosis. 
a
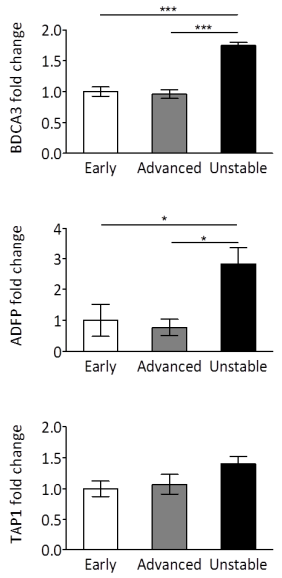

C
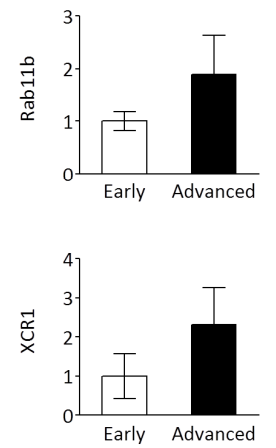

b
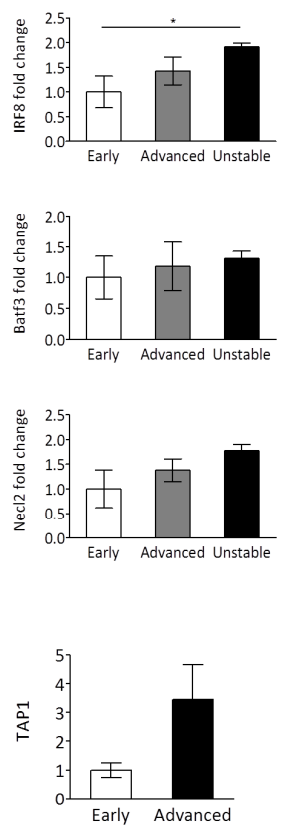

d
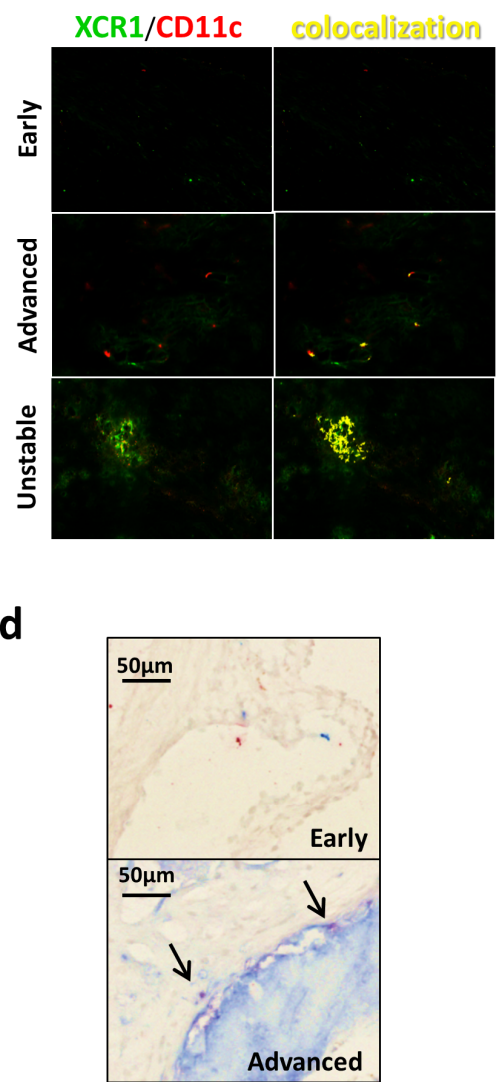

Figure 1. Expression of cross presentation markers in human and mouse atherosclerosis

(a) Total RNA was isolated from fresh-frozen human atherosclerotic plaques. Real-time PCR results of expression levels of BDCA3, IRF8, ADFP, Batf3, TAP1 and Necl2 are shown as mean \pm SEM. All expression levels were first normalized for levels of $\beta$-actin expression, and are depicted as fold induction when compared to expression levels in early plaques. Samples were grouped based on histological qualification of plaque stage according to Virmani et al. ${ }^{57}$. Early: Intimal Thickening/ Pathological Intimal Thickening $(n=5)$, Advanced: Thick/Thin Fibrous Cap Atheroma $(n=6)$, Unstable: Intra Plaque Hemorrhage $(n=5){ }^{*}: p<0.05, * * *: p<0.001$. (b) Representative images of frozen human carotid plaque sections $(n=8-10)$ doublestained with antibodies against XCR1 (green) and CD11c (red) to identify cross-presenting DCs. Colocalization was determined using a Nuance Spectral Imaging System and is indicated in yellow. (c) Total RNA was isolated from fresh-frozen mouse aorta's. Real-time PCR results of expression levels of Rab11b, TAP1 and XCR1 are shown as mean \pm SEM. All expression levels were first normalized for levels of GAPDH expression, and are depicted as fold 
induction when compared to expression levels in early plaques. Early: 8 wk old C57BI6 mice ( $n=6)$, Advanced: $>35$ wk old C57BI6 $A p o E^{\%}$ mice $(n=5)$

(d) Representative images of frozen mouse aortic root sections doublestained with antibodies against CD8 $\alpha$ (red) and CD11c (blue) to identify cross-presenting DCs. Nuclei were lightly counterstained with MethylGreen. Arrow: doublestained cell.

\section{Cross-presentation occurs under hyperlipidemic conditions}

Hyperlipidemia is known to affect the behavior and activation state of many immune cell types ${ }^{(1)}$, and could thus influence the efficacy of immune responses mediated by these cells. Therefore, efficiency of cross-presentation in hyperlipidemic conditions was evaluated. $L d / r^{-/-}$mice on chow or western type diet (WTD, $0.25 \%$ cholesterol) were injected with fluorescently labeled $\mathrm{T}$ cells isolated from OT-I mice. These cells express a $\mathrm{T}$ cell receptor (TCR) engineered to recognize a specific chicken ovalbumin (OVA) antigen (SIINFEKL) only when it is presented in context of mouse $\mathrm{MHCl}-\mathrm{K}^{\mathrm{b}}{ }^{(37)}$. Mice also received OVA-expressing necrotic cells, which are taken up and processed by endogenous dendritic cells. Only cross-presentation of the OVA epitope leads to direct activation and proliferation of the OT-I T cells. In chow-fed mice most OT-I T cells had proliferated. OT-I T cell mitogenic capacity was unaffected in WTD fed mice, establishing normal, functional cross-presentation is able to occur in a hyperlipidemic environment (Figure $\mathbf{2 a}, \mathbf{b}$ ). 

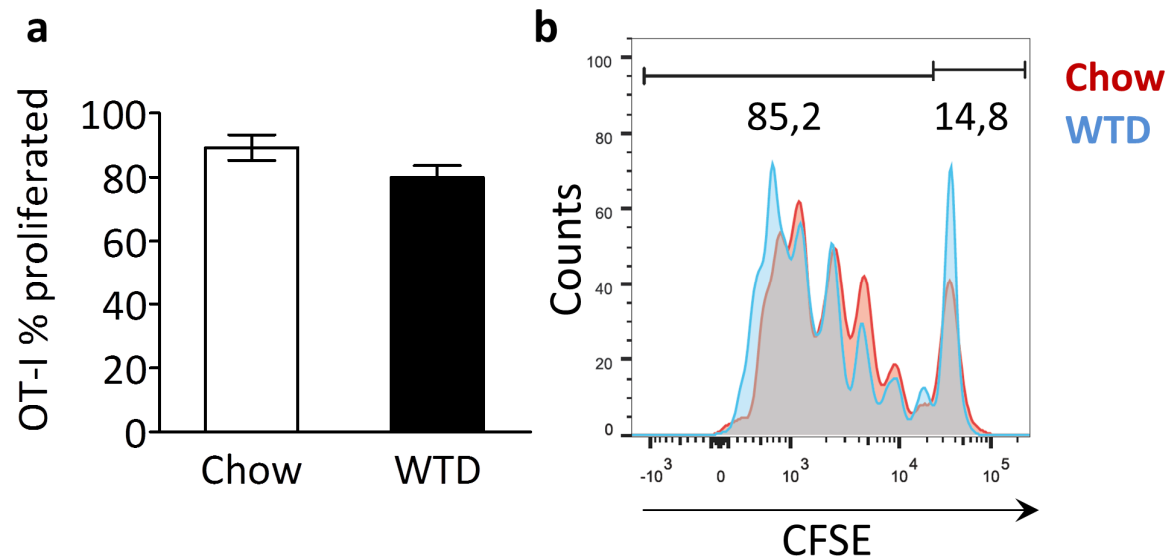

Figure 2. Cross-presentation occurs under hyperlipidemic conditions

Ldlr $r^{-/}$mice $(n=3)$ on a normal chow diet or fed a Western type diet (WTD) for three weeks were i.v. injected with irradiated OVA-expressing splenocytes and CFSE-labeled OT-I T cells. After 72 hrs, spleens were harvested and cross-presentation was assessed by flow cytometry, quantifying the proportion of proliferating OT-I T cells (cells with a diluted CFSE signal) within the total OT-I T cell population, normalized for amount of injected cells. (a) Bar graph of proliferated OT-I T cells (\% of total OT-I T cells) in spleen of chow or WTD-fed IdI $r^{--}$mice. (b) Representive CFSE dilution peaks of the OT-I T cell population. Data are presented as mean \pm SEM.

\section{Batf3-dependent DCs are efficiently depleted in atherosclerotic batf3 ${ }^{-/-}$ chimeric mice}

Local inflammatory processes are very important in atherosclerosis. To ensure the effectiveness of our planned approach we tested whether vascular dendritic cells could be successfully depleted and reconstituted by a bone marrow transplant experiment. CD45.2 $/ d / r^{-/}$mice were lethally irradiated and received bone marrow from CD45.1 mice. Without induction of atherosclerosis, dendritic cells in the aortas of the transplanted mice were very scarce $(0.8 \%$ of immune cells), and they were completely ablated 4 days after irradiation treatment (Supplementary Figure S2a, b). In addition, we could show by flow cytometry that 6 weeks after irradiation, only $1.3 \%$ of immune cells in the vessel wall are CD45.2 positive (i.e. from the host), instead they were almost exclusively CD45.1 positive, demonstrating effective reconstitution of the resident immune cells in the vessel wall by donor cells (Supplementary Figure S2e, f). Antibody stainings against CD45.1 and CD45.2 
confirm the flow cytometry results (Supplementary Figure S2g). We therefore concluded that we could use a bone marrow transplantation approach to efficiently disturb cross-presentation in atherosclerosis.

In order to investigate the relative contribution of Batf3-dependent cross-presentation in development and progression of atherosclerosis, lethally irradiated $I d I^{-1-}$ mice were reconstituted with bone marrow from batf $3^{-/}$mice or wild type (wt) control mice. Batf ${ }^{-\%}$ mice selectively lack CD8 $\alpha^{+}$and $\mathrm{CD} 103^{+}$ DCs and are not able to effectively cross-present necrotic cell exposed epitopes ${ }^{(27)}$. After recovery, mice were given a Western type diet (WTD) for 10 weeks to induce atherosclerotic plaque formation (Figure 3a). Batf $3^{-/-}$transplanted $/ \mathrm{d} / \mathrm{r}^{-1-}$ mice (hereafter batf $3^{\%}$ chimeras) showed more than $80 \%$ reductions in $\mathrm{CD} 8 \alpha^{+}$ DCs in spleen (Figure $\mathbf{3 b}, \mathbf{c}$ ) and lymphoid organs (data not shown). As expected, $\mathrm{CD}_{103}{ }^{+} \mathrm{DCs}$ were equally diminished by Batf3 deficiency (Figure 3d), because their development is also Batf3 dependent ${ }^{(28)}$. Illustrating specificity of the batf $3^{-/}$model, other leukocyte populations in blood (Supplementary. Figure S3), spleen (Supplementary Figure S4) or peripheral lymph nodes (Supplementary Figure S5) were not affected. At sacrifice, batf $3^{-\%}$ chimeras did not differ in body weight from mice transplanted with wt bone marrow (Figure 3e). Both groups showed equivalent and significant increases in plasma cholesterol (Figure 3f). These parameters indicate efficient induction of the atherosclerosis model. 
4 | CD8 $\alpha^{+}$dendritic cells and cross-presentation in atherosclerosis

a wt or batf3 $\%$ BMT

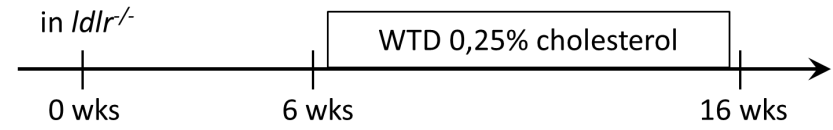

b

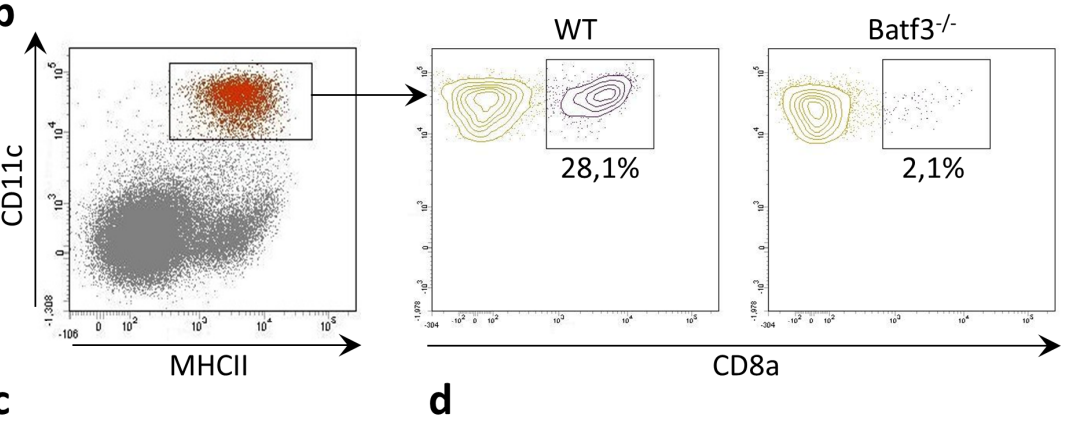

C
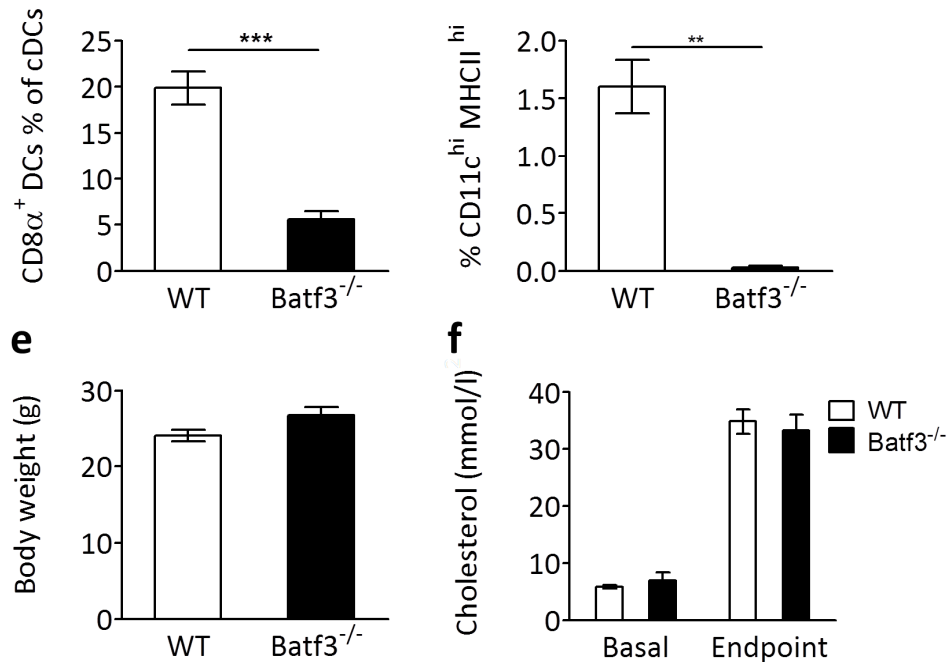

Figure 3. Batf3 deficiency results in severe $\mathrm{CD} 8 \alpha^{+} \mathrm{DC}$ depletion in the atherosclerosis model

(a) Lethally irradiated $I d l r^{-/}$mice were reconstituted with wt $(n=15)$ or batf3 ${ }^{-/}(n=12)$ bone marrow, and after 6 weeks recovery, put on a WTD containing 0,25\% cholesterol for 10 weeks. (b) Representative flow cytometry gating of CD8 $\alpha^{+} D C$ population (Lin;, $\left.\mathrm{CD} 11 \mathrm{c}^{\text {high }}, \mathrm{MHCII}^{\text {high }}, \mathrm{CD} 8 \alpha^{+}\right)$. (c) Bar graph of CD8 $\alpha^{+} \mathrm{DCs}$ as percentage of CDCs. (d) Bar graph of $\mathrm{CD}_{103^{+}} \mathrm{DCs}$ as percentage of CDCs. (e) Body weight at sacrifice. (f) Total cholesterol content in serum at sacrifice. Data are presented as mean $\pm \mathrm{SEM}$, ${ }^{* *}: p<0,01,{ }^{* * *}: p<0,001$. 
We next investigated if other DC populations with, albeit lower, capacity to cross-present might have expanded to compensate for the loss of Batf3-dependent DCs. Merocytic DCs can cross-present in a context of diabetes ${ }^{(38)}$, and even plasmacytoid DCs (pDCs) were reported to have some crosspresentation abilities ${ }^{(39)}$. However, no differences were found in merocytic DC or pDC numbers in spleen (Supplementary Figure S6a, b) and lymph nodes (data not shown). Recently, a subset of $\mathrm{CD} 169^{+}$macrophages $\left(\mathrm{CD} 11 \mathrm{~b}^{+} \mathrm{CD} 11 \mathrm{C}^{+} \mathrm{CD} 169^{+} \mathrm{F} 4 / 80^{+}\right.$) efficiently cross-presenting tumor antigens was described in spleen ${ }^{(40)}$. This population did not change in spleens of mice on a normal diet compared to mice on a western type diet (Supplementary Figure S6c), rendering their role in atherosclerosis-related cross-presentation not very likely. In summary, we did not identify other DC or DC-like populations likely to have taken over cross-presentation from the depleted CD8 $\alpha^{+} D C s$ in this atherosclerosis model.

Hyperlipidemic CD8 $\alpha+$ DC depletion profoundly affects systemic crosspresentation ability

In accordance with the severe $\mathrm{CD} 8 \alpha^{+} \mathrm{DC}$ depletion observed, hematopoietic Batf3 deficiency in atherosclerotic mice had a profound effect on cross-presentation. Batf3 ${ }^{\%}$ chimeras and control mice were injected with fluorescently labeled OT-I T cells and with necrotic OVA-expressing cells as described above. OT-I T cell proliferation was severely diminished from $80 \%$ in control mice to $23 \%$ in batf $3^{\%}$ animals (Figure $4 \mathbf{a}, \mathbf{b}$ ). Interestingly, the number of residual $\mathrm{CD} 8 \alpha^{+} \mathrm{DCs}$ in batf3 $3^{--}$chimeras correlated with the cross-presenting capacity $\left(r^{2}=0.89, p=0.01\right)$, establishing the significant role of this DC subset in cross-presentation, even in a hyperlipidemic setting (Figure 4c). 

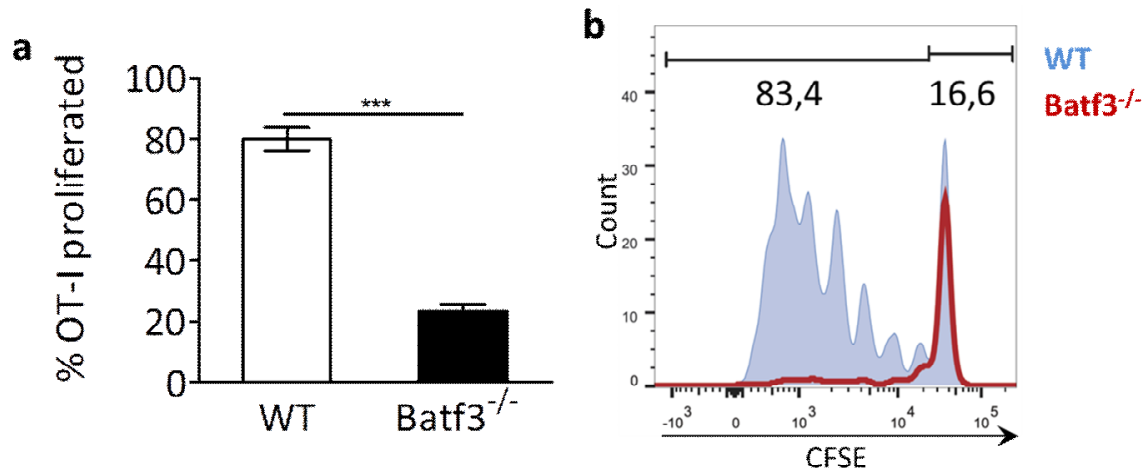

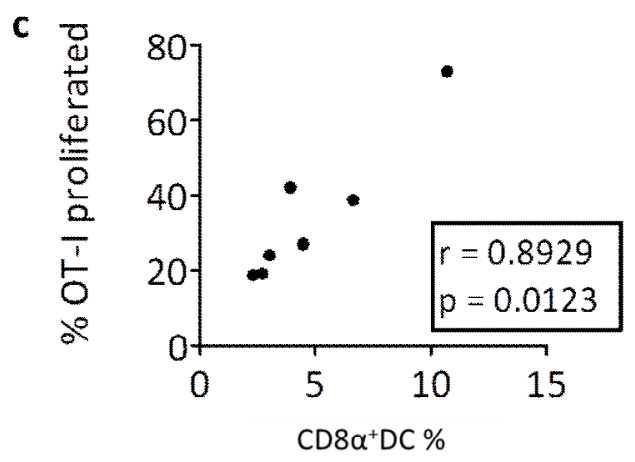

Figure 4. Cross-presentation is affected in batf $3^{-/-}$chimeric mice

Batf $^{-/}$chimeric or wt $/ d l r^{-/}$mice $(n=7)$ were i.v. injected with necrotic OVA-expressing splenocytes and CFSE-labeled OT-I T cells. After $72 \mathrm{hrs}$, spleens were harvested and cross-presentation was assessed by flow cytometry, quantifying the proportion of proliferating OT-I T cells (cells with a diluted CFSE signal) within the total OT-I T cell population, normalized for amount of injected cells. (a) Bar graph of proliferated OT-I T cells (\% of total OT-I T cells) in spleen. (b) Representive CFSE dilution peaks of the OT-I T cell population. (c) Correlation analysis between amount of residual CD8 $\alpha^{+}$ DCs and the remaining cross-presentation capacity in batf3 $3^{-/}$chimeras. Data are presented as mean \pm SEM, $* * *: p<0,001$.

\section{CD8 $\alpha+$ dendritic cell depletion does not affect atherosclerosis}

First, we analyzed aortic roots from batf3 ${ }^{\%}$ chimeras and control mice which had been fed a normal chow diet to evaluate whether $\operatorname{CD} 8 \alpha^{+} \mathrm{DC}$ depletion affected initial plaque formation. However, while some mice exhibited very small initial lesions, plaque sizes of both groups were similar (Supplementary Figure 7). Next, the effect of significantly hampered crosspresentation ability on atherosclerosis could be analyzed. Unexpectedly, neither advanced plaques in the aortic root nor initial plaques in 
brachiocephalic artery showed differences in plaque size, necrotic core size or necrotic core percentage between batf $3^{-\%}$ chimeras and control mice (Figure $5 a, b)$. Plaques from batf3 $3^{-}$chimeras and control mice also contained the same amount of macrophages (Figure $\mathbf{6 a}$, b: first panel). In addition, features of plaque stability were similar in both groups, as we observed no changes in vascular smooth muscle cell content or collagen (Figure 6a, b: second and third panel, Supplementary Figure S9). To exclude unknown local environmental or other contributory factors, we repeated the study in the same setup in the laboratory of our collaborator Prof. Dr. E. Janssen, Cincinnati, US, with $I d l r^{-/}$and batf $3^{-/}$mice from Jackson Laboratories. Again, cross-presenting CD8 $\alpha^{+}$DCs were severely depleted in batf $3^{-/}$chimeras, yet no differences were seen in atherosclerosis phenotype (Supplementary Figure S8). Thus, $C D 8 \alpha^{+} D C$ depletion does not alter plaque size or the stable plaque phenotype in atherosclerotic mice.
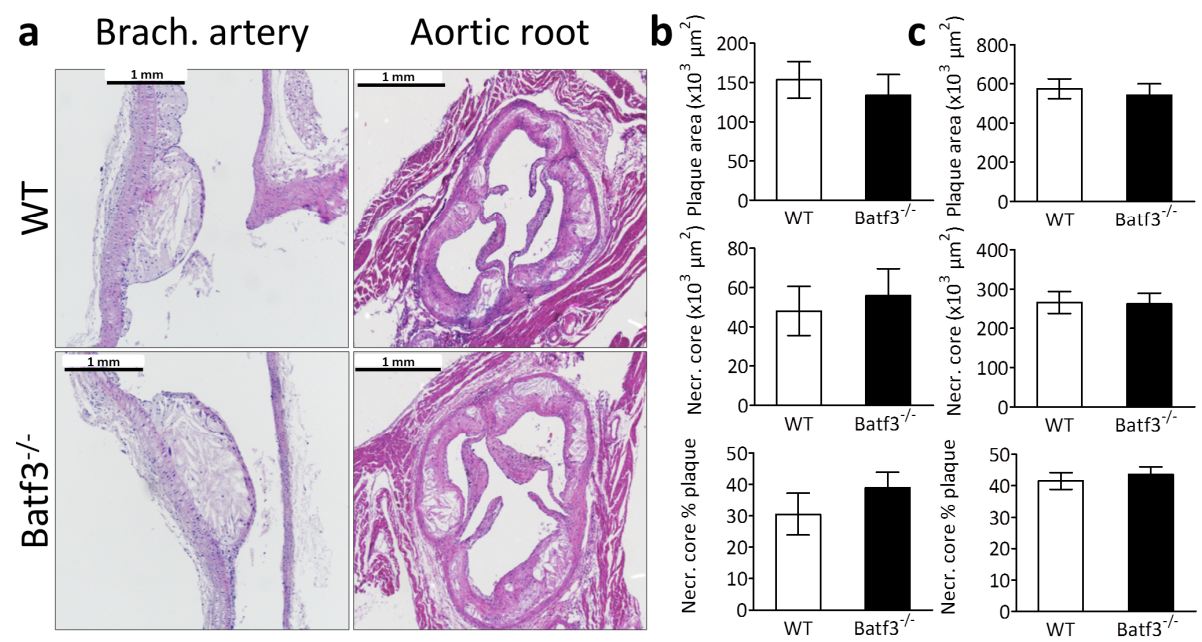

Figure 5. Batf3 deficiency does not influence atherosclerotic plaque size

Aortic arch and root were dissected from wt $(n=15)$ or batf3 ${ }^{-/-}(n=12) / d l r^{-/}$mice and analyzed by histology. (a) Aortic arch and root were H\&E stained for plaque size analysis. (b, c) Plaque area, necrotic core area and percentage necrotic core relative to plaque area are did not differ in the brachiocephalic artey (b) and aortic root (c). Data are presented as mean \pm SEM. 


\section{T cell activation is unchanged in $\mathrm{CD} 8 \boldsymbol{\alpha}^{+} \mathrm{DC}$ depleted atherosclerotic mice}

We postulated that cross-presentation of plaque epitopes would lead to expansion of cytolytic plaq ${ }^{2}$ ue-targeted $\mathrm{CD}^{+} \mathrm{T}$ cells, resulting in plaque destabilization. However, consistent with the observations regarding plaque size or phenotype, $\mathrm{T}$ cell content and plaque apoptosis did not differ between batf $3^{\%}$ chimeric mice and control mice (Figure 6a, b: fourth and fifth panel). Moreover, total $\mathrm{CD} 4^{+}$and $\mathrm{CD} 8^{+} \mathrm{T}$ cell numbers in blood, spleen and peripheral lymph nodes and were not changed by batf3 deficiency (Supplementary Figure S3-5). As we would primarily expect effects on T cell biology at the site of atherosclerosis, we also analyzed T cell phenotype in the aorta-draining lymph nodes (Inn. mediastinalis dorsalis, strongly enlarged in atherosclerosis) but no relevant differences in the proportion of regulatory $T$ cells (Figure $7 a$ ) were found. Naïve (CD44 $\left.{ }^{\text {low }}, C D 62 \mathrm{~L}^{\text {high }}\right)$, effector memory (CD44 $\left.{ }^{\text {high }}, C D 62 L^{\text {low }}\right)$ and central memory $\mathrm{T}$ cell counts (CD44 ${ }^{\text {high }}, \mathrm{CD}_{2} \mathrm{~L}^{\text {high }}$ ) in the aorta-draining lymph nodes were not affected by Batf3 deficiency (Figure 7b, c) as well. These data suggest that cross-presentation does not play an active role in the clonal expansion of atherosclerosis-relevant $T$ cells, neither locally in the aortadraining lymph node nor systemically in the lymphoid organs. 
a

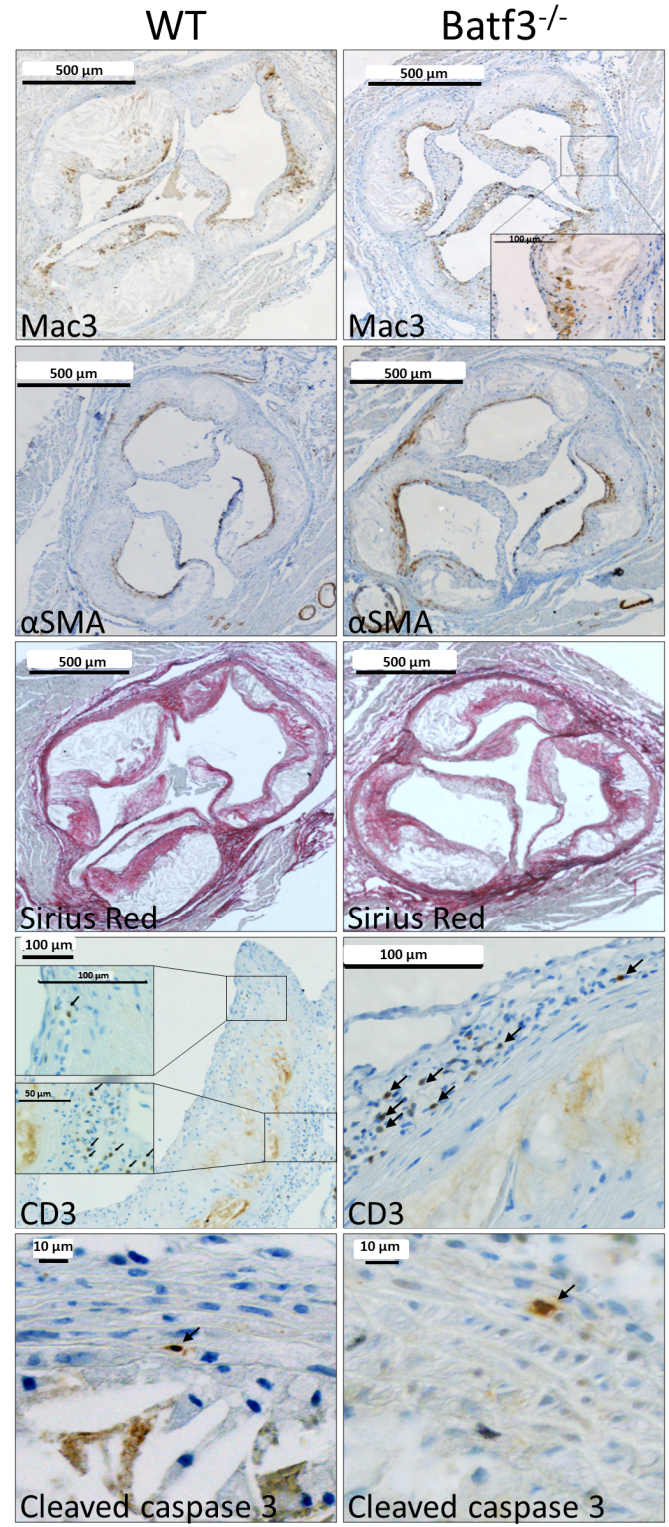

b
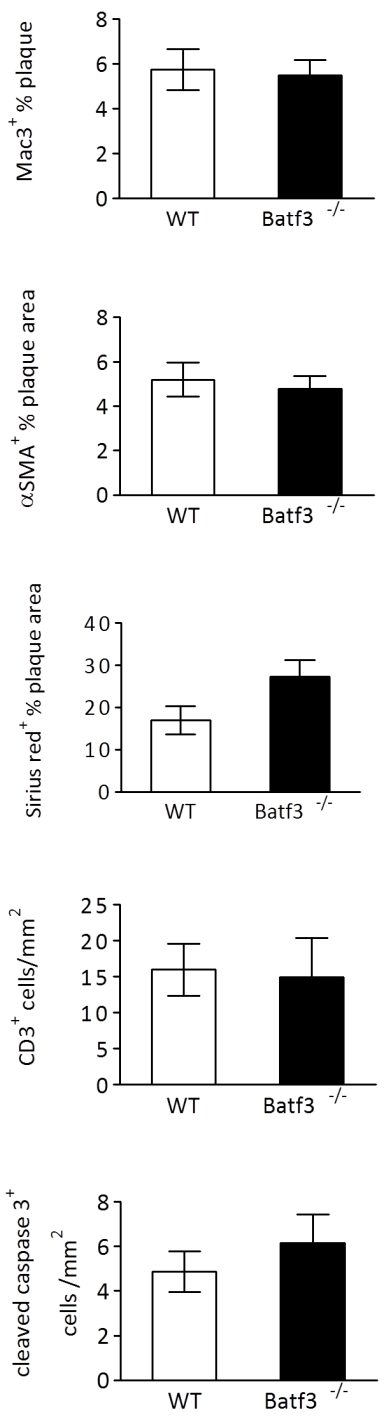

Figure 6. Batf3 deficiency does not influence atherosclerotic plaque composition Aortic arch and root were dissected from wt $(n=15)$ or batf ${ }^{-/}(n=12) / d l r^{-/}$mice and analyzed by immunohistochemistry. (a) Representative images of Macrophages (Mac3 staining), vascular smooth muscle cells ( $\alpha$ SMA staining), T cells (CD3 staining), collagen (Sirius Red staining) and apoptosis (cleaved caspase 3 staining) in the aortic roots of wt and batf $^{\%}$ chimeric mice. (b) Quantification of immunohistochemical stainings shown in (a). Data are presented as mean \pm SEM. 
4 I CD8 $\alpha^{+}$dendritic cells and cross-presentation in atherosclerosis

a
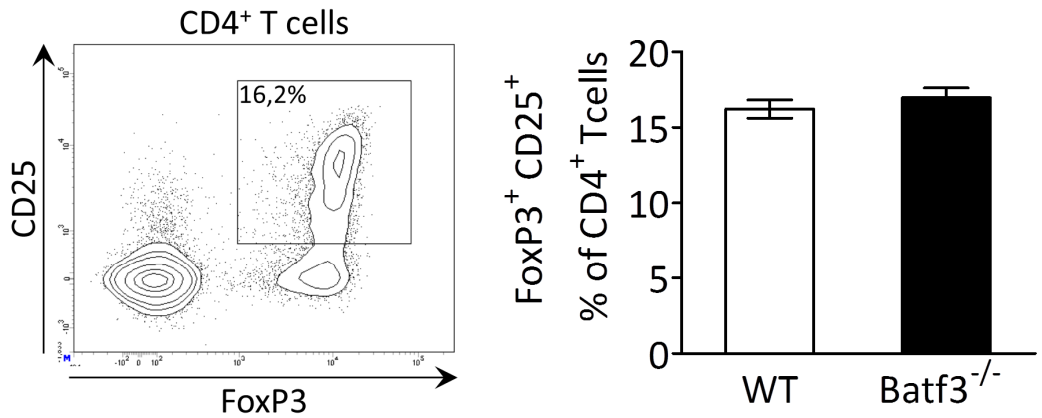

b
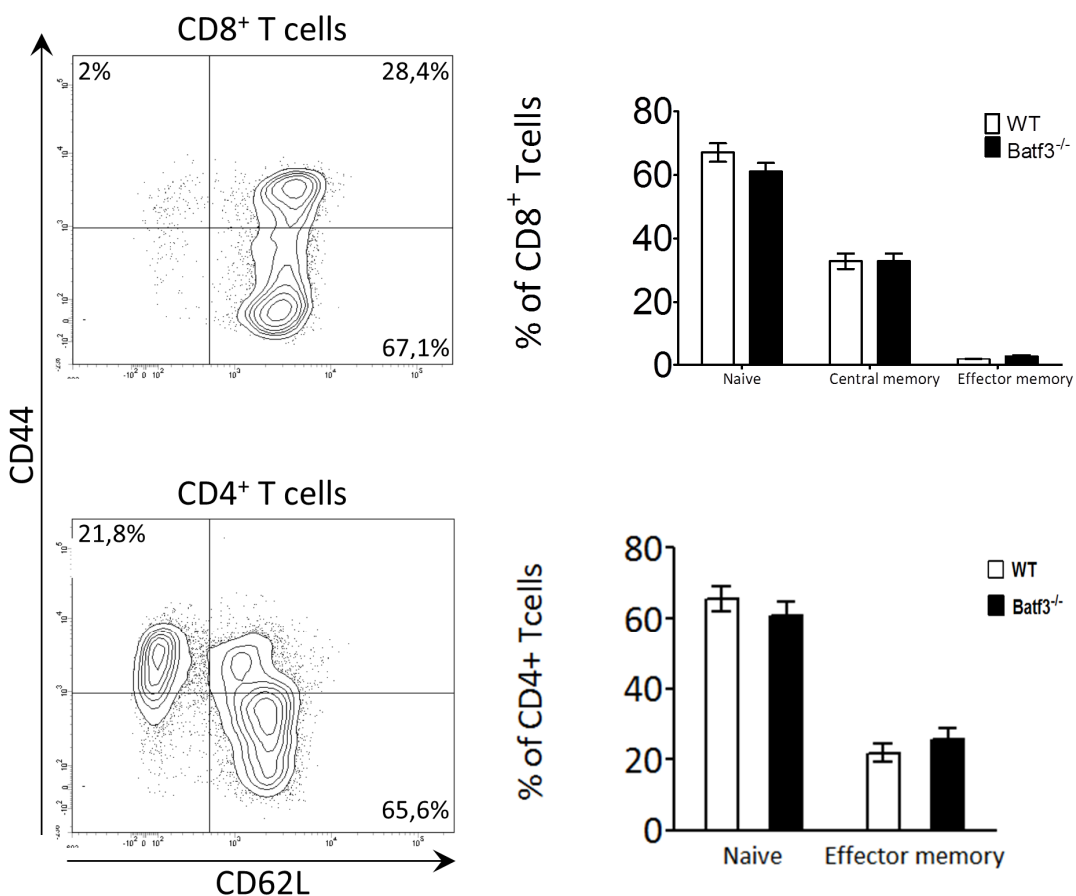

C

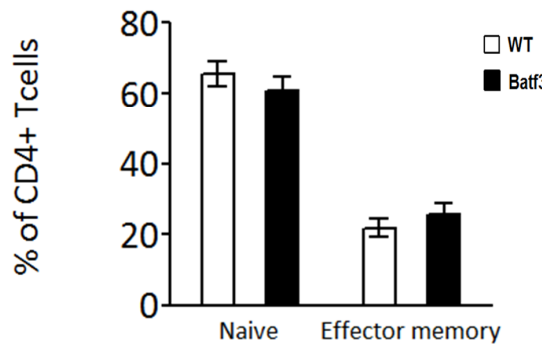

Figure 7. $\mathrm{T}$ cell numbers are unchanged in batf $3^{-/-}$chimeras

$T$ cell subset numbers were analyzed in the aorta-draining lymph node by flow cytometry. (a) $\mathrm{CD} 25^{+}$, FoxP3 ${ }^{+}$regulatory $\mathrm{T}$ cells are presented relative to the $\mathrm{CD} 4^{+} \mathrm{T}$ cell population. (b) Naïve $\left(\mathrm{CD} 62 \mathrm{~L}^{\mathrm{hi}}, \mathrm{CD} 44^{\mathrm{lo}}\right)$, central memory $\left(\mathrm{CD} 62 \mathrm{~L}^{\mathrm{hi}}, \mathrm{CD} 44^{\mathrm{hi}}\right)$ and effector memory (CD62 $\left.\mathrm{L}^{\mathrm{lo}}, \mathrm{CD} 44^{\mathrm{hi}}\right)$ populations are presented as percentages of $\mathrm{CD} 8^{+} \mathrm{T}$ cells. (c) Naïve $\left(\mathrm{CD} 62 \mathrm{~L}^{\mathrm{hi}}, \mathrm{CD} 44^{\mathrm{lo}}\right)$, and effector memory $\left(\mathrm{CD} 62 \mathrm{~L}^{\mathrm{lo}}, \mathrm{CD} 44^{\mathrm{hi}}\right)$ populations are presented as percentages of $\mathrm{CD} 4^{+} \mathrm{T}$ cells. Data are presented as mean $\pm \mathrm{SEM}$. 


\section{Discussion}

Cytotoxic immunity is emerging as a key process in advanced atherosclerosis ${ }^{(22)}$, but its actors and triggers are hitherto largely unknown. We opted for cross-presentation as plausible candidate, considering that all components for effective cross-presentation are present in the advanced atherosclerotic plaque and that several genes involved in cross-presentation were more expressed in ruptured compared to early atherosclerotic lesions of CVD patients. Moreover, exposure to high LDL/VLDL levels in advanced atherosclerosis would most likely not interfere with the cross-presentation machinery, as we showed that systemic cross-presentation efficacy in mice was not affected by hyperlipidemia. Likewise, $C D 11 c^{+} D C s$ under conditions of hyperlipidemia take up and process antigens normally, and are able to activate T cells ${ }^{(41)}$.

Cross-presentation of necrotic plaque epitopes could theoretically take place in the plaque itself, in analogy to antigen presentation by DCs to $\mathrm{CD}^{+}{ }^{+}$cells ${ }^{(42)}$, or in plaque-draining lymphoid organs. $\mathrm{CD} 103^{+} \mathrm{DC}$ increase in the atherosclerotic aortic wall ${ }^{(26)}$ and might activate $\mathrm{CD}^{+}{ }^{+}$cells in situ or migrate to adjacent lymph nodes. Alternatively, $C D 8 \alpha^{+} \mathrm{DCs}$ could cross-present shed plaque material in lymphoid organs, as they very efficiently do so with dying cell particles during intracellular pathogen infections ${ }^{(43)}$, upon which activated $\mathrm{CD}^{+} \mathrm{T}$ cell clones may travel to the plaque. Here, both routes of cross-presentation were ablated by depleting $C D 8 \alpha^{+} \mathrm{DC}$ and $\mathrm{CD}_{103^{+}} \mathrm{DC}$ in a well-established mouse model of atherosclerosis. Concordant with previous studies in whole-body batf $3^{-/}$mice ${ }^{(27,28)}$, chimeric batf $3^{-/}$mice exclusively targeted the aforementioned Batf3 dependent cell populations, leaving other leukocyte subsets unaffected. In addition, cross-presentation capability - again similar to the full batf3 $3^{-}$phenotype - was profoundly reduced in batf $3^{-1}$ chimeras with a more than $70 \%$ loss of OVA-OT-I cross priming capacity. Moreover, a strong correlation between the amount of residual CD8 $\alpha^{+}$DCs and the ability to cross-present OVA to OT-I T cells could be established. $C D 8 \alpha^{+}$DCs can develop independently of Batf3 and in conditions of infection compensatory batf3 $3^{--}$CD8 $\alpha^{+}$DC development was reported ${ }^{(44,45)}$. Nevertheless, effective numerical as well as functional depletion of this subset suggests that any batf3-independent $C D 8 \alpha^{+} \mathrm{DC}$ development is not opportune for the present study setup. 
Remarkably, the severe $\mathrm{CD} 8 \alpha^{+}$and/or $\mathrm{CD} 103^{+} \mathrm{DC}$ cross-presentation defect did not alter atherosclerotic plaque phenotype in batf $3^{\%-}$ chimeric mice. This is in agreement with the reported lack of effect of TAP1 deficiency, which transports antigen- $\mathrm{MHCl}$ complexes to the cell surface, on plaque formation in $A p o E^{\prime-}$ mice ${ }^{(24)}$, albeit that the interpretation of this study was complicated by reductions in peripheral $\mathrm{CD}^{+}{ }^{\mathrm{T}}$ cell numbers ${ }^{(46)}$. By contrast, $\mathrm{MHCl} \mathrm{KO}$ mice develop $150 \%$ bigger plaques when fed a high fat diet for 15 weeks ${ }^{(25)}$. However, apart from being unable to cross-present, $\mathrm{MHCl}$ deficiency influences a broad range of stromal and hematopoietic cells. These mice suffer from $\mathrm{CD}^{+}$lymphocytopenia, and profound iron overload ${ }^{(47)}$, which can both impact atherosclerosis development ${ }^{(22,48)}$. Similarly, loss of function studies in $\mathrm{flt}^{-/} \mathrm{Idl} \mathrm{r}^{-/}$mice suggested an athero-protective role of aortic $\mathrm{CD} 103^{+} \mathrm{DCs}$, possibly by increasing regulatory $\mathrm{T}$ cells in the lesion ${ }^{(26)}$. Of note, Flt3 is involved in the development of several types of hematopoietic cells ${ }^{(49)}$, and its deficiency affects $T$ cells and several DC subsets systemically and directly as well ${ }^{(50)}$. Our study setup differs from the above-mentioned studies in the fact that we achieve specific functional targeting of cross-presenting cell populations, allowing us to evaluate for the first time their single contribution to atherosclerosis development.

Moreover, compared to murine plaques, human lesions are more advanced, vulnerable to rupture and contain more $\mathrm{CD} 8^{+} \mathrm{T}$ cells ${ }^{(51)}$. Although the lesions observed in our model were quite advanced and contained large necrotic cores, we cannot exclude that cytotoxic $\mathrm{CD}^{+} \mathrm{T}$ cells and crosspresentation are of more importance in the human setting.

Even so, cross-presentation of necrotic plaque epitopes could be mediated by other cell populations, which were not targeted with the batf $3^{-}$ model. Therefore, subsets with reported cross-presentation ability such as merocytic DCs ${ }^{(38)}$, pDCs ${ }^{(39)}$ or $\mathrm{CD} 169^{+}$macrophages ${ }^{(40)}$ were analyzed. PDCs are present in scarce amounts in the intima of atherosclerotic arteries, but their role in atherosclerosis remains inconclusive ${ }^{(52,53)}$. The role of merocytic $\mathrm{DCs}$ or $\mathrm{CD} 169^{+}$macrophages in CVD is hitherto unknown. Investigating cross-presentation of plaque epitopes by those cell types would require a specific merocytic DC knockout model (not available to date) or combining the inducible CD169-DTR macrophage knockout model ${ }^{(54)}$ with an atherosclerosis 
model. Nevertheless, we did not find any relevant expansion of these populations in batf $^{-/}$chimeras, rendering a compensatory effect in Batf3 deficiency unlikely.

We postulated that cross-presentation deficiency would reduce atherosclerosis by failing to induce cytotoxic $\mathrm{CD} 8^{+} \mathrm{T}$ cells involved in plaque vulnerability ${ }^{22}$. However, in accordance with the unchanged plaque phenotype, $T$ cell subset numbers in blood and lymphoid organs as well as in plaques of chimeric batf3 $3^{--}$mice were similar to those in wt controls. This suggests that $\mathrm{CD} 8 \alpha^{+}$and $C D 103^{+}$DCs cannot account for the marked increase in $\mathrm{CD}^{+} \mathrm{T}$ cells in advanced atherosclerotic plaques ${ }^{(17)}$. In analogy to Cytomegalovirus infection, where priming of $\mathrm{CD}^{+} \mathrm{T}$ cells is largely dependent on Batf3-cross-presentation only in disease onset and not during latent infection ${ }^{(55)}$, cross-presentation by Batf3-dependent cells in the chronic stages of advanced atherosclerosis could be obsolete. In support of this view, it has been reported that only apoptotic cells (much more abundant in initial atherosclerotic lesions) elicit mature functional $\mathrm{CD}^{+} \mathrm{T}$ cells ${ }^{(56)}$. Therefore studying the impact of cross-presentation deficiency in early atherosclerosis can be of interest. Necrotic cells, which hallmark advanced atherosclerosis, may well fail to induce sufficient CD40 expression on DCs, which is an essential step to subsequent $\mathrm{CD}^{+} \mathrm{T}$ cell activation. Alternatively, it has been shown that apoptotic tissue antigens are cross-presented to tolerize autoreactive $\mathrm{CD}^{+} \mathrm{T}^{\mathrm{T}}$ cells ${ }^{(57)}$ and that sustained cross-priming by $\mathrm{CD} 8 \alpha^{+} \mathrm{DCs}$ can result in tolerance ${ }^{(58)}$. Vaccination studies using tolerogenic DCs loaded with oxLDL or ApoB100 have a positive effect on atherosclerotic disease progression ${ }^{(59,60)}$. However, as severe $C D 8 \alpha^{+} D C$ depletion did not increase plaque burden, a cross-tolerogenic role for $\mathrm{CD} 8 \alpha^{+} \mathrm{DC}$ in atherosclerosis seems unlikely. 
In summary, Batf3 deficiency in hyperlipidemic conditions leads to a highly specific, severe defect in cross-presentation, with no effect on $\mathrm{T}$ cell immunity or other leukocyte subsets. We clearly demonstrate that $\mathrm{CD} 8 \alpha^{+} / \mathrm{CD}_{103}{ }^{+} \quad \mathrm{DC}$-dependent cross-presentation does not impact atherosclerotic plaque size or features of plaque stability and consequently has no major causal role in plaque rupture or the generation of a cardiovascular event. Taken together, we present convincing evidence that the contribution of cross-presentation of atherogenic antigens to atherosclerotic plaque progression is marginal at best. Our study thereby raises the intriguing possibility that in advanced atherosclerosis $\mathrm{CD} 8^{+} \mathrm{T}$ cell immunity is steered by other mechanisms, involving for instance Th1 T cell activation ${ }^{(61)}$, which warrants further efforts to dissect the driving forces in cytolytic plaqueattacking $T$ cell generation. 


\section{Supplementary Figures}

a

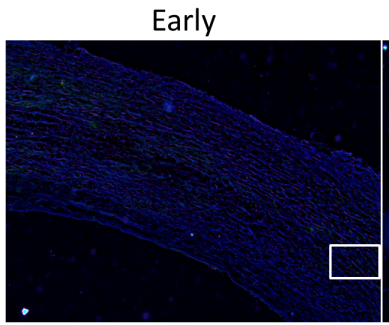

Advanced

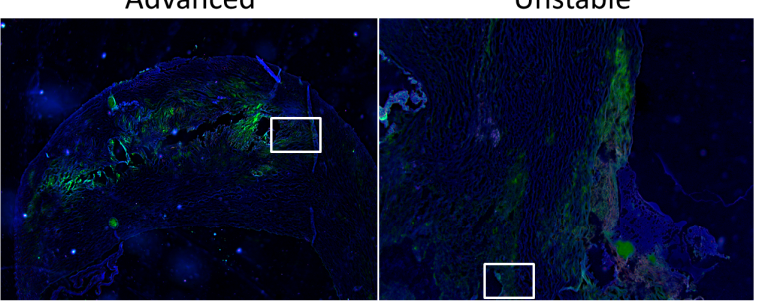

b

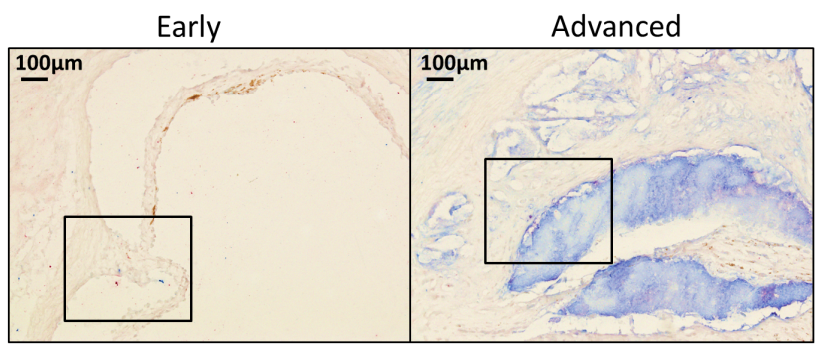

Supplementary Figure S1. Overview images of human and mouse plaque immunohistochemistry

(a) Representative images of frozen human carotid plaque sections ( $n=8-10)$ doublestained with antibodies against XCR1 (green) and CD11C (red) to identify crosspresenting DCs. Images were acquired with the Nuance Spectral Imaging System and colocalization was analyzed. Background structure of the tissue is indicated in blue. White rectangles indicate regions used in Figure 1b. (b) Representative images of frozen mouse aortic root sections doublestained with antibodies against CD8 $\alpha$ (red) and CD11c (blue) to identify cross-presenting DCs. Nuclei were lightly counterstained with MethylGreen. Black rectangles indicate regions used in Figure $1 \mathrm{~d}$. 

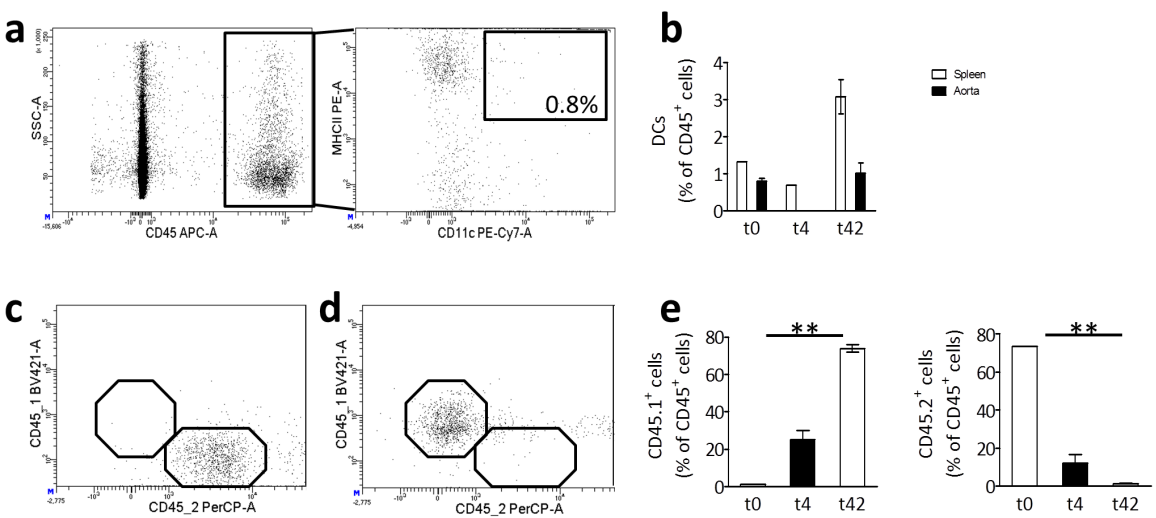

f
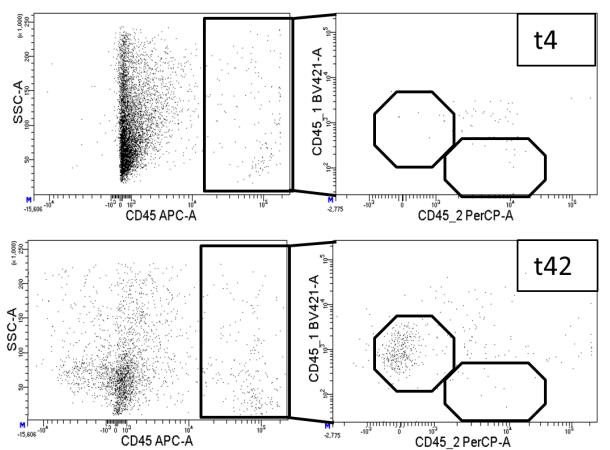

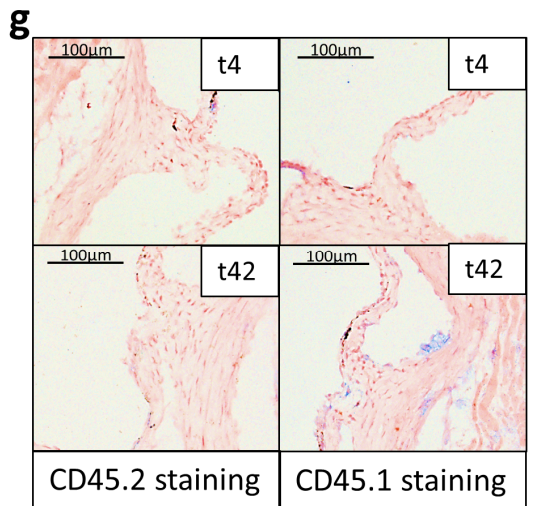

Supplementary Figure S2. CD45.2 immune cells in the vessel wall are replaced by CD45.1 donor cells after bone marrow transplantation

(a) Flow cytometry of mouse aorta showing $\mathrm{CD}^{+} 5^{+}$gate and $\mathrm{DC}$ subgate $\left(\mathrm{CD} 11 \mathrm{c}^{\text {high }}\right.$, $\mathrm{MHCII}^{\text {high }}$ ). (b) Using gating strategy shown in (a), DC populations in mouse spleen as well as aorta were determined by flow cytometry. t0: control CD45.2 $2^{+} \mathrm{ddlr} \mathrm{r}^{-/}$mouse $(\mathrm{n}=5), \mathrm{t} 4: \mathrm{CD} 45.2^{+} / d / r^{-/}$mouse 4 days after total body irradiation and transplantation with $\mathrm{CD} 45.1^{+}$bone marrow $(n=4), \mathrm{t} 42$ : $\mathrm{CD} 45.2^{+} / \mathrm{d} / r^{-/-}$mouse 6 weeks after total body irradiation and transplantation with $\mathrm{CD} 45.1^{+}$bone marrow $(n=8)$. Data is shown as mean \pm SEM. ${ }^{* *}: p<0.01$. (c) CD45.1/CD45.2 flow cytometry plot of the CD45 population in aorta of an acceptor CD45.2 $2^{+} / d l r^{-/-}$mouse. (d) CD45.1/CD45.2 flow cytometry plot of the $\mathrm{CD}_{4} 5^{+}$population in aorta of a donor CD45.1 $1^{+} / \mathrm{d} / \mathrm{r}^{-/}$mouse. (e) Aortic CD45. $1^{+}$donor-descendant cells (left panel) and CD45.2 $2^{+}$acceptor-descendant cells (right panel) were quantified by flow cytometry 4 days $(n=4)$ and 6 weeks after bone marrow transplantation $(n=8)$. (f) Representative flow cytometry plots of aortic $\mathrm{CD}^{+} 5^{+}$cells in CD45.1-transplanted $\mathrm{CD}_{4} 5.2^{+} / \mathrm{d} / \mathrm{r}^{-/}$mice 4 days and 6 weeks after transplantation. (g) Immunohistochemical staining of CD45.1 (blue) or CD45.2 (blue) positive cells in frozen aortic root sections of CD45.1-transplanted CD45.2 $2^{+} / \mathrm{d} / \mathrm{r}^{-/}$mice 4 days and 6 weeks after transplantation $(n=4)$. Counterstaining: Nuclear Fast Red. 
a

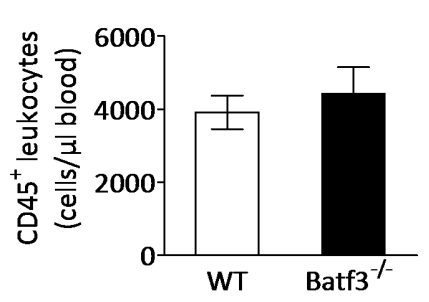

C

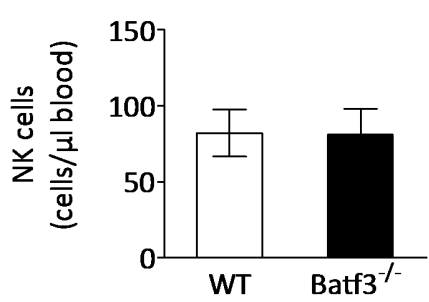

e

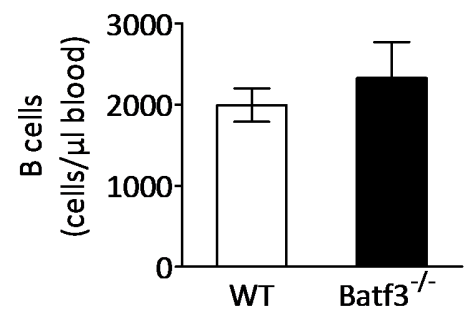

g

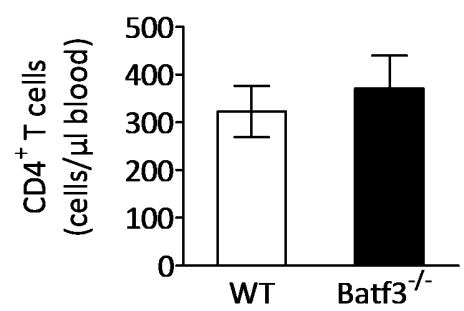

b

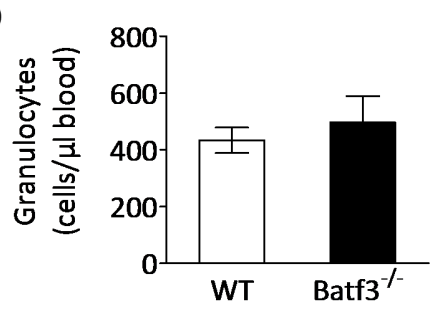

d

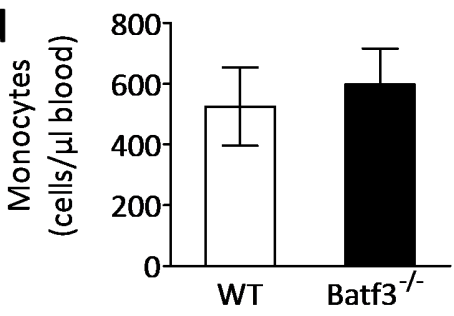

f

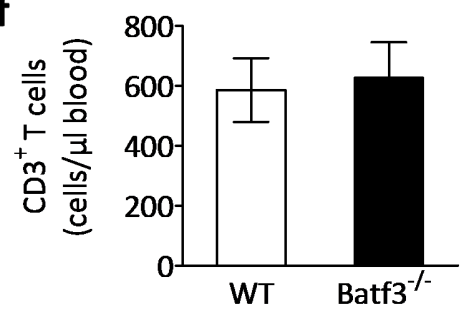

h

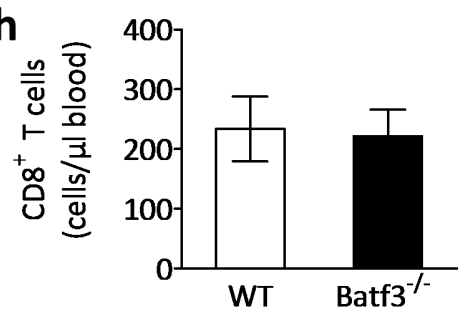

Supplementary Figure S3. Blood leukocyte patterns in wt and batf $3^{-/}$transplanted Idlir/- mice after 10 weeks of WTD

TruCount tubes and flow cytometry were used to determine exact cell numbers of (a) leukocytes $\left(\mathrm{CD} 45^{+}\right)$, (b) granulocytes $\left(\mathrm{CD} 11 \mathrm{~b}^{\text {high }} \mathrm{Ly}_{6 \mathrm{G}^{+}}\right)$, (c) NK cells $\left(\mathrm{CD} 3^{-} \mathrm{NK} 1.1^{+}\right)$, (d) monocytes (CD11 b $\left.{ }^{\text {high }} \mathrm{Ly6G}^{-}\right)$, (e) B cells $\left(B 220^{+}\right)$, (f) $\mathrm{T}$ cells $\left(\mathrm{CD} 3^{+} \mathrm{NK1.1}\right)$, (g) $\mathrm{CD}^{+} \mathrm{T}$ cells $\left(\mathrm{CD}^{+}{ }^{+} \mathrm{NK} 1.1^{-} \mathrm{CD} 4^{+}\right)$and $(\mathrm{h}) \mathrm{CD}^{+} \mathrm{T}^{-}$cells $\left(\mathrm{CD}^{+}{ }^{+} \mathrm{NK} 1.1^{-} \mathrm{CD} 8^{+}\right)$in wt and batf $3^{-\%}$ transplanted $/ d l r^{-/}$mice after 10 weeks of WTD $(n=8)$. Graphs show number of cells per microliter blood, and depict mean \pm SEM. 
$4 \mid \mathrm{CD} 8 \alpha^{+}$dendritic cells and cross-presentation in atherosclerosis

a

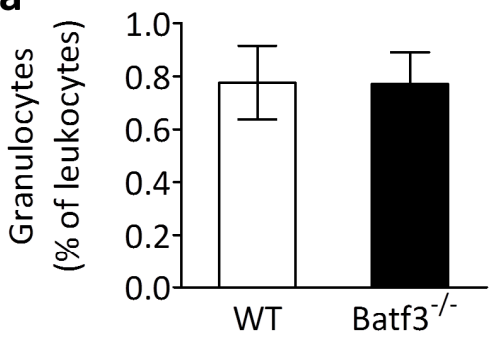

C

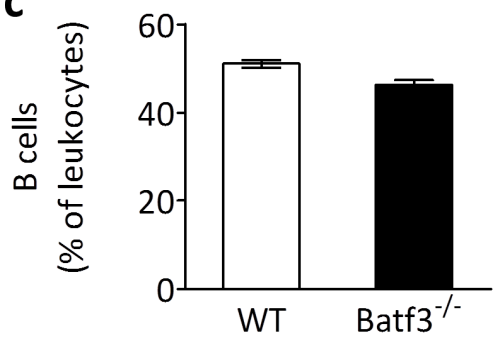

e

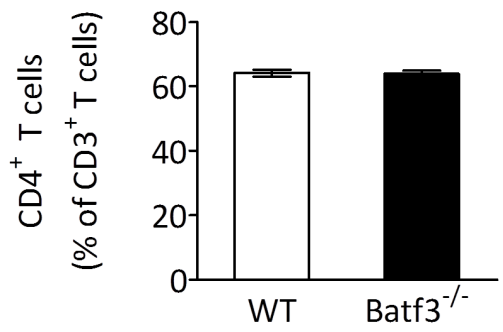

b

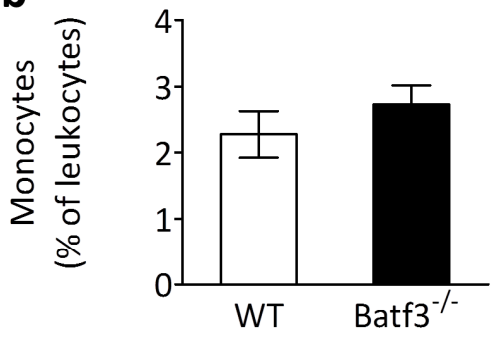

d

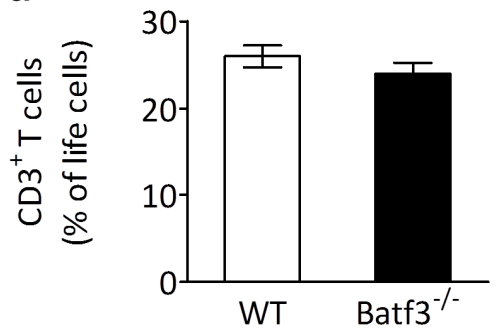

f

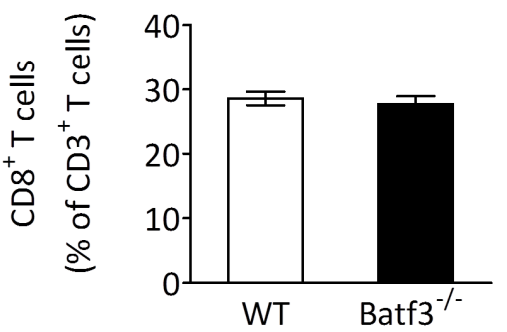

Supplementary Figure S4. Spleen leukocyte subset counts in wt and batf $3^{-/}$transplanted Idlr/ mice after 10 weeks of WTD

Splenic cell populations were determined by flow cytometry in wt and batf $3^{-1-}$ transplanted $I d r^{-1}$ mice after 10 weeks of WTD $(n=8)$ : (a) granulocytes (CD11 bigh Ly6G ${ }^{+}$), (b) monocytes (CD11 bigh Ly6G $^{-}$), (c) B cells $\left(B 220^{+}\right)$and (d) T cells (CD3 ${ }^{+}$NK1.1) are shown as percentage of leukocytes $\left(C D 45^{+}\right)$, (e) $C D 4^{+}$T cells $\left(C D 3^{+} N K 1.1^{-} C D 4^{+}\right)$and

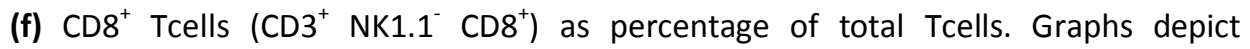
mean \pm SEM. 
a

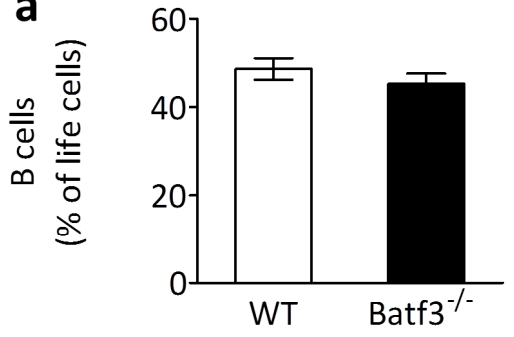

C

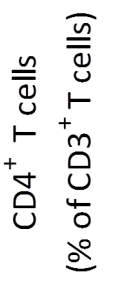

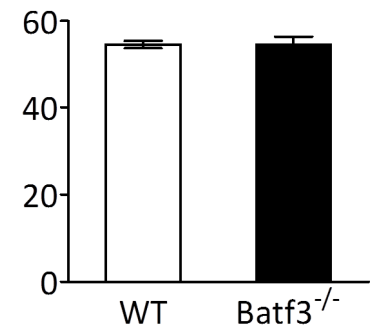

b

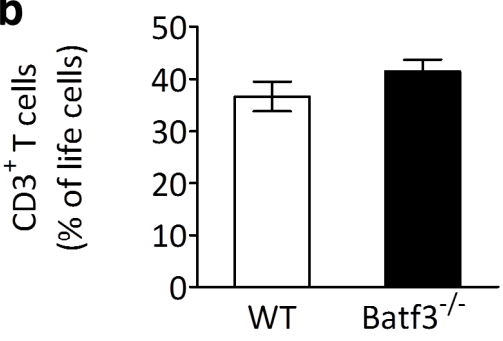

d

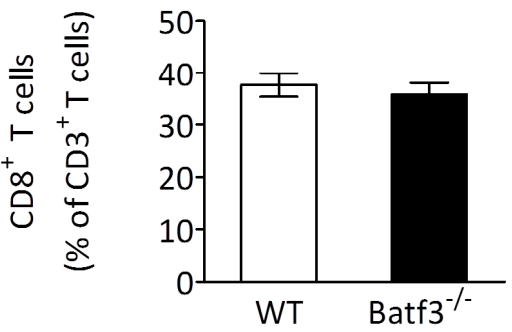

Supplementary Figure S5. Lymph node leukocyte subset distribution in wt and batf $^{-/-}$transplanted Idlr ${ }^{-/-}$mice after 10 weeks of WTD

Lymphocyte cell populations were determined in a mix of peripheral lymph nodes (axillary, mandibular, mesenteric) by flow cytometry in wt and batf $3^{-1}$ transplanted Idlr $r^{-/}$mice after 10 weeks of WTD ( $\left.n=8\right)$ : (a) B cells $\left(B 220^{+}\right)$and (b) T cells $\left(\mathrm{CD}^{+}\right.$NK1.1) are shown as percentage of life cells. (c) $\mathrm{CD}^{+}{ }^{+}$cells $\left(\mathrm{CD}^{+} \mathrm{NK} 1.1^{-} \mathrm{CD} 4^{+}\right)$and

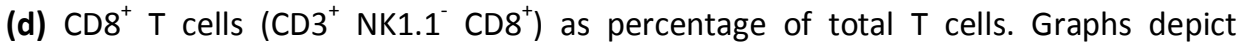
mean \pm SEM. 
4 | CD8 $\alpha^{+}$dendritic cells and cross-presentation in atherosclerosis

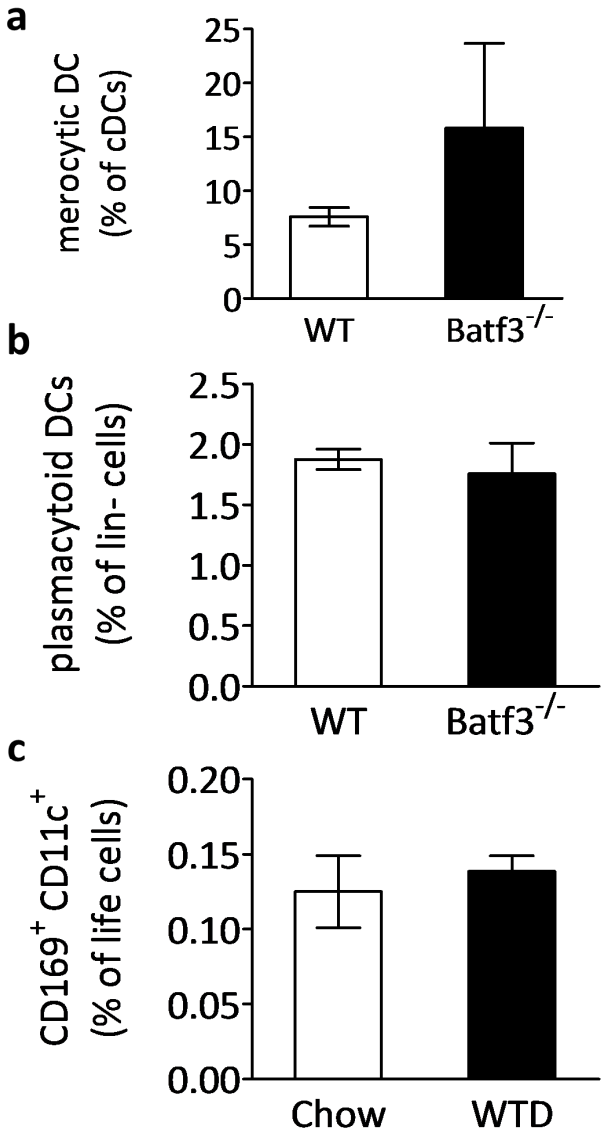

Supplementary Figure S6. Prevalence of other cross-presenting populations in batf $^{-/}$chimeric and wt $/ d r^{-/}$mice

(a, b) Splenocytes were analyzed by flow cytometry in batf $3^{-/}$chimeric and wt $/ d / r^{-/}$ mice after 10 weeks of WTD. Graphs depict (a) merocytic DCs as percentage of Lin CD11 $\mathrm{c}^{\text {high }} \mathrm{MHCII}^{\text {high }} \mathrm{cDCs}$, (b) pDCs as percentage of Lin $^{-}$cells. (c) $\mathrm{CD}_{169}{ }^{+} \mathrm{CD} 11 \mathrm{c}^{+}$crosspresenting macrophages were compared in mice on chow and after being fed 3 weeks WTD. Data is presented as mean \pm SEM. 
a

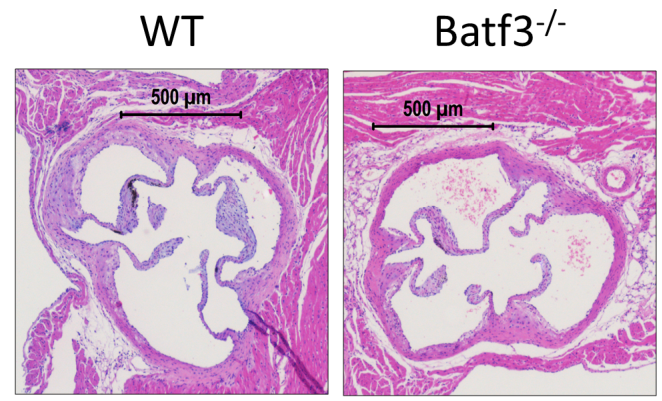

b

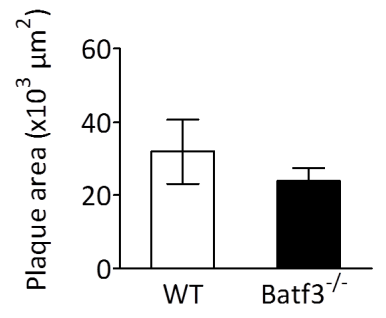

Supplementary Figure S7. Plaque analysis in wt and batf $3^{-/}$transplanted $/ d l r^{-/}$mice on normal chow diet

(a) Representative H\&E stainings and (b) measurements of plaque area, are shown for aortic root plaques of wt $(n=3)$ and batf $3^{--}(n=4)$ transplanted $/ d l r^{--}$mice. Data is presented as mean \pm SEM. 
a
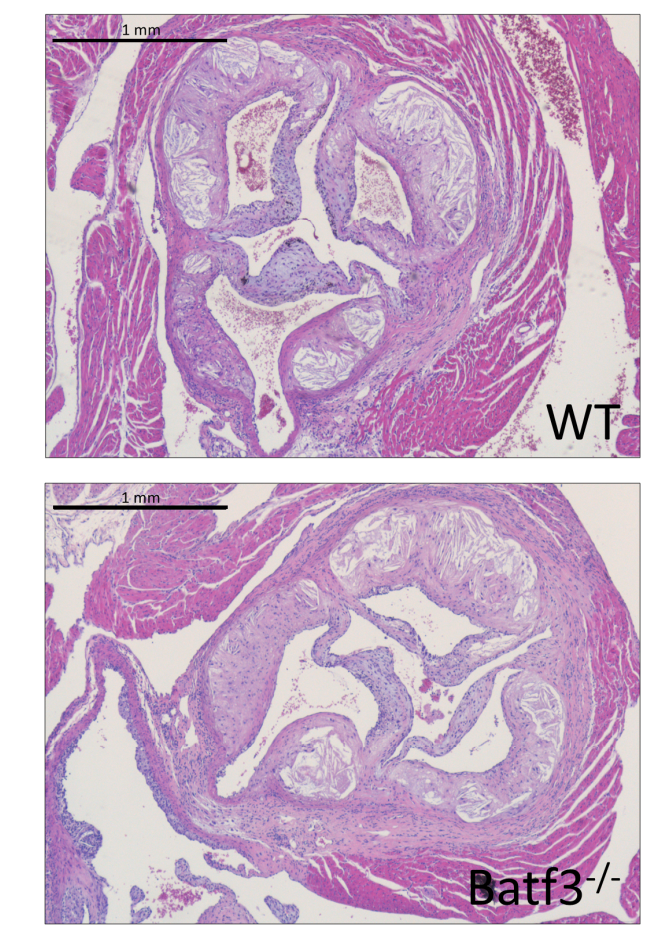

C

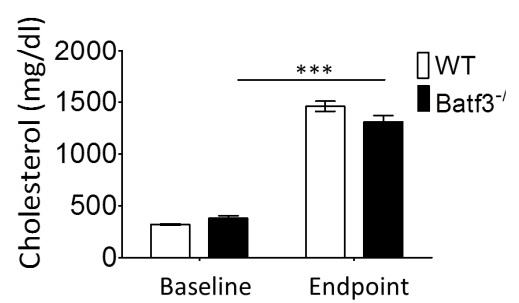

b
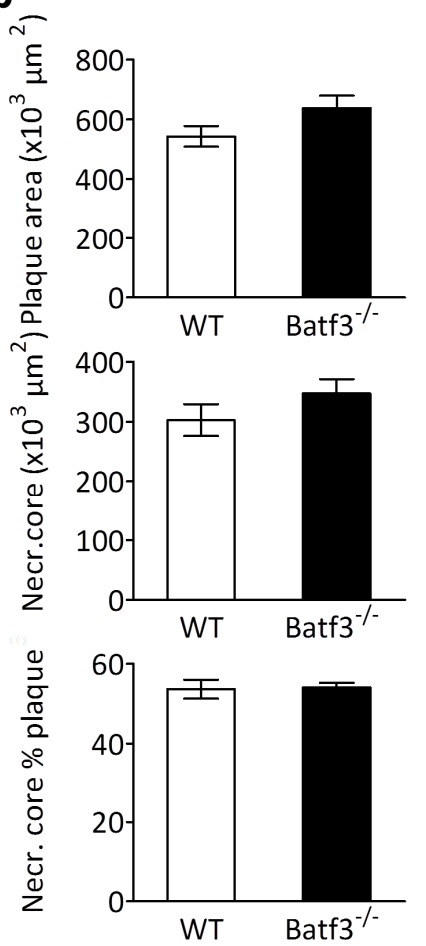

d

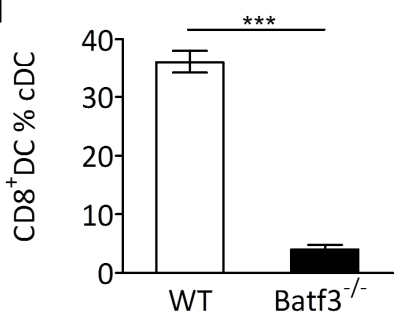

Supplementary Figure S8. Plaque analysis, plasma cholesterol and $C D 8 \alpha^{+} \mathrm{DC}$ depletion in wt and batf $3^{-/-}$transplanted $/ d / r^{-/-}$mice of the Cincinnati study

(a) Representative H\&E stainings and (b) measurements of plaque area, necrotic core size and percentage necrotic core relative to plaque area are shown for aortic root plaques of wt $(n=15)$ and batf3 $3^{--}(n=15)$ transplanted $/ d / r^{-/}$mice. (c) Cholesterol quantity in serum before start of Western Type Diet (baseline) and at sacrifice (endpoint) are shown for wt and batf3 ${ }^{-/}$chimeras. (d) Flow cytometry of splenocytes showing $\mathrm{CD} 8 \alpha^{+} \mathrm{DCs}$ as percentage of $\mathrm{CDCs}\left(\mathrm{Lin}^{-} \mathrm{CD} 11 \mathrm{c}^{\text {high }} \mathrm{MHClI}^{\text {high }}\right.$ ). Data are presented as mean $\pm \mathrm{SEM}, * * *$ : $p<0.001$. 

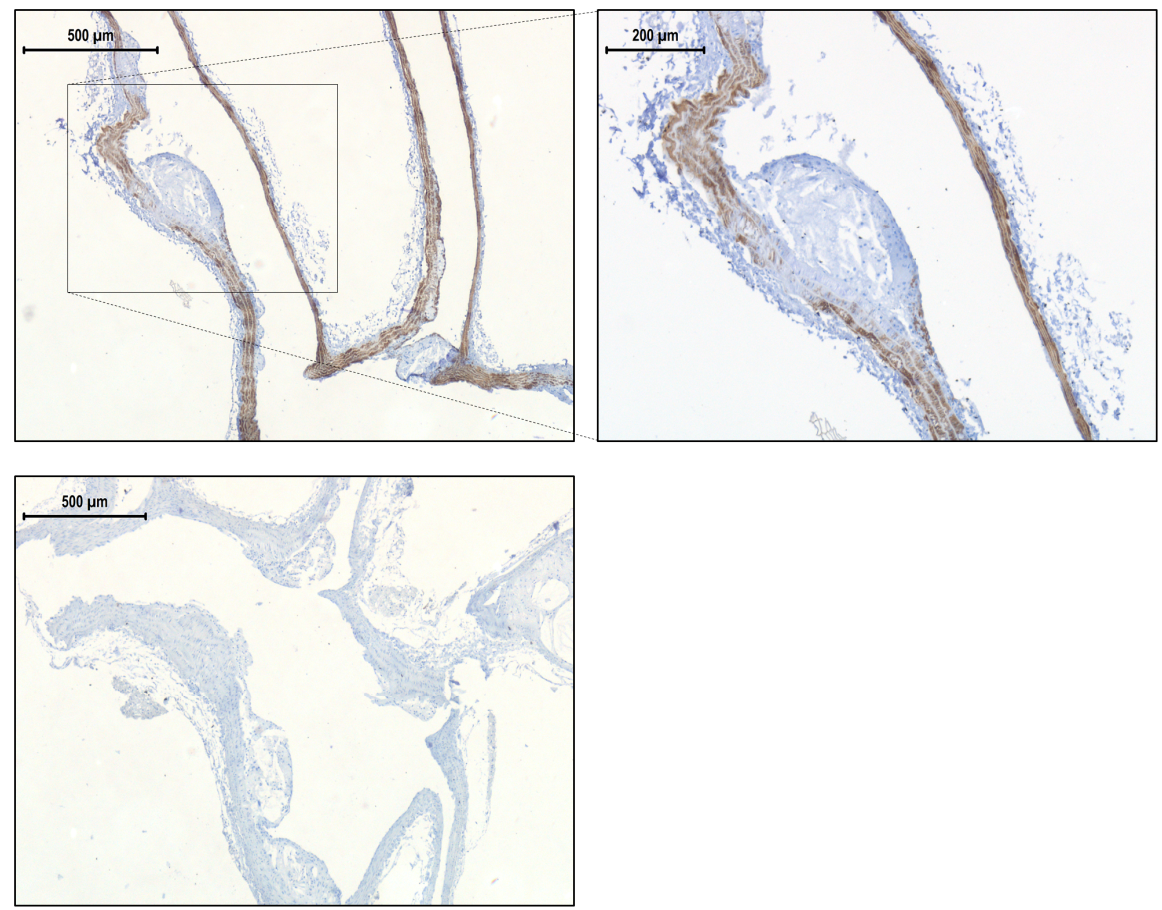

\section{Supplementary Figure S9. Staining control for $\alpha$ SMA immunohistochemistry}

Aortic arches of wt and batf3 $3^{--}$transplanted $/ d / r^{-/}$mice were taken along as staining controls for the aSMA immunohistochemistry performed on aortic root sections shown in Figure 6. Top panels: positive control showing clear $\alpha \mathrm{SMA}$ staining in the media, lower panel: negative isotope control. 


\section{Supplementary Table I: Primers for cross-presentation markers used in real-time PCR}

\begin{tabular}{|c|c|c|c|}
\hline Gene & NCBI Refseq ID & $\begin{array}{l}\text { Forward primer sequence } \\
\left(5^{\prime} \rightarrow 3^{\prime}\right)\end{array}$ & $\begin{array}{l}\text { Reverse primer sequence } \\
\left(5^{\prime} \rightarrow 3^{\prime}\right)\end{array}$ \\
\hline hTAP1 & NM_000593.5 & gcaagaaataaagacactcaacca & cccactttcagcagcatacc \\
\hline hADFP & NM_001122.3 & tcagctccattctactgttcacc & cctgaattttctgattggcact \\
\hline hBDCA3 & NM_000361.2 & aattgggagcttgggaatg & tgaggacctgattaaggctagg \\
\hline hIRF8 & NM_002163.2 & gaggtggtccaggtcttcg & cggccctggctgttatag \\
\hline hNecl2 & NM_014333.3 & gagttaacatgtgaagccatcg & cgactctcacccaagttacca \\
\hline hBatf3 & NM_018664.2 & cagcgtcctgcagaggag & cttcggaccttcctgtcatc \\
\hline hRab11b & NM_004218.3 & gcattcaagaacatcctcacag & tgatgtccaccacgttgttc \\
\hline $\mathrm{h} \beta$-actin & NM_001101.3 & tcacccacatgtgcccatctacga & cagcggaaccgctcattgccaatgg \\
\hline mRab11b & ENSMUST00000172894.1 & ggaggttggtaggatggaca & gcggtttcgatctctgaagt \\
\hline mTAP1 & ENSMUST00000171148.1 & gggtgaggcccagaagtt & gcagcattcccgagacac \\
\hline mXCR1 & NM_011798.4 & ctcaacctgtgtctctcagacct & aaccaactccattgtgctga \\
\hline
\end{tabular}

\section{Acknowledgements}

This study was cofunded by the National Institutes of Health via National Cancer Institute grant CA138617 (E.M.J.) and by a Charlotte Schmidlapp Award (E.M.J.). B.L. received a Boehringer Ingelheim Travel Grant to perform experiments in Cincinnati. 
References

1. Hansson GK, Libby P. The immune response in atherosclerosis: A double-edged sword. Nature reviews. Immunology. 2006;6:508-519

2. Galkina E, Ley K. Immune and inflammatory mechanisms of atherosclerosis (*). Annual review of immunology. 2009;27:165-197

3. Sancho D, Joffre OP, Keller AM, Rogers NC, Martinez D, Hernanz-Falcon P, Rosewell I, Reis e Sousa C. Identification of a dendritic cell receptor that couples sensing of necrosis to immunity. Nature. 2009;458:899-903

4. Sancho D, Mourao-Sa D, Joffre OP, Schulz O, Rogers NC, Pennington DJ, Carlyle JR, Reis e Sousa C. Tumor therapy in mice via antigen targeting to a novel, dc-restricted c-type lectin. The Journal of clinical investigation. 2008;118:2098-2110

5. Bevan MJ. Cross-priming for a secondary cytotoxic response to minor $h$ antigens with h-2 congenic cells which do not cross-react in the cytotoxic assay. The Journal of experimental medicine. 1976;143:1283-1288

6. Shortman K, Heath WR. The cd8+ dendritic cell subset. Immunological reviews. 2010;234:18-31

7. van der Aa E, van Montfoort N, Woltman AM. Bdca3clec9a human dendritic cell function and development. Seminars in cell \& developmental biology. 2014

8. Villadangos JA, Shortman K. Found in translation: The human equivalent of mouse cd8+ dendritic cells. The Journal of experimental medicine. 2010;207:1131-1134

9. Poulin LF, Salio M, Griessinger E, Anjos-Afonso F, Craciun L, Chen JL, Keller AM, Joffre O, Zelenay S, Nye E, Le Moine A, Faure F, Donckier V, Sancho D, Cerundolo V, Bonnet $D$, Reis e Sousa C. Characterization of human dngr-1+ bdca3+ leukocytes as putative equivalents of mouse cd8alpha+ dendritic cells. The Journal of experimental medicine. 2010;207:1261-1271

10. Jongbloed SL, Kassianos AJ, McDonald KJ, Clark GJ, Ju X, Angel CE, Chen CJ, Dunbar PR, Wadley RB, Jeet V, Vulink AJ, Hart DN, Radford KJ. Human cd141+ (bdca-3)+ dendritic cells (dcs) represent a unique myeloid dc subset that cross-presents necrotic cell antigens. The Journal of experimental medicine. 2010;207:1247-1260

11. Bachem A, Guttler S, Hartung E, Ebstein F, Schaefer M, Tannert A, Salama A, Movassaghi K, Opitz C, Mages HW, Henn V, Kloetzel PM, Gurka S, Kroczek RA. Superior antigen cross-presentation and $\mathrm{xcr} 1$ expression define human cd11c+cd141+ cells as homologues of mouse cd8+ dendritic cells. The Journal of experimental medicine. 2010;207:1273-1281

12. Crozat K, Guiton R, Contreras V, Feuillet V, Dutertre CA, Ventre E, Vu Manh TP, Baranek T, Storset AK, Marvel J, Boudinot P, Hosmalin A, Schwartz-Cornil I, Dalod M. The $\mathrm{xc}$ chemokine receptor 1 is a conserved selective marker of mammalian cells homologous to mouse cd8alpha+ dendritic cells. The Journal of experimental medicine. 2010;207:1283-1292

13. Niessner A, Weyand CM. Dendritic cells in atherosclerotic disease. Clinical immunology. 2010;134:25-32

14. Roselaar SE, Kakkanathu PX, Daugherty A. Lymphocyte populations in atherosclerotic lesions of apoe -/- and Idl receptor -/- mice. Decreasing density with disease progression. Arteriosclerosis, thrombosis, and vascular biology. 1996;16:1013-1018

15. Zhou X, Stemme S, Hansson GK. Evidence for a local immune response in atherosclerosis. $\mathrm{Cd} 4+\mathrm{t}$ cells infiltrate lesions of apolipoprotein-e-deficient mice. The American journal of pathology. 1996;149:359-366 
16. Yilmaz A, Lochno M, Traeg F, Cicha I, Reiss C, Stumpf C, Raaz D, Anger T, Amann K, Probst T, Ludwig J, Daniel WG, Garlichs CD. Emergence of dendritic cells in ruptureprone regions of vulnerable carotid plaques. Atherosclerosis. 2004;176:101-110

17. Gewaltig J, Kummer M, Koella C, Cathomas G, Biedermann BC. Requirements for cd8 tcell migration into the human arterial wall. Human pathology. 2008;39:1756-1762

18. Grivel JC, Ivanova O, Pinegina N, Blank PS, Shpektor A, Margolis LB, Vasilieva E. Activation of $\mathrm{t}$ lymphocytes in atherosclerotic plaques. Arteriosclerosis, thrombosis, and vascular biology. 2011;31:2929-2937

19. Stemme S, Faber B, Holm J, Wiklund O, Witztum JL, Hansson GK. T lymphocytes from human atherosclerotic plaques recognize oxidized low density lipoprotein. Proceedings of the National Academy of Sciences of the United States of America. 1995;92:38933897

20. Ahrens S, Zelenay S, Sancho D, Hanc P, Kjaer S, Feest C, Fletcher G, Durkin C, Postigo A, Skehel M, Batista F, Thompson B, Way M, Reis e Sousa C, Schulz O. F-actin is an evolutionarily conserved damage-associated molecular pattern recognized by dngr-1, a receptor for dead cells. Immunity. 2012;36:635-645

21. Profumo E, Buttari B, Petrone L, Lacroce G, Tesori MC, Capoano R, Salvati B, Rigano R. Actin is a target of t-cell reactivity in patients with advanced carotid atherosclerotic plaques. Mediators of inflammation. 2013;2013:261054

22. Kyaw $T$, Winship A, Tay C, Kanellakis P, Hosseini H, Cao A, Li P, Tipping P, Bobik A, Toh $\mathrm{BH}$. Cytotoxic and proinflammatory $\mathrm{cd} 8+\mathrm{t}$ lymphocytes promote development of vulnerable atherosclerotic plaques in apoe-deficient mice. Circulation. 2013;127:10281039

23. Elhage R, Gourdy P, Brouchet L, Jawien J, Fouque MJ, Fievet C, Huc X, Barreira Y, Couloumiers JC, Arnal JF, Bayard F. Deleting tcr alpha beta+ or cd4+t lymphocytes leads to opposite effects on site-specific atherosclerosis in female apolipoprotein edeficient mice. The American journal of pathology. 2004;165:2013-2018

24. Kolbus D, Ljungcrantz I, Soderberg I, Alm R, Bjorkbacka H, Nilsson J, Fredrikson GN. Tap1-deficiency does not alter atherosclerosis development in apoe-/- mice. PloS one. 2012; 7:e33932

25. Fyfe Al, Qiao JH, Lusis AJ. Immune-deficient mice develop typical atherosclerotic fatty streaks when fed an atherogenic diet. The Journal of clinical investigation. 1994;94:2516-2520

26. Choi JH, Cheong C, Dandamudi DB, Park CG, Rodriguez A, Mehandru S, Velinzon K, Jung IH, Yoo JY, Oh GT, Steinman RM. Flt3 signaling-dependent dendritic cells protect against atherosclerosis. Immunity. 2011;35:819-831

27. Hildner K, Edelson BT, Purtha WE, Diamond M, Matsushita H, Kohyama M, Calderon B, Schraml BU, Unanue ER, Diamond MS, Schreiber RD, Murphy TL, Murphy KM. Batf3 deficiency reveals a critical role for cd8alpha+ dendritic cells in cytotoxic $t$ cell immunity. Science. 2008;322:1097-1100

28. Edelson BT, Kc W, Juang R, Kohyama M, Benoit LA, Klekotka PA, Moon C, Albring JC, Ise W, Michael DG, Bhattacharya D, Stappenbeck TS, Holtzman MJ, Sung SS, Murphy TL, Hildner K, Murphy KM. Peripheral cd103+ dendritic cells form a unified subset developmentally related to cd8alpha+ conventional dendritic cells. The Journal of experimental medicine. 2010;207:823-836

29. Virmani R, Kolodgie FD, Burke AP, Farb A, Schwartz SM. Lessons from sudden coronary death: A comprehensive morphological classification scheme for atherosclerotic lesions. Arteriosclerosis, thrombosis, and vascular biology. 2000;20:1262-1275

30. Sambrook J, Fritsch E, Maniatis T. Molecular cloning: A laboratory manual. Cold Spring Harbor, NY: Cold Spring Harbor Laboratory Press; 1989. 
31. Marsch E, Theelen TL, Demandt JA, Jeurissen $M$, van Gink $M$, Verjans $R$, Janssen $A$, Cleutjens JP, Meex SJ, Donners MM, Haenen GR, Schalkwijk CG, Dubois LJ, Lambin P, Mallat Z, Gijbels MJ, Heemskerk JW, Fisher EA, Biessen EA, Janssen BJ, Daemen MJ, Sluimer JC. Reversal of hypoxia in murine atherosclerosis prevents necrotic core expansion by enhancing efferocytosis. Arteriosclerosis, thrombosis, and vascular biology. 2014;34:2545-2553

32. Lutgens E, Gorelik L, Daemen MJ, de Muinck ED, Grewal IS, Koteliansky VE, Flavell RA. Requirement for cd154 in the progression of atherosclerosis. Nature medicine. 1999;5:1313-1316

33. Poulin LF, Reyal Y, Uronen-Hansson H, Schraml BU, Sancho D, Murphy KM, Hakansson UK, Moita LF, Agace WW, Bonnet D, Reis e Sousa C. Dngr-1 is a specific and universal marker of mouse and human batf3-dependent dendritic cells in lymphoid and nonlymphoid tissues. Blood. 2012;119:6052-6062

34. Bougneres L, Helft J, Tiwari S, Vargas P, Chang BH, Chan L, Campisi L, Lauvau G, Hugues $S$, Kumar P, Kamphorst AO, Dumenil AM, Nussenzweig M, MacMicking JD, Amigorena $\mathrm{S}$, Guermonprez P. A role for lipid bodies in the cross-presentation of phagocytosed antigens by mhc class $\mathrm{i}$ in dendritic cells. Immunity. 2009;31:232-244

35. Zelenay S, Keller AM, Whitney PG, Schraml BU, Deddouche S, Rogers NC, Schulz O, Sancho D, Reis e Sousa C. The dendritic cell receptor dngr-1 controls endocytic handling of necrotic cell antigens to favor cross-priming of ctls in virus-infected mice. The Journal of clinical investigation. 2012;122:1615-1627

36. Raghavan M, Del Cid N, Rizvi SM, Peters LR. Mhc class i assembly: Out and about. Trends in immunology. 2008;29:436-443

37. Ehst BD, Ingulli E, Jenkins MK. Development of a novel transgenic mouse for the study of interactions between $\mathrm{cd} 4$ and $\mathrm{cd} 8 \mathrm{t}$ cells during graft rejection. American journal of transplantation : official journal of the American Society of Transplantation and the American Society of Transplant Surgeons. 2003;3:1355-1362

38. Katz JD, Ondr JK, Opoka RJ, Garcia Z, Janssen EM. Cutting edge: Merocytic dendritic cells break $\mathrm{t}$ cell tolerance to beta cell antigens in nonobese diabetic mouse diabetes. Journal of immunology. 2010;185:1999-2003

39. Di Pucchio T, Chatterjee B, Smed-Sorensen A, Clayton S, Palazzo A, Montes M, Xue Y, Mellman I, Banchereau J, Connolly JE. Direct proteasome-independent crosspresentation of viral antigen by plasmacytoid dendritic cells on major histocompatibility complex class i. Nature immunology. 2008;9:551-557

40. Asano K, Nabeyama A, Miyake Y, Qiu CH, Kurita A, Tomura M, Kanagawa O, Fujii S, Tanaka M. Cd169-positive macrophages dominate antitumor immunity by crosspresenting dead cell-associated antigens. Immunity. 2011;34:85-95

41. Packard RR, Maganto-Garcia E, Gotsman I, Tabas I, Libby P, Lichtman AH. Cd11c(+) dendritic cells maintain antigen processing, presentation capabilities, and $\mathrm{cd} 4(+) \mathrm{t}$-cell priming efficacy under hypercholesterolemic conditions associated with atherosclerosis. Circulation research. 2008;103:965-973

42. Koltsova EK, Garcia Z, Chodaczek G, Landau M, McArdle S, Scott SR, von Vietinghoff S, Galkina E, Miller YI, Acton ST, Ley K. Dynamic t cell-apc interactions sustain chronic inflammation in atherosclerosis. The Journal of clinical investigation. 2012;122:31143126

43. Neuenhahn M, Busch DH. Unique functions of splenic cd8alpha+ dendritic cells during infection with intracellular pathogens. Immunology letters. 2007;114:66-72

44. Tussiwand R, Lee WL, Murphy TL, Mashayekhi M, Kc W, Albring JC, Satpathy AT, Rotondo JA, Edelson BT, Kretzer NM, Wu X, Weiss LA, Glasmacher E, Li P, Liao W, Behnke M, Lam SS, Aurthur CT, Leonard WJ, Singh H, Stallings CL, Sibley LD, Schreiber 
RD, Murphy KM. Compensatory dendritic cell development mediated by batf-irf interactions. Nature. 2012;490:502-507

45. Seillet C, Jackson JT, Markey KA, Brady HJ, Hill GR, Macdonald KP, Nutt SL, Belz GT. Cd8alpha+ dcs can be induced in the absence of transcription factors id2, nfil3, and batf3. Blood. 2013;121:1574-1583

46. Ljunggren HG, Glas R, Sandberg JK, Karre K. Reactivity and specificity of cd8+ t cells in mice with defects in the mhc class $\mathrm{i}$ antigen-presenting pathway. Immunological reviews. 1996;151:123-148

47. Schaible UE, Collins HL, Priem F, Kaufmann SH. Correction of the iron overload defect in beta-2-microglobulin knockout mice by lactoferrin abolishes their increased susceptibility to tuberculosis. The Journal of experimental medicine. 2002;196:15071513

48. Araujo JA, Romano EL, Brito BE, Parthe V, Romano M, Bracho M, Montano RF, Cardier J. Iron overload augments the development of atherosclerotic lesions in rabbits. Arteriosclerosis, thrombosis, and vascular biology. 1995;15:1172-1180

49. Mackarehtschian K, Hardin JD, Moore KA, Boast S, Goff SP, Lemischka IR. Targeted disruption of the $f|k 2 / f| t 3$ gene leads to deficiencies in primitive hematopoietic progenitors. Immunity. 1995;3:147-161

50. McKenna HJ, Stocking KL, Miller RE, Brasel K, De Smedt T, Maraskovsky E, Maliszewski CR, Lynch DH, Smith J, Pulendran B, Roux ER, Teepe M, Lyman SD, Peschon JJ. Mice lacking flt3 ligand have deficient hematopoiesis affecting hematopoietic progenitor cells, dendritic cells, and natural killer cells. Blood. 2000;95:3489-3497

51. Gewaltig J, Kummer M, Koella C, Cathomas G, Biedermann BC. Requirements for cd8 tcell migration into the human arterial wall. Hum Pathol. 2008;39:1756-1762

52. Daissormont IT, Christ A, Temmerman L, Sampedro Millares S, Seijkens T, Manca M, Rousch $M$, Poggi $M$, Boon L, van der Loos C, Daemen $M$, Lutgens $E$, Halvorsen $B$, Aukrust $P$, Janssen $E$, Biessen EA. Plasmacytoid dendritic cells protect against atherosclerosis by tuning t-cell proliferation and activity. Circulation research. 2011;109:1387-1395

53. Doring $Y$, Manthey HD, Drechsler M, Lievens D, Megens RT, Soehnlein O, Busch $M$, Manca M, Koenen RR, Pelisek J, Daemen MJ, Lutgens E, Zenke M, Binder CJ, Weber C, Zernecke A. Auto-antigenic protein-DNA complexes stimulate plasmacytoid dendritic cells to promote atherosclerosis. Circulation. 2012;125:1673-1683

54. Miyake $\mathrm{Y}$, Asano K, Kaise H, Uemura M, Nakayama M, Tanaka M. Critical role of macrophages in the marginal zone in the suppression of immune responses to apoptotic cell-associated antigens. The Journal of clinical investigation. 2007;117:22682278

55. Torti N, Walton SM, Murphy KM, Oxenius A. Batf3 transcription factor-dependent dc subsets in murine $\mathrm{cmv}$ infection: Differential impact on t-cell priming and memory inflation. European journal of immunology. 2011;41:2612-2618

56. Buckwalter MR, Srivastava PK. Mechanism of dichotomy between cd8+ responses elicited by apoptotic and necrotic cells. Cancer immunity. 2013;13:2

57. Luckashenak N, Schroeder S, Endt K, Schmidt D, Mahnke K, Bachmann MF, Marconi P, Deeg CA, Brocker T. Constitutive crosspresentation of tissue antigens by dendritic cells controls cd8+t cell tolerance in vivo. Immunity. 2008;28:521-532

58. Steinman RM, Hawiger D, Nussenzweig MC. Tolerogenic dendritic cells. Annual review of immunology. 2003;21:685-711

59. Hermansson A, Johansson DK, Ketelhuth DF, Andersson J, Zhou X, Hansson GK. Immunotherapy with tolerogenic apolipoprotein b-100-loaded dendritic cells 
attenuates atherosclerosis in hypercholesterolemic mice. Circulation. 2011;123:10831091

60. Habets KL, van Puijvelde GH, van Duivenvoorde LM, van Wanrooij EJ, de Vos P, Tervaert JW, van Berkel TJ, Toes RE, Kuiper J. Vaccination using oxidized low-density lipoprotein-pulsed dendritic cells reduces atherosclerosis in Idl receptor-deficient mice. Cardiovascular research. 2010;85:622-630

61. Buono C, Binder CJ, Stavrakis G, Witztum JL, Glimcher LH, Lichtman AH. T-bet deficiency reduces atherosclerosis and alters plaque antigen-specific immune responses. Proceedings of the National Academy of Sciences of the United States of America. 2005;102:1596-1601 
Anette Christ*

Bart Legein*

Tammy Oth

Erwin Wijnands

Joris Vanderlocht

Martin Zenke

Mat J.A.P Daemen

Erik. A.L. Biessen 
This chapter is embargoed at request

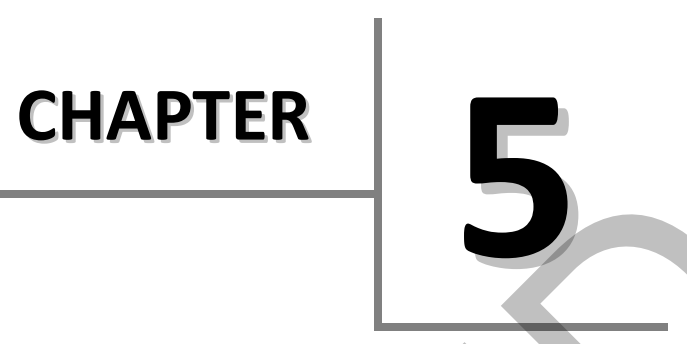

Low density lipoprotein exposure interferes with TLR7 and 9 induced plasmacytoid dendritic cell activation

- in preparation -

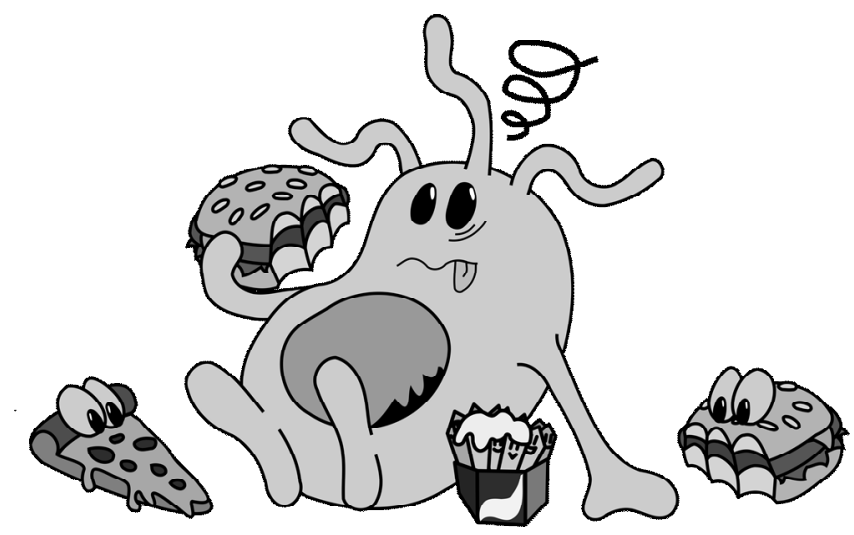


Early adaptive effects of peripheral dendritic cell subsets to hyperlipidemia: impact on phenotype and capacity to prime naïve $T$ cells

- in preparation -

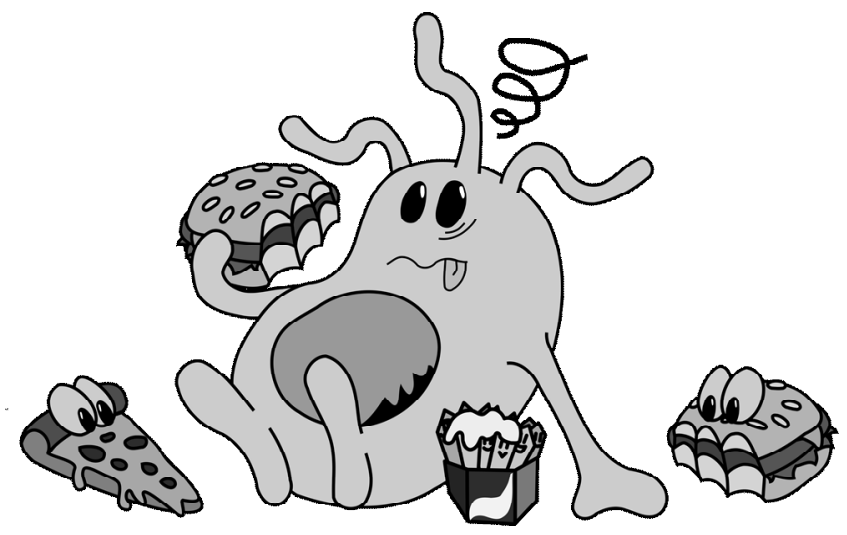


This chapter is embargoed at request

\section{CHAPTER}

Quaking deficiency in CD11c dendritic cells attenuates atherosclerosis by shifting CD4 to CD8 $T$ cell balance and favoring CD4 $T$ cell polarization towards a regulatory phenotype

- in preparation -

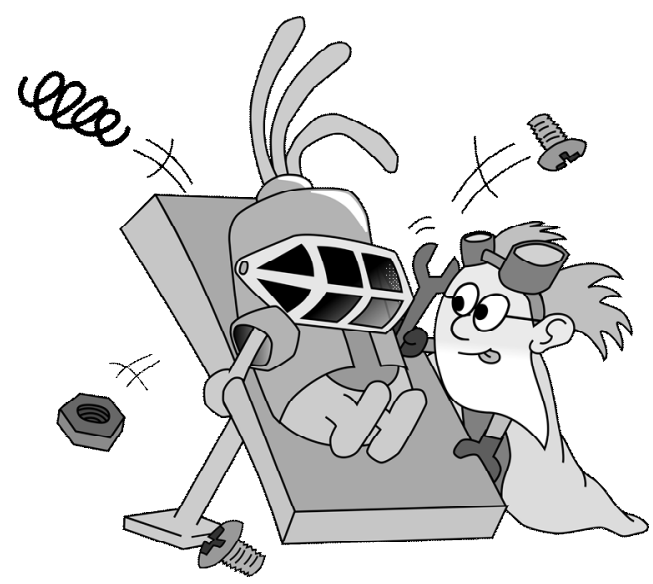




\section{CHAPTER}

Constitutively active Dendritic Cell CD40signaling paradoxically retards atherosclerosis due to GI-tract inflammation and ensuing cholesterol lowering

- in preparation -

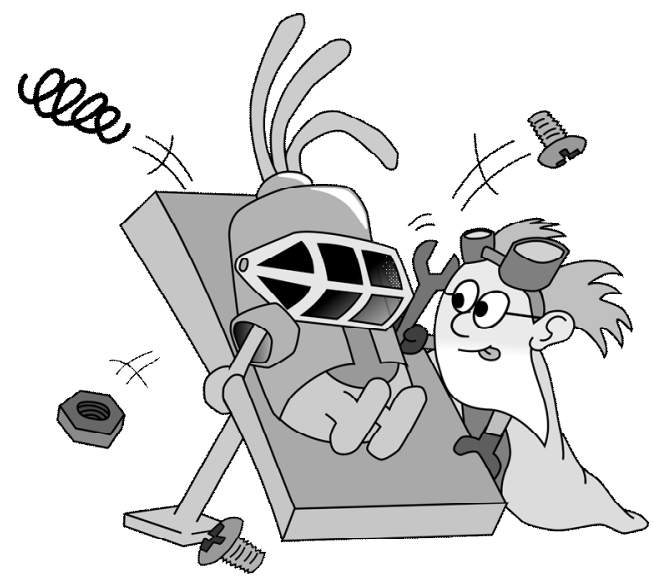




\section{Abstract}

The co-stimulatory molecule CD40 is a major driver of atherosclerosis. It is expressed on a wide variety of cell types, amongst which mature dendritic cells (DCs), and is required for optimal $T$ cell activation and expansion, an important process in atherosclerosis. It remains to be determined if and how CD40 on DCs impacts the pathogenesis of this disease. Here, we examined the effects of constitutively active CD40 in DCs on atherosclerosis, using $\mathrm{Idll}^{-/}$ chimeras that express an engineered latent membrane protein 1 (LMP), /CD40 fusion protein conferring constitutive CD40 signaling, under the DC specific CD11c promoter (CD4OCa) and wild-type littermates (CD4Owt) served as controls. As expected, DCs of CD4Oca $l d l r^{-/}$chimeras show increased antigen presenting capacity and $\mathrm{T}$ cell numbers, but develop extensive neutrophilia. Despite overt T-cell expansion and neutrophilia, we observed a profound, 8.8fold reduction in atherosclerosis $\left(22.080 \pm 3.763 \mu \mathrm{m}^{2}\right.$ vs $2.511 \pm 1.256 \mu \mathrm{m}^{2}$, $\mathrm{p}=0.0004)$. Further study revealed that cholesterol and triglyceride levels had decreased by $36 \%$ and $37 \%$, in CD40 ca Idlr $^{-/}$chimeras, as well as indicated gastrointestinal tract inflammation, characterized by massive influx of leukocytes into the muscularis externa, submucosa, and, in some cases, in the mucosa, resulting in villous degeneration. In conclusion, constitutive activation of CD40 in dendritic cells results in inflammation of the gastrointestinal tract, thereby impairing lipid uptake, which consequently results in attenuated atherosclerosis. 


\section{Introduction}

Atherosclerosis is a lipid-driven inflammatory disease, and is characterized by accumulations of lipids and immune cells, i.e. plaques, in the arterial intima ${ }^{(1,2)}$. In the past few years, dendritic cells (DCs) have been recognized to play an important role in atherogenesis. DCs were found to be present in atherosclerosis-prone areas of healthy aortas, and to accumulate at this location at onset of atherosclerosis ${ }^{(3)}$. Upon antigen exposure, DCs upregulate $\mathrm{MHCll}$, as well as the co-stimulatory molecules CD40, CD80 and CD86 ${ }^{(4)}$. Moreover, antigens derived from lipoproteins, more in particular ApoB100, are internalized in DCs and can subsequently be presented via MHC complexes, thereby activating naïve $T$ cells ${ }^{(5,6)}$. Activated $\mathrm{CD} 4^{+} \mathrm{T}$ cells of the Th1 type and $C D 8^{+}$T cells are well known drivers of atherosclerosis ${ }^{(1,7)}$.

Co-stimulatory molecules are crucial for antigen presentation associated priming of $T$ cells ${ }^{(8,9)}$. The co-stimulatory molecule CD40 is constitutively expressed on DCs, and is strongly upregulated upon encounter of antigen and subsequent DC maturation. Upon interaction with T-cell CD40L, both $\mathrm{CD}^{+}$and $\mathrm{CD}^{+} \mathrm{T}$ cells expand and polarize, often with concomitant generation of Tregs ${ }^{(10)}$.

Previously, we, and others have demonstrated the importance of CD40 and CD40L for atherosclerosis. Inhibition of CD40-CD40L interactions not only led to reduced atherosclerosis, but also was seen to induce a favorable fibrotic plaque phenotype that only contains few immune cells and small necrotic cores ${ }^{(11-14)}$. However the relative contribution of CD40 expression by DCs to atherosclerosis remains unclear. Here, we have investigated the role of constitutively active CD40 signaling in DCs in atherosclerosis, using the $c d 11 c$ CD40ca mouse, which express engineered latent membrane protein 1 (LMP)CD40 fusion protein, which confers constitutive activation of CD40 signaling, under the DC specific CD11c promoter. 


\section{Materials and Methods}

\section{Animals}

Cd11c-CD40ca mice (further referred to as CD40ca) were generated at the Ludwig Maximilians University, Munich by breeding cd11c-cre mice to $L M P / c d 40 f^{\text {stop }}$ mice which express a loxP-flanked stop-codon protected latent membrane protein 1 (LMP1)/CD40 chimeric protein from the Rosa26 locus. The LMP1/CD40-fusion protein consists of the signaling domain of CD40 and the transmembrane domain of LMP1. It has previously been shown that expression of this chimeric LMP/CD40 fusion protein in B cells leads to constitutive CD40 signaling ${ }^{(15,16)}$. Male $/ d / r^{-/-}$mice (The Jackson laboratories) $(n=30)$ were bred and housed at the animal facility of the Academic Medical Center, Amsterdam. All study protocols were approved by the committee for Animal Welfare of the University of Amsterdam.

\section{Bone marrow transplantation}

CD40ca and CD40wt mice $(n=4)$ were sacrificed and bone marrow from femurs and tibias was harvested in ice cold PBS, and subsequently diluted in RPMI medium containing $5 \mathrm{U} / \mathrm{ml}$ of heparin (Heparin Leo). Recipient $/ d / r^{-/}$mice $(n=30)$ were housed in filter top cages and received drinking water containing antibiotics (polymixin B sulfate, $60000 \mathrm{U} / \mathrm{L}$ and neomycin, $100 \mathrm{mg} / \mathrm{L}$ ) starting 1 week before the bone marrow transplantation. Recipient mice were sublethally irradiated on two consecutive days (2x $6 \mathrm{~Gy})$. After the second irradiation, each $I d / r^{-/-}$recipient received $2 \times 10^{6}$ bone marrow cells of either CD40ca or CD40wt mice. After a 6-week recovery period, chimeric $/ d / r^{-/}$mice were fed a high cholesterol diet $(0.15 \%$ cholesterol, $16 \%$ fat, Hope Farms) for 6 weeks.

\section{Hematology, lipoproteins \& autopsy}

Blood was obtained by cardiac puncture and collected into EDTA containing tubes. Hematological parameters (cell counts, hemoglobin $(\mathrm{Hb})$, hematocrite $(\mathrm{Ht})$ ) were determined using a Scilvet abc plus (Scilvet). Cholesterol and triglyceride levels were determined according to manufacturer's protocols (CHOD-PAP, Roche Diagnostics). Autopsy was performed and $>20$ organs were analyzed macroscopically and microscopically on $4 \mu \mathrm{m}$, paraffin embedded, hematoxylin \& eosin (HE) stained sections. 


\section{Flow cytometry}

Spleen and lymph nodes were harvested in ice cold PBS. Single cell suspensions were prepared and filtered through a $70 \mu \mathrm{m}$ mesh. Spleens were digested using $1 \mathrm{mg} / \mathrm{ml}$ collagenase $\mathrm{D}$ (Roche) and $20 \mu \mathrm{g} / \mathrm{ml}$ DNase I (Roche). Blood and spleens were treated with red blood cell lysis buffer. Staining against CD45, CD3, CD4, CD8, CD44, CD62L, FoxP3, CD25, CD11C, MHClI, CD80 was performed using anti-mouse antibodies (BD Bioscience, Biolegend). Nonspecific binding was prevented using the Fc receptor blocking antibody $\mathrm{CD} 16 / 32$ (BD Bioscience). Intracellular staining was performed using the Fixation/Permeabilization Solution kit (BD bioscience). Flow cytometry was performed using a FACS Canto II (BD Bioscience).

\section{Atherosclerosis}

Upon sacrifice, aortic roots and aortic arches containing its main branch points were dissected, fixed in $1 \%$ paraformaldehyde, processed and sectioned. Twenty consecutive sections were selected for histological analysis, and stained for $\mathrm{HE}$, picrosirius red, CD3 (AbD Serotec) or CD68 (Abcam). Morphometric analyses were performed using the Las4.1 software (Leica), as described before ${ }^{(14)}$. 


\section{Results}

Constitutive overexpression of CD40-signaling in DCs reduces atherosclerosis

During the $6 \mathrm{wk}$ high cholesterol diet feeding period, 4 out of 15 CD40ca Idlrt- chimeras died or had to be sacrificed at the $4^{\text {th }}$ week of diet feeding because of wasting syndrome and excessive weight loss ( $>8 \%$ body weight in one week) (Figure 1A). None of the wild type chimeras died. At sacrifice, body weights of the remaining CD4Oca Idlr- chimeras did not differ significantly compared to the CD4Owt Idlr $r^{-/}$chimeras (Figure 1A). However, plasma cholesterol and triglyceride levels were significantly reduced by $37 \%$ and $36 \%$, respectively in these mice (Figure $1 \mathrm{~B}$ ).

Consistent with the decrease in plasma cholesterol and triglyceride levels, atherosclerotic plaque area in the aortic root was profoundly decreased by 8.7 fold in $\mathrm{CD} 40 \mathrm{Ca} / \mathrm{d} / \mathrm{r}^{-/}$chimeras, indicating lesion progression was reduced in these mice (data not shown). Comparing root plaque areas of mice with equivalent cholesterol levels, revealed that CD4Oca $/ \mathrm{dll} \mathrm{r}^{-/}$chimeras still displayed a decrease in aortic root plaque area by 2.3 fold

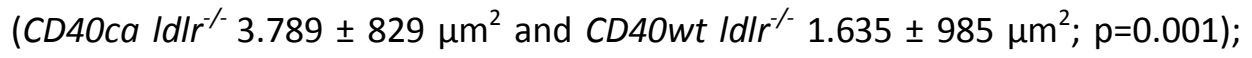
and similar findings were obtained when adjusting for differences in triglyceride levels (Supplementary Figure S1), suggesting that constitutive overexpression of CD40 on DCs exerts beneficial effects on atherosclerosis in addition to its cholesterol lowering (Figure 1D). A similar atheroprotective effect was observed in the aortic arch, with 3.5 fold smaller plaques compared

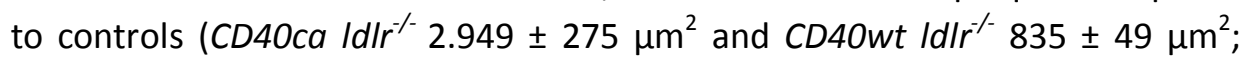
$\mathrm{p}=0.001$ ) (Figure 1D). Of note, the aortic arch only contained very small intimal xanthomas at this stage. Both number and size of individual lesions per aortic arch were decreased in the CD40 ca Idlr ${ }^{-/}$compared to CD4Owt Idlr $r^{-/}$chimeras (data not shown).

Regarding plaque composition, initial lesions in the aortic arches mainly contained macrophages and were devoid of T cells or collagen in either genotype (data not shown). In the aortic root collagen $\left(2,29 \pm 0,04 \mu \mathrm{m}^{2}\right.$ and $\left.3.56 \pm 0.18 \mu \mathrm{m}^{2}, \mathrm{p}=0.87\right)$ and macrophages $\left(97,33 \pm 3,29 \mu \mathrm{m}^{2}\right.$ and $\left.96,54 \pm 6.94 \mu \mathrm{m}^{2}, \mathrm{p}=0.90\right)$ were observed with no relative difference between the genotypes, whereas T cells were not present in the lesions (data not shown). 

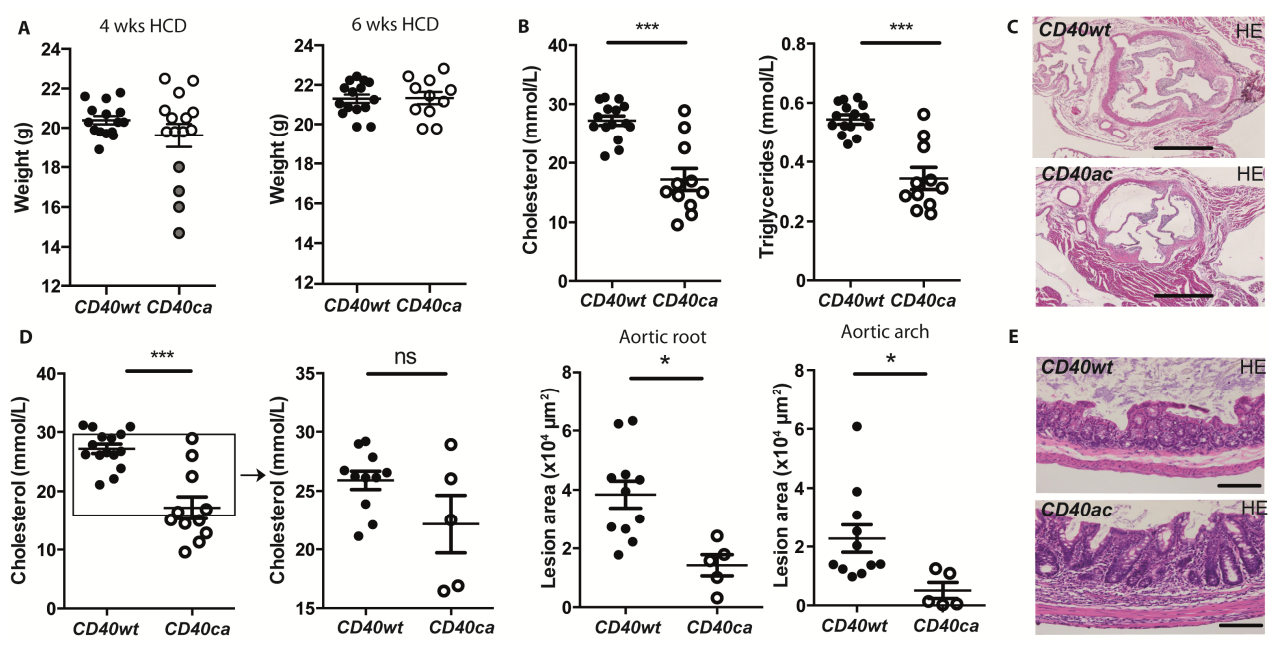

Figure 1. Constitutive overexpression of CD40-signaling in DCs reduces atherosclerosis

(A) Body weight of CD4Owt $(n=15)$ and CD4Oca $(n=15) / d l r^{-/}$chimeras upon 4 weeks (left panel) and 6 weeks (right panel) of high cholesterol diet (HCD), grey circles represent sick mice. (B) Cholesterol (left panel) and triglyceride (right panel) level of CD40wt $(\mathrm{n}=15)$ and CD40ca $(\mathrm{n}=11) / \mathrm{d} / \mathrm{r}^{-/}$chimeras. (C) Representative photos of hematoxylin and eosin stained aortic roots of CD4Owt and CD40ca Idlr/- chimeras. Bars represent $500 \mu \mathrm{m}$. (D) Mice with comparable cholesterol levels were selected from CD40wt $(\mathrm{n}=11)$ and CD40ca $(\mathrm{n}=5) / \mathrm{d} / \mathrm{r}^{-/-}$chimeras (left panels) to analyze atherosclerotic lesion formation independent of cholesterol level. Lesion formation in hematoxylin and eosin stained sections from aortic arch and root was quantified from the selected mice (right panels). (E) Representative photos of hematoxylin and eosin stained cecum specimens from CD4Owt and CD4Oca ldlr $r^{-/}$chimeras. Error bars represent $100 \mu \mathrm{m}$. mean \pm SEM. ${ }^{*}, \mathrm{p}<0.05 ; * * *, \mathrm{p}<0.001$.

\section{Constitutive overexpression of CD40-signaling in DCs causes neutrophilia, DC and T-cell activation}

CD4Oca $/ \mathrm{dlr}^{-/}$chimeras developed leukocytosis (Figure 2A) and flow cytometry analysis of blood and lymphoid organs indicated that this was attributable to pronounced neutrophilia, accompanied by an increase in the number of Ly6C $\mathrm{C}^{\text {high }}$ monocytes (Figure 2B, C). Spleens and LNs of CD40ac $/ \mathrm{dll}^{-1}$ chimeras had reduced numbers of $\mathrm{CD} 11 \mathrm{c}^{+} \mathrm{MHCII}^{+} \mathrm{DCs}$ (Figure 2D), with a shift from CD8 CD4 DCs (CD40wt Idlr/ 35,14 \pm 0.76 of DCs and

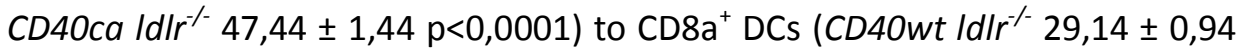
of DCs and CD40ac Idl $\left.r^{-1} 17,27 \pm 1,26 \mathrm{p}<0,0001\right)$ (data not shown) ${ }^{(17)}$. 
Interestingly, the $\mathrm{CD}^{+} \mathrm{DC}$ skewed $\mathrm{DC}$ differentiation was not mirrored by a shift in CD4/CD8 $T$ cell balance. Compatible with the constitutive CD40 signaling of the CD4Oca, DCs of CD40ca Idlr/- chimeras were more activated as judged by the increased CD40 and CD80 expression. This was paralleled by an increase in $\mathrm{CD}_{4} 4^{+} \mathrm{CD} 62 \mathrm{~L}^{-}$effector memory $\mathrm{CD}^{+} \mathrm{T}$-cells (Figure $2 \mathrm{E}, \mathrm{F}$ ) and of $\mathrm{CD} 8^{+} \mathrm{T}$ cells (data not shown).
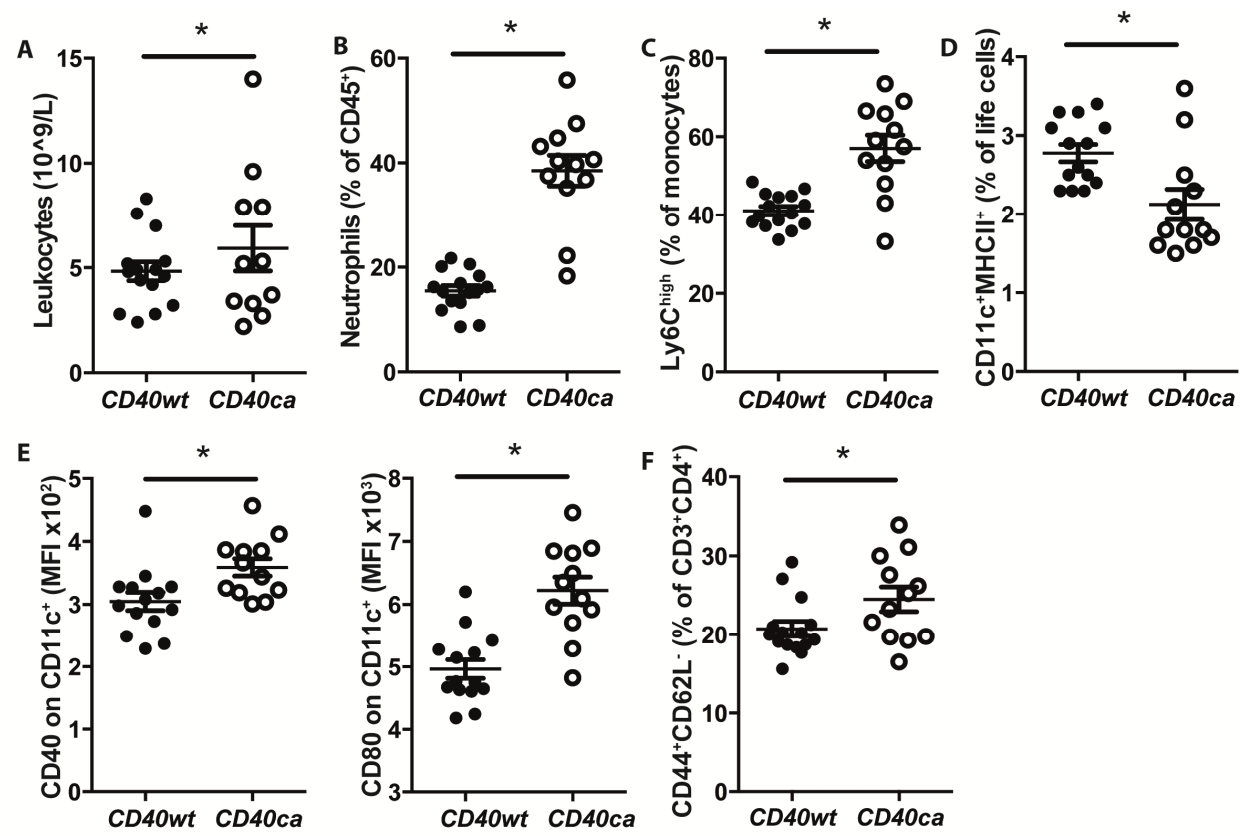

Figure 2. Constitutive CD40-signaling in DCs causes neutrophilia, DC and T-cell activation

(A) Blood count of leukocyte numbers in CD40wt $(n=15)$ and CD40ca Idlr $r^{-/}(n=11)$ chimeras; Flow cytometry analysis in CD4Owt $(n=15)$ and CD4Oca Idlr $r^{-/}(n=11)$ chimeras of (B) blood neutrophil; (C) Ly6 $\mathrm{C}^{\text {high }}$ monocyte; (D) splenic dendritic cell (CD11c $\mathrm{MHCII}^{+}$) numbers; (E) splenic dendritic cell CD40 and CD80 expression; (F) blood effector memory T cell numbers. Error bars represent mean \pm SEM. ${ }^{*}, p<0.05 ; * * *, p<0.001$. 


\section{Constitutive overexpression of CD40-signaling in DCs causes colitis}

Analysis of $>20$ organs revealed that high cholesterol diet fed CD40ca Idlr $r^{-/}$chimeras developed severe inflammation of the gastro-intestinal tract. Pathological examination of gastrointestinal specimens revealed massive infiltration of leukocytes in the tunica muscularis, the submucosa and mucosa, resulting in dysplasia of the villous epithelium in CD4Oca $/ d / r^{-/}$chimeras (Figure 1E). This phenomenon was most prominent in the cecum. No abnormalities or enhanced leukocyte infiltration was observed in any of the other organs.

\section{Discussion}

The co-stimulatory molecule CD40 has a profound role in DC maturation, antigen presentation and DC dependent T-cell expansion ${ }^{(2)}$. In our previous studies using $\mathrm{CD}_{40} 0^{-/}$mice or $\mathrm{CD} 40^{-/-}$bone marrow chimeras, we indeed showed altered immune status in CD40 deficient mice, with a reduction in effector T cells and CD4 ${ }^{-}$CD8 ${ }^{-}$DCs as most prominent features, resulting in a profound reduction of atherosclerosis ${ }^{(14)}$.

Here, we deployed the CD11c-CD40ca model, with CD11c ${ }^{+}$DC specific expression of the late membrane protein LMP, fused to CD40 intracellular domain to confer constitutive activation of CD40 signaling, to study the impact of DC CD40 signaling on atherosclerosis. We confirm that constitutive activation of CD40 on DCs results in an expansion of $\mathrm{CD}^{+}$and $\mathrm{CD}^{+}$effector $\mathrm{T}$ cells. Moreover, DCs from CD40ca $\mathrm{Idlr}^{-/-}$mice had augmented costimulatory capacity with increased $\mathrm{MHCll}$ and $\mathrm{CD} 80$ expression. Moreover CD40ca featured increased neutrophil counts. This is probably caused by inflammation of the gastro-intestinal tract, with signs of ulcerative colitis and inflammation, especially in the cecum, in CD40ca mice. As known from patients suffering from inflammatory bowel disease, colitis can induce a decrease in plasma cholesterol level ${ }^{(18)}$. The involvement of CD40-signaling in IBD has been reported before ${ }^{(19)}$. Immunodeficient SCID mice reconstituted with CD45RB ${ }^{\text {high }}$ $\mathrm{CD}^{+} \mathrm{T}$ cells increases the CD40 expression in colitis colon through infiltration of granulomatous cells. Anti-CD40L antibody administration to these mice prevented signs of colitis, showing the CD40-CD40L dyad essential in colitis 
development ${ }^{(20)}$. Given this strong pro-atherogenic phenotype, we were surprised to observe sharply reduced atherogenic responses in this model, which may be partly due to the reduced plasma cholesterol and triglyceride levels.

Dendritic cell numbers and their immunogenicity are implicated in the regulation of the plasma cholesterol level. Increased DC lifespan as seen upon $\mathrm{Bcl} 2$ overexpression or bim deficiency not only led to increased DC numbers and activation status, as well as an expansion of autoreactie T/B-cells (bim) but was also accompanied by decreased cholesterol levels ${ }^{(21)}$. Similarly, CD11c ${ }^{+}$DC ablation by DT-treatment of cd11c-DTR Apoe ${ }^{-/}$mice caused a transient decrease in plasma cholesterol level ${ }^{(21)}$. How cholesterol levels are impacted by conventional DC numbers is still not elucidated, but DCs might promote lipoprotein uptake and clearance from the circulation ${ }^{(21)}$. Our data suggests that the enhanced activation status of CD40ac DC rather than absolute DC numbers is causative for reduction in plasma cholesterol level.

The original aim of our study was to investigate the role of CD40 on dendritic cells in atherosclerosis. Although constitutive expression of CD40 on DCs in CD40ca Id/ $r^{-/}$resulted in the expected inflammatory phenotype of $\mathrm{T}$ cells and DCs in CD40ca Idlr $r^{-/}$chimeras, the animals developed gastro-intestinal tract inflammation and a reduction in lipid levels, which makes the model less suitable to study the role of DC CD40 in atherosclerosis.

\section{Acknowledgements}

We acknowledge support from the Netherlands Organization for Scientific Research (NWO) (VICl grant to E.L.), the Netherlands CardioVascular Research Initiative (CVON2011-19 to E.L.), and Deutsche Forschungsgemeinschaft (DFG) (CRC1054-B04 to E.L. and CRC1123-A5 to E.L. and NG) and the European Research Council (ERC Cons to E.L). 


\section{Supplementary figures}

A
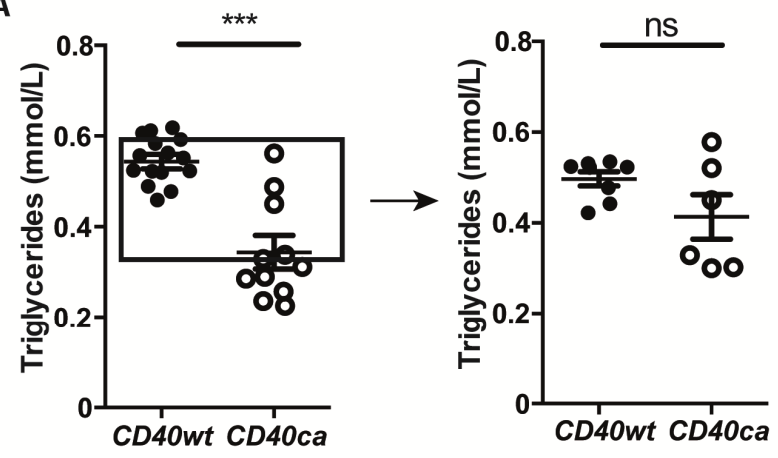

B
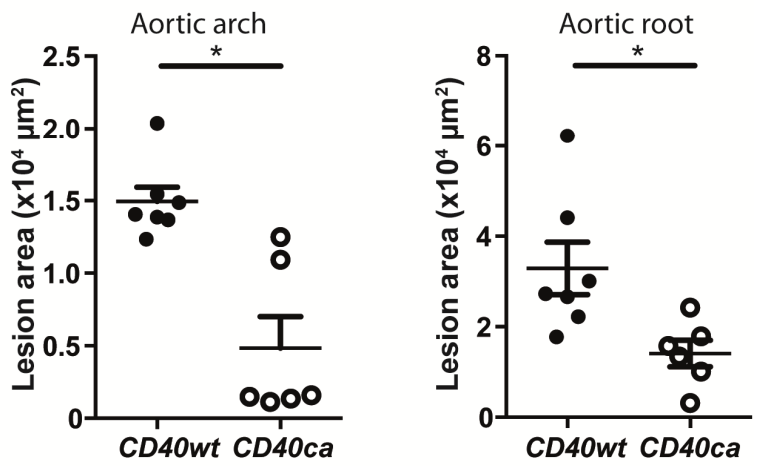

Supplementary Figure 1. Constitutive overexpression of CD40-signaling affects triglyceride levels

(A) Mice with comparable triglyceride levels were selected from CD40wt $(n=7)$ and CD40ca $(n=6) / d l r^{-/}$chimeras to analyze atherosclerotic lesion formation independent of triglyceride level. (B) Lesion formation in hematoxylin and eosin stained sections from aortic arch and root was quantified from mice selected in A. Error bars represent mean \pm SEM. ${ }^{*}, \mathrm{p}<0.05$. 
8 | Role of Dendritic cell constitutively active CD40 in atherosclerosis

\section{References}

1. Hansson GK. Inflammation, atherosclerosis, and coronary artery disease. $N$ Engl J Med. 2005;352:1685-1695

2. Legein B, Temmerman L, Biessen EA, Lutgens E. Inflammation and immune system interactions in atherosclerosis. Cell Mol Life Sci. 2013;70:3847-3869

3. Millonig G, Niederegger H, Rabl W, Hochleitner BW, Hoefer D, Romani N, Wick G. Network of vascular-associated dendritic cells in intima of healthy young individuals. Arterioscler Thromb Vasc Biol. 2001;21:503-508

4. Subramanian M, Tabas I. Dendritic cells in atherosclerosis. Semin Immunopathol. 2014;36:93-102

5. Banchereau J, Steinman RM. Dendritic cells and the control of immunity. Nature. 1998;392:245-252

6. Ait-Oufella $H$, Sage AP, Mallat $Z$, Tedgui A. Adaptive ( $t$ and $b$ cells) immunity and control by dendritic cells in atherosclerosis. Circ Res. 2014;114:1640-1660

7. Hedrick CC. Lymphocytes in atherosclerosis. Arterioscler Thromb Vasc Biol. 2015;35:253257

8. Shortman K, Liu YJ. Mouse and human dendritic cell subtypes. Nat Rev Immunol. 2002;2:151-161

9. Chen L, Flies DB. Molecular mechanisms of t cell co-stimulation and co-inhibition. Nat Rev Immunol. 2013;13:227-242

10. Guermonprez $\mathrm{P}$, Valladeau J, Zitvogel L, Thery $\mathrm{C}$, Amigorena S. Antigen presentation and $\mathrm{t}$ cell stimulation by dendritic cells. Annu Rev Immunol. 2002;20:621-667

11. Lutgens E, Gorelik L, Daemen MJ, de Muinck ED, Grewal IS, Koteliansky VE, Flavell RA. Requirement for cd154 in the progression of atherosclerosis. Nat Med. 1999;5:1313-1316

12. Lutgens E, Cleutjens KB, Heeneman S, Koteliansky VE, Burkly LC, Daemen MJ. Both early and delayed anti-cd40l antibody treatment induces a stable plaque phenotype. Proc Natl Acad Sci U S A. 2000;97:7464-7469

13. Schonbeck U, Sukhova GK, Shimizu K, Mach F, Libby P. Inhibition of cd40 signaling limits evolution of established atherosclerosis in mice. Proc Natl Acad Sci U S A. 2000;97:74587463

14. Lutgens E, Lievens D, Beckers L, Wijnands E, Soehnlein O, Zernecke A, Seijkens T, Engel D, Cleutjens J, Keller AM, Naik SH, Boon L, Oufella HA, Mallat Z, Ahonen CL, Noelle RJ, de Winther MP, Daemen MJ, Biessen EA, Weber C. Deficient cd40-traf6 signaling in leukocytes prevents atherosclerosis by skewing the immune response toward an antiinflammatory profile. J Exp Med. 2010;207:391-404

15. Homig-Holzel C, Hojer C, Rastelli J, Casola S, Strobl LJ, Muller W, Quintanilla-Martinez L, Gewies A, Ruland J, Rajewsky K, Zimber-Strobl U. Constitutive cd40 signaling in b cells selectively activates the noncanonical nf-kappab pathway and promotes lymphomagenesis. J Exp Med. 2008;205:1317-1329

16. Baxendale AJ, Dawson CW, Stewart SE, Mudaliar V, Reynolds G, Gordon J, Murray PG, Young LS, Eliopoulos AG. Constitutive activation of the cd40 pathway promotes cell transformation and neoplastic growth. Oncogene. 2005;24:7913-7923

17. Hochrein H, Shortman K, Vremec D, Scott B, Hertzog P, O'Keeffe M. Differential production of il-12, ifn-alpha, and ifn-gamma by mouse dendritic cell subsets. J Immunol. 2001;166:5448-5455

18. Agouridis AP, Elisaf M, Milionis HJ. An overview of lipid abnormalities in patients with inflammatory bowel disease. Ann Gastroenterol. 2011;24:181-187 
19. Annacker O, Coombes JL, Malmstrom V, Uhlig HH, Bourne T, Johansson-Lindbom B, Agace WW, Parker CM, Powrie F. Essential role for cd103 in the $t$ cell-mediated regulation of experimental colitis. J Exp Med. 2005;202:1051-1061

20. Paik J, Fierce Y, Treuting PM, Brabb T, Maggio-Price L. High-fat diet-induced obesity exacerbates inflammatory bowel disease in genetically susceptible mdr1a-/- male mice. $J$ Nutr. 2013;143:1240-1247

21. Gautier EL, Huby T, Saint-Charles F, Ouzilleau B, Pirault J, Deswaerte V, Ginhoux F, Miller ER, Witztum JL, Chapman MJ, Lesnik P. Conventional dendritic cells at the crossroads between immunity and cholesterol homeostasis in atherosclerosis. Circulation. 2009;119:2367-2375 


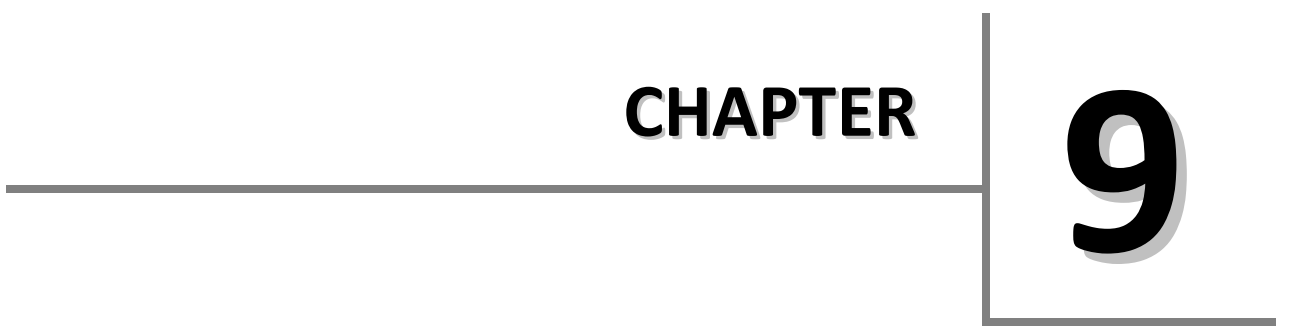

General Discussion

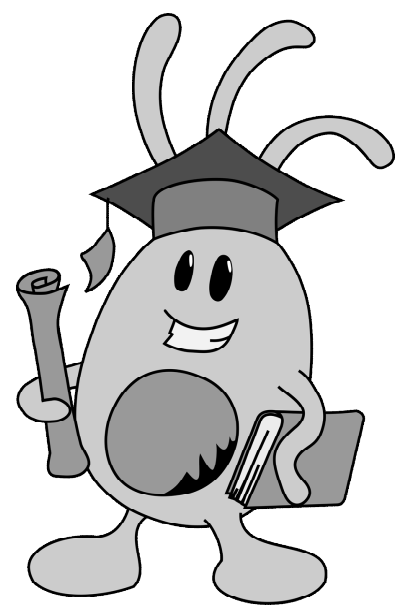




\section{General Discussion}

The aim of this thesis was (1) to better understand the impact of different DC subsets in atherosclerosis, (2) to study whether the hyperlipidemic milieu, associated with atherosclerosis, influences DC function, and (3) to explore new strategies to modulate DC function in order to ameliorate disease.

\section{Goal 1: Dissecting the role of DC subsets in atherosclerosis}

Genetic approaches aimed to expand or deplete the complete DC pool provided disappointing results as these interventions did not influence atherosclerosis burden ${ }^{(1)}$. However, DCs were also found to influence cholesterol modulation ${ }^{(1)}$ along with controlling myelogenesis ${ }^{(2)}$, masking any potential role of DCs in atherogenesis. In addition, depleting the complete DC population might result in a net neutral effect as both protective as well as detrimental DC processes are lost. Therefore studies unraveling DC subset specific contributions to atherosclerosis are necessary.

\section{A role for the $C D 8^{+} D C$ subset and cross-presentation?}

Research on $T$ cell responses in atherosclerosis has so far mainly focused on $\mathrm{CD}^{+} \mathrm{T}$ cell responses, nevertheless there are also indications for a role of $\mathrm{CD}^{+}{ }^{+} \mathrm{T}$ cells in vascular inflammation. $\mathrm{CD} 8^{+} \mathrm{T}$-cells can be detected in the atherosclerotic plaque ${ }^{(3)}$, at numbers that increase with disease progression, as well as in the arterial tertiary lymphoid organs ${ }^{(4)}$. In advanced human lesions, they can even comprise $\geq 50 \%$ of the lymphocyte pool ${ }^{(5,6)}$. Moreover, even less is known regarding $\mathrm{CD} 8^{+} \mathrm{T}$ cell priming in atherogenesis. In that sense, the $C D 8^{+} \mathrm{DC}$ subset is of particular interest, as they possess the unique ability to prime cytotoxic $\mathrm{CD} 8^{+} \mathrm{T}$ cell responses to exogenous antigens via cross-presentation on $\mathrm{MHC}$ I molecules. In a cancer setting, $\mathrm{CD} 8^{+} \mathrm{DC}$ s were shown to take up dead cell remnants from the tumor and elicit potent cytotoxic $T$ cell responses that are essential for tumor clearance ${ }^{(7,8)}$. In analogy to tumors, the plaque also contains apoptotic/necrotic cell derived vesicles that may function as a substrate for cross-presentation in atherosclerosis. However, information on the impact of $C D 8^{+} D C s$ in atherosclerosis and crosspresentation in general was lacking. In Chapter 4, we therefore examined the impact of hematopoietic Batf3 deficiency in $\mathrm{LDLr}^{-/-}$mice. Loss of Batf3 induced 
a selective loss of $C D 8^{+} D C$ and $C D 103^{+} D C$, resulting in a severe defect in crosspresentation. As atherosclerosis burden and composition was unaffected in these mice, our findings suggest that $C D 8^{+} D C s$ and potentially crosspresentation only play a minor role in the pathogenesis of atherosclerosis.

Three possible conclusions can be drawn from our study.

1. Cross-presentation of plaque derived peptides is irrelevant in the pathophysiology of atherosclerosis

2. Cross-presentation of plaque derived peptides is relevant for atherosclerosis, but it is not mediated by Batf3 dependent $\mathrm{CD} 8^{+}$or CD103 ${ }^{+}$DCs.

3. Cross-presentation does play a role in atherosclerosis and is mediated by Batf3 dependent DCs, but its effects are counteracted by other protective functions of these DC subsets.

Option 1: Cross-presentation of plaque derived peptides is irrelevant in the pathophysiology of atherosclerosis.

$C D 8^{+} D C s$ are abundantly present in the spleen and LNs, but are very scarce in the plaque. It is possible that plaque derived antigens for crosspresentation are retained in the plaque and do not make it to LNs or spleen. Therefore, there is no possibility of cross-presentation of plaque neo-epitopes and likewise no contribution of cross-presentation to atherosclerosis progression. However, migratory and cross-presentation capable $C D 103^{+} D C$ were shown to be present inside atherosclerotic lesions ${ }^{(9)}$. These cells could therefore potentially sample and present antigen locally or migrate to draining LNs for cross-presentation or cross-dressing. However, and in analogy with our findings of Chapter 5 and 6, it may be that the $C D 103^{+} D C s$ in the atherosclerotic plaque are dysfunctional and/or unable to migrate to LNs because of the high lipid environment. Nevertheless, as our Batf ${ }^{-/-}$model targets both cell types we can rule out the alternative cross-presentation via CD103 ${ }^{+}$DCs.

Importantly, our data do not rule out a role for $\mathrm{CD}^{+} \mathrm{T}$ cells in atherosclerosis, but indicate that the conventional $\mathrm{MHC}$ I presentation rather than cross-presentation is likely the way to influence $\mathrm{CD} 8^{+} \mathrm{T}$ cell responses in atherosclerosis. Conventional MHC I presentation primarily leads to 
presentation of cytosolic antigens, such as viral components upon infection. As atherosclerosis has been associated with viral infections (e.g. cytomegalovirus, Epstein-Barr virus) ${ }^{(10)}$, this might be an interesting topic for further research. Along the line of presenting cytosolic antigens, DCs are known to take up (modified) lipoproteins ${ }^{(11)}$. Moreover, $\mathrm{CD}^{+} \mathrm{T}$ cells recognizing lipoprotein derived epitopes, such as the ApoB100 peptide p210, have indeed been identified ${ }^{(12)}$. Therefore, it is of interest to investigate whether lipoprotein constituents are able to leak into the cytosol of DCs and eventually end up in the conventional $\mathrm{MHCl}$ presentation pathway, leading to the generation of lipid-specific $\mathrm{CD}^{+} \mathrm{T}$ cells.

Option 2: Cross-presentation of plaque derived peptides is relevant for atherosclerosis, but it is not mediated by Batf3 dependent $C D 8^{+}$or $C D 103^{+} D C s$.

It is possible that deletion of the main cross-presenting DCs (CD8 ${ }^{+}$and CD103 ${ }^{+} \mathrm{DC}$ ) leads to compensation by other cell populations. Functional testing using OT- 1 cells indicated we achieved $>70 \%$ reduction of cross-presentation in our model. Nevertheless, we cannot completely rule out that the other $30 \%$ is still enough to induce atherosclerosis-relevant $\operatorname{CD}^{+} T$ cell priming. Interestingly, another non-dendritic cell population was recently described to have cross-presentation ability, the $\mathrm{CD}_{169}{ }^{+}$marginal zone metallophilic macrophages (MPs) ${ }^{(13)}$. Remarkably, these MPs seem able to generate CTLs with broader repertoires as compared to CTLs induced by $\mathrm{CD}^{+} \mathrm{DCs}{ }^{(14)}$ (see also discussion disease related epitopes below). Moreover, $\mathrm{CD}_{169^{+}}$macrophages are present in the plaque and CD169 expression was shown to increase during (chronic) inflammation (15). Therefore, these MPs might just be the cell responsible for atherosclerosis-related $\mathrm{Ag}$ cross-presentation to $\mathrm{CD}^{+} \mathrm{T}$ cells. One way to answer this question would be to study the CD169-DTR mouse in an atherosclerosis context. Moreover, it would be interesting to know whether cross-presentation is completely blunted in CD169-DTR Batf3 $^{-/}$double knockout mice. However, one needs to be cautious in interpreting the results as CD169-DTR leads to deletion of $\mathrm{CD} 169^{+}$macrophages in the marginal zone as well as in the sinus, affecting not only the cross-presenting cells, thus potentially masking any effects of compromised cross-presentation on atherosclerosis. Another option would be to use a CD169-targetting adenoviral construct, as previously described to selectively target $\mathrm{CD}_{169^{+}}$metalophillic 
macrophages (14), and employ this in the Batf3 $^{-/-}$LDLr $^{-1}$ model. However, a drawback of this system is that repeated injection of the viral vector, necessary due to the chronic nature of atherosclerosis, might induce immune responses that will neutralize the viral vector, although this has to be investigated.

Another point is that the OT-I/OVA system used to test the functionality of cross-presentation in our model is an atherosclerosis-unrelated model antigen system. Therefore, one could argue that this system does not truly reproduce the regulation of disease-specific immune responses. Unfortunately, there aren't any atherosclerosis Ag-related tools available to solve this issue. For example, comparing atherosclerosis relevant cytotoxic T lymphocyte (CTL) priming responses requires the use of athero-epitope specific MHC multimers, which have not been generated so far. Interestingly, Hermansson et al developed a murine $C D 4^{+} T$ cell hybridoma recognizing human ApoB100 ${ }^{(16)}$, which was recently used to study MHCll presentation by pDCs ${ }^{(17)}$. Generating a $\mathrm{CD} 8^{+} \mathrm{T}$ cell equivalent might help in understanding $\mathrm{CD}^{+} \mathrm{T}$ cell responses in atherosclerosis.

Option 3: Cross-presentation does play a role in atherosclerosis and is mediated by Batf3 dependent DCs, but its effects are counteracted by other protective functions of these $D C$ subsets.

Finally, as Batf3 deficiency leads to complete lack of Batf3-dependent DC rather than affecting certain aspects of these cells it is possible that interference with the generation of pro-atherogenic $C D 8^{+} T$ cell responses is counterbalanced by interference with possible atheroprotective effects of these DCs, resulting in a net effect that is neutral. In this regard it is of interest to mention that immunization with p210 yielded an atheroprotective effect through generation of atheroprotective $\mathrm{CD} 8^{+} \mathrm{T}$ cells ${ }^{(12)}$. Another possibility is that the atheroprotective effect of losing the cytotoxic priming capacity of the $C D 8^{+} D C s$ is counterbalanced by loss of the atheroprotective effect ascribed to $\mathrm{CD}_{103}{ }^{+} \mathrm{DCs}{ }^{(9)}$. 
In summary, studies on DC subset specific roles in atherosclerosis are necessary but limited up to now. Regarding pDCs, Sage et al confirmed a proatherogenic role for pDC favoring the notion that pDCs are detrimental in the disease process ${ }^{(17)}$. Interestingly, our work on the $C D 8^{+} D C$ subset, using the genetic Batf3 ${ }^{-/-}$model, (Chapter 4) showed no contribution of this subset to atherosclerosis. Furthermore, as our $C D 8^{+} D C$ study as well as earlier work on pDCs did not observe any changes in cholesterol levels or myeloid cell populations, these observations indicate that both $C D 8^{+} D C s$ and $\mathrm{pDC}$ are not the DC subsets responsible for the myeloproliferative or cholesterol modulating effects observed in the CD11c-DTR model. By exclusion this would mean that either DN DCs or monocyte-derived (mono)DCs are responsible. This underpins the diverse functions exerted by separate DC subsets in atherosclerosis and refines the rather gross insights obtained from CD11c DC depletion studies. Once again, this emphasizes the importance of precise models to be able to dissect the involvement of particular cell subsets/processes in disease. Unfortunately, lack of these specific tools hamper the investigation of other DC subsets (such as $C D 4^{+} C D 11 b^{+} D C$, $\mathrm{CD}^{-} \mathrm{CD} 11 \mathrm{~b}^{+}$, and monocyte derived DCs) in atherosclerosis. In that respect, some progress was made by the work of Satpathy et al, as they identified the transcription factor Zbtb46 to be selectively expressed by cDCs, but not by pDCs, monocytes, macrophages, or other lymphoid or myeloid lineages ${ }^{(18)}$. Even though Zbtb46 is also expressed on some non-immune cells, such as erythroid progenitors and endothelial cells, Zbtb46 promoter driven genetic approaches might help unravel the role of cDCs in the future.

Goal 2: is DC function affected by hyperlipidemia?

Recognition of danger signals by pattern recognition receptors (PRRs) is a pivotal step in DC maturation and activation and subsequent generation of innate and adaptive immune functions. DC subsets differ in the profile and activity of expressed PRRs, and hence in their innate/adaptive immune functions. For instance, pDCs are crucial in host defense against viral and bacterial antigens through rapid secretion of large amount of cytokines, such as type I IFNs, upon TLR7 and TLR9 mediated recognition of pathogens $(19,20)$. cDCs on the other hand, are superior in T cell priming upon DC activation. PRR activity and expression is modulated by several stimuli present in the direct 
microenvironment and immediate stimulation history, for example endotoxin tolerance upon secondary stimulation ${ }^{(21,22)}$, as is the case upon recovering from sepsis.

Therefore, it is conceivable that exposure of dendritic cells to factors in the microenvironment influences DC signaling pathways which will impact on host immune responses against yeast, bacteria, viruses and cancer. In this regard, the literature on the effects of hyperlipidemia is somewhat controversial as studies describe DC activation or no effect by hyperlipidemia (23, 24), while others show that hyperlipidemia impairs the immune response against infections ${ }^{(25-27)}$. For example, dyslipidemia was shown to interfere with CD8 ${ }^{-} \mathrm{CDC}$ but not $\mathrm{CD} 8 \alpha^{+} \mathrm{CDC}$ responses by uncoupling of TLR-mediated signaling, a process in which oxLDL appeared to be the key player ${ }^{(28)}$. Thus, impairment of DC maturation and function seems to be DC subtype specific. The contradictarory literature clearly demonstrates that the relevance and kinetics of lipid loading by DC subsets and the underlying mechanisms are not completely understood. Moreover, studies investigating the influence of hypercholesterolemia on the pDC subset are lacking. In Chapter 5, we therefore studied the influence of lipoproteins on human pDC functionality. We were able to demonstrate that human pDCs accumulate lipoproteins, resulting in dampening of $\mathrm{CpG}$ induced maturation, decreased cytokine secretion and failure to mount effective Th cell polarization in vitro. Effective incorporation of oxLDL by pDCs is in line with previous findings, however in contrast to our findings oxLDL exposure in vitro did not lead to altered surface expression of maturation markers in that study ${ }^{(24)}$. This discrepancy could be due to the fact that we used human pDCs and human lipoproteins compared to the use of pDCs isolated from C57BI6 mice. Although mouse and human pDCs share many characteristics, such as expression of TLR7 and TLR9 and their production of high amounts of type 1 IFN upon pathogen exposure, they are not identical. For example, they differ in expression of CD11c, CD123 and TLR8 ${ }^{(29)}$. Therefore, extrapolating the results from murine models (in vitro or in vivo ) to human diseases is sometimes difficult.

Another note of caution relates to the context. Obviously, the local pDC microenvironment in vivo under conditions of atherosclerosis and/or hyperlipidemia is much more complex than plain oxLDL exposure in cell culture. In addition, one could wonder whether DC get into close contact with 


\section{9 | General Discussion}

oxLDL as is the case in culture. Indeed, pDCs are relatively scarce in the atherosclerotic lipid-rich plaque, however they are also present in blood, which is the transport route of lipoproteins, and in LNs, which drain from lipid rich areas such as atherosclerotic lesions. Therefore, it will be of interest to investigate whether the effects of hyperlipidemia on pDCs seen in vitro also hold true in vivo.

While (ox)LDL interferes with TLR7 and 9 induced pDC-activation, our preliminary data indicate that oxLDL does not interfere with CpG uptake or binding to TLR9. Thus, interference probably takes place further downstream in the TLR signaling cascade, although the mechanism of action remains elusive. Interestingy, oxLDL binds to several pDC surface receptors, such as BDCA2, dendritic cell immune-receptor (DCIR), CXCL16 or immunoglobulin-like receptor 7 (ILT7)), which were shown to regulate/impair type I IFN production ${ }^{(30-33)}$. Another option may be through oxLDL induced uncoupling of TLR-NF-KB signaling, as has been described for dyslipidemia-induced impairment of $\mathrm{CD}^{-} \mathrm{DC}^{(28)}$ and macrophage ${ }^{(34)}$ activation. Whether oxLDL also interferes with TLR signaling in other immune cells or with activation induced by other receptors important in host defense, such as CD40, remains to be elucidated. In addition oxLDL may influence the TLR response by acting on nuclear receptors, such as LXR or PPAR. Transcriptome analysis studies are currently underway to unravel the relevant pathways by which oxLDL tones TLR7/9 and pDC activation.

As lipids have a pronounced effect on human pDCs in vitro we were also interested in studying the effect of hyperlipidemia on DC subsets in an in vivo mouse model. In Chapter 6 we therefore mapped the early adaptive effects of DCs to hyperlipidemia in vivo. High fat diet feeding of $\mathrm{LDLr}^{-/}$mice resulted in a rapid increase of myeloid dendritic cell progenitor (MDP) frequency, but did not result in increased DC numbers in peripheral compartments, such as blood and lymphoid organs. High blood cholesterol resulted in increased granularity of classical DC subsets, correlating with intracellular lipoprotein accumulation. Lipid loading was most apparent in the CD8 ${ }^{-D C}$ population and interestingly only the lipid-loaded fraction of the CD8 DC population showed increased ROS activity, costimulatory molecule expression and cytokine production, but impaired $\mathrm{CD}^{+} \mathrm{T}$ cell priming. The latter is in line with previous observations in $\mathrm{ApoE}^{-/-}$, where also reduced $\mathrm{T}$ cell proliferation was observed ${ }^{(28)}$. However and in contrast to our results, the 
authors also described a reduction in cytokine production and costimulatory molecule expression by CD8DCs. This discrepancy may be due to the fact that the authors fed $\mathrm{ApoE}^{-/-}$mice a HFD for 10 weeks, therefore studying the longterm effects in a more aggressive model, while we studied rather short-term effects in a milder model ( 3 wks diet in $\mathrm{LDLr}^{-/-}$mice). It may be that the longterm exposure eventually leads to exhaustion of the CD8DCs, leading to reduced cytokine production and costimulatory molecule expression. In addition, Shamshiev et al studied the whole CD8 DC population, while we were able to show that only the lipid-laden fraction of the CD8 ${ }^{-}$DCs show impaired function. Transcriptome analysis (in progress) of these cells is therefore of biological interest.

Our data from Chapters $\mathbf{5}$ and $\mathbf{6}$ clearly indicate that lipoprotein exposure in vitro or in vivo impairs intrinsic functions of DC subsets, such as pDCs and CD8 DCs. As hyperlipidemia interferes with dendritic cell immune responses, this may have implications for (TLR driven) host defense against pathogens and trauma, but also for tolerance to self, resulting in vulnerability to infections, increased cancer risk or development of auto-immune diseases $(35,36)$

Indeed epidemiological and basic studies associate hypercholesterolemia with cancer risk ${ }^{(37-40)}$. Although some papers ascribed this to a direct impact of cholesterol (metabolites) on tumor growth ${ }^{(41,42)}$, it may very well be that a hypercholesterolemic microenvironment also compromises DC responses to eradicate cancer cells. In addition, the tumor microenvironment is known to be tolerogenic, reducing effectiveness of immune responses that target the tumor. As the tumor is often lipid rich this hyperlipidemic micromilieu may therefore induce hyporesponsiveness of certain DCs contributing to impaired $\mathrm{T}$ cell priming and tumor clearance. Therefore, lowering cholesterol levels might not only reduce the risk of cardiovascular events, but also lower the risk of cancer. Of note, we have to be cautious in using statins as additional therapy in cancer, as these have antiinflammatory and immunomodulating properties that might worsen cancer outcome. Regarding cytotoxic T cells, cross-presentation has been implicated as an important feature in priming $\mathrm{CD}^{+} \mathrm{T}$ cells for tumor immune responses ${ }^{(7,43-45)}$. Concordant with the observation by others on general $C D 8^{+} D C$ function ${ }^{(28)}$, our results from Chapter 4 indicate that cross-presentation by $C D 8^{+} D C$ is 


\section{9 | General Discussion}

not affected by hyperlipidemia. Thus, priming of tumor-specific cytotoxic $C D 8^{+} T$ cells by $C D 8^{+} D C s$ in the periphery likely is not affected hyperlipidemia, whereas the effect of the lipid-rich tumor environment on the CD8 ${ }^{-}$DC subset needs further investigation.

As said, impaired DC activation and functionality by excessive (ox)LDL in the DC environment may also compromise the host defense against infections. In line with our data, dyslipidemia in general was shown to increase host susceptibility to yeast ${ }^{(26)}$, protozoa ${ }^{(28)}$, viruses ${ }^{(27)}$ and bacteria ${ }^{(25)}$ in mice, and was suggested to result in impaired contact hypersensitivity and delayedtype hypersensitivity in Apolipoprotein $\mathrm{E}^{-/-}$mice ${ }^{(46)}$. These findings can at least in part be explained by our results on the effects of lipids in DCs. Whether hyperlipidemia also renders humans more susceptible to infections needs further investigation. Of note, hyperlipidemia is often accompanied by lower or dysfunctional HDL. HDL can further affect immune responses as it indirectly influences inflammatory processes, for example HDL was shown to act antiinflammatory on endothelial cells and smooth muscle cells ${ }^{(47,48)}$ and to have both anti- and pro-inflammatory effects on macrophages $\left({ }^{49}\right.$, van der Vorst, in press).

One could argue that the dyslipidemia-induced reduction in DC immune responses would be beneficial for atherosclerosis. However, besides initiating immune responses, DCs also regulate anergy and immune tolerance, for example by thymic selection of $\mathrm{T}$ cells or by priming Tregs in the periphery ${ }^{(50)}$. As Tregs have strong protective properties ${ }^{(51)}$ in cardiovascular disease, especially in atherosclerosis, suppression of their formation by impaired DC function may be detrimental in the disease process. Along this line, Flt3 deficiency resulted in accelerated atherosclerosis attributed to lower Treg numbers induced by loss of protective $\mathrm{CD} 103^{+} \mathrm{DC}{ }^{(9)}$. However, little is known regarding which DC subsets act tolerogenic and their mechanisms of action. In addition to inference with tolerance induction, hyperlipidemia-induced impairment of emigration of matured/activated DCs from plaque to secondary lymphoid organs will lead to entrapment of DCs in the atherosclerotic plaque. As the plaque environment, not only contains lipids but also many proinflammatory factors, these might overrule the lipid-related dampening effect and therefore promote atherosclerosis. Finally, depletion of DCs using CD11cDTR mice indicated that interference with immune function is not necessarily 
beneficial for atherosclerosis ${ }^{(1)}$, but involves a delicate and complex balance of different (immune) mechanisms.

In conclusion, hyperlipidemia leads to impaired immune function in certain DC subsets, such as PDC and CD8DCs. Whether these findings have implications for human health and disease remains uncertain, therefore further research is needed to understand the effect of hyperlipidemia-induced reduction of DC function and their implications for host defense and disease. In that regard, it will be of particular interest to analyze the phenotype and functionality of DCs as well as the association between cholesterol levels and infections, cancer and auto-immune diseases in patients with familial hypercholesterolemia or between patients with high and low cholesterol levels in general.

\section{Goal 3: Modulating DC activity to ameliorate atherosclerosis}

As dendritic cells play crucial roles in various diseases, it is, from a therapeutic point of view, important to know whether and how DC function can be modulated to improve disease outcome. Here we discuss three important levels of DC modulation to influence disease outcome.

a. Influencing DC differentiation/function post-transcriptionally (Chapter 7)

b. Influencing DC costimulation (Chapter 8)

c. DC-based immunization/vaccination (not in this thesis)

\section{a. Influencing DC differentiation/function post-transcriptionally (chapter 7)}

DC differentiation and function is a complex process regulated at several levels: transcriptionally, via transcription factors ${ }^{(52)}$, posttranscriptionally via miRNA ${ }^{(53)}$, such as miR-24, and likely also by RNA binding proteins. RNA binding proteins are emerging as key regulators of cell differentiation. Recently, the RBP Quaking (QKI) has been identified as a master regulator of differentiation and/or function of lymphocytes ${ }^{(54)}$, vascular smooth muscle cells ${ }^{(55)}$ as well as monocytes/macrophages (de Bruin, in press). As dendritic cells partly share their ontogeny and have overlapping functions with macrophages, it is plausible that QKI also functions as a master switch in 


\section{9 | General Discussion}

DC differentiation and function. In Chapter 7, we have studied whether DC function can be manipulated at a post-transcriptional level by quenching RNAbinding protein Quaking (QKI) expression and whether this affects atherosclerosis. For this purpose we used a CD11c-restricted QKI deletion model. Our data indicate that loss of QKI in DCs reduces DC development, skews $\mathrm{DC}$ differentiation and $\mathrm{T}$ cell profile towards $\mathrm{CD} 8^{+}$and reduces proinflammatory cytokine production by DCs. The observed reduction in DC generation is in line with previous literature on oligodendrocytes ${ }^{(56)}$, vSMCs ${ }^{(55)}$ and monocytes/macrophages (de Bruin et al, Nat Commun, 2016) describing decreased proliferation/differentiation of these cells, indicating QKI as a master regulator of the cell cycle. Furthermore, QKI deficiency in these cells also reduced their migratory capacity. Therefore, it is likely that also DC migration is impaired by blunted QKI expression. As migration is an important feature in DC biology, this is an interesting topic for further research. In addition, vSMCs from $\mathrm{Qk}^{\mathrm{vb}}$ mice show reduced ECM production, whereas $\mathrm{QK}^{\mathrm{vb}}$ macrophages have reduced foam cell formation. In line, we describe a decrease in DC cytokine production upon QKI loss, indicating that QKI is involved in specialized cell functions.

Loss of Quaking in the total DC population reduced atherosclerosis. However, loss in specific DC subsets may influence atherosclerosis very differently. In this regard, the results from Chapter 4, suggest that studying QKI in pDCs or CD8-DCs is of more importance for atherosclerosis then studying the $C D 8^{+} D C s$. Of not contribution of different subset could be studied by using different promoter driven cre mice (not all are available yet): Siglec H/BDCA2cre (pDCs), Zbtb46-cre (cDCs), Batf3-cre (CD8 $\left.{ }^{+} D C s\right)$. However, as our data indicate that QKI impacts on DC development and differentiation, the effects on DC functionality may be blurred because of defective DC differentiation. Therefore temporal control of QKI expression is preferred, which can be achieved by using lentiviral vectors or CreER models.

\section{Quaking follow-up}

Models using full QKI deficiency are probably not the best way to go as the murine QKI gene generates different QKI protein isoforms through alternative splicing. These isoforms (e.g. Qk-5, Qk-6 and Qk-7) partly reside in distinct cellular compartments. Depending on its location and the presence of 
QKI responsive targets, each isoform may regulate distinct biological processes, even within the same cell ${ }^{(57-59)}$. Therefore it is of importance to elucidate the role of the separate isoforms in the different DC subsets. This can, for example, be achieved by using lentiviral vectors targeting different QKI isoforms in vitro.

Another problem however, is that QKI proteins are ubiquitously expressed and have a broad set of functions, therefore targeting of QKI in DCs specifically without side effects will be therapeutically challenging. Thus, a better strategy to study QKI function is to focus on finding the molecular (DC specific) targets of QKI. This could be achieved by combining RNA-sequencing (RNAseq) of QKI deficient and control DCs with in silico analysis. One option would be to filter RNAseq results for targets containing a Quaking responsive element (QRE) and subsequently screen these for DC relevance (and proximity to a splicing construct).

In conclusion, QKI may represent an interesting target for therapy as it has the ability to influence key DC functions. Interestingly, QKI deficiency in DCs reduced its pro-inflammatory cytokine production in vitro and ameliorated the Th17/Treg balance in vivo, therefore this RBP not only holds potential for atherosclerosis therapy but is also an interesting target for other inflammatory and auto-immune diseases ${ }^{(60)}$. However, extensive research into the molecular targets of QKI and more in-depth knowledge on its biological functions is required to unravel and validate QKI RBPs potential as a therapeutic target.

\section{b. Influencing DC costimulation (chapter 8)}

Another way to influence DC functions is by modifying DC costimulatory abilities. In Chapter $\mathbf{8}$, we investigated the role of dendritic cell CD40 in atherosclerosis, through a gain of function approach using mice with constitutively active CD40 signaling in CD11c ${ }^{+}$DCs. Previous studies showed an anti-inflammatory state in mice with hematopoietic CD40 deficiency or with hematopoietic $\mathrm{MHClI}^{+}$cells expressing TRAF6 signaling defective $\mathrm{CD} 40$, as judged from the reduced effector $T$ cell levels ${ }^{(61,62) .}$ As these mice were protected against atherosclerosis, we actually expected increased, not reduced plaque formation in our constitutive active CD40 model. However, mice with constitutively active CD40 had strongly reduced plaque size, an effect that could be attributed to the decreased cholesterol levels resulting from strong 


\section{9 | General Discussion}

intestinal inflammation. In general, these data indicate that the atherosclerosis outcome of altering CD40 activity strongly depends on the context. Moreover, we confirmed that modifying CD40 activity in DCs can profoundly affect the status of the immune system, rendering CD40 a strong candidate for targeted immune therapy. As systemic anti-CD40 intervention is not feasible, more specific approaches are required. In this regard, modulation of TRAF6 signaling by CD40 through genetic approaches or through peptides that interfere with TRAF6-CD40 binding is more specific and resulted in a strong reduction of atherosclerosis ${ }^{(61)}$. Although this method might circumvent the problems with thromboembolemic events seen using anti-CD40 antibodies, it is likely that this approach is still too broad to use in a clinical setting as long-term treatment during atherosclerosis could compromise the patients immune system. Cell specific targeting might resolve this issue, for example by targeting specific DC subsets using specialized viral vectors, although this has to be investigated. Of note, the CD40/LMP construct might by of interest in the development of effective $D C$ vaccination in cancer, where a maintained pro-inflammatory state of the Ag-loaded DC is of critical importance.

\section{c. DC-based immunization/vaccination}

Vaccination is one of the greatest advances in human health in the past 100 years. Given the central role of the immune system in atherosclerosis, it is of therapeutic interest to develop immunization strategies that fine-tune these responses towards a beneficial clinical outcome with reduced atherothrombotic events. Current studies focus on dampening pro-atherogenic immune responses, activating atheroprotective responses or neutralizing atherosclerosis promoting agents. Immunization of experimental animals against known endogenous atherosclerosis-related antigens such as apolipoprotein fragments (63-65) and modified LDL (66-68) demonstrated atheroprotective effects. The choice of adjuvants as well as the route of administration used, are critical factors in order to achieve efficient and safe vaccination. As DCs are potent antigen-presenting cells they can be used as an alternative route for delivery of antigens to the host in order to provoke an efficient immune response ${ }^{(69)}$. This can be achieved by loading DCs with a specific antigen ex vivo and subsequently transferring them in recipients (70). Because of the potential of DCs to either stimulate or dampen immune responses they can be used to influence both pro-atherogenic as well as anti268 
atherogenic responses. In this regard, Habets et al used LPS as a maturation marker in oxLDL-loaded DC vaccination. Transfer of these DCs, resulted in oxLDL-specific $T$ cells with a reduced Th1 profile and increased titers of protective oxLDL IgG, leading to diminished atherosclerosis (71). Similarly, Hermansson et al have rendered ApoB100 peptide pulsed DCs tolerogenic by incubation with IL10 and tested their vaccination potential in mice, observing significantly reduced atherosclerosis ${ }^{(72)}$.

Despite the incomplete understanding of DC functions in atherosclerosis, DC-based immunotherapy may be a valid option in the prevention or treatment of atherosclerosis. However, before DC vaccination can be used as a therapy some aspects have to be critically addressed. What are the best antigens, adjuvants etc. to use? Is DC vaccination effective in already established atherosclerosis? What is the ideal time point for vaccination? Is DC vaccination still effective in aged people ${ }^{(73)}$ ? Does it affect the patients' comorbidities or defense against pathogens? Is DC vaccination compatible with current medication? Furthermore, data from Chapters 5 and 6 suggest that DC vaccination may be influenced by the hyperlipidemic context of the patient. In addition, Chapter 4 indicates that the CD8 ${ }^{+} D C s$ are not the subset of choice for the development of DC-vaccination in atherosclerosis.

\section{Conclusions and future perspectives}

The continuing impact of atherosclerosis on morbidity and mortality in the western society, despite the advances in its diagnosis and therapy, indicates the importance to understand its pathogenesis in order to enable the development of effective treatment/prevention. New therapeutic approaches might induce selective suppression of pro-atherogenic immune responses or activation of anti-atherogenic responses to treat atherosclerosis. In that respect, knowledge regarding DCs as immune regulators is of particular interest. The role of DCs in atherosclerosis development and progression has been studied quite extensively in recent years. Nevertheless, DC subset contribution to atherosclerosis and their mechanisms of action remain poorly understood. In this thesis we were the first to describe that CD8 ${ }^{+} D C s$ and the process of cross-presentation are not major contributors to atherosclerosis progression (Chapter 4). Although we cannot completely exclude that cross- 


\section{9 | General Discussion}

presentation via other subsets is implicated in the pathogenesis of atherosclerosis, our data seem to disqualify $C D 8^{+} \mathrm{DC}$ cross presentation as a target for intervention. This thesis also explored the potential modulators of DC differentiation and function relevant to atherosclerosis, such as hypercholesterolemia, CD40 and the RNA-binding protein Quaking, in human cells as well as in mouse disease models. We showed that hyperlipidemia leads to lipid loading in pDCs and subpopulations of CDCs, leading to hyporesponsiveness and reduced DC functionality (Chapters 5 \& 6). These observations indicate that hyperlipidemia could have profound implications to host defense against pathogens and cancer, as well as to tolerance to self. Further investigation (RNA-sequencing, functional assays, etc.) is needed to unravel the mechanism of lipid loading, quenching of immune responses, as well as the total impact on the human immune system and diseases. Our attempts to modulate DC function at a post-transcriptional level establish a role for the RNA-binding protein (RBP) Quaking (QKI) in DC development and function and identified it as an interesting therapeutic target in the treatment of atherosclerosis and/or other inflammatory or auto-immune diseases (Chapter 7). However, knowledge regarding this emerging class of expression pattern regulators is still in its infancy, and strong research efforts are needed to unravel the targets of QKI or to discover the role of the different $\mathrm{QKI}$ isoforms in the various subsets of both murine and human DCs. Although these RBPs or their downstream targets hold promise for new therapeutic options, more knowledge regarding its mechanism of action is required before one can start developing QKI based CVD therapies. Finally, we show that constituve activation of CD40 signaling in DCs reduced atherosclerosis by strong intestinal inflammation resulting in reduced cholesterol levels, a critical driver of atherosclerosis (Chapter 8).

In conclusion, despite the efforts of recent years to characterize DC biology in the context of hyperlipidemia associated atherosclerosis, further studies defining DC (subset) functionality are required before targeted DC therapy will become a valid and safe option to treat cardiovascular diseases. This thesis provides novel insights into the biology of DC subsets in atherosclerosis, establishing the profound impact of hypercholesterolemia on DC function and a minor relevance for cross-presentation and CD8 ${ }^{+} D C s$ in the disease process. Moreover, we identified two interesting avenues for further research in DC modulation as potential therapy for cardiovascular disease. 


\section{References}

1. Gautier EL, Huby T, Saint-Charles F, Ouzilleau B, Pirault J, Deswaerte V, Ginhoux F, Miller ER, Witztum JL, Chapman MJ, Lesnik P. Conventional dendritic cells at the crossroads between immunity and cholesterol homeostasis in atherosclerosis. Circulation. 2009;119:2367-2375

2. Birnberg T, Bar-On L, Sapoznikov A, Caton ML, Cervantes-Barragan L, Makia D, Krauthgamer R, Brenner O, Ludewig B, Brockschnieder D, Riethmacher D, Reizis B, Jung $\mathrm{S}$. Lack of conventional dendritic cells is compatible with normal development and $t$ cell homeostasis, but causes myeloid proliferative syndrome. Immunity. 2008;29:986997

3. Roselaar SE, Kakkanathu PX, Daugherty A. Lymphocyte populations in atherosclerotic lesions of apoe -/- and Idl receptor -/- mice. Decreasing density with disease progression. Arterioscler Thromb Vasc Biol. 1996;16:1013-1018

4. Hu D, Mohanta SK, Yin C, Peng L, Ma Z, Srikakulapu P, Grassia G, MacRitchie N, Dever G, Gordon P, Burton FL, Ialenti A, Sabir SR, McInnes IB, Brewer JM, Garside P, Weber C, Lehmann T, Teupser D, Habenicht L, Beer M, Grabner R, Maffia P, Weih F, Habenicht AJ. Artery tertiary lymphoid organs control aorta immunity and protect against atherosclerosis via vascular smooth muscle cell lymphotoxin beta receptors. Immunity. 2015;42:1100-1115

5. van Dijk RA, Duinisveld AJ, Schaapherder AF, Mulder-Stapel A, Hamming JF, Kuiper J, de Boer OJ, van der Wal AC, Kolodgie FD, Virmani R, Lindeman JH. A change in inflammatory footprint precedes plaque instability: A systematic evaluation of cellular aspects of the adaptive immune response in human atherosclerosis. J Am Heart Assoc. 2015;4

6. Gewaltig J, Kummer M, Koella C, Cathomas G, Biedermann BC. Requirements for cd8 tcell migration into the human arterial wall. Hum Pathol. 2008;39:1756-1762

7. Sancho D, Joffre OP, Keller AM, Rogers NC, Martinez D, Hernanz-Falcon P, Rosewell I, Reis e Sousa $C$. Identification of a dendritic cell receptor that couples sensing of necrosis to immunity. Nature. 2009;458:899-903

8. Hildner K, Edelson BT, Purtha WE, Diamond M, Matsushita H, Kohyama M, Calderon B, Schraml BU, Unanue ER, Diamond MS, Schreiber RD, Murphy TL, Murphy KM. Batf3 deficiency reveals a critical role for cd8alpha+ dendritic cells in cytotoxic $t$ cell immunity. Science. 2008;322:1097-1100

9. Choi JH, Cheong C, Dandamudi DB, Park CG, Rodriguez A, Mehandru S, Velinzon K, Jung $\mathrm{IH}$, Yoo JY, Oh GT, Steinman RM. Flt3 signaling-dependent dendritic cells protect against atherosclerosis. Immunity. 2011;35:819-831

10. Campbell LA, Rosenfeld ME. Infection and atherosclerosis development. Arch Med Res. 2015;46:339-350

11. Paulson KE, Zhu SN, Chen M, Nurmohamed S, Jongstra-Bilen J, Cybulsky MI. Resident intimal dendritic cells accumulate lipid and contribute to the initiation of atherosclerosis. Circ Res. 2010;106:383-390

12. Chyu KY, Zhao X, Dimayuga PC, Zhou J, Li X, Yano J, Lio WM, Chan LF, Kirzner J, Trinidad $P$, Cercek B, Shah PK. Cd8+t cells mediate the athero-protective effect of immunization with an apob-100 peptide. PLoS One. 2012;7:e30780

13. Asano K, Nabeyama A, Miyake Y, Qiu CH, Kurita A, Tomura M, Kanagawa O, Fujii S, Tanaka M. Cd169-positive macrophages dominate antitumor immunity by crosspresenting dead cell-associated antigens. Immunity. 2011;34:85-95

14. Bernhard CA, Ried C, Kochanek S, Brocker T. Cd169+ macrophages are sufficient for priming of ctls with specificities left out by cross-priming dendritic cells. Proc Natl Acad Sci U S A. 2015;112:5461-5466 


\section{9 | General Discussion}

15. Crocker PR, Hartnell A, Munday J, Nath D. The potential role of sialoadhesin as a macrophage recognition molecule in health and disease. Glycoconj J. 1997;14:601-609

16. Hermansson A, Ketelhuth DF, Strodthoff D, Wurm M, Hansson EM, Nicoletti A, Paulsson-Berne G, Hansson GK. Inhibition of t cell response to native low-density lipoprotein reduces atherosclerosis. J Exp Med. 2010;207:1081-1093

17. Sage AP, Murphy D, Maffia P, Masters LM, Sabir SR, Baker LL, Cambrook H, Finigan AJ, Ait-Oufella H, Grassia G, Harrison JE, Ludewig B, Reith W, Hansson GK, Reizis B, Hugues $\mathrm{S}$, Mallat Z. Mhc class ii-restricted antigen presentation by plasmacytoid dendritic cells drives proatherogenic t cell immunity. Circulation. 2014;130:1363-1373

18. Satpathy AT, Kc W, Albring JC, Edelson BT, Kretzer NM, Bhattacharya D, Murphy TL, Murphy KM. Zbtb46 expression distinguishes classical dendritic cells and their committed progenitors from other immune lineages. J Exp Med. 2012;209:1135-1152

19. Swiecki M, Colonna M. The multifaceted biology of plasmacytoid dendritic cells. Nat Rev Immunol. 2015;15:471-485

20. Siegal FP, Kadowaki N, Shodell M, Fitzgerald-Bocarsly PA, Shah K, Ho S, Antonenko S, Liu YJ. The nature of the principal type 1 interferon-producing cells in human blood. Science. 1999;284:1835-1837

21. Monticelli S, Natoli G. Short-term memory of danger signals and environmental stimuli in immune cells. Nat Immunol. 2013;14:777-784

22. Farber DL, Netea MG, Radbruch A, Rajewsky K, Zinkernagel RM. Immunological memory: Lessons from the past and a look to the future. Nat Rev Immunol. 2016;16:124-128

23. Packard RR, Maganto-Garcia E, Gotsman I, Tabas I, Libby P, Lichtman AH. Cd11c(+) dendritic cells maintain antigen processing, presentation capabilities, and cd4(+) t-cell priming efficacy under hypercholesterolemic conditions associated with atherosclerosis. Circ Res. 2008;103:965-973

24. Doring Y, Manthey HD, Drechsler M, Lievens D, Megens RT, Soehnlein O, Busch M, Manca M, Koenen RR, Pelisek J, Daemen MJ, Lutgens E, Zenke M, Binder CJ, Weber C, Zernecke A. Auto-antigenic protein-DNA complexes stimulate plasmacytoid dendritic cells to promote atherosclerosis. Circulation. 2012;125:1673-1683

25. de Bont N, Netea MG, Demacker PN, Verschueren I, Kullberg BJ, van Dijk KW, van der Meer JW, Stalenhoef AF. Apolipoprotein e knock-out mice are highly susceptible to endotoxemia and klebsiella pneumoniae infection. J Lipid Res. 1999;40:680-685

26. Netea MG, Demacker PN, de Bont N, Boerman OC, Stalenhoef AF, van der Meer JW, Kullberg BJ. Hyperlipoproteinemia enhances susceptibility to acute disseminated candida albicans infection in low-density-lipoprotein-receptor-deficient mice. Infect Immun. 1997;65:2663-2667

27. Ludewig B, Jaggi M, Dumrese T, Brduscha-Riem K, Odermatt B, Hengartner $H$, Zinkernagel RM. Hypercholesterolemia exacerbates virus-induced immunopathologic liver disease via suppression of antiviral cytotoxic t cell responses. J Immunol. 2001;166:3369-3376

28. Shamshiev AT, Ampenberger F, Ernst B, Rohrer L, Marsland BJ, Kopf M. Dyslipidemia inhibits toll-like receptor-induced activation of cd8alpha-negative dendritic cells and protective th1 type immunity. J Exp Med. 2007;204:441-452

29. Barchet W, Cella M, Colonna M. Plasmacytoid dendritic cells--virus experts of innate immunity. Semin Immunol. 2005;17:253-261

30. Gursel M, Klinman DM, Gursel I. Plasmacytoid dendritic cell response to cpg odn correlates with cxcl16 expression and is inhibited by ox-Idl. Mediators Inflamm. 2013;2013:312590

31. Dzionek A, Sohma Y, Nagafune J, Cella M, Colonna M, Facchetti F, Gunther G, Johnston I, Lanzavecchia A, Nagasaka T, Okada T, Vermi W, Winkels G, Yamamoto T, Zysk M, 
Yamaguchi Y, Schmitz J. Bdca-2, a novel plasmacytoid dendritic cell-specific type ii ctype lectin, mediates antigen capture and is a potent inhibitor of interferon alpha/beta induction. J Exp Med. 2001;194:1823-1834

32. Cao W, Rosen DB, Ito T, Bover L, Bao M, Watanabe G, Yao Z, Zhang L, Lanier LL, Liu YJ. Plasmacytoid dendritic cell-specific receptor ilt7-fc epsilonri gamma inhibits toll-like receptor-induced interferon production. J Exp Med. 2006;203:1399-1405

33. Meyer-Wentrup F, Benitez-Ribas D, Tacken PJ, Punt CJ, Figdor CG, de Vries IJ, Adema GJ. Targeting dcir on human plasmacytoid dendritic cells results in antigen presentation and inhibits ifn-alpha production. Blood. 2008;111:4245-4253

34. Ohlsson BG, Englund MC, Karlsson AL, Knutsen E, Erixon C, Skribeck H, Liu Y, Bondjers $G$, Wiklund O. Oxidized low density lipoprotein inhibits lipopolysaccharide-induced binding of nuclear factor-kappab to DNA and the subsequent expression of tumor necrosis factor-alpha and interleukin-1beta in macrophages. J Clin Invest. 1996;98:7889

35. Just SA, Nybo M, Laustrup H, Hansen IJ, Junker P, Vinholt PJ. Single test isolated lupus anticoagulant positivity is associated with increased plasma levels of inflammatory markers and dyslipidemia. Lupus. 2015

36. Toms TE, Panoulas VF, Kitas GD. Dyslipidaemia in rheumatological autoimmune diseases. Open Cardiovasc Med J. 2011;5:64-75

37. Rodrigues Dos Santos C, Fonseca I, Dias S, Mendes de Almeida JC. Plasma level of Idlcholesterol at diagnosis is a predictor factor of breast tumor progression. BMC Cancer. 2014;14:132

38. De Stefani E, Mendilaharsu M, Deneo-Pellegrini H, Ronco A. Influence of dietary levels of fat, cholesterol, and calcium on colorectal cancer. Nutr Cancer. 1997;29:83-89

39. Platz EA, Clinton SK, Giovannucci E. Association between plasma cholesterol and prostate cancer in the psa era. Int J Cancer. 2008;123:1693-1698

40. Zielinski CC, Stuller I, Rausch P, Muller C. Increased serum concentrations of cholesterol and triglycerides in the progression of breast cancer. J Cancer Res Clin Oncol. 1988;114:514-518

41. Nelson ER, Wardell SE, Jasper JS, Park S, Suchindran S, Howe MK, Carver NJ, Pillai RV, Sullivan PM, Sondhi V, Umetani M, Geradts J, McDonnell DP. 27-hydroxycholesterol links hypercholesterolemia and breast cancer pathophysiology. Science. 2013;342:1094-1098

42. Alikhani N, Ferguson RD, Novosyadlyy R, Gallagher EJ, Scheinman EJ, Yakar S, LeRoith D. Mammary tumor growth and pulmonary metastasis are enhanced in a hyperlipidemic mouse model. Oncogene. 2013;32:961-967

43. Orange DE, Jegathesan M, Blachere NE, Frank MO, Scher HI, Albert ML, Darnell RB. Effective antigen cross-presentation by prostate cancer patients' dendritic cells: Implications for prostate cancer immunotherapy. Prostate Cancer Prostatic Dis. 2004;7:63-72

44. McDonnell AM, Robinson BW, Currie AJ. Tumor antigen cross-presentation and the dendritic cell: Where it all begins? Clin Dev Immunol. 2010;2010:539519

45. Hakerud M, Selbo PK, Waeckerle-Men Y, Contassot E, Dziunycz P, Kundig TM, Hogset A, Johansen P. Photosensitisation facilitates cross-priming of adjuvant-free protein vaccines and stimulation of tumour-suppressing cd $8 \mathrm{t}$ cells. J Control Release. 2015;198:10-17

46. Angeli V, Llodra J, Rong JX, Satoh K, Ishii S, Shimizu T, Fisher EA, Randolph GJ. Dyslipidemia associated with atherosclerotic disease systemically alters dendritic cell mobilization. Immunity. 2004;21:561-574 


\section{9 | General Discussion}

47. Bursill CA, Castro ML, Beattie DT, Nakhla S, van der Vorst E, Heather AK, Barter PJ, Rye KA. High-density lipoproteins suppress chemokines and chemokine receptors in vitro and in vivo. Arterioscler Thromb Vasc Biol. 2010;30:1773-1778

48. van der Vorst EP, Vanags LZ, Dunn LL, Prosser HC, Rye KA, Bursill CA. High-density lipoproteins suppress chemokine expression and proliferation in human vascular smooth muscle cells. Faseb J. 2013;27:1413-1425

49. De Nardo D, Labzin LI, Kono H, Seki R, Schmidt SV, Beyer M, Xu D, Zimmer S, Lahrmann C, Schildberg FA, Vogelhuber J, Kraut M, Ulas T, Kerksiek A, Krebs W, Bode N, Grebe A, Fitzgerald ML, Hernandez NJ, Williams BR, Knolle P, Kneilling M, Rocken M, Lutjohann D, Wright SD, Schultze JL, Latz E. High-density lipoprotein mediates anti-inflammatory reprogramming of macrophages via the transcriptional regulator atf3. Nat Immunol. 2014;15:152-160

50. Suwandi JS, Toes RE, Nikolic T, Roep BO. Inducing tissue specific tolerance in autoimmune disease with tolerogenic dendritic cells. Clin Exp Rheumatol. 2015;33:S97103

51. Meng X, Yang J, Dong M, Zhang K, Tu E, Gao Q, Chen W, Zhang C, Zhang Y. Regulatory t cells in cardiovascular diseases. Nat Rev Cardiol. 2015

52. Belz GT, Nutt SL. Transcriptional programming of the dendritic cell network. Nat Rev Immunol. 2012;12:101-113

53. Fordham JB, Naqvi AR, Nares S. Regulation of mir-24, mir-30b, and mir-142-3p during macrophage and dendritic cell differentiation potentiates innate immunity. $J$ Leukoc Biol. 2015;98:195-207

54. Turner M, Hodson DJ. An emerging role of rna-binding proteins as multifunctional regulators of lymphocyte development and function. Adv Immunol. 2012;115:161-185

55. van der Veer EP, de Bruin RG, Kraaijeveld AO, de Vries MR, Bot I, Pera T, Segers FM, Trompet S, van Gils JM, Roeten MK, Beckers CM, van Santbrink PJ, Janssen A, van Solingen C, Swildens J, de Boer HC, Peters EA, Bijkerk R, Rousch M, Doop M, Kuiper J, Schalij MJ, van der Wal AC, Richard S, van Berkel TJ, Pickering JG, Hiemstra PS, Goumans MJ, Rabelink TJ, de Vries AA, Quax PH, Jukema JW, Biessen EA, van Zonneveld AJ. Quaking, an rna-binding protein, is a critical regulator of vascular smooth muscle cell phenotype. Circ Res. 2013;113:1065-1075

56. Chenard CA, Richard S. New implications for the quaking rna binding protein in human disease. J Neurosci Res. 2008;86:233-242

57. Fu X, Feng Y. Qki-5 suppresses cyclin d1 expression and proliferation of oral squamous cell carcinoma cells via mapk signalling pathway. Int J Oral Maxillofac Surg. 2015;44:562-567

58. Wang $\mathrm{Y}$, Vogel G, Yu Z, Richard S. The qki-5 and qki-6 rna binding proteins regulate the expression of microrna 7 in glial cells. Mol Cell Biol. 2013;33:1233-1243

59. Doukhanine E, Gavino C, Haines JD, Almazan G, Richard S. The qki-6 rna binding protein regulates actin-interacting protein-1 mrna stability during oligodendrocyte differentiation. Mol Biol Cell. 2010;21:3029-3040

60. Foks AC, Lichtman AH, Kuiper J. Treating atherosclerosis with regulatory t cells. Arterioscler Thromb Vasc Biol. 2015;35:280-287

61. Lutgens E, Lievens D, Beckers L, Wijnands E, Soehnlein O, Zernecke A, Seijkens T, Engel D, Cleutjens J, Keller AM, Naik SH, Boon L, Oufella HA, Mallat Z, Ahonen CL, Noelle RJ, de Winther MP, Daemen MJ, Biessen EA, Weber C. Deficient cd40-traf6 signaling in leukocytes prevents atherosclerosis by skewing the immune response toward an antiinflammatory profile. J Exp Med. 2010;207:391-404

62. Donners MM, Beckers L, Lievens D, Munnix I, Heemskerk J, Janssen BJ, Wijnands E, Cleutjens J, Zernecke A, Weber C, Ahonen CL, Benbow U, Newby AC, Noelle RJ, 
Daemen MJ, Lutgens E. The cd40-traf6 axis is the key regulator of the cd40/cd40I system in neointima formation and arterial remodeling. Blood. 2008;111:4596-4604

63. Chyu KY, Zhao X, Reyes OS, Babbidge SM, Dimayuga PC, Yano J, Cercek B, Fredrikson GN, Nilsson J, Shah PK. Immunization using an apo b-100 related epitope reduces atherosclerosis and plaque inflammation in hypercholesterolemic apo e (-/-) mice. Biochem Biophys Res Commun. 2005;338:1982-1989

64. Fredrikson GN, Andersson L, Soderberg I, Dimayuga P, Chyu KY, Shah PK, Nilsson J. Atheroprotective immunization with mda-modified apo $b-100$ peptide sequences is associated with activation of th 2 specific antibody expression. Autoimmunity. 2005;38:171-179

65. Fredrikson GN, Bjorkbacka H, Soderberg I, Ljungcrantz I, Nilsson J. Treatment with apo b peptide vaccines inhibits atherosclerosis in human apo b-100 transgenic mice without inducing an increase in peptide-specific antibodies. J Intern Med. 2008;264:563-570

66. Palinski W, Miller E, Witztum JL. Immunization of low density lipoprotein (Idl) receptordeficient rabbits with homologous malondialdehyde-modified Idl reduces atherogenesis. Proc Natl Acad Sci U S A. 1995;92:821-825

67. Ameli S, Hultgardh-Nilsson A, Regnstrom J, Calara F, Yano J, Cercek B, Shah PK, Nilsson J. Effect of immunization with homologous Idl and oxidized Idl on early atherosclerosis in hypercholesterolemic rabbits. Arterioscler Thromb Vasc Biol. 1996;16:1074-1079

68. Freigang S, Horkko S, Miller E, Witztum JL, Palinski W. Immunization of Idl receptordeficient mice with homologous malondialdehyde-modified and native Idl reduces progression of atherosclerosis by mechanisms other than induction of high titers of antibodies to oxidative neoepitopes. Arterioscler Thromb Vasc Biol. 1998;18:19721982

69. Shah PK, Chyu KY, Dimayuga PC, Nilsson J. Vaccine for atherosclerosis. J Am Coll Cardiol. 2014;64:2779-2791

70. Eyrich M, Schreiber SC, Rachor J, Krauss J, Pauwels F, Hain J, Wolfl M, Lutz MB, de Vleeschouwer S, Schlegel PG, Van Gool SW. Development and validation of a fully gmp-compliant production process of autologous, tumor-lysate-pulsed dendritic cells. Cytotherapy. 2014;16:946-964

71. Habets KL, van Puijvelde GH, van Duivenvoorde LM, van Wanrooij EJ, de Vos P, Tervaert JW, van Berkel TJ, Toes RE, Kuiper J. Vaccination using oxidized low-density lipoprotein-pulsed dendritic cells reduces atherosclerosis in Idl receptor-deficient mice. Cardiovasc Res. 2010;85:622-630

72. Hermansson A, Johansson DK, Ketelhuth DF, Andersson J, Zhou X, Hansson GK. Immunotherapy with tolerogenic apolipoprotein b-100-loaded dendritic cells attenuates atherosclerosis in hypercholesterolemic mice. Circulation. 2011;123:10831091

73. Grubeck-Loebenstein B, Della Bella S, lorio AM, Michel JP, Pawelec G, Solana R. Immunosenescence and vaccine failure in the elderly. Aging Clin Exp Res. 2009;21:201209 



\section{Summary}

Cardiovascular diseases are still the leading cause of mortality worldwide. Its most common underlying cause, atherosclerosis, is a lipiddriven chronic inflammatory disease of the arterial wall, involving both innate and adaptive immune responses. Specialized immune cells such as monocytes, macrophages, granulocytes, B and T cells, exert a range of inflammatory processes that drive disease progression. Data from the last decade indicate that another set of immune cells, the dendritic cells (DCs), known immune orchestrators, are involved in the disease process. DCs are present in atheroscleris-prone regions in healthy vessels and accumulate during disease progression. Moreover, they are in close contact with $\mathrm{T}$ cells inside the atherosclerotic lesion and were shown to present prototype/model antigens to $\mathrm{CD} 4^{+} \mathrm{T}$ cells in aortic explants. Although dendritic cells hold potential for the development of new efficient therapies, knowledge regarding the mechanisms by which DCs, in particular DC subsets, influence the pathogenesis of atherosclerosis is largely lacking. In addition, how DC subsets function in an atherosclerosis relevant hyperlipidemic environment and how DCs can be efficiently modulated to improve disease outcome remain poorly understood. Consequently, this thesis focuses on elucidating the contribution of DC subsets in hyperlipidemia-associated atherosclerosis and discusses potential modulators of DC differentiation and function relevant to atherosclerosis. In Chapter 2, we reviewed the current knowledge on the pathogenesis of atherosclerosis as a chronic inflammatory disorder, discussing the involvement of different innate and adaptive immune cells, as well as their interactions. Chapter 3 summarizes the current view on the role of particular DC subsets in cardiovascular diseases, identifying underlying patterns, gaps in knowledge, as well as describing their potential as therapeutic targets in CVDs. In Chapter 4, we made use of the $\mathrm{Batf}^{--}$model to investigate the role of $\mathrm{CD} 8^{+} \mathrm{CDCs}$, and more general cross-presentation in atherosclerosis. As $C D 8^{+} C D C$ deficiency did not alter atherosclerosis outcome, we concluded that $C D 8^{+} \mathrm{CDCs}$ and crosspresentation exerted by this subset play only a minor role in atherosclerosis. As hyperlipidemia, a key risk factor for atherosclerosis, was suggested to interfere with DC function we investigated its impact on DC progenitors, on mature DC subsets and on their activation status and function in Chapters 5 and 6 . Chapter 5 focuses on the impact of hyperlipidemia on human pDCs. We 
demonstrated that human pDCs engulf lipids when exposed to excessive amounts of LDL or oxLDL in vitro, resulting in ablation of Toll-like receptor 7 and 9 induced pDC activation as witnessed by quenched production of proinflammatory cytokines as well as by downregulation of maturation markers. Eventually, oxLDL- abrogation of pDC activation resulted in impaired $\mathrm{CD}^{+} \mathrm{T}^{-}$ cell polarization. In Chapter 6, we addressed the early adaptive effects of hypercholesterolemia in DC (precursor) homeostasis, on DC lipid accumulation and on its consequences for T cell priming capacity in vivo. Our results indicate that HFD feeding augments MDP proliferation and numbers, but did not affect DC subset numbers in lymphoid compartments. However, HFD resulted in lipid accumulation by $\mathrm{CD}^{-}$, and to a lesser extent $\mathrm{CD} 8^{+}$conventional $\mathrm{DCs}$ (cDC), but not plasmacytoid DCs (pDCs). Lipid loading resulted in increased costimulatory molecules expression, accumulation, and baseline TLR activation-associated cytokine release (IL-1 $\beta, \mathrm{IL}-6, \mathrm{TNF}-\mathrm{a})$ by $\mathrm{CD} 8^{-} \mathrm{cDCs}$, but caused a reduction in CD8 ${ }^{-} D C s^{\prime}$ capacity to stimulate naïve $\mathrm{CD}^{+} \mathrm{T}$ cells. Whether hyperlipidemia results in impaired host's defense against pathogens in humans remains elusive. In Chapters $\mathbf{7}$ and 8, we investigated potential targets to modulate DC function in order to improve atherosclerosis disease outcome. Chapter 7 focused on the role of the RNA-binding protein Quaking (QKI) in DC development and function, and its impact on atherosclerosis. We used a model in which QKI was conditionally deleted in CD11c expressing DCs. QKI deficiency resulted in reduced $D C$ generation and proinflammatory cytokine production by DCs in vitro and skewed DC differentiation towards CD8 ${ }^{-} D C$ in vivo. CD11Crestricted loss of QKI indirectly resulted in a $\mathrm{CD}^{+}$shifted $\mathrm{T}$ cell profile and decreased $\mathrm{CD}^{+}$Th17 to Treg ratio. In the context of atherosclerosis, CD11C restricted loss of QKI expression attenuated plaque development and necrotic core size formation, indicating the potential as a target for therapy. In Chapter 8, we show that constituve activation of CD40 signaling in DCs reduced atherosclerosis by strong intestinal inflammation resulting in reduced cholesterol levels, a critical driver of atherosclerosis. Finally, Chapter 9 summarizes and discusses the most important findings of this thesis and defines the most relevant outstanding questions and future perspectives. 
Altogether, this thesis provides novel insights into the biology of DC subsets in atherosclerosis, establishing the profound impact of hypercholesterolemia on DC function and a minor relevance for crosspresentation and $C D 8^{+} D C s$ in the disease process. Moreover, we identified two interesting avenues for further research in DC modulation as potential therapy for cardiovascular disease. 



\section{Samenvatting}

Hart- en vaatziekten (HVZ) zijn tot op heden nog steeds de belangrijkste doodsoorzaak wereldwijd. Het meest voorkomende pathologische proces dat hieraan ten grondslag ligt is atherosclerose. Atherosclerose is een lipide gedreven chronische ontstekingsziekte van de vaatwand, waarbij zowel aangeboren als verworven immuunreacties een grote rol spelen. Gespecialiseerde immuuncellen, zoals monocyten, macrofagen, granulocyten, B en T cellen, zijn verantwoordelijk voor een groot aantal ontstekingsreacties die samen bijdragen aan de progressie van de ziekte. Uit bevindingen van de laatste tien jaar blijkt dat ook een andere groep immuuncellen, namelijk de dendritische cellen (DCs), betrokken zijn in het ziekteproces. DCs zijn sleutelfiguren in het regelen van het immuunsysteem en het koppelen van aangeboren en verworven immuunreacties. Ze zijn aanwezig in atherosclerose-gevoelige gebieden van gezonde bloedvaten en stapelen daar op naarmate de ziekte verergert. Bovendien worden ze in atherosclerotische leasies aangetroffen in nauw contact met $T$ cellen en heeft men aangetoond dat ze in gedissecteerde aortas in staat zijn om prototype/model antigenen te presenteren aan $\mathrm{CD}^{+} \mathrm{T}$ cellen. Hoewel dendritische cellen potentieel hebben voor het ontwikkelen van nieuwe efficiënte behandelingen ontbreekt voor een groot deel de kennis van de mechanismen waarbij DCs, en in het bijzonder hun specifieke subsets, de pathogenese van de ziekte beïnvloeden. Verder is er nog maar weinig bekend over hoe DC subsets functioneren in een ovematig vetrijke omgeving (relevant in atherosclerose) en over hoe DCs efficiënt kunnen worden beïnvloed om de uitkomst voor de patient te verbeteren. Dit proefschrift focust dan ook op de bijdrage van DC subtypes tot hyperlipidemia-geassocieerde atherosclerose. Daarnaast bespreken we potentiële regelmechanismen van DC ontwikkeling en functie relevant voor de behandeling van atherosclerose. In hoofdstuk $\mathbf{2}$ geven we een overzicht van de stand van zaken over de pathogenese van atherosclerose als chronische ontstekingsziekte. Hierbij wordt zowel de betrokkenheid van, alsook de onderlinge interacties tussen, cellen van het aangeboren en verworven immuunsysteem besproken. Hoofdstuk 3 beschrijft de huidige kennis over de rol van DC subtypes in HVZ. Hierbij ontrafelen we onderliggende patronen en brengen we tekortkomingen en mogelijkheden van DCs als therapeutische targets in HVZ in kaart. In hoofdstuk 4 maken we 


\section{Samenvatting}

gebruiken van het $\mathrm{Batf}^{-/}$model om de rol van $\mathrm{CD} 8^{+} \mathrm{CDC}$, en meer algemeen kruis-presentatie, in atherosclerose te bestuderen. Gezien verlies aan $\mathrm{CD} 8^{+} \mathrm{CDCs}$ en hun kruispresentatie geen impact hadden op atherosclerose kunnen we besluiten dat deze slechts een beperkte rol spelen in atherosclerose. Aangezien hyperlipidemie, een belangrijke risicofactor van atherosclerose, mogelijks een invloed heeft op DC functie hebben we het effect hiervan op DC voorlopercellen, mature DC subsets, DC activatie status en hun functies bestudeerd in hoofdstukken $\mathbf{5}$ en $\mathbf{6}$. Hoofdstuk $\mathbf{5}$ focust op de impact van hyperlipidemie op humane plasmacytoide DCs (pDCs). We tonen aan dat human pDCs lipiden opnemen wanneer ze in vitro worden blootgesteld aan overmatige hoeveelheden LDL of oxLDL. Dit resulteert in een remming van Toll-like receptor 7 en 9 geïnduceerde activatie van pDCs, leidend tot verminderde productie van pro-inflammatoire cytokines alsook een verlaagde expressie van maturatie merkers. Uiteindelijk zorgt de blokkering van $\mathrm{pDC}$ activatie door oxLDL voor verminderde $\mathrm{CD}^{+}{ }^{+} \mathrm{T}$ polarisatie. In hoofdstuk 6 onderzoeken we in vivo de vroege adaptieve effecten van hypercholesterolemie op DC (voorloper) homeostase, opstapeling van lipiden door DCs en de gevolgen voor hun T cel priming capaciteit. Onze resultaten tonen aan dat vetrijke dieet (HFD) zorgt voor een verhoging van monocyt en dendritische cell voorloper (MDP) deling en aantallen, maar geen invloed heeft op DC subset aantallen in lymfoïde compartimenten. Echter, HFD resulteert wel in opstapeling van lipiden in $\mathrm{CD} 8^{-} \mathrm{CDCs}$ en in mindere mate ook $\mathrm{CD} 8^{+} \mathrm{CDCs}$, maar niet in pDCs. Lipide lading in $\mathrm{CD} 8 \mathrm{CDCs}$ zorgt voor een verhoogde expressie van costimulatoire moleculen en verhoogde secretie van cytokines (IL-1 $\beta$, IL-6, TNF- $\alpha$ ), maar veroorzaakt een vermindering van de capaciteit CD8CDCs om naïeve $\mathrm{CD}^{+} \mathrm{T}$ cellen te stimuleren. Desondanks moet nog bevestigd worden of de effecten van hyperlipidemie leiden tot een verminderde afweer tegen ziekteverwekkers bij de mens. In hoofdstuk 7 en 8 bestuderen we potentiële mechanismen om DC functie te regelen om zo atherosclerose te verbeteren. Hoofdstuk 7 focust op de rol van de RNA-bindende eiwitten Quaking (QKI) in DC ontwikkeling en function, en hun impact op de ontwikkeling van atherosclerose. We gebruiken een model waarbij QKI conditioneel wordt verwijderd in cellen die CD11c tot uitdrukking brengen.

In vitro resulteert QKI deficiëntie in een afname van DC ontwikkeling en pro-inflammatoire cytokine productie door DCs. In vivo duwt CD11c-QKI deletie de differentiatie van $D C$ in de richting $C D 8{ }^{-} D C$ en resulteert het 
indirect in een meer $\mathrm{CD} 8^{+}$getint $\mathrm{T}$ cel profiel en een vermindere $\mathrm{CD} 4^{+} \mathrm{Th} 17$ over Treg balans. In een context van atherosclerose leidt deletie van QKI in $\mathrm{CD}_{11} \mathrm{c}^{+}$cellen tot een vermindering van plaque ontwikkeling en tot een kleinere necrotische kern. Dit wijst op een mogelijkheid voor QKI als doelwit voor therapie. In hoofdstuk 8 tonen we aan dat aanhoudende activatie van CD40 signalisatie in DCs atherosclerose vermindert door het induceren van ernstige intestinale inflammatie resulterend in cholesterol verlaging, een belangrijke factor in atheroslcerose. Tot slot bediscussiert hoofdstuk 9 de meest opmerkelijke bevindingen van deze thesis en geeft het de meeste relevante openstaande vragen en toekomstperspectieven aan.

Samenvattend, bieden de resultaten van deze thesis nieuwe inzichten in de biologie van DC subtypes en hun rol in atherosclerose, duidend op de grote invloed van hypercholesterolemie op DC functie en draagt het bij aan de kennis betreffende de rol van kruispresentatie en $C D 8^{+} \mathrm{CDCs}$ in het ziekteproces. Bovendien definieren we twee interessante mogelijkheden voor verder onderzoek naar het regelen van DCs als potentiële therapie voor harten vaatziekten. 



\section{Valorisation}

\section{Cardiovascular diseases, more than a killer}

As mentioned previously, cardiovascular diseases (CVDs) are still the leading cause of mortality worldwide, accounting for 17.5 million deaths in 2012 (World Health Organization, WHO). These numbers are even expected to rise to 24 million by 2030. Besides the enormous impact on human health, CVD also has a profound effect on healthcare costs. In the United States (US) alone CVD was responsible for $17 \%$ of national health expenditures in 2010 and this percentage is expected to increase dramatically in the coming years. Between 2010 and 2030 medical costs of CVD in the US are projected to triple, from \$273 billion to \$818 billion (Heidenrich et al., 2011, Circulation). Importantly, CVD also impacts on the patietns social life as clinical events can lead to immobilization, brain damage etc.

CVDs and their socio-economic impact can be combatted by multiple approaches. First, primary prevention is a key determinant as reduction of behavioural risk factors such as tobacco use, unhealthy diet, obesity, physical inactivity and alcohol abuse, will in the long run strongly diminish CVD incidence (WHO). Moreover, these factors can be addressed at low cost. Second, secondary prevention in people with already established disease should be addressed. Current treatment such as lipid lowering drugs (e.g. statins, ezetimide, fibrates), antihypertensive drugs (e.g. ACE inhibitors, AT receptor antagonists, beta-blockers) and antithromobtic therapy (e.g. aspirin, clopidogrel) have shown their effectiveness. Third, costly surgery (e.g. coronary bypass, valve replacement) sometimes is an option to treat CVD (WHO) and to reduce the risk of clinical complications. Fourth, improving (early) diagnosis and fine tune the appropriate treatment groups for tailored therapy,is important as today people are often only diagnosed upon an overt clinical event. Although progress in all of these areas has been made, CVD remains the major cause of death. Therefore, development of new therapies that show effectiveness, preferably at a low cost, is required. 


\section{CVD reduction by targetting atherosclerosis}

The main underlying cause of most CVDs is atherosclerosis. A better understanding of the complex disease pathology is necessary in order to discover new therapeutic options, indicating the importance of fundamental research in parallel to applied research. Here, we discuss some contributions of this thesis towards valorization possibilities and discuss future perspectives.

$C D 8^{+} D C s$ can be excluded as interesting therapeutic target for atherosclerosis

The role of the immune system in atherosclerosis has been studied extensively, however research on dendritic cells (DCs) is relatively new. DCs hold potential as therapeutic target as they play a major function in regulating the immune system. However, they are a heterogenous population of cells and each subset probably contributes to the disease in a different way. Except for pDCs, little is known regarding DC subset contribution to atherosclerosis. This thesis provides new insight in the DC biology in atherosclerosis, as our findings in Chapter 4 indicate that $C D 8^{+} D C s$ and possibly cross-presentation are at most minor contributors to atherosclerosis progression. In addition, DCs have been implicated in regulating cholesterol homeostasis, we here show that CD8 ${ }^{+} D C s$ are not the DC subset responsible for this effect. Altogether, our study suggested that $C D 8^{+} D C$ can be exluded as interesting therapeutic target option for atherosclerosis treatment.

Quaking as potential therapy for inflammatory and auto-immune diseases

In Chapter 7, we show that QKI deficiency was able to reduce atherosclerosis, suggesting it has potential as a new target for treatment of vascular disease. Moreover, loss of QKI augmentated Treg and reduced Th17 T cell numbers. Both cell types and their balance are important in inflammation as well as auto-immune disease, rendering QKI also a possible candidate for the treatment of these disorders.

Quaking isoforms are ubiquitously expressed and influence a wide range of cellular functions, making it difficult to specifically target certain cell types for therapy without inducing undesireable side effects. Therefore, identifying the 
disease-relevant targets of Quaking will help to develop specific, efficient and safe therapy. We are currently analyzing RNA sequencing data that will provide us this new information. Moreover, delivery systems, like viral vectors, have greatly improved over the past years. Specific targeting of certain cell types by use of specially designed viral vectors may reduce the risk for off target effects.

A possibility to implement Quaking targeting drugs into therapy may involve Quaking (or the Quaking target) gene therapy, in analogy to miRNA regulation or CRISPR/Cas9-based genome engineering in the treatment of cardiovascular, inflammatory or auto-immune diseases (Rincon et al., 2015, Cardiovascular Research). miRNAs have emerged as potential therapeutic targets in CVD as they are able to mediate quantitative and coordinate changes to the transcriptome of disease relevant gene sets. RNA-binding proteins like Quaking represent an additional level of control as they are also able to qualitatively influence the transcriptome. However, this approach also has its limitations as Quaking is ubiquitously expressed and is involved in the regulation of many critical processes (neural development and maintenance, myeloid cell regulation, smooth and cardiac muscle cell regulation). Therefore, influencing specific Quaking targets will be required in order to minimize side effects.

Influencing CD40 signaling as a new generation of atherosclerosis therapy

Inhibition of CD40-CD40L interactions strongly reduces atherosclerosis. However, complete inhibition of CD40-CD40L signaling is not therapeutically feasible as long-term treatment will compromise systemic immune responses and was shown to entail thromboembolic complications (Lutgens E, 2010, J Exp Med). Therefore, more specific approaches which induce fewer and less severe side effects are required. Cell-specific targeting could reduce side effects and CD40 signaling on both platelets and leukocytes were shown responsible for the beneficial effect on atherosclerosis. DCs are interesting candidates for CD40 treatment as they strongly express these molecules and are able to influence immune reponses. However, as we showed that altering CD40 activity can have a profound effect on the autoimmune control (as reflected by the gastro-intestinal inflammation in CD11C-LMPca), more specific approaches are necessary (Chapter $\mathbf{8}$ ). In that respect, interference in CD40 TRAF6- 
signaling, genetically or with targeted small molecule drugs, was shown to confer an almost equal atheroprotective effect as seen with complete CD40 deficiency. Therefore, these drugs may hold promise for the development of a new effective therapy for atherosclerosis.

\section{Hypercholesterolemia, more than a risk factor for CVD}

Dendritic cells play a crucial role in host immune responses to pathogens. Chapter 5 and 6 show that hypercholesterolemia profoundly impacts DC function, therefore people suffering from hypercholesterolemia are not only at risk for developing CVD, but are possibly also more vulnerable to viral and bacterial infections. Treating these patients with lipid-lowering drugs may therefore not only benefit CVD outcome but also restore patient's defense against pathogens.

\section{Implications of thesis findings for cancer therapy}

\section{A possible role for Quaking in DC-based cancer vaccination}

Cancer immunotherapy, at least in part, focusses on designing vaccines to promote strong tumor specific $\mathrm{T}$ cell responses in order to eradicate tumors. DCs as the most potent antigen presenting cells play key roles in this process.. In the past, various strategies of DC-based immunotherapy were adopted in clinical studies, however clinical responses remain relatively low (van Lint, 2014, Cancer immunology, immunotherapy). Besides antigen choice also the immune state of the dendritic cell is of great importance. Better outcome can therefore be achieved by enhancing the maturation state of the DCs, for example by co-electroporation of antigen with mRNA encoding for CD40L, CD70 and a constitutive active form of TLR4 (van Lint, 2014, Cancer immunology, immunotherapy). As our results in Chapter 7, indicate that Quaking influences DC cytokine production and likely also maturation, Quaking could be an interesting candidate to improve DC activation state for DC immunotherapy. 
A role for constitutive CD40 signaling in tumor-DC vaccination?

As mentioned previously, the immune state of the $D C$ is a cricital factor for succesfull tumor-DC vaccination. As CD40 signaling is important in DC maturation and function, the constitutive CD40 signaling chimeric LMP/CD40 protein may provide a beneficial contribution in DC activation required for effective DC immunotherapy (Chapter 8). Currently, scientist are using electroporation of mRNA of CD40 or CD80 along with the Ag loading in DCs to boost the immune state of DCs. Electroporation of LMP-CD40 mRNA might improve these results.

In conclusion, noticeable progression has been made in the treament of atherosclerosis. However, as CVD remains the major cause of death we need to continue our efforts. With the inflammatory component of atherosclerosis pathogenesis being well established, developing new drugs that influence atherosclerosis specific immune responses is of importance. 



\section{Academic curriculum vitae \\ PERSONAL INFORMATION \\ Full name: \\ Bart (Roger Jozef) Legein \\ Nationality: \\ Belgian \\ Date of birth: \\ $16^{\text {th }}$ June 1988 \\ Place of birth: \\ Knokke}

\section{PROMOTION/EDUCATION}

09/2011 - 12/2015:

Ph.D. program at the Experimental Vascular Pathology lab, Cardiovascular Research Institute Maastricht (CARIM), University of Maastricht, NL. Thesis title: Role of dendritic cell subsets in hyperlipidemia and atherosclerosis

09/2006 - 06/2011: $\quad$ Studies of Biomedical Sciences (Bachelor and Master) - Biomedical research at the Free University of Brussels, Campus Jette - Faculty of Medicine and Pharmacy, Belgium. (final grade = summa cum laude)

09/2010 - 06/2011: Diploma thesis at the Beta Cell Neogenesis (BeNe) lab, Diabetes Research Center, Free University of Brussels.

Thesis title: Impact of the estrogen receptor antagonist tamoxifen on pancreatic beta cell proliferation and neogenesis

\section{(INTER)NATIONAL INTERNSHIPS}

01/2014-02/2014: Internship at the Division of Cellular and Molecular Immunology; Cincinnati Children's Hospital Research Foundation; University of Cincinnati College of Medicine; Cincinnati, OH USA. Supported by Boehringer Ingelheim Travel Grant

07/2013:

Internship at the Experimental Vascular Biology lab, University of Amsterdam, Academic Medical Center (AMC), Amsterdam, The Netherlands.

04/2012 - 05/2012: Internship at Institute for Cardiovascular Prevention (IPEK), Ludwig Maximilian University (LMU), Munich, Germany. Supported by Boehringer Travel Grant

02/2010 - 05/2010: Internship at the Department of Pathology, Maastricht University (CARIM), Maastricht, The Netherlands. Supported by Erasmus 


\section{PRESENTATIONS AT SCIENTIFIC CONFERENCES}

09/2014:

Poster presentation: $13^{\text {th }}$ International symposium on Dendritic Cells, Tours, France

07/2014:

Poster presentation: European Society of Cardiology, Frontiers in CardioVascular Biology 2014 Congres, Barcelona, Spain

$03 \& 11 / 2014$ :

2 Oral presentations: MIMSA symposium, Maastricht, The Netherlands

10/2013:

Oral and poster presentation: Hartstichting Cardiovascular PhD training course:

Atherothrombosis and Coagulation. Papendal, The Netherlands

09/2012:

Poster presentation: Abcam meeting on Inflammation and Atherosclerosis. Munich, Germany

04/2011: Poster presentation: Maastricht Medical Student Research Conference, Maastricht, The Netherlands.

\section{PRICES-AWARDS-GRANTS}

10/2015:

01/2014:

10/2013:

04/2012:

04/2011:
Oral presentationaward at Pathology Maastricht Science Day

Boehringer Ingelheim Travel grant as support for internship Cincinnati

Poster oral presentation award: Hartstichting Cardiovascular PhD training course

Boehringer Ingelheim Travel grant as support for internship Munich

Poster award: Maastricht Medical Student Research Conference, Maastricht, The Netherlands. 


\section{PUBLICATIONS}

Legein B, Vogel G, van der Veer E, Wijnands E, Theelen TL, Zonneveld AJ, Temmerman L, Schalkwijk CG, Lutgens E, Zenke M, Richard S, and Biessen EA. Quaking deficiency in $\mathrm{CD} 11 \mathrm{c}$ dendritic cells attenuates atherosclerosis by shifting CD4 to CD8 T cell balance and favoring CD4 T cell polarization towards a regulatory phenotype. In preparation.

Christ A*, Legein B*, Oth T, Wijnands E, Vanderlocht J, Zenke M, Daemen MJ, Biessen EA. Low density lipoprotein exposure interferes with TLR7 and 9 induced plasmacytoid dendritic cell activation .

In preparation.

Christ A, Legein B, Wijnands E, Otten J, Temmerman L, Daemen MJ, Biessen EA. Early adaptive effects of peripheral dendritic cell subsets to hyperlipidemia: impact on phenotype and capacity to prime naïve T cells. In preparation.

Smeets E, Legein B, Seijkens T, Gijbels M, Bürger C, Barthels C, Biessen EA, Brocker $T$, Gerdes N, Lutgens E. Constitutively active Dendritic Cell CD40-signaling paradoxically retards atherosclerosis due to GI-tract inflammation and ensuing cholesterol lowering. In preparation.

Theelen TL, Marsch E, Legein B, Austen L, Janssen A, Jeurissen ML, Shiri-Sverdlov R, Gijbels MJ, Biessen EA, Betsholtz C, Daemen MJ, Sluimer JC. Deficiency of platelet derived growth factor $B$ retention motif is associated with increased atherosclerotic plaque fibrosis and size. In preparation.

Legein B, Janssen E, Theelen T, Gijbels M, Walraven J, Klarquist J, Hennies C, Wouters K, Seijkens T.T.P., Wijnands E, Sluimer J, Lutgens E, Zenke M, Hildner K, Biessen E.A.L., Temmerman L. Ablation of CD8 $\alpha+$ dendritic cell mediated crosspresentation does not impact atherosclerosis in hyperlipidemic mice. Sci Rep. 2015 Yuchi Y, Cai Y, Legein B, Leuckx G, De Groef S, Coppens V, Van Overmeire E, Staels W, De Leu N, Martens G, Van Ginderachter J, Heimberg H, Van de Casteele M. Estrogen receptor alpha regulates beta cell formation during pancreas development and following injury. Diabetes. 2015 Sep.

Christ A, Temmerman L, Legein B, Daemen M, Biessen E. Dendritic cells in cardiovascular diseases: epiphenomenon, contributor or therapeutic opportunity. Circulation. 2013 Dec 17.

Legein B, Temmerman L, Biessen EA, Lutgens E. Inflammation and immune system interactions in atherosclerosis. Cell Mol Life Sci. 2013 Feb 21. 



\section{List of abbreviations}

(N)STEMI

7-AAD

$\mathrm{Ab}$

ABCA1

ABCG1

Abs

ACAT

ACE inhibitor

$\mathrm{ACl}-\mathrm{S}$

ADFP

$\mathrm{Ag}$

AGEs

AHS

AIS

AMI

Ang II

AP-1

APC

APC

ApoA

ApoB100

ApoE

Arg

ASMA

AT receptor

ATLO

ATP

BATF3, Batf3

BCA

BDCA-2

BDCA-3

BDCA-4

BM

BrdU

BSA (non) ST-segment elevation myocardial infarction

7-Aminoactinomycin D

Antibody

ATP-binding cassette transporter ABCA1

ATP-binding cassette sub-family $\mathrm{G}$ member 1

antibodies

acyl-CoA cholesterol ester transferase

angiotensin-converting-enzyme inhibitor

asymptomatic cerebral infarction stenosis

Adipose differentiation-related protein

antigen

advanced glycation end products

acute haemorrhagic stroke

acute ischemic stroke

acute myocardial infarction

angiotensin II

activator protein 1

antigen presenting cell

allophycocyanin

Apolipoprotein A

Apolipoprotein B100

Apolipoprotein $\mathrm{E}$

arginase

alpha smooth muscle actin

Angiotensin II receptor

Artery Tertiary Lymphoid Organs

Adenosine triphosphate

basic leucine zipper transcription factor ATF-like 3

bicinchoninic acid

blood leukocyte antigen 2

Thrombomodulin

blood dendritic cell antigen 4

bone marrow

5-bromo-2'-deoxyuridine

bovine serum albumin 
BST2

BW

C/EBP

Ca blockers

CAD

CBA

CCL2

CCR4

CCR7

CD

CD11c-Qk

CDC

CDP

CEA

centr. memory

CFSE

$\mathrm{CIA}$

CLI

CLP

CLR

CMP

CRAMP

cre

CreER

CTL

CTLA-4

Ctr, Ctrl

CVD

CX3CR1

CXCL

DAMPs

DC

DCF

DCFDA

DCIR

DC-SIGN bone marrow stromal antigen 2

body weight

CCAAT-enhancer-binding proteins

Calcium blokkers

coronary artery disease

Cytometric Bead Array

chemokine ( $\mathrm{C}-\mathrm{C}$ motif) ligand 2

C-C chemokine receptor type 4

C-C chemokine receptor type 7

cluster of differentiation

CD11c-cre x Quaking flox/flox

conventional dendritic cell

common DC progenitor

carotid endarterectomy

central memory

Carboxyfluorescein succinimidyl ester

Central Intelligence Agency

critical limb ischemia

common lymphoid progenitor

c-type lectin receptor

common myeloid progenitor

cathelin-related antimicrobial peptide, cathelicidin

cre recombinase

tamoxifen inducible cre recombinase

cytotoxic T lymphocyte

cytotoxic T lymphocyte antigen 4

control

cardiovascular diseases

CX3C chemokine receptor 1

CXC-chemokine ligand

danger associated molecular patterns

dendritic cell

2', 7' -dichlorofluorescin

$2^{\prime}, 7^{\prime}$-dichlorofluorescein diacetate

dendritic cell immuno-receptor

dendritic Cell-Specific Intercellular

Grabbing Non-integrin adhesion

molecule-3- 


\begin{tabular}{|c|c|}
\hline DEPC & Diethylpyrocarbonate \\
\hline Dil & $\begin{array}{l}\text { 1,1'-dioctadecyl-3,3,3',3'-tetramethylindocarbocyanine } \\
\text { perchlorate }\end{array}$ \\
\hline DN DC & double negative dendritic cell, being $\mathrm{CD} 4^{-} \mathrm{CD} 8^{-}$ \\
\hline DNA & Deoxyribonucleic acid \\
\hline DTA & diphtheria toxin fragment $A$ \\
\hline DTR & diphtheria toxin receptor \\
\hline e.g. & exempli gratia, for example \\
\hline E4BP4 & promoter-binding protein 4 \\
\hline EC & endothelial cell \\
\hline ECM & extracellular matrix; \\
\hline EDTA & Ethylenediaminetetraacetic acid \\
\hline eff. memory & effector memory \\
\hline ELISA & enzyme-linked immunosorbent assay \\
\hline ER & endoplasmic reticulum \\
\hline etc. & et cetera, "and so forth" \\
\hline FACS & fluoresence activated cell sorter \\
\hline FCS & fetal calf serum \\
\hline FcyRI & Fc gamma receptor 1 \\
\hline FITC & fluorescein isothiocyanate \\
\hline FLT3 & Fms-like tyrosine kinase 3 \\
\hline FLT3L & Fms-like tyrosine kinase 3 ligand \\
\hline FLT3R & Fms-like tyrosine kinase 3 receptor \\
\hline FoxP3 & forkhead box P3 \\
\hline FSC & forward scatter \\
\hline GAGs & glycosaminoglycans \\
\hline GAPDH & Glyceraldehyde 3-phosphate dehydrogenase \\
\hline GFI1 & growth factor independent 1 . \\
\hline GM-CSF & Granulocyte Macrophage colony-stimulating factor \\
\hline GM-CSFR & granulocyte-macrophage colony-stimulating factor receptor \\
\hline GVHD & graft-versus-host disease \\
\hline Gy & gray \\
\hline $\mathrm{H} \& \mathrm{E}$ or $\mathrm{HE}$ & hematoxylin eosin \\
\hline $\mathrm{Hb}$ & hemoglobin \\
\hline HDL & high-density lipoprotein \\
\hline HDL & high-density lipoprotein \\
\hline $\mathrm{HF}$ & heart failure \\
\hline
\end{tabular}




\begin{tabular}{|c|c|}
\hline HFD & high fat diet \\
\hline HFD-hi & high fat diet high granular/high SSC \\
\hline HFD-lo & high fat diet low granular/low SSC \\
\hline HLA & human leukocyte antigen \\
\hline $\mathrm{HO}-1$ & Heme oxygenase-1 \\
\hline $\mathrm{HOCl}$ & hypochlorous acid \\
\hline hrs & hours \\
\hline HSC & hematopoietic stem cell \\
\hline HSP & heat-shock protein \\
\hline HSPCS & hematopoietic stem and progenitor cells \\
\hline HT & heart transplantation \\
\hline $\mathrm{Ht}$ & Hematocrite \\
\hline i.e. & id est, that is \\
\hline i.p. & intraperitoneal injection \\
\hline i.v. & intravenous \\
\hline IC & intermittent claudication \\
\hline ICAM-1 & intercellular adhesion molecule \\
\hline ICOS(-L) & Inducible T-cell COStimulator (-ligand) \\
\hline ID2 & inhibitor of DNA binding 2 \\
\hline iDCs & inflammatory DCs \\
\hline IDO & indoleamine-2,3-dioxygenase \\
\hline IFN & interferon \\
\hline $\lg$ & Immunoglobulin \\
\hline IL- & interleukine- \\
\hline ILT & immunoglobin-like transcript \\
\hline ILT7 & immunoglobulin-like receptor 7 \\
\hline IMI & imiquimod \\
\hline iNOS & inducible Nitric oxide synthases \\
\hline $\mathrm{IPH}$ & intra plaque hemorrhage \\
\hline IRAK-4 & interleukin-1 receptor-associated kinase- 4 \\
\hline IRF & interferon-regulatory factor \\
\hline IRI & Ischemia reperfusion injury \\
\hline IT & intimal thickening \\
\hline KO & knockout \\
\hline L.major & Leishmania major \\
\hline LAL & Limulus Amebocyte Lysate \\
\hline LC & Langerhans cells \\
\hline
\end{tabular}




\begin{tabular}{|c|c|}
\hline LDL & low-density lipoprotein \\
\hline LDLr, Idlr & low-density lipoprotein receptor \\
\hline LFA-1 & Leukocyte function-associated molecule 1 \\
\hline $\operatorname{Lin}^{-}$ & lineage negative \\
\hline LMP1 & laten membrane protein 1 \\
\hline LMPP & lymphoid-primed multipotent progenitor \\
\hline LN & lymph node \\
\hline LPS & Lipopolysaccharide \\
\hline $\mathrm{mAb}$ & monoclonal antibody \\
\hline MAPK & Mitogen-activated protein kinases \\
\hline MCP-1 & $\mathrm{CCL} 2$ \\
\hline M-CSF & Macrophage colony-stimulating factor \\
\hline M-CSFR & macrophage colony-stimulating factor receptor \\
\hline MDA-LDL & malondialdehyde modified LDL \\
\hline MDP & monocyte/macrophage and DC progenitor \\
\hline MFI & mean fluorescence intensity \\
\hline $\mathrm{MHC}$ & Major histocompatibility complex \\
\hline MHCp & MHC containing peptide antigen \\
\hline MIF & Macrophage migration inhibitory factor \\
\hline $\operatorname{miR}$ & microRNA \\
\hline $\mathrm{mLN}, \mathrm{MLN}$ & mesenteric lymph node \\
\hline MLR & mixed leukocyte reaction (MLR) \\
\hline MMPs & matrix metalloproteases \\
\hline MNR & mannose receptor \\
\hline Mn-SOD & Manganese superoxide dismutase \\
\hline moDCs & monocyte-derived DCs \\
\hline mOVA & membrane bound ovalbumin \\
\hline Мф & macrophage \\
\hline MPO & myeloperoxidase \\
\hline MPs & $\mathrm{CD} 169^{+}$marginal zone metallophilic macrophages \\
\hline mRNA & messenger RNA \\
\hline MyD88 & Myeloid differentiation primary response gene 88 \\
\hline $\mathrm{Necl} 2$ & nectin-like molecule 2 \\
\hline NFIL3 & Nuclear factor interleukin 3 regulated \\
\hline NF-kB & nuclear factor kappa-light-chain-enhancer of activated B cells \\
\hline NGAL & neutrophil gelatinase-associated lipocalin \\
\hline NK cell & natural killer cell \\
\hline
\end{tabular}




\begin{tabular}{|c|c|}
\hline NKT cell & Natural killer T cell \\
\hline NLR & NOD-like receptor \\
\hline NLRP3 & $\begin{array}{l}\text { also known as NACHT, LRR and PYD domains-containing protein } \\
3 \text { (NALP3) }\end{array}$ \\
\hline Notch2 & Neurogenic locus notch homolog protein 2 \\
\hline NRF2 & NFE2L2, Nuclear factor (erythroid-derived 2)-like 2 \\
\hline NYHA & New York Heart Association (classification for heart failure) \\
\hline ORO & Oil-red O staining \\
\hline OVA & ovalbumin \\
\hline oxLDL & oxidized low-density lipoprotein \\
\hline OXPAPC & $\begin{array}{l}\text { Oxidation products of 1-palmitoyl-2-arachidonoyl-sn-glycerol-3- } \\
\text { phosphatidylcholine }\end{array}$ \\
\hline PAD & peripheral artery disease \\
\hline PAMPS & pathogen associated molecular patterns \\
\hline PBMC & Peripheral blood mononuclear cells \\
\hline PBS & phosphate buffered saline \\
\hline PD-1 & programmed cell death 1 \\
\hline $\mathrm{pDC}$ & plasmacytoid dendritic cell \\
\hline PD-L1 & Programmed cell death 1 ligand \\
\hline PE & phycoerithrin \\
\hline Pen/Strep & Penicillin/Streptomycin \\
\hline PerCp & Peridinin chlorophyll \\
\hline PFA & paraformaldehyde \\
\hline PIT & pathological intimal thickening \\
\hline pre-DC & DC precursor \\
\hline PRRs & pattern recognition receptors \\
\hline PSGL1 & P-selectin glycoprotein ligand-1 \\
\hline PSGL-1 & P-selectin glycoprotein ligand-1 \\
\hline QKI & Quaking \\
\hline $\begin{array}{l}\text { QKI-5, QKI-6 and } \\
\text { QKI-7. }\end{array}$ & Quaking isoform 5, 6 or 7 \\
\hline $\mathrm{Qk}^{\mathrm{vb}}$ & Quaking viable model \\
\hline qPCR & quantitative real-time polymerase chain reaction \\
\hline QRE & Quaking responsive element \\
\hline Rab11b & Ras-related protein $11 \mathrm{~b}$ \\
\hline Rag2 & Recombination activating gene 2 \\
\hline RBP & RNA binding protein \\
\hline RBP-J & Recombining binding protein suppressor of hairless \\
\hline
\end{tabular}




\begin{tabular}{|c|c|}
\hline RNA & Ribonucleic acid \\
\hline RNAseq & RNA sequencing \\
\hline ROS & reactive oxygen species \\
\hline RT PCR & Real-time PCR \\
\hline Runx3 & Runt-related transcription factor 3 \\
\hline SAP & stable angina pectoris \\
\hline SEB & Staphylococcus Enterotoxin B \\
\hline SEM & standard error of the mean \\
\hline SFD & standard fat diet \\
\hline Siglec-H & sialic acid binding immunoglobulin -like lectin $\mathrm{H}$ \\
\hline SLE & systemic lupus erythematosus \\
\hline SMC & smooth muscle cell \\
\hline SOCS3 & Suppressor of cytokine signaling 3 \\
\hline SPF & specific pathogen free \\
\hline SR-A, SRA & Scavenger receptor $A$ \\
\hline SSC & side scatter \\
\hline STAT & Signal transducer and activator of transcription \\
\hline T2D & type 2 diabetes \\
\hline TAP & transporter associated with antigen processing, \\
\hline T-bet & T-box transcription factor TBX21 \\
\hline TCR & T cell receptor \\
\hline TF & transcription factor \\
\hline TGF & Transforming growth factor \\
\hline Th & T helper cell \\
\hline TIA & transient ischemic attack \\
\hline Tk FCA & thick fibrous cap atheroma \\
\hline TLR & Toll-like receptor \\
\hline Tn FCA & thin fibrous cap atheroma \\
\hline TNF & Tumor necrosis factor \\
\hline TNFR & Tumor necrosis factor receptor \\
\hline tPA & Tissue plasminogen activator \\
\hline TRAFs & TNF-receptor associated factors \\
\hline TRAIL & tumor necrosis factor-related apoptosis-inducing ligand \\
\hline Treg & regulatory $\mathrm{T}$ cell \\
\hline UAP & unstable angina pectoris \\
\hline UPA & urokinase plasminogen activator \\
\hline UPR & unfolded protein response \\
\hline
\end{tabular}


List of abbreviations

VCAM-1

VLA-4

VSMC

WHO

wks

wt or WT

WTD

$\alpha \mathrm{CD} 3$

Vascular cell adhesion molecule-1

Very Late Antigen-4

vascular smooth muscle cell

World Health Organization

weeks

wild type

western type diet

anti-CD3 antibody 
List of abbreviations 



\section{Dankwoord}

Graag wil ik iedereen bedanken die op welke manier dan ook hebben bijgedragen aan de totstandkoming van dit boekje.

Professor Biessen, beste Erik, 4.5 jaar geleden werd ik aan je voorgesteld als 'de nieuwe AIO van Esther'. Door omstandigheden werd je plots de promotor van iemand waarvan je geen idee had wie hij was of wat hij wel of niet kon, maar zonder aarzelen sprong je in het ongewisse en nam je de uitdaging aan. Bedankt om mij die mogelijkheid te geven! De afgelopen jaren in je lab hebben mij veel bijgebracht, zowel op wetenschappelijk als op persoonlijk gebied. Bovendien heb ik door jou voor het eerst voet kunnen zetten op een ander continent, een ervaring die me bij zal blijven. Je bent een wetenschapper in hart en nieren. Je blijft me fascineren met je ongelooflijk grote berg aan kennis en bruisend vat vol goede ideeën en inzichten. Respect! Verder heb ik je ook leren kennen als een warm en sympathiek persoon, ik ben dan ook blij om jou als promotor te hebben gehad.

Professor Lutgens, beste Esther, onze paden kruisten voor het eerst toen ik in mijn $4^{\mathrm{e}}$ jaar biomedische wetenschappen samen met Dirk het lab kwam bezoeken. Het voelde meteen goed en vroeg dan ook om stage te lopen in jouw lab. Na een leerrijke periode in Maastricht keerde ik terug naar Brussel om er mijn laatste jaar in te zetten. Halfweg dat jaar wist je me te overhalen om na mijn studies in jouw lab een doctoraat te doen. Hoewel door omstandigheden onze paden al snel splitsten wil ik je graag bedanken om mijn Maastrichtse avontuur mogelijk te maken. Graag wil ik je ook bedanken voor de leerrijke stage in je lab in Munchen, waar ik naast een fantastische wetenschappelijke ervaring ook een geweldig sfeervol team heb leren kennen.

Erwin, my buddy and roommate, waar moet ik beginnen? Al vanaf mij masterstage konden we het goed met elkaar vinden. Je hebt me geïntroduceerd in de fantastische wereld van flow cytometrie, maar je bijdrage aan mijn boekje reikt veel verder dan dat. Je wetenschappelijke input en de vele malen waarbij je na de reguliere werktijden bent gebleven om mij te helpen met pipeteren van grote proeven zal ik nooit vergeten. Naast een ijverige en fantastische wetenschapper ben je ook een vriend voor het leven. 
We hebben vele leuke momenten samen beleefd, maar je stond ook altijd klaar als het eens iets minder goed ging. Dus ook als mijn persoonlijke mental coach heb je een grote bijdrage geleverd aan dit boekje $(-)$. Je blijft voor mij de zotte sympathieke assertieve (en stiekem ook beetje West-Vlaamse) Nederlander met een groot hart. Dank je voor alles! Ik hoop dat we in de toekomst contact blijven houden!

Beste Lieve, mede-Belg en begeleidster van mijn Maastrichtse avontuur. Dank je voor je begeleiding, alle wetenschappelijke input en bijdrage aan het Batf3 project, het is een solide verhaal geworden om trots op te zijn. Als spraakwaterval vol enthousiasme wist je steeds de lunchpauze te vullen en de groep te inspireren. Samen vormden we ook een sterk team om het op te nemen tegen de Nederlanders/Duitsers tijdens de grote voetbalfurie. Dank je voor het aanleren van de vele labtechnieken en je bijdrage aan dit boekje.

Beste Judith, Marjo, Sylvia, Marion en Jack, dank jullie voor de wetenschappelijke bijdrage tijdens de labmeetings, jullie kritische vragen en interesse. Marion, ook bedankt voor je bijdrage aan alle histologie aanwezig in het boekje. Jack, dank je voor je quantimet en microscopie kennis, dit heeft mij het analyseren van de plaques een stuk makkelijker gemaakt!

Graag wil ik de analisten bedanken: Mat, Anique, Clairy, Petra en natuurlijk nog eens Erwin. Dank jullie voor alle info betreffende qPCR, kweek, flow cytometrie, histologie en het beantwoorden van de vele logistieke vragen die ik op jullie heb afgevuurd. Cor, Elly, Danielle en alle andere dames van het secretariaat bedankt voor jullie ondersteuning gedurende de afgelopen 4.5 jaar.

Dank aan alle AIOs, ex-AIOs en (ex)post-docs. Thomas, Elke, Kosta, Anke, Margaux, Marchy, Emiel, David, Timo, Jeroen, Karen, Anette, Anjana en Floor, dank jullie voor de hulp bij opofferingen, tips, tricks, de leuke sfeer in het lab en natuurlijk ook de vele feestjes. Jullie zijn allemaal hard werkende en slimme AIOs waarvoor ik veel respect heb. Veel succes met jullie carrière in de toekomst. Thomas, naast alle hulp bij het uithalen van boogjes wil ik je nog eens extra bedanken voor alle i.v. injecties die je voor mij hebt uitgevoerd en de zachte verblijfplaats die je hebt aangeboden tijdens mijn nachtelijke werkdagen. Je bent een topkerel en ik wens je veel succes met je verdere carrière in Brussel. Elke, je bent een briljante wetenschapster en ik ben dan 
ook niet verwonderd dat je een post-doc positie hebt verkregen bij een toplab! Hartelijk dank ook voor het aanbieden van je appartement in mijn laatste maanden als kamperende AIO $;$. Kosta, de grappige Nederlander met Griekse roots. Dank je voor alle hulp in het lab, de gyros uit Roermond $(-)$, en voor je immer opgewekte persoonlijkheid. Ik wens je veel succes in het afwerken van je doctoraat. Anke, de MD onder de PhDs. In het begin kwam je nogal verlegen over, maar na een tijdje door te brengen in de zotte AIO kamer kwam je helemaal los. Dank je voor alle hulp tijdens de opofferingen en het afnemen van liters bloed voor mijn proeven! Veel succes met je PhD, en *wrijf over bolletje* (-). Margaux, j'essaierai d'écrire quelques mots de merci en Français. Tu es une femme très sympathique qui s'est immédiatement intègré dans le groupe de AIOs. J'ai aimé nos conversations en Français/Néerlandais. Merci pour m'aider avec les sacrifices des souris. Je te souhaite beaucoup de succès avec votre PhD, et je suis sûr qu'avec votre intelligence et enthousiasme votre thèse sera bonne. Dear Marchy, thank you for your assistance during sacrifices and for being the sunshine within our AIO team. Good luck with finishing your thesis. Karen and Anette, my ex-roommates, thank you both for all your help during my first years as a PhD student. Thank you for teaching me the necessary lab skills, giving me scientific input, answering all my questions and being a beacon during hard times. Special thanks to Anette for all oversees scientific input and the contribution to my thesis chapters. David, special thanks to you for functioning as my supervisor during my master internship in Maastricht. You prepped me to become a successful PhD student.

Thanks to Tammy and Joris for all the work and scientific input on the lipid chapters. Thanks to Joep, Erik, Aimee and Boukje, the students who contributed to the research in this thesis during their internships in our lab.

Professor Edith Janssen, Jared, Maria and Cassie, thank you for all your help during my internship in Cincinnati. Special thanks to Jared and Maria for making me feel welcome and giving me a tour in the city center and welcoming me at your home.

Dank aan Benoit en zijn team voor de vele HE coupes die jullie gekleurd hebben en voor het gebruik van jullie materiaal bij het uitvoeren van de Sirius Rood kleuringen. Extra dank aan Kathleen voor de leuke gesprekken, hulp met het sectie materiaal en voor het meermaals gebruik van droogijs. 
Dank aan volgende leden van het Esther team: Tom, voor het helpen met i.v. injecties tijdens het Batf3 project en voor de assistentie tijdens mijn periode in Amsterdam; kleine Esther, dank je voor je bijdrage aan het LMP hoofdstuk, veel succes in de VS. Norbert, Dirk, Holger, Tobias, Geli and Yvonne, thank you for all your help during the experiments in Munich, and thank you for making this trip a memorable experience. Extra dank aan Dirk, je hebt mij ook geholpen in het maken van de beslissing om naar Maastricht te komen voor mijn PhD. Grote dank aan Linda, dank je voor alles wat je mij geleerd hebt gedurende zowel mijn stage als het prille begin van mijn PhD traject: boogjes uithalen en snijden, histologie en zoveel meer. Bedankt ook voor je hulp bij de AMS offeringen en voor het zijn van de warme persoon die je bent.

Thanks to all collaborators: Prof. Martin Zenke, Prof. Christian Weber, Associate Prof.E.Janssen, Prof. Thomas Brocker, Prof. Hildner, Prof. S. Richard, Prof.CG Schalkwijk, Prof. E. van der Veer, Prof. AJ Zonneveld, dr. Germeraad, dr.K.Sere, dr. Kristiaan Wouters, Gillian Vogel. Thank you for your scientific input, use of antibodies, breeding of mice etc.

Liefste papa en mama, dank jullie voor alles! Zonder jullie liefde en volharding in mijn prille leventje had ik waarschijnlijk nooit de mogelijkheid gehad dit avontuur aan te gaan. Dank jullie om er altijd voor mij te zijn, om het voor mij mogelijk te maken om te studeren en voor de oneindige steun die jullie steeds bieden. Ik heb het jullie niet gemakkelijk gemaakt afgelopen jaren door zo weinig thuis te zijn (jobstudent, basket, kot, werken,...), maar ik kijk er naar uit om terug meer te doen samen nu ik in Brugge woon. Ik weet dat jullie fier zullen zijn met mijn doctoraatstitel, maar weet dat ik superfier ben om jullie als ouders naast me te hebben. Dit boekje is dan ook stiekem een beetje van jullie. Dank je wel!

Lieve broer en zus, dank jullie voor de steun en het luisterend oor. Sorry dat jullie mij de afgelopen jaren zo weinig hebben gezien en ik niet veel tijd kon doorbrengen met jullie en met Niels, Lukas, Jonas en Simon, ik hoop daar verandering in te brengen nu we in Brugge wonen. 
Liefste moesje en paps, dank jullie voor alle steun tijdens mijn doctoraat ondanks dat het feit dat ik jullie dochter meenam naar de andere kant van België. Dank jullie ook voor het opvangen van onze kleine zieke Kobe, voor de vele uren werk tijdens onze verbouwingen en voor mijn warme plaatsje in jullie familie. Ik had mij geen betere schoonouders kunnen inbeelden. Ook Rolf en Fien, bedankt voor alle hulp bij het maken van de cover van deze thesis, voor de opluchtende gesprekken over het doctoreren en voor het zijn wie jullie zijn. Veel succes met jullie trouw, het zal een spetterend feest worden! Fien, ik wens je ook superveel succes met het afwerken van je eigen doctoraat. Ik ben ervan overtuigd dat het een mooi verhaal zal worden.

Liefste keppe, mijn elfje en super mama, dank je voor je onvoorwaardelijke liefde en steun! Het is niet altijd even gemakkelijk/eerlijk geweest voor jou. Vele keren bleef je alleen achter in Hasselt (buitenlandse stages, congressen, overwerken), maar je hebt je er altijd weten door te slaan. Afgelopen jaren zijn intens geweest en we hebben in die korte periode al een heel traject doorlopen: samenwonen, trouwen, huisje kopen, verbouwen en kindje krijgen! Dit boekje is dan ook voor jou. Het einde van een moeilijk hoofdstuk in ons leven, maar het begin van een spannend nieuw avontuur! Als supermama vorm je samen met Kobe voor mij het perfecte gezinnetje, een veelbelovend uitzicht voor de toekomst!

Flinke Kobe, al ben je nog veel te klein om dit allemaal te lezen, graag zeg ik je even dat je geboorte een hele nieuwe wending bracht in mijn leven. Je was het zonnetje in een moeilijke periode voor mij. Je lach, je speelsheid, je vrolijkheid en ja ook je luiers $(;)$ hebben mij telkens gesterkt en gemotiveerd om alles efficiënt en succesvol af te werken zodat ik er meer voor je kon zijn. Je beseft het nog niet, maar ook jij hebt een belangrijke bijdrage geleverd aan dit verhaal. 